\title{
Poverty, social mobility, and the middle class The case of South Africa
}

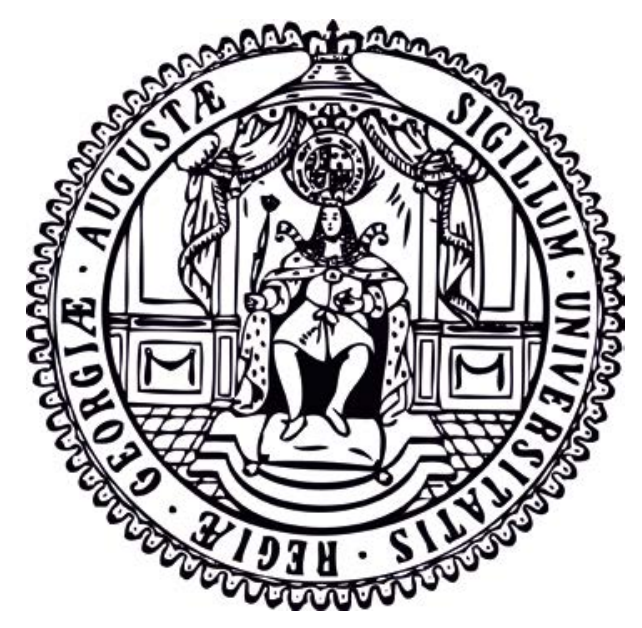

\section{DISSERTATION}

Submitted in accordance with the requirements for the doctoral degree in economic sciences at the Georg-August-Universität Göttingen

\section{Simone Schotte}

Born in Haan, Germany 


\section{Thesis Committee}

First supervisor: $\quad$ Apl.-Prof. Dr. Jann Lay

Second supervisor: $\quad$ Prof. Dr. Stephan Klasen, Ph.D.

Third examiner: $\quad$ Prof. Dr. Thomas Kneib

Date of submission: 3 August 2018 


\section{Acknowledgements}

First and foremost, I am grateful to my first supervisor, Jann Lay, for his guidance, confidence, and encouragement, for his creativity and enthusiasm in developing new research ideas, and his continuous support and academic advice. I also thank my second supervisor, Stephan Klasen, for excellent thesis supervision and many helpful comments, suggestions, and discussions through the learning process of this dissertation.

It would have been impossible to conduct this research without the help and contributions of a large number of colleagues. Nevertheless, two key collaborators stand out as having played a major role in the development of this thesis. My sincere thanks goes to professor Murray Leibbrandt, who gave me the opportunity to join his research team at the Southern Africa Labour and Development Research Unit (SALDRU) and who continuously encouraged my work and provided valuable guidance and expertise. A very special gratitude further goes to Rocco Zizzamia for his wonderful collaboration. His input has been indispensable throughout the time of research and writing of this thesis - both as a research partner and as a friend.

This thesis has been elaborated at the GIGA German Institute of Global and Area Studies, which offered me an inspiring study and research environment. I am particularly grateful to all members of the Institute of African Affairs (IAA), the Research Programme 3 ("Growth and Development") and the GIGA Doctoral Programme for many helpful comments and suggestions. I am also indebted to all members of the "Globalization and Development" research training group at the University of Göttingen, who provided valuable comments and feedback on earlier revisions of the articles included in this dissertation.

This thesis would not have been possible without the generous financial support received from the Evangelisches Studienwerk Villigst. The provided doctoral studies grant enabled me to focus on my research by supporting me financially, for which I am extremely thankful.

Last but by far not the least important, I owe more than thanks to my mother, my partner, and my friends for their support and encouragement during my doctoral studies and beyond. Thank you for trusting me in pursuing my own path. 



\section{CONTENTS}

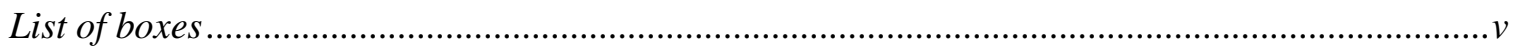

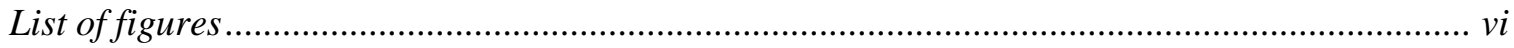

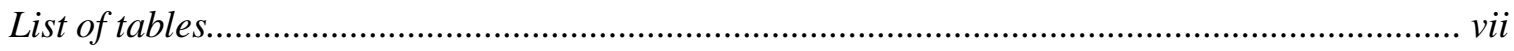

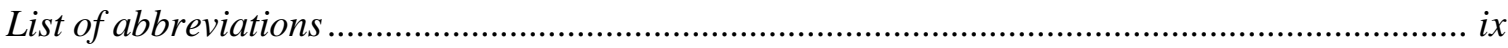

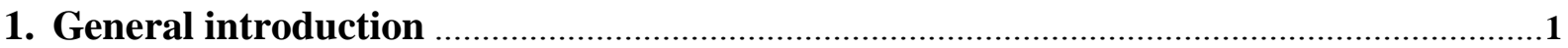

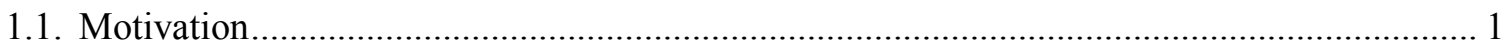

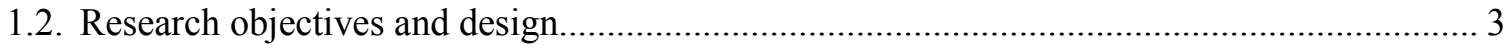

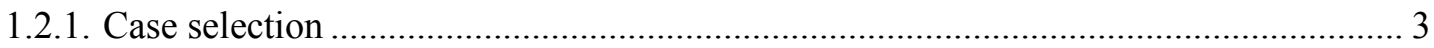

1.2.2. Research questions and approaches........................................................................... 4

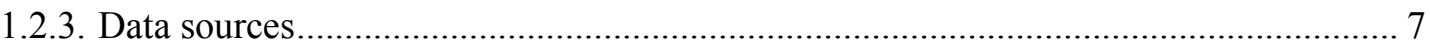

1.3. Contribution to the literature and resulting lessons for policy ............................................ 8

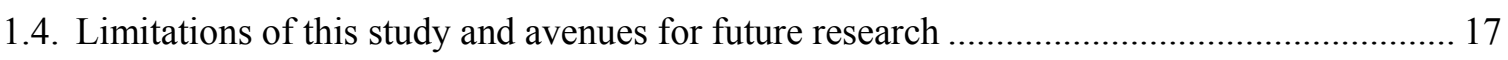

\section{Defining the middle class in the Global South: A quantitative perspective from}

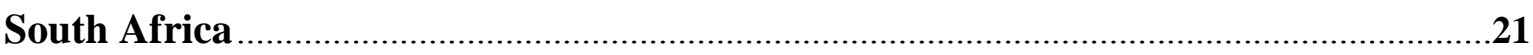

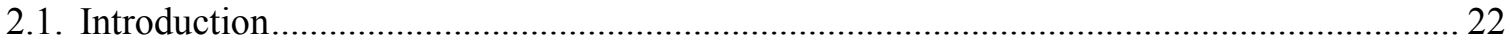

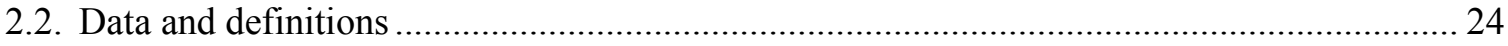

2.3. Brief historic recap of the extent of income polarisation in South Africa ............................. 25

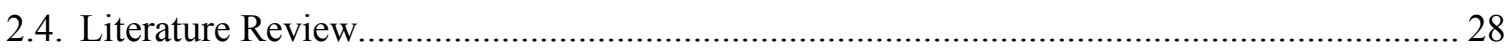

2.4.1. Definitions of the middle class based on money metric measures ............................. 29

2.4.2. The size of South Africa's middle class under alternative money metric measures.... 32

2.4.3. Definitions of the middle class based on non-money metric measures ........................ 35

2.5. A vulnerability approach to defining the middle class in South Africa .................................. 37

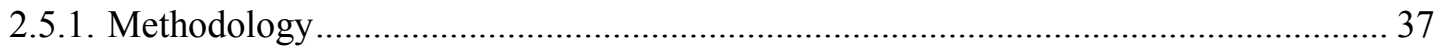

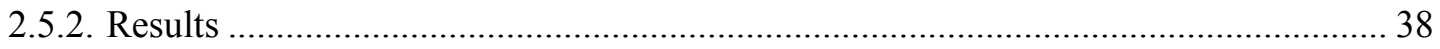

2.5.3. Sensitivity analysis and caveats of the approach ......................................................... 43

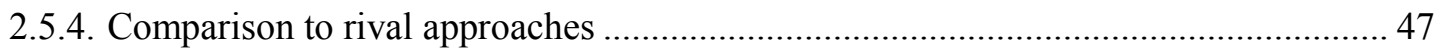

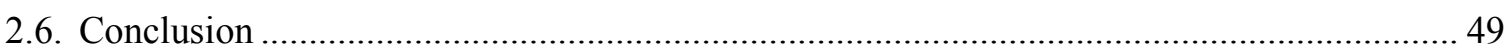

3. A poverty dynamics approach to social stratification: The South African case ............53

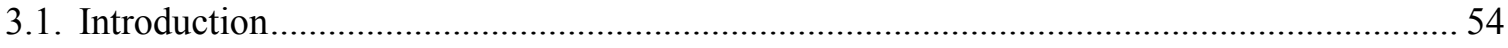

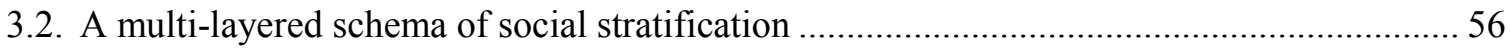




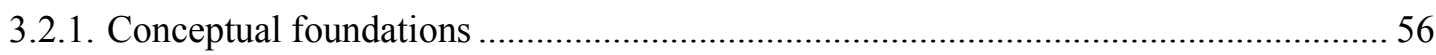

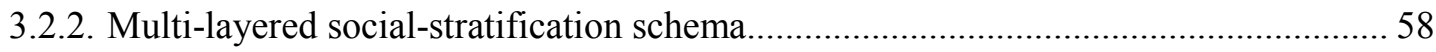

3.2.3. Econometric modelling of the risk of poverty ........................................................... 59

3.3. An empirical application of the stratification schema: The case of South Africa................... 60

3.3.1. Data, definitions, and descriptive poverty transitions................................................ 60

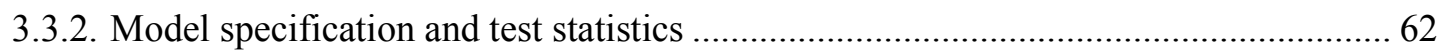

3.3.3. Estimated effects of the explanatory variables on transition probabilities ................... 66

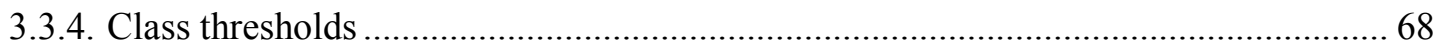

3.4. Class formations, social inequality, and mobility in South Africa......................................... 71

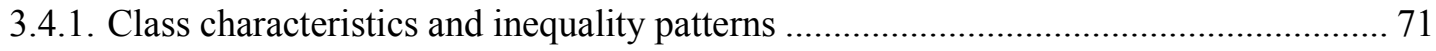

3.4.2. A dynamic perspective on the determinants of class membership and inter-class

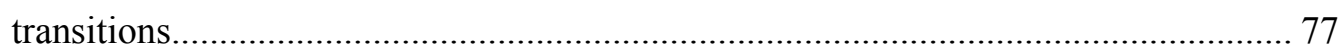

3.4.3. The distribution of risks and coping mechanisms across class categories................... 80

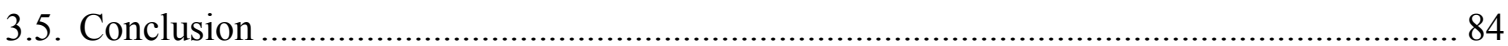

4. Structural poverty dynamics in urban South Africa: A mixed method investigation .87

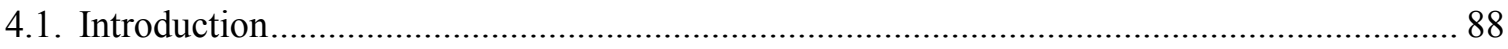

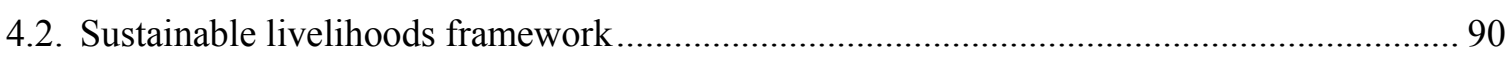

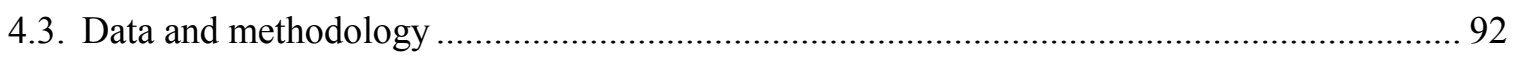

4.3.1. Panel data description and quantitative poverty measures ...................................... 92

4.3.2. Qualitative case-study design and description of study sites...................................... 96

4.4. Magnitude of structural and stochastic poverty transitions.................................................. 100

4.4.1. Movements into and out of monetary poverty ......................................................... 100

4.4.2. Decomposing poverty transitions into structural and stochastic components ........... 102

4.5. Drivers of structural poverty escapes and descents.......................................................... 105

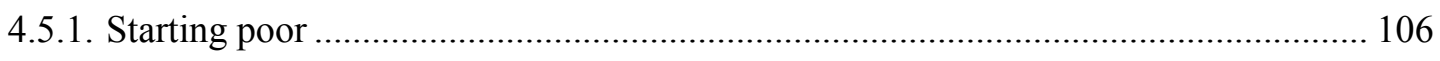

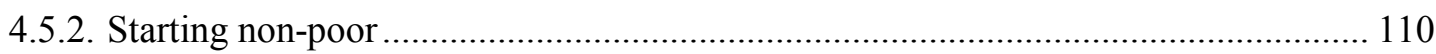

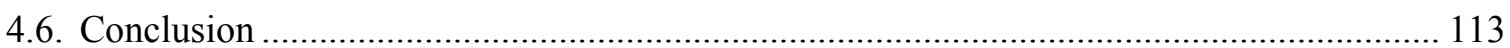

\section{The Anxious and the Climbers: Ambivalent Attitudes towards Democracy among}

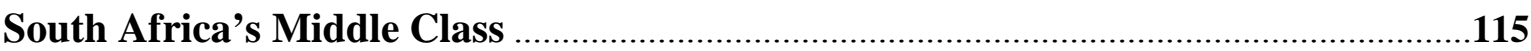

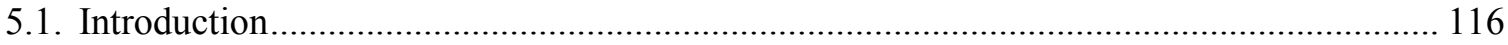

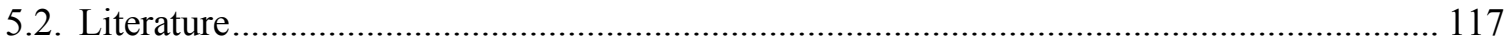

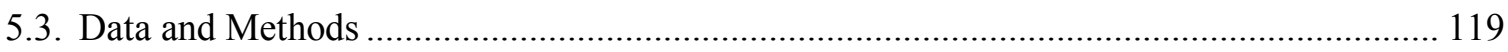

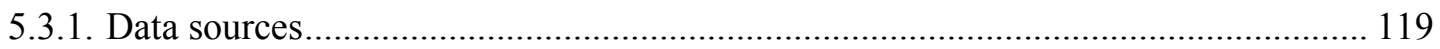

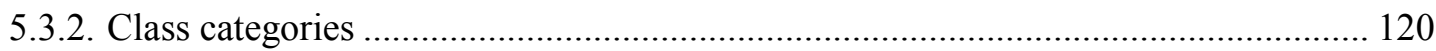

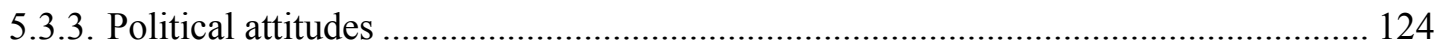




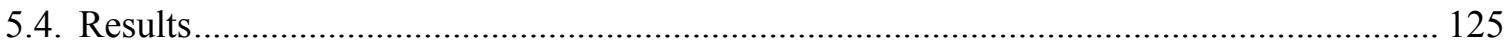

5.4.1. System support and the legitimacy assigned to democratic institutions .................... 125

5.4.2. Attitudes and Value Orientations of a Broader Social Concern ................................. 130

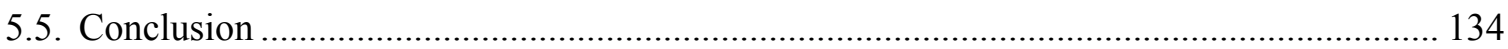

REFERENCES

APPENDIX A

A.1. Vulnerability approach to defining the middle class ........................................................ 149

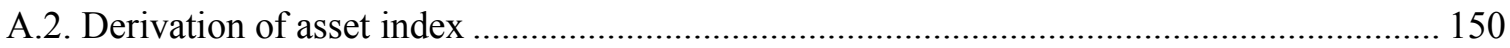

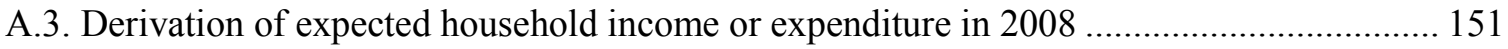

APPENDIX B

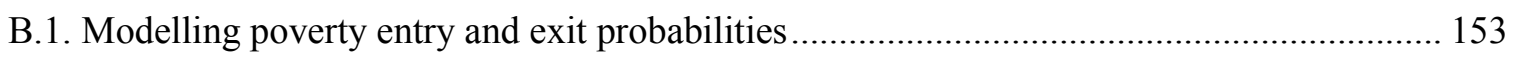

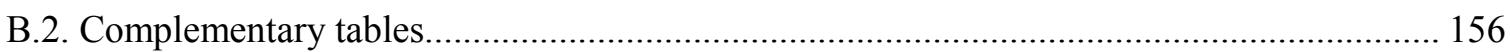

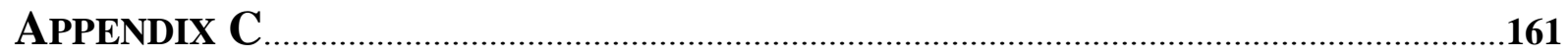

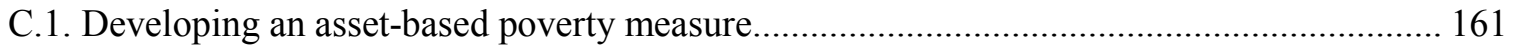

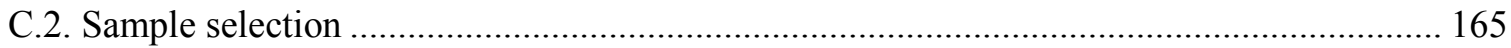

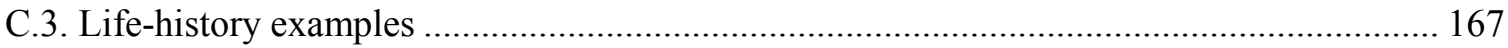

APPENDIX D

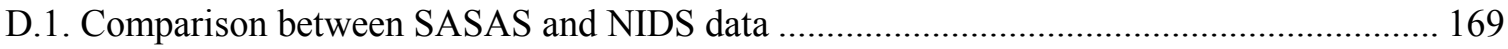

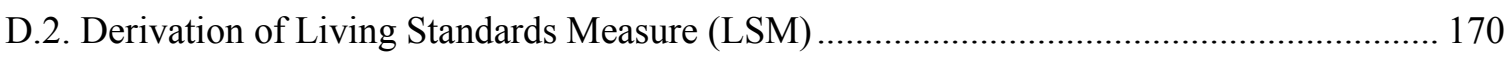

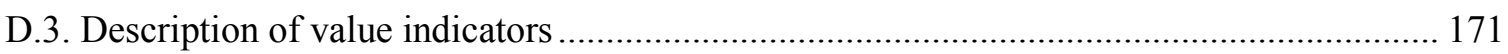

D.4. Robustness check using monthly per capita household income instead of LSM to differentiate between poor, middle class, and elite .............................................................. 173

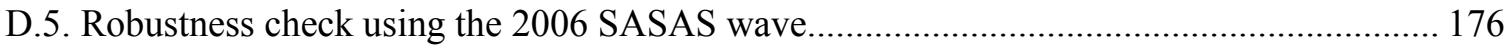

D.6. Regression tables, LSM-based class divisions, SASAS 2012 ............................................ 179

\section{List of boxes}

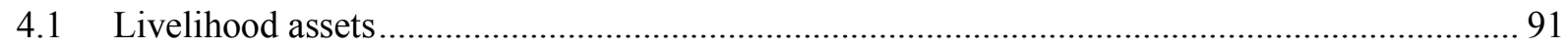

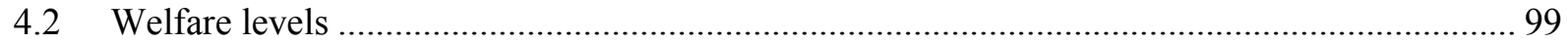

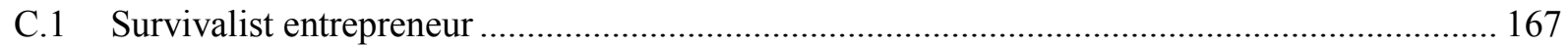

C.2 Escape from poverty during working life and re-impoverishment at old age .......................... 167

C.3 High stability from long-term employment and family networks........................................... 168 


\section{List of figures}

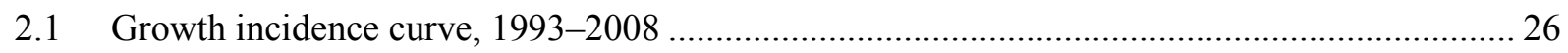

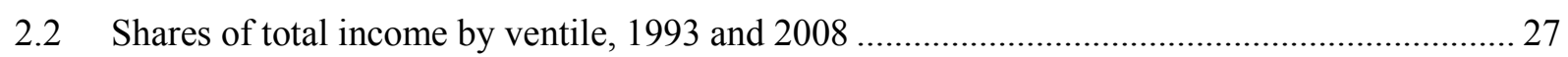

2.3 Comparison of rival approaches to the definition of the middle class ....................................... 33

2.4 Four-tiered class stratification following a vulnerability-based approach ................................. 37

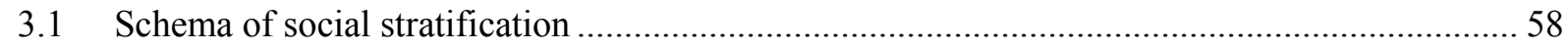

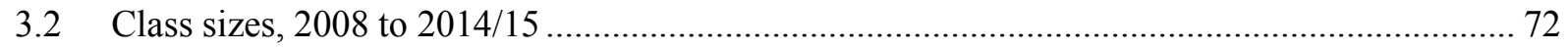

3.3 Population share of South Africa's five social classes by province, 2008 to 2014/15............... 75

3.4 Racial composition of South Africa's five social classes, 2008 and 2014/15 ........................... 76

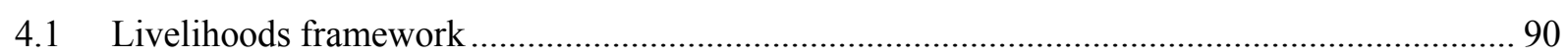

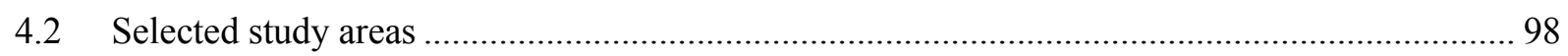

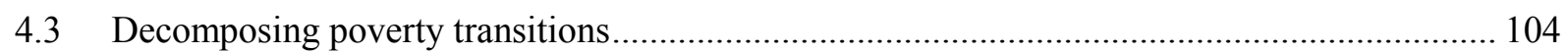

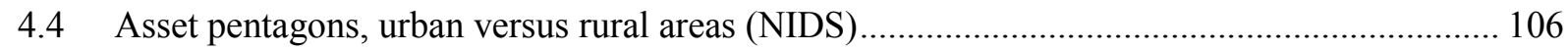

4.5 Asset pentagons, structurally poor versus structurally upwardly mobile (NIDS).................... 108

4.6 Asset pentagons, stochastically versus structurally upwardly mobile (NIDS) ........................ 108

4.7 Trigger events associated with a rise/fall in human capital (LHIs) .......................................... 109

4.8 Trigger events associated with a rise/fall in other capital types (LHIs) .................................. 111

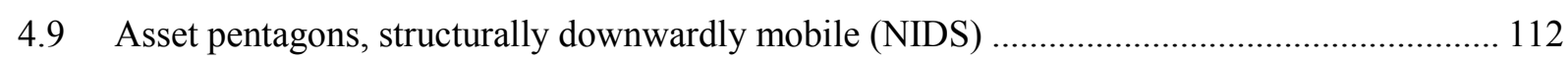

5.1 Relationship between class and trust in public institutions ................................................... 129

5.2 Relationship between class and satisfaction with governmental performance .......................... 130

5.3 Relationship between class and attitudes toward voting ...................................................... 131

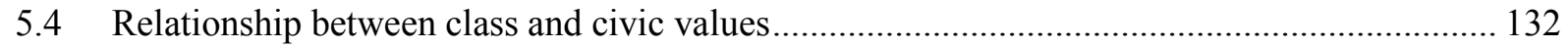

5.5 Relationship between class and priorities for public policy ................................................... 134

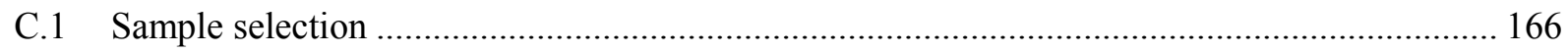

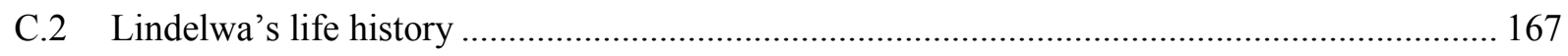

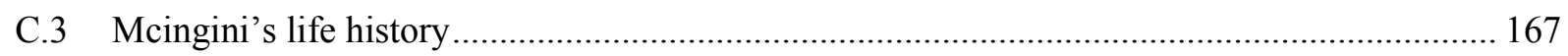

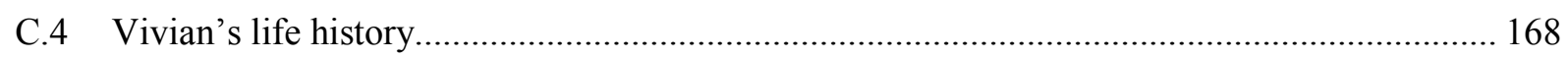

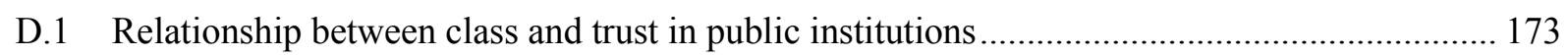

D.2 Relationship between class and satisfaction with governmental performance ......................... 174

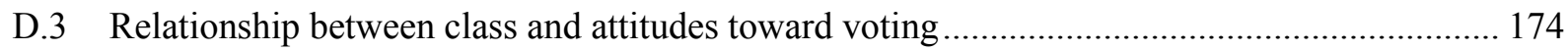

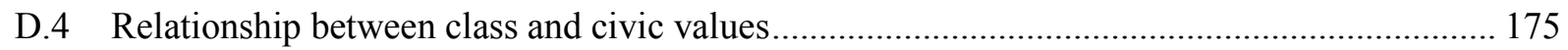

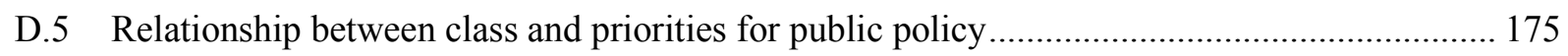

D.6 Relationship between class and trust in public institutions................................................... 176

D.7 Relationship between class and satisfaction with governmental performance ........................ 177

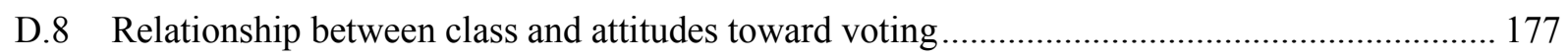

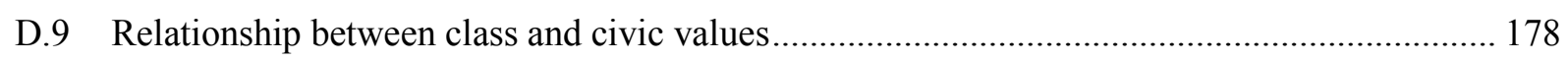

D.10 Relationship between class and priorities for public policy ................................................. 178 


\section{List of tables}

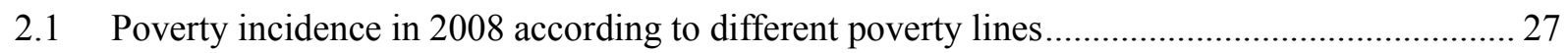

2.2 Size of the South African middle class according to rival absolute and relative definitions ....... 34

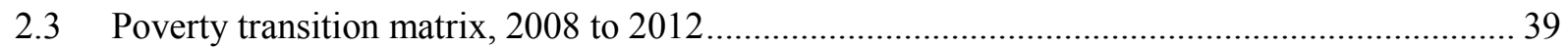

2.4 Probit estimates (average marginal effects) on probability of being poor in 2012 .................... 41

2.5 Movements in and out of poverty by initial class status, 2008 to 2012 .................................... 43

2.6 Relative class shares in South Africa, 1993 to 2014/15 ............................................................ 43

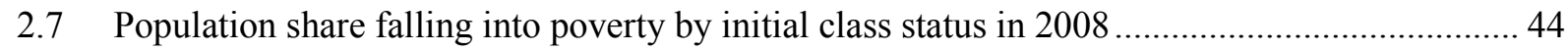

2.8 Sensitivity of the vulnerability thresholds to the choice of the probability cut-off..................... 45

2.9 Sensitivity of the vulnerability thresholds to the choice of the poverty line............................... 45

2.10 Criteria for comparing approaches to defining the middle class in South Africa ...................... 48

2.11 Comparing rival approaches to defining the middle class in South Africa in 2008 ................... 49

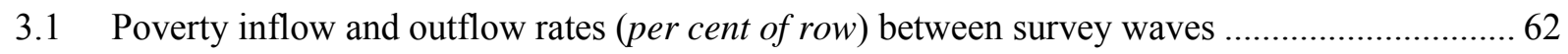

3.2 Poverty inflow and outflow rates (per cent of row) between survey waves .............................. 65

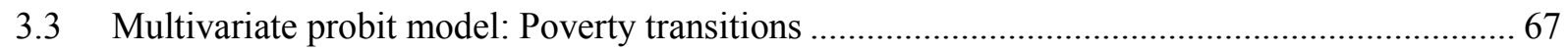

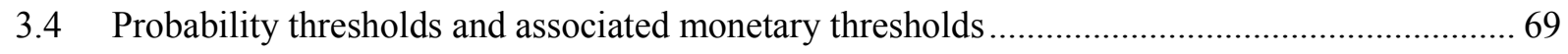

3.5 Monthly household expenditure per person by social class, 2008 to $2014 / 15$.......................... 69

3.6 Classes identified by poverty propensity vs. monetary thresholds, 2008 to $2014 / 15$................ 70

3.7 Average class size and mobility patterns by identification method, 2008 to $2014 / 15$............... 71

3.8 Average household (HH) characteristics by social class, 2008 to $2014 / 15$............................... 74

3.9 Characteristics of the head of household ( $\mathrm{HoH})$ by social class, 2008 to $2014 / 15 \ldots \ldots \ldots \ldots \ldots \ldots . . . . . . . .77$

3.10 Predicted poverty risks for persons with different combinations of characteristics..................... 78

3.11 Events associated with entries into the middle class (or elite), 2008 to $2014 / 15$...................... 82

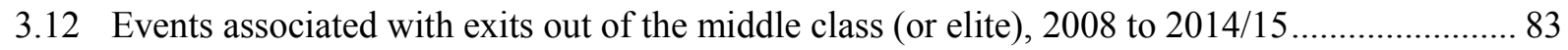

3.13 Instruments associated with staying in the middle class (or elite), 2008 to $2014 / 15$................. 84

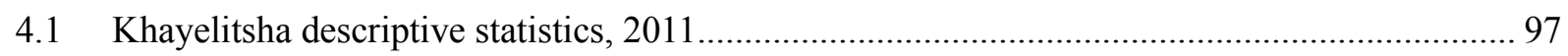

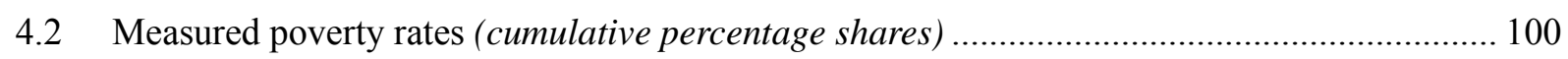

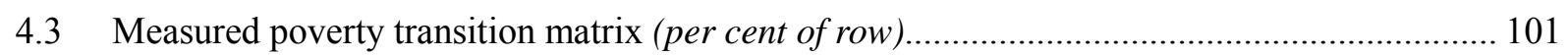

4.4 Decomposing poverty transitions (per cent of individuals) ...................................................... 103

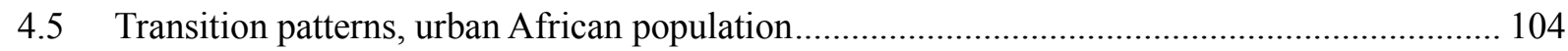

4.6 Livelihood trajectory patterns and poverty dynamics (LHIs) ............................................... 105

5.1 Class categories based on living standards and perceptions of social mobility ........................ 120

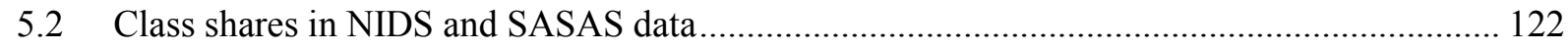

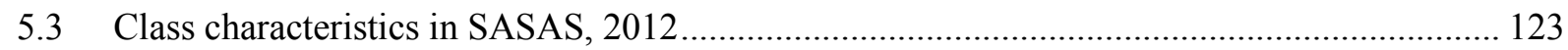

5.4 Political culture approaches on the link between attitudes and democracy .............................. 124

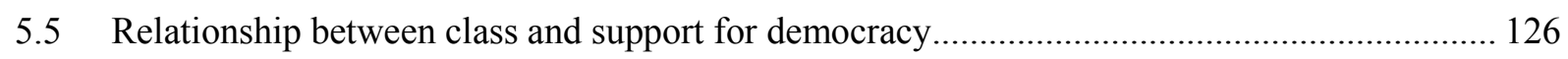

5.6 Determinants of the relationship between class and support for democracy ........................... 127 
A.1 Variables included in and weights obtained from MCA analysis.......................................... 150

A.2 Linear model of household income or expenditure in 2008 ................................................... 151

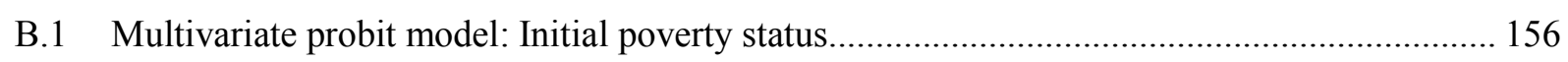

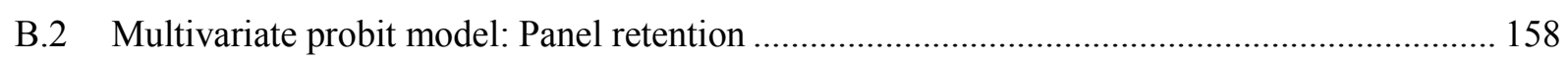

B.3 Linear model of logarithmised per capita household expenditure ......................................... 159

C.1 Variables included in and weights obtained from MCA analysis............................................. 161

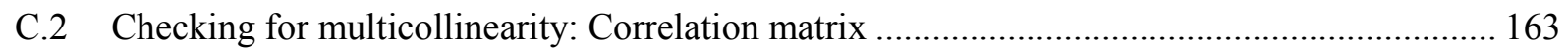

C.3 Checking for multicollinearity: Variance inflation factor (VIF) ........................................... 163

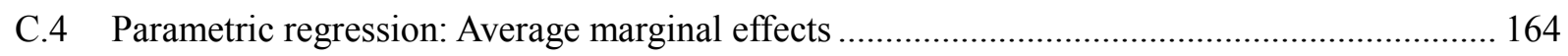

C.5 Non-parametric regression: Average marginal effects ......................................................... 164

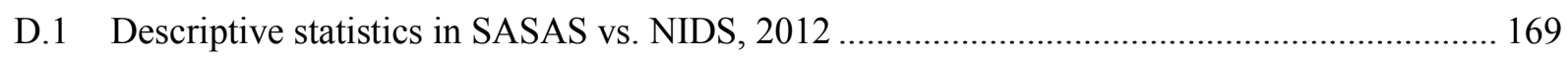

D.2 Variables included in and weights obtained from MCA analysis........................................... 170

D.3 Three most important challenges facing South Africa today ................................................ 172

D.4 Class division based on LSM vs. per capita income, 2012 .................................................. 173

D.5 Overlap of class divisions based on LSM vs. per capita income, 2012 .................................... 173

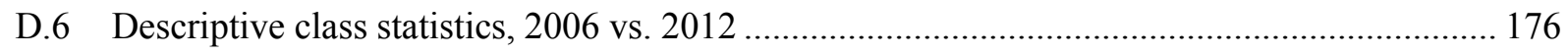

D.7 Relationship between class and support for democracy....................................................... 179

D.8 Determinants of the relationship between class and support for democracy ........................... 180

D.9 Robustness check for the relationship between class and support for democracy .................... 181

D.10 Relationship between class and trust into public institutions................................................. 182

D.11 Determinants of the relationship between class and trust into public institutions ................... 183

D.12 Relationship between class and satisfaction with governmental performance ........................ 184

D.13 Relationship between class and attitudes toward voting ....................................................... 185

D.14 Determinants of the relationship between class and attitudes toward voting............................186

D.15 Relationship between class and support for civil rights and condemnation of corruption.........187

D.16 Determinants of the relationship between class and support for civil rights and condemnation

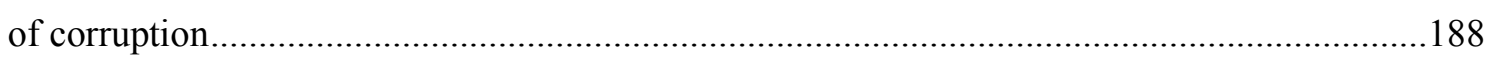

D.17 Determinants of the relationship between class and support for civil rights and condemnation

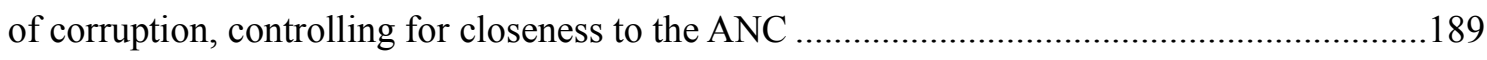

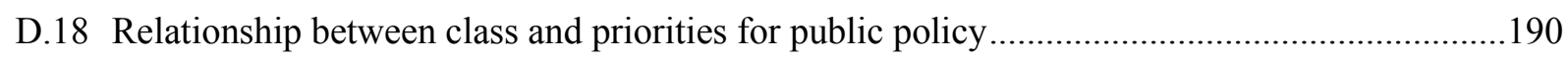

D.19 Determinants of the relationship between class and priorities for public policy .......................191 


\section{List of abbreviations}

$\begin{array}{ll}\text { ANC } & \text { African National Congress } \\ \text { CoBN } & \text { Cost-of-basic-needs } \\ \text { FGD } & \text { Focus group discussion } \\ \text { FPL } & \text { Food poverty line } \\ \text { HH } & \text { Household } \\ \text { HoH } & \text { Head of Household } \\ \text { HSRC } & \text { Human Sciences Research Council } \\ \text { LBPL } & \text { Lower-bound poverty line } \\ \text { LHI } & \text { Life-history interview } \\ \text { LSM } & \text { Living standards measure } \\ \text { MCA } & \text { Multiple correspondence analysis } \\ \text { NIDS } & \text { National Income Dynamics Study } \\ \text { NP } & \text { Non-parametric } \\ \text { OLS } & \text { Ordinary Least Squares } \\ \text { OSM } & \text { Original sample member } \\ \text { P.c. } & \text { Per capita } \\ \text { PPP } & \text { Purchasing power parities } \\ \text { PSLSD } & \text { Project for Statistics on Living Standards and Development } \\ \text { QLFS } & \text { Quarterly Labour Force Survey } \\ \text { SALDRU } & \text { Southern Africa Labour and Development Research Unit } \\ \text { SASAS } & \text { South African Social Attitudes Survey } \\ \text { SLF } & \text { Sustainable Livelihoods Framework } \\ \text { Stats SA } & \text { Statistics South Africa } \\ \text { TSM } & \text { Temporary sample member } \\ \text { UBPL } & \text { Upper-bound poverty line } \\ & \end{array}$





\section{CHAPTER 1}

\section{General introduction}

\subsection{Motivation}

Over the past decade, debates centring on the "African growth tragedy" have made room for a radically different grand narrative that portrays an Africa "on the rise." This mood swing has been accompanied by glamorous images of an emerging African middle class playing a leading role in this new narrative (see Giesbert \& Schotte, 2016). Encouraged by an influential report by the African Development Bank (Ncube, Lufumpa, \& Kayizzi-Mugerwa, 2011) business analysts and policy makers have set great expectations in the new middle-class consumers (Deloitte, 2012; Hattingh, Russo, Sun-Basorun, \& Van Wamelen, 2012).

Beyond the hopes that Africa's new middle class will trigger further economic growth by shifting the composition of consumer demand (for a theoretical discussion on the link between changes in the distribution of income and industrialisation, see Murphy, Shleifer, \& Vishny, 1989), the list of favourable value orientations often attributed to the middle class is long. Amongst others, it includes traits such as a commitment to saving and investment, a belief in meritocracy, entrepreneurial spirit, and the importance attached to education (see, inter alia, Bhalla, 2007; Cárdenas, Kharas, \& Henao, 2015). Furthermore, in the tradition of modernisation theory, a sizeable and well-established middle class has been associated with a shift in public priorities away from a focus on the satisfaction of "basic needs," which are the main concern of the poor, towards so-called "higher order" goods that may benefit the creation and consolidation of democratic institutions (Birdsall, Graham, \& Pettinato, 2000; Easterly, 2001; Inglehart, 1990).

Inherent to many of the expectations commonly placed on the middle class's role in politics and economic development is an understanding of this class as an "empowered" and economically secure part of society. Due to their better income situation compared to the poor, middle-class citizen are assumed to be equipped with a higher capacity and tolerance for delayed gratification (Acemoglu \& Zilibotti, 1997), be less vulnerable to credit market imperfections (Galor \& Zeira, 1993), and thus be able to engage in mid- and long-term planning. In accordance with these assumptions, being in an economically stable position has 
been found essential for people to self-identify as belonging to the middle class (see Phadi \& Ceruti, 2011). In consequence, most interpretations of what constitutes the middle class relate in some way to the degree of economic security and self-sufficiency that people experience.

Nevertheless, standard approaches found in the economics literature to operationalise class concepts do not sufficiently account for this dynamic aspect that characterises a "stable" middle class. Instead, there is a dominance of static approaches that locate the middle class within a particular income or expenditure range, where the lower boundary is often set at the poverty line (see Chapter 2). These studies, however, fail to acknowledge that being able to afford a certain basket of goods at a given point in time provides an insufficient indication of whether the same will be true in the near future. In other words, they ignore that some of those who are currently non-poor may face a non-negligible risk of falling into poverty. This economic insecurity may not only be a source of considerable discomfort, bearing the risk of negative psychological and health effects (Cafiero \& Vakis, 2006), but also tends to affect people's economic choices and may create a low-income trap; for example, if the vulnerable, in order to minimise risks, are forced to engage in economic activities which are low-risk and guarantee constant, but low returns (Cafiero \& Vakis, 2006; Dercon, 2006).

Furthermore, the unequal distribution of poverty risks - or, generally speaking, of chances of upward and downward social mobility - may also condition people's political choices (see, for example, Acemoglu, Egorov, \& Sonin, 2018). While it is often assumed that the middle class is fairly homogenous in terms of the political attitudes of its members, the fact that individuals within the middle-class income stratum may perceive themselves as being on different economic trajectories may in turn condition their political values and priorities in various ways. This may result in an important, but so far not sufficiently explored extent of heterogeneity in the political attitudes of middle-class citizens (see Chapter 5).

Another related aspect, which even the few studies that differentiate between the vulnerable and the stable middle class are blind to (see, for example, Birdsall, 2015; LopezCalva \& Ortiz-Juarez, 2014), is the fact that not all households below the poverty line are alike. Many people, especially in the developing world, experience poverty at some time in their lives, but some face significantly higher chances of (re-)escaping from poverty than others. In this regard, the lived realities and policy needs of those who experience transitory poverty as the result of a temporary financial setback are likely to be very different from those who are stuck in a situation of structural deprivation (see Dercon, 2006; Glewwe \& Gibson, 2006; Klasen \& Povel, 2013). In this regard, if the growth of a stable middle class is a desired development outcome and focus of government policy, then it will be indispensable to gain a 
better understanding of the multidimensional causal mechanisms, processes, and pathways that can either facilitate or impede sustained escapes from poverty.

\subsection{Research objectives and design}

The previous section highlights a number of issues that, in my view, up to date have been insufficiently addressed in the economics literature on the middle class in the Global South. This dissertation aims to speak to these gaps.

Contrary to most standard approaches in the economic realm, the main argument I make is that social class is insufficiently understood by a person's current standard of living alone. Therefore, in this dissertation I propose a conceptual framework that takes the distribution of chances of upward and downward social mobility explicitly into consideration. I compare my proposed approach to those that have been suggested in the previous literature and illustrate the main messages that can be learnt from linking the demarcation of social strata to an in-depth analysis of mobility patterns.

\subsubsection{Case selection and generalisability}

To this end, South Africa is used as a case study. This focus has been chosen for three main reasons: First, given its middle-income status, South Africa has been identified as one of the countries in sub-Sahara Africa with a relatively large and growing middle class (Ncube et al., 2011). Second, despite important advances towards poverty reduction over the past two decades, the level of economic inequality in the country remains among the highest in the world (see, inter alia, Leibbrandt, Finn, \& Woolard, 2012; Özler 2007). Moreover, even though the extent, nature, and legacy of poverty and inequality are relatively well understood in the country, there is still only limited knowledge about the drivers of poverty transitions, particularly in urban settings (see discussion below). Third, the dynamic perspective adopted in this dissertation critically relies on the availability of panel data. While panel surveys are now being conducted for an increasing number of low- and middle-income countries, South Africa is among the few countries in sub-Sahara Africa where multiple survey rounds have been collected within the last ten years at regular and not too widely spaced time intervals.

Most of the empirical analysis presented in this dissertation looks at South Africa as a whole. However, some parts concentrate on the South African urban context specifically. This is owed to ongoing shifts in the geography of poverty. Although pockets of deep poverty persist in rural regions, de-agrarianisation, rural-to-urban migration and high population 
growth in cities are pushing the absorptive capacities of South Africa's urban centres to their limits (Viljoen \& Sekhampu, 2013). In consequence, particular attention is given to the vulnerability context associated with the resulting proliferation of informal settlements and increasingly densely populated townships, suffering from high un- and underemployment and socio-economic insecurity (Visagie \& Turok, forthcoming). The use of newly available nationwide longitudinal data analysed through a particular urban focus define this research in relation to most of the previous literature, which has mainly been confined to exploring poverty traps and transition pathways in rural settings (see Adato, Carter, \& May, 2006; Adato, Lund, \& Mhlongo, 2007; Agüero, Carter, \& May, 2007; Carter \& May, 1999, 2001).

Even though the focus of this dissertation is on South Africa, I highlight a number of key messages that are considered relevant beyond the South African case and that may - to some extent - be generalizable to similar country contexts in the Global South.

In this regard, it is worth noting that throughout this thesis poverty is defined in absolute terms. As such, it is tailored to low- and middle-income countries rather than highincome countries, where relative-poverty concepts dominate. In addition, the relevance of the developed conceptual framework that links the analysis of patterns of social stratification to the distribution of chances of upward and downward social mobility is highest in country contexts marked by systematised and enduring (or even rising) socioeconomic inequality including an unequal distribution of risks and access to coping mechanisms as well as of opportunities for upward mobility. The proposed conceptual angle furthermore is considered most informative when applied to economies experiencing fast growth spurts that are not sustained, with the consequence that those rising out of poverty may remain vulnerable to falling back, or to countries experiencing slow growth that occurs in a context marked by significant volatility around the poverty line. Lastly, the predominantly urban lens of this study has implications for than a few low- and middle-income countries where rapid urbanisation offers both opportunities and challenges, placing high demands on infrastructure and service provision, and job creation (see Rakodi, 2002).

\subsubsection{Research questions and approaches}

This dissertation features four stand-alone research articles presented in Chapters 2 to 5 . While all four contributions can be read and understood independently, they are connected to each other thematically and build successively upon each other. Chapters 2 and 3 are joint work with researchers from the Southern Africa Labour and Development Research Unit (SALDRU) at the University of Cape Town. Chapters 4 and 5 are single-authored. 


\section{Chapter 2}

Setting the scene for the remainder of the dissertation, Chapter 2 aims to add clarity to the debate that is currently unfolding regarding the size, growth and purchasing power of South Africa's middle class, by making two main contributions: First, we provide a structured overview of a wide array of definitions of the middle class that have been suggested in the economics literature, and assess their strengths and shortcomings with an application to South Africa. Second, arguing that the notion of economic (in-)security is central to the social and political meanings of being middle class, we then focus our analysis on an empirical strategy recently suggested by López-Calva and Ortiz-Juarez (2014). This approach importantly relies on the notion that members of the middle class should be at reasonably low risk of falling into a situation of precarity in which they are incapable of meeting their basic needs. We replicate López-Calva and Ortiz-Juarez's (2014) original approach by estimating a simple model of poverty transitions using South African panel data. This way, we provide an indication of the minimum income or expenditure level that, following this vulnerability approach, identifies the stable middle class in the given country context, and compare the size of the identified middle class to the class sizes under alternative definitions.

The main research questions that this chapter seeks to address are:

2.1. How do previous approaches to define the middle class compare in their implications for the size and growth of South Africa's middle class?

2.2. What are the main advantages and disadvantages of these various approaches?

2.3. What is the minimum income or expenditure level associated with being stably middle class in South Africa?

\section{Chapter 3}

Chapter 3 builds on the analysis presented in Chapter 2, but seeks to move beyond existing approaches. In this chapter, we suggest a framework of social stratification that links the demarcation of social strata to an in-depth analysis of poverty transitions. Extending previous approaches, the proposed schema not only distinguishes between the vulnerable and the stable middle, but also allows differentiating between transient and chronic poverty. In doing so, we aim to bridge the gap between the poverty dynamics literature and the middle class literature in economics, which - in our understanding - should no longer be treated in isolation. Applying this schema to the same South African panel dataset, we strive to provide a better understanding of the key characteristics that differentiate each of the identified social groups 
and to explore the positive and negative economic events and coping strategies that help to explain observed mobility patterns.

The main research questions that this chapter seeks to address are:

3.1. How can previous economic approaches to define the middle class be strengthened and expanded? Specifically, how can dynamic approaches to the study of poverty, vulnerability and the middle class be combined into a coherent framework that allows analysing patterns of social stratification more broadly?

3.2. What are the key characteristics that define South Africa's stable middle class?

3.3. What are the main challenges that impede people from entering the ranks of the stable middle class in South Africa?

\section{Chapter 4}

Chapter 4 shifts the focus onto those in society who cannot yet be considered as members of the stable middle class. Given the close interlinkage between poverty dynamics and middle class growth, it aims to provide a nuanced understanding of the key factors that both facilitate and hinder structural poverty escapes and descents in South Africa, with special attention given to the urban African population. ${ }^{1}$ To this end, going beyond conventional monetary definitions and approaches to studying poverty dynamics, I adopt an asset-based approach that draws on the concept of sustainable livelihoods, which allows me to decompose poverty transitions into structural and stochastic components. This quantitative analysis is triangulated with evidence from qualitative interviews that I conducted in the township of Khayelitsha, Cape Town. Using this mix of quantitative and qualitative research methods, I attempt to provide a deeper understanding of the key sources of risk and vulnerability, on the one hand, and determinants of economic stability and progress, on the other.

The main research questions that this chapter seeks to address are:

4.1. How much of the mobility into and out of poverty observed in South African panel data can be accounted for by stochastic factors? And conversely, to what extent do these movements reflect a change in people's livelihood assets?

4.2. What are the main dimensions of urban poverty in South Africa?

4.3. What are the main trigger events associated with upward and downward mobility? How do these events relate to each other?

\footnotetext{
${ }^{1}$ In South Africa, four main racial groups are commonly distinguished: Africans (Blacks), Coloured people (people of mixed race), people of Indian/Asian descent, and Whites.
} 


\section{Chapter 5}

Chapter 5 deals with the question of how patterns of social stratification are manifest in political attitudes. Albeit middle-class citizens have generally been assumed to support democracy, studies investigating this class's political attitudes using opinion survey data have produced mixed results. While some studies find suggestive evidence consistent with prodemocratic civic and political engagement on the part of the middle class (see, for example, Cheeseman, 2015), others have, quite to the contrary, concluded that this class appears rather "apathetic" in terms of their political participation (Resnick, 2015). Diverging from the previous literature that generally treats the middle class as a homogeneous group, this chapter aims to offer a more nuanced perspective that may help to reconcile these two opposing views. Specifically, consistent with the main line of reasoning adopted throughout this dissertation, I explore how diverging perceptions of social mobility tend to condition political attitudes toward democracy within different social strata, particularly within the middle class.

The main research questions that this chapter seeks to address are:

5.1. In theory, what is the link between class and attitudes toward democracy?

5.2. How do differences in living standards reflect in South Africans' political attitudes? Is South Africa's middle class more pro-democracy than the poor and the elite?

5.3. How can we explain differences in the attitudes toward democracy among people that share similar living standards? What role do patterns of upward and downward social mobility play in this regard?

\subsubsection{Data sources}

The main source of data for Chapters 2 and 3 is the South African National Income Dynamics Study (NIDS) implemented by SALDRU at the University of Cape Town (SALDRU 2016a, b, c, d). NIDS is South Africa's first national panel study, which started in 2008 with a nationally representative sample of over 28,000 individuals in 7,300 households. At present, there are four waves of data available, each of which is spaced approximately two years apart (2008, 2010/11, 2012, 2014/15). The NIDS data is publicly accessible and can be downloaded at: http://www.datafirst.uct.ac.za/dataportal/index.php/catalog/NIDS/about.

The primary data source for the qualitative element presented in Chapter 4 consists of 30 semi-structured life-history interviews (LHIs), which my colleague, Rocco Zizzamia, and I conducted together with a local research team between July and September 2017 in the township of Khayelitsha, Cape Town. The LHIs were supplemented by four independent focus group discussions as well as a short quantitative questionnaire. 
Chapter 5 draws on the South African Social Attitudes Survey (SASAS), which has been conducted annually since 2003 by the Human Sciences Research Council (HSRC, 2012a, 2012b). Each data round is designed to yield a nationally representative sample of the adult population (16 years and older). Respondents are drawn from 500 enumeration areas, stratified by province, geographical subtype, and majority population group. The publicly released SASAS data can be downloaded at: http://www.hsrc.ac.za/en/departments/sasas/data.

The empirical analysis presented in this dissertation was performed using Stata 14.2 and Stata 15. All codes will be made available upon request.

\subsection{Contribution to the literature and resulting lessons for policy}

This dissertation is intended to fill some of the research gaps outlined in Section 1.1. To this end, it establishes a direct link between the class position of individuals and their chances of social mobility. Analysing quantitative and qualitative evidence for South Africa, I identify and characterise upwardly and downwardly mobile class-sublayers and draw conclusions about the main opportunities, risk factors, constraints, and policy needs that they are facing.

To this effect, Chapters 2 and 3 focus on conceptual and methodological issues, grappling with the definitional problem of who exactly constitutes the middle class. In theory, there should be an important overlap between the varying approaches to study the same phenomenon subsumed under the umbrella "middle class." However, our analysis presented in Chapter 2 reveals that in practice, depending on the chosen classification method, very different parts of society are identified as middle class, which can make up between 10 and 60 per cent of the national population. While none of these definitions should be seen as right or wrong (Reeves, Guyot, \& Krause, 2018), we argue that in country contexts marked by high levels of inequality along with widespread poverty - as in the case of South Africa - some definitions can be considered more suitable than others.

First, as a starting point to any definition that aims to capture an economically stable, secure, and empowered middle class, we emphasize the need to define an absolute minimum consumption floor necessary for long-term physical well-being. We argue that this is most adequately captured by the specification of a cost-of-basic-needs poverty line, below which people are considered unable to satisfy their basic needs (not only in terms of food, housing, and clothing, but also including other consumer goods, health, education, and transport, for example) and thus should not be identified as middle class. This speaks against most purely relative definitions that locate the middle class in the literal middle of the income or 
expenditure distribution in a country context, where more than half of the population are considered poor by national standards. Similarly, this perspective also opposes a number of absolute definitions that identify the middle class in relation to the two-dollar-a-day international poverty line or a similarly low minimum income requirement.

Second, we highlight the importance of accounting explicitly for the volatility that people face in terms of being capable to meet their basic needs. As the available panel data allows us to follow individuals over time, we can observe movements into and out of poverty. We find that out of 11 million South Africans who were non-poor in 2008, about one in four had fallen into poverty by 2012. From our point of view, those individuals who stand just at the edge of poverty should not be considered part of the middle class.

Summarising, we argue that to be considered stably middle class, households need to be able to meet their basic needs at present, and be sufficiently secure against falling into poverty in the near future. That is, they must be non-poor and must face an acceptably low degree of vulnerability to poverty (compare Section 1.1).

Based on these considerations, López-Calva and Ortiz-Juarez's (2014) vulnerability approach provides a promising starting point to conceptualising the middle class. Their approach had originally been developed in reference to a set of Latin American countries and our replication of their methodology is one of the first applications to a different country context. In line with the original approach, we use a simple probability model fitted to NIDS panel data to provide an estimation of the risk a person faces to either remain poor or fall into poverty over a given time horizon, conditional on a set of observable characteristics of the household that the person lives in at present. On this basis, we propose a monetary definition of the middle class, where we select the expenditure level associated with a maximum risk to poverty of 10 per cent as the lower bound, and the expenditure level associated with effective invulnerability to poverty as the upper bound. This gives us a monthly per capita expenditure range of R2,794 to R10,954 (in January 2015 prices), equivalent to $\$ 11.7$ to $\$ 45.7$ (in 2005 PPPs), which is relatively close to the range of $\$ 10$ to $\$ 50$ that had originally been identified by López-Calva and Ortiz-Juarez (2014) in the Latin American context. Using these thresholds, we find that South Africa's stable middle class is smaller than most previous studies suggest, and has grown sluggishly since 1993. Despite this, there has been a considerable demographic transformation within the middle class, with Africans now outnumbering whites by a significant margin. However, even though the share of Africans in the middle class has tripled since 1993, it still remains far removed from demographic representativeness. 
Notwithstanding the foregoing argumentation in favour of using a vulnerability criterion to define the middle class, there are a number of limitations to this approach. In particular, the simple probability model which is used to derive the vulnerability index that identifies the middle class falls short in a number of aspects compared to state-of-the-art approaches in the poverty dynamics literature. Therefore, in Chapter 3 we move away from this simple modelling framework and instead fit a multivariate model of poverty transitions to the same data. Our approach follows a methodology originally suggested by Cappellari and Jenkins $(2002,2004,2008)$ to model low income transitions in British panel data. The advantage of the proposed regression design is that it explicitly allows for possible feedback effects from past poverty experiences and accounts for the potential endogeneity of initial conditions, unobserved heterogeneity, and non-random panel attrition - four factors that the vulnerability approach presented in Chapter 2 failed to account for.

Another limitation of the class concept presented in Chapter 2 consists in the exclusive focus on the distribution of poverty risks among those with expenditure levels above the poverty line. In fact, just as some of the non-poor face much higher chances of falling into poverty than others, some of the poor face much higher chances of exiting poverty than others. To account for these discrepancies in mobility patterns, in Chapter 3 we incorporate the differentiation between the middle class and a non-poor but vulnerable group into an extended schema of social stratification that additionally differentiates between transient and chronic poverty. Our analysis identifies an important extent of variation in the poverty risks predicted based on traditional social stratification variables (such as education and occupation) and demographic characteristics (such as race, gender, and household composition) - faced by people with similar current income or consumption levels. Unlike in the previous approach presented in Chapter 2, in Chapter 3 we therefore refrain from the definition of absolute monetary thresholds to identify class sublayers and instead base our analysis directly on the predicted poverty transition probabilities (derived from the endogenous switching model) and defined risk cut-offs. In our view, this revised and expanded conceptual framework presents a relevant addition to both the poverty dynamics literature and the middle-class literature in economics, proving a link between the two.

Five key findings emerge from our application of this framework to the South African case: First, with an average population share close to 24 per cent between 2008 and 2014/15, we re-confirm that the share of South African's who can be considered as stably middle class or elite is considerably smaller than most other studies suggest. However, the share of the middle class is approximately five percentage points larger (and, accordingly, the group of the 
vulnerable is five percentage points smaller) than the relative class share that would have been identified if a monetary threshold was applied. That is, by using a monetary threshold to identify the stable middle class, we risk missing out on a non-negligible share of the population that falls below that threshold but is nevertheless relatively secure against falling into poverty. At the same time, by directly basing the classification on the latent poverty propensity scores, we are better able to identify those in the population who have crossed the expenditure threshold but nevertheless face an elevated risk to poverty.

Second, we find that the transient poor and the vulnerable, at 27 per cent, constitute a considerable share of South Africa's population. Interestingly, these two groups who straddle the poverty line are strikingly similar in terms of their average household characteristics. We argue that they differ from both the chronically poor and the stable middle class and elite not only in terms of household characteristics, but likely also in policy needs (see also Chapter 5). In this regard, the perspective that our social-stratification schema affords us is valuable in that it challenges the meaningfulness, in a dynamic sense, of the standard division of society into poor and non-poor groups.

Third, investigating the differences between class categories, the number of household members in employment and particularly the employment status and the type of employment of the household head are exposed as key distinguishing factors. Specifically, most household heads in the middle class and elite are formally employed with a permanent work contract and union coverage. Among the vulnerable and the transient poor class, in contrast, unstable and informal employment relationships dominate and a larger share is either unemployed or economically inactive. From this we conclude that closing the skills gap and increasing both the quantity and quality of jobs will certainly remain central challenges that South Africa's government, as many others, will need to address in order to lift larger parts of the population into the middle class and prevent backslides into poverty. In this regard, policymakers are likely to face an important trade-off between flexible labour market arrangements to foster job creation and the creation of fewer, but better and more stable jobs that will allow more people to escape poverty over the longer term. This is likely to be true not only in South Africa but also in other parts of both the Global South and North, where growing flexibility and precariousness in the labour market have been increasingly exposed as sources of rising economic insecurity (International Labour Office, 2004). In this context, it is also worth noting that under the proposed framework, economic growth per se will not necessarily translate into the emergence a stable middle class. Instead, the effect will depend on the distributional nature, sustainability and employment intensity of growth. 
Fourth, notwithstanding the substantial extent of churning around the poverty line, the transient poor and vulnerable groups still remain outnumbered by the chronic poor, who constitute the lion's share of the South African population at close to 50 per cent. In spite of the recent interest in the middle class, particularly in country contexts marked by enduringly high socioeconomic inequality, policymakers should not lose sight of the large share of the population that remains locked in persistent poverty with very low chances of being fruitfully integrated into the labour market. In addition to the provision of basic services that ensure that this group's health, education and nutritional needs are met, social transfers will remain an indispensable source of income for many of the chronic poor.

Finally, there is indicative evidence that the poor and the vulnerable are not only more exposed to several risk factors but, in addition, also seem disproportionately deprived in terms of their access to effective formal and informal insurance mechanisms to confront these socioeconomic risks. This higher risk exposure and inadequacy of existing coping strategies gives scope for targeted social protection interventions. However, to fill this space, policymakers will require a closer investigation into how social stratification is related to the distribution, frequency and intensity of poverty-triggering events, on the one hand, and access to coping mechanisms, on the other.

Picking up on these findings, Chapter 4 specifically focuses on investigating in greater detail the social realities and risk factors that affect particularly those in society who cannot yet be considered as members of the stable middle class. In the previous chapters, we were able to identify and profile those individuals who have good chances to exit from poverty temporarily at some point of their lives, but who rarely manage to escape sustainably. However, our investigation into the economic precarity of these groups was limited by the fact that the quantitative data at our disposal could only offer a limited understanding of the multidimensional causal processes and pathways that condition poverty escapes and descents. In other words, the quantitative analysis presented in Chapters 2 and 3 cannot tell us why exactly particular factors, or a combination thereof, are important in explaining poverty trajectories.

Using a mix of quantitative and qualitative research methods, Chapter 4 attempts to provide some insights to this question. While the empirical analysis presented in Chapter 2 and particularly Chapter 3 mainly serves to single out individual characteristics of the household (or the head of household) that can be associated with transitions into and out of monetary poverty, the sustainable livelihoods approach that is adopted in Chapter 4 offers a more holistic perspective. It considers the specific vulnerability context that South Africa's 
poor urban dwellers typically face, and examines their ability to access a range of tangible and intangible assets - comprising human, financial, physical, social, and geographic capital -, paying attention to the interlinkages between these.

Under this framework, the pool of opportunities and resources that people can draw on to construct their livelihoods depends upon their asset holdings, which cut across all five capital types. This notion offers a more nuanced perspective on the poverty transitions examined in the preceding chapter. As discussed above, Chapter 3 identifies those among the poor who have above average chances of moving out of poverty. Chapter 4 points to two distinct factors that may underpin these dynamics. On the one hand, some of those who are expected to be upwardly mobile may have simply been unlucky in the present period. That is, they are stochastically poor. For them, the escape from poverty would reflect a return to an expected non-poor standard of living, given their available asset base. On the other hand, there may be a group of individuals who are structurally (asset) poor at present, but face above average chances of moving out of poverty through the successful accumulation of productive assets (or an increase in the returns to those assets). These two types of upward social mobility represent distinctly different experiences that need to be clearly distinguished.

While both these movements would be expected to be sustained over time, there is also a third type of upward mobility that is stochastic in nature. That is, some of those who move across the money-metric poverty line from one period to the next may have simply been lucky in the respective period, without any accompanying change in the underlying incomegenerating processes and asset structure. These stochastic movements must be considered less likely to be sustained over time and therefore should not be confused with structural escapes.

If the sustainable reduction of poverty is a major concern, then gaining a better understanding of the pathways that facilitate structural escapes from poverty as well as the processes that condition structural descents into poverty is a worthwhile endeavour. To this end, in the first part of the analysis presented in Chapter 4, I decompose the poverty transitions observed in NIDS panel data into stochastic and structural components. The assetbased approach used for this purpose is conceptually similar to the one recently proposed by Radeny, Van den Berg, and Schipper (2012) to study poverty dynamics in rural Kenya, drawing on earlier work by Carter and May $(1999,2001)$ and Carter and Barrett (2006). This asset framework on its own, however, may be insufficient to identify the main determinants that explain transitions into and out of poverty (Radeny et al., 2012). Therefore, in the second part of the analysis, I triangulate my quantitative findings with evidence from 30 life history interviews that I conducted, together with a local research team, between July and September 2017 in the township of Khayelitsha, Cape Town. The qualitative research design was partly 
informed by the life-history interview techniques used by Davis and Baulch (2011) in rural Bangladesh and Adato et al.'s (2007) "household events mapping” technique used in rural KwaZulu-Natal. The urban focus and distinction between structural and stochastic movements distinguish my research from previous mixed-method investigations of poverty dynamics in sub-Saharan Africa, which - to my knowledge - either focus on rural settings or do not differentiate between stochastic and structural mobility patterns.

Using data visualisation methods in the form of asset pentagons and livelihood trajectory diagrams, Chapter 4 illustrates the multidimensional deprivation and main risk factors that structurally poor urban households experience. Four interrelated dimensions characterising urban poverty in South Africa can be extracted from the analysis:

First, reconfirming the findings from Chapters 2 and 3, transitions into or out of employment and job-to-job transitions are among the main trigger events associated with both poverty entries and exits.

Second, given the low returns and high job volatility associated with low-skilled labour, people typically require additional physical and social assets to achieve and sustain a position of economic security. This matches with the findings by Carter and May (1999) for rural South Africa. While urban living has generally been associated with a fragmentation of social relationships, this may apply less to the urban poor, who are embedded in township community networks and often maintain strong linkages with their rural kin (Du Toit and Neves, 2009). Depending on the "quality" of the network, these social contacts may play a dual role - both enabling and constraining upward mobility.

Third, as it is well-established in the literature, higher levels of education constitute an important enabling factor for upward social mobility (see, for example, Adato et al., 2006). Nonetheless, today's youth struggle to enter the labour market and have particular difficulties in finding stable employment, this despite often having completed secondary schooling. Beyond the lack of jobs, this may be related to the poor quality of education as well as to a lack of work experience and the nonexistence of a social network that could facilitate contacts with potential employers (see Spaull, 2015, for further discussion).

Fourth, reconfirming the findings by Carter and May (1999) for rural South Africa, poverty is not only a matter of few assets, but also of constraints to effectively using these assets. A specific constraint in this regard concerns the lack of access to financial capital, which especially affects people preparing for retirement. While access to credit generally presents an important enabling factor, my findings also suggest that accumulated debt can easily turn into a curse. Another constraint concerns the environmental or geographic context 
confronted by the urban poor, characterised by a high exposure to risk factors from natural hazards and crime that threaten life and property.

While the three preceding chapters have been concerned with formalising the link between class and social mobility and explaining key determinants, Chapter 5 deals with the question of how patterns of social stratification are manifest in political attitudes. Adding to the previous literature that generally looks at homogenous income groups, in this chapter I discuss the ways in which differences in perceived chances of social mobility tend to condition the political attitudes of people with otherwise similar living standards.

To this end, I suggest a classification schema that distinguishes between five social classes: (i) the persistently poor; (ii) the upwardly mobile poor, called "escapers"; (iii) the downwardly mobile middle class, called "anxious"; (iv) the upwardly mobile middle class, called "climbers"; and (v) the elite. My empirical findings demonstrate the limits to understanding people's political attitudes in relation to their current standard of living alone and illustrate the importance of taking mobility patterns explicitly into consideration. Using the suggested classification schema, I am able to show that it is not primarily differences in material well-being but in perceived chances of upward social mobility that account for significant variations in people's political values and priorities.

Specifically, the two upwardly mobile strata - the "escapers" and the "climbers" show the strongest generic support for democratic rule. They also display the highest levels of trust in public institutions and inherit the firmest beliefs that voting is an effective tool to influence political processes in the country. At the same time, however, these two groups who perceive themselves as upwardly mobile may have earned some of their privileges through the existing political system and therefore, on average, are less likely to take on a more critical or demanding stance in politics. In fact, they are over-proportionally satisfied with government performance and are alarmingly more likely to tolerate government constraints on political freedoms and less likely to advocate for the immediate dismissal of corrupt politicians.

In contrast, the "anxious" - despite being comparable to the climbers in terms of their standard of living, levels of education, and employment - show signs of political resignation. In fact, their political attitudes are closest to the ones displayed by the persistently poor. These two groups, who see threats of downward mobility and tend to perceive themselves as being cut off from opportunities to ascend the social ladder, are much less trusting of public institutions and less satisfied with governance performance. However, instead of raising their concerns, they show signs of disillusionment about the influence of their vote on politics in the country and are thus more likely to opt out of the political process. 
Summarising, four main messages emerge from the analysis presented in this thesis: First, the chosen indicator(s) of social class will certainly make a clear difference not only with respect to the estimated size and growth of the middle class, but especially with regard to its characteristics, needs, and relationship to other economic or political outcomes (see also Burger, McAravey, \& Van der Berg, 2017; Reeves, Guyot, \& Krause, 2018; Visagie \& Posel 2013; Visagie, 2015). Therefore, when studying the middle class, it is extremely important to think carefully about which definition appears the most appropriate in view of both the given country context and the main research objective, and provide a careful reasoning for the conceptual decisions and modelling choices that are being made.

Second, the notion of economic security and stability is central to the social and political meanings of being middle class. Approaches to conceptualizing and measuring social class should account for this notion and be capable of identifying a middle class that is free from concern about meeting basic needs - both statically and dynamically. The stable middle class that is identified using this stability criterion will generally be much smaller than approaches relying on less demanding criteria suggest. For the specific case of South Africa, this research shows that only one out of four persons can be considered stably middle class or elite. Conversely, about half of the population are locked in persistent structural poverty.

Third, if the growth of a stable middle class is a desired development outcome and focus of government policy, then an explicit focus on the stability and quality of employment is essential. Not only the lack of jobs, but also the prevalence of casual and precarious forms of work impede the development of a stable middle class. In this regard, policymakers will likely face an important trade-off between high market flexibility to foster job creation, and the creation of fewer, but better and more stable jobs. However, the creation of employment is not the only concern. People must also be capacitated to take on the jobs that are being created. In this regard, improvements in the quality of education as well as in the provision of infrastructure and transport (at accessible prices) are indispensable.

Lastly, the middle class that is identified using standard economic approaches is not a homogenous political actor and will not unambiguously support democratic processes and institutions (see also Neubert, 2014). Rather, even within the middle class, there is an important extent of heterogeneity in the political orientations and priorities of those who perceive themselves as winners or losers under the existing political system. Nonetheless, on the basis of my results, neither the upwardly nor the downwardly mobile sublayers within the middle class can be expected to move political processes in South Africa into a more liberal and inclusive direction. While those who perceive themselves as being cut off from 
opportunities to ascend the social ladder display signs of political resignation, those people who perceive themselves as upwardly mobile tend, on average, to be less concerned with corruption and more tolerant of government constraints on political freedoms.

\subsection{Limitations of this study and avenues for future research}

Although this research was carefully prepared, there were some limitations that could not be fully addressed. Among these, three issues deserve particular attention.

\section{Endogeneity concerns}

First, there are a number of endogeneity concerns associated with analysing the effect of household characteristics on poverty transitions. Chapter 3 makes an attempt to address some of these. The multivariate regression model used which is here explicitly allows for possible feedback effects from past poverty experiences and accounts for the potential endogeneity of initial conditions, unobserved heterogeneity, and non-random panel attrition, each of which has been insufficiently addressed in previous studies that dynamically define the middle class based on simpler models of poverty risks, including the one replicated in Chapter 2.

Nonetheless, there are two major limitations to the approach presented in Chapter 3. The first concerns the strict exogeneity assumption of the parental background variables used to instrument initial poverty status. While the provided test statistics seem encouraging and we provide careful reasoning for the selection of variables, ruling out all potential threats to instrument exogeneity is not an easy task particularly in the context of poverty transitions reflecting intricate social processes.

The second shortcoming concerns the limited assessment of events that trigger upward and downward mobility (such as losing or finding a job, for example). These have been excluded from the regression model due to issues of endogeneity that may arise if there are omitted factors which influence, for example, whether someone participates in the labour market, and which also affect the chances of poverty entry or exit (Jenkins, 2011). Feedback effects from the dependent variable are another potential source of endogeneity, in the sense that changes in adjustable characteristics such as the composition of the household and employment decisions are likely to be influenced by changes in the poverty status. While the approach that I apply circumvents these concerns and presents a valid method to examine the effects of state dependence in the presence of unobserved heterogeneity, it does not allow investigating the nature and direction of these possible feedback effects (Biewen, 2009). 
Assessing the causal mechanisms that trigger poverty entries, on the one hand, and lift people out of poverty into the middle class, on the other, presents an important area of research that will require further attention in the future. However, it is a complex and difficult task as researchers need to model several processes simultaneously (Jenkins, 2011). While the livelihood strategies of the rural poor importantly rely on natural resources where weatherrelated shocks present an imortant source of external variation, this becomes all the more relevant as poverty is becoming an increasingly urban phenomenon.

\section{Respondent bias in qualitative data}

During our field research in Khayelitsha, we were aware of the risk of respondents answering questions in a way that they perceive personally or socially desirable. Potential biases may range from respondents presenting their living conditions in the worst possible light in expectation of assistance or other benefits (expectancy bias), to reporting inaccurately on sensitive or personal topics to present themselves in the best possible light in order to be accepted and liked (social desirability bias). To minimise these biases, we worked with a small number of experienced research assistants that were carefully trained. Assistants were instructed to use a standard opening statement which clarified the purpose of the study, explicitly excluding any type of direct or indirect material benefit, to avoid words with strong connotations such as "poor" or "rich", and to phrase questions in a neutral way.

When assessing the positive or negative welfare effects of events reported during the LHIs, emotional bias was another concern. For example, the birth of a child was generally perceived as a positive event, even if it weakened the economic position of the household, while the death of a household member was generally perceived as a negative event, even if the material impact was small. While clearly visible during the interviews, these effects were generally mitigated when respondents were asked to rate their welfare status at each state in life at the end of the interview. My impression was that the comparison across all events that had occurred over the life cycle helped respondents to evaluate the welfare effects of individual events. In my view, a similar (simplified) relative anchoring exercise could also be usefully incorporated when designing shock modules for quantitative surveys, in which respondents are asked to retrospectively rate the impact of certain events. However, this will require further research and testing.

Finally, related to the former, recall bias was a major issue. The livelihood trajectories assessed in Chapter 4 fully rely on self-reported, retrospective information. In this regard, it is important to keep in mind that, when people remember past events, they may not always have 
a complete or accurate picture of what happened and may misrecall or misinterpret the causal interlinkages between events. Furthermore, consistent with the notion of a positivity bias in old age, evidence from psychological research suggests that people generally perceive positive memories as more central to their life story and identity than negative events (Berntsen, Rubin, \& Siegler, 2011). These issues could not be resolved completely and must be kept in mind when interpreting results.

\section{Non-material dimensions of well-being}

Fourth, it is worth noting that the focus of this dissertation is on material dimensions of wellbeing. This implies that social-psychological dimensions of poverty, deprivation and economic (in-)security, which tend to affect individual and household livelihood strategies, are not explicitly discussed.

In this regard, an interesting observation from our field research is that, in spite of stubbornly high levels of unemployment in South Africa, respondents surprisingly frequently reported having turned down or quitted wage jobs. This behaviour was most often observed among young men with few dependents to support and strong family networks to rely on. These voluntary quits are generally explained by high levels of dissatisfaction with precarious forms of work, often marked by low pay, poor working conditions, long commuting distances, and/or low social recognition. In face of the considerable expansion of temporary employment services in South Africa over the past decade (Bhorat \& Van Der Westhuizen, 2013), which are largely exempt from formal labour protections, a closer investigation of the effects of work precarity and volatility in the labour market on individual wellbeing may present a fruitful avenue for future research. 



\title{
CHAPTER 2
}

\section{Defining the middle class in the Global South: A quantitative perspective from South Africa}

\author{
Simone Schotte, Rocco Zizzamia, Murray Leibbrandt, and Vimal Ranchhod \\ An earlier version of this chapter appeared as Zizzamia, R., Schotte, S., Leibbrandt, \\ M., \& Ranchhod, V. (2016). Vulnerability and the middle class in South Africa. \\ SALDRU Working Paper Number 188, NIDS Discussion Paper 2016/15. \\ Cape Town: SALDRU, University of Cape Town.
}

\begin{abstract}
The wave of upbeat stories on the developing world's emerging middle class has sparked a debate on how social class in general and the middle class in particular can be defined and empirically captured. In economics, this debate has been focused on locating the middle class within a particular income or expenditure range, where the most appropriate class boundaries - especially the cut-off that separates the poor from the middle class - remain heavily contested. Adding to this literature, in this chapter we provide a structured overview of a wide array of definitions that have been proposed in the economics literature, and assess their strengths and limitations with an application to South Africa. Arguing that the notion of economic security and stability is central to the social and political meanings of being middle class, in the main part of this chapter we replicate an empirical strategy recently developed by López-Calva and Ortiz-Juarez (2014), which uses (in-)vulnerability to poverty as the key criterion defining middle-class status. To our knowledge, this chapter provides the first application of this method to the case of South Africa. Using this approach, we find that South Africa's stable middle class is smaller than most previous studies suggest, and has grown only sluggishly since 1993. Despite this, there has been considerable demographic transformation within the middle class, with Africans now outnumbering whites by a significant margin.
\end{abstract}

Acknowledgements: We acknowledge support from the European Union represented by the European Commission, on behalf of the Government of the Republic of South Africa, for Research on Inequality for the Programme to Support Pro-poor Policy Development. We would also like to thank Joshua Budlender, Arden Finn, and participants at the GIGA Workshop on Inequality and Middle Class Development in Africa held in Cape Town in May 2016 for helpful discussions and comments. Any remaining errors are our own. 


\subsection{Introduction}

The emerging middle class in the Global South has gained growing attention since the turn of the century. It has been touted as a new and powerful consumer market that could drive economic growth, and as a torch-bearer of liberal democracy and good governance (Birdsall, Graham, \& Pettinato, 2000; Kharas, 2010; Cárdenas, Kharas, \& Henao, 2015). ${ }^{2}$ Specifically in the African context, this optimism has been fuelled by a number of reports which have claimed that the region's middle class has experienced rapid growth over the past decades and now makes up a considerable share of the population (Hattingh, Russo, Sun-Basorun, \& Van Wamelen, 2012; Ncube, Lufumpa, \& Kayizzi-Mugerwa, 2011). However, recent research across the continent is increasingly providing evidence that estimations of the size and economic potential of Africa's new middle class may have been exaggerated (see, for example, Giesbert \& Schotte, 2016; Rodas, Molini \& Oseni, 2017; Visagie \& Posel, 2013).

At the core of these opposing views is a long-standing debate on what constitutes the middle class (see Melber, 2016). Countless criteria, subject to which social classes in general and the middle class in particular may be defined, have been proposed in the literature. In economics, most class definitions are based on financial indicators, which commonly locate the middle class within a particular range of the income distribution (see Reeves, Guyot, \& Krause, 2018). An important complication in this regard concerns the selection of adequate class boundaries. In particular, the lower cut-off point that separates the poor from the middle class remains heavily contested (see Giesbert \& Schotte, 2016).

In order to bring some clarity to this debate on how to define and empirically measure the middle class, in this chapter we provide a structured overview of a wide array of rival approaches, focusing on the literature in economics. To enable direct comparisons, we apply these varying definitions to the same income distribution and discuss their advantages and limitations using South Africa as a case study.

In view of the given country context marked by high inequality along with widespread poverty, for the purpose of this study, we chose freedom from concern about meeting basic needs as the main criterion to evaluate alternative approaches. Accordingly, people who are currently unable to purchase adequate food and non-food items should - in our understanding - not be identified as middle class. However, if we go further, and include economic security and stability as central elements of the social and political meanings of being "middle class"

\footnotetext{
${ }^{2}$ These propositions draw on an established international literature which sees the middle class as having the potential to play an important social, political, and economic role in a country's development process (see, for example, Barro, 1999; Chun, Hasan, \& Ulubasoglu, 2011; Easterly, 2001; Josten, 2013; Loayza, Rigolini, \& Llorente, 2012; Solimano, 2008).
} 
(see Chapter 1), then this static requirement will not suffice. Taking on a dynamic perspective, we argue that members of the middle class should also be at a reasonably low risk of falling into a situation of precarity in the near future. Accounting for this latter criterion for middleclass membership, in the main part of this chapter, we replicate an empirical strategy recently suggested by López-Calva and Ortiz-Juarez (2014), which aims to differentiate the "stable" middle class from a non-poor but vulnerable group. To our knowledge, this study presents one of the first applications of this method (originally developed in reference to a set of Latin American countries) to a different country context (see also Rodas et al., 2017 for Nigeria).

Following López-Calva and Ortiz-Juarez's (2014) original approach, in this chapter, we use panel data from the National Income Dynamics Study (NIDS) to estimate a simple model of poverty transitions for the South African case. The coefficient estimates allow us to predict a person's risk of staying in or falling into poverty over a medium-term time frame, depending on a broad array of initial household conditions. On this basis, we propose a monetary definition of the middle class, where we select the expenditure level associated with a maximum risk to poverty of 10 per cent as the lower bound, and the expenditure level associated with effective invulnerability to poverty as the upper bound. This gives us a monthly per capita expenditure range of R2,794 to R10,954 (in January 2015 prices), equivalent to $\$ 11.7$ to $\$ 45.7$ (in $2005 \mathrm{PPPs}$ ), which is relatively close to the range of $\$ 10$ to $\$ 50$ that had originally been identified by López-Calva and Ortiz-Juarez (2014).

Using these thresholds, we find that South Africa's stable middle class is smaller than most previous studies suggest, and has grown sluggishly since 1993 - from about 12.4 per cent of the total population to about 15 per cent in 2012. Despite the unimpressive growth story of the middle class since the end of apartheid, consistent with the existing literature, we detect a considerable demographic transformation within the middle class. However, even though the share of Africans in the middle class has tripled since 1993 according to our findings, it still remains far removed from demographic representativeness.

The remainder of this chapter is structured as follows: Section 2.2 introduces the data and explains the way that poverty is measured in this study. Section 2.3 sets the context for the subsequent analysis by providing a quick overview of the extent of poverty, inequality and income polarisation in South Africa. Section 2.4 provides an extended review of previous approaches to the definition of the middle class that have been suggested in the economics literature, both nationally and internationally. Section 2.5 presents our replication of LópezCalva and Ortiz-Juarez's (2014) vulnerability approach. It first describes the method and then presents our results along with a number of sensitivity checks. Section 2.6 concludes. 


\subsection{Data and definitions}

The main source of data for this chapter is the National Income Dynamics Study (NIDS) implemented by the Southern Africa Labour and Development Research Unit (SALDRU) at the University of Cape Town (SALDRU 2016a, b, c, d). NIDS is South Africa's first national panel study, which started in 2008 with a nationally representative sample of over 28,000 individuals in about 7,300 households. At present, there are four waves of data available, which are each spaced approximately two years apart (2008, 2010/11, 2012, 2014/15).

As with all panel studies, there is some attrition between the different survey waves. Of the 26,775 interviews that were completed in $2008,21,111$ individuals were successfully re-interviewed in 2010/11. In comparison to this relatively high attrition rate of 21.2 per cent between the first two waves, attrition was negative in wave 3 (relative to wave 2). That is, 21,390 individuals of the initial sample were observed again in 2012. In 2014/15 attrition went up again. 20,773 core household members were successfully re-interviewed. To mitigate the bias potentially caused by non-random panel attrition, panel weights (provided by SALDRU) have been used when investigating inter-wave transitions.

As a supplementary data source that will allow us to give an indication of historic trends, we use data from the World Bank Project for Statistics on Living Standards and Development (PSLSD) - a nationwide survey conducted in 1993. It covers approximately 9000 households, which were drawn from a representative sample.

All monetary values used in this chapter are deflated to January 2015 prices using the Statistics South Africa (Stats SA) headline consumer price index (2015a). ${ }^{3}$ Following Stats SA's general practice, poverty is defined in terms of per capita household expenditure, which is assumed to provide a better approximation of permanent household income than the reported income. As explained in the introduction and discussed in further detail in Sections 2.4 and 2.5 below, in this chapter, we understand the satisfaction of basic needs as a necessary condition for being considered middle class. Accordingly, we classify household as being poor versus non-poor using Stats SA's (2015b) upper-bound poverty line (UBPL). This line is set at R963 per person per month, equivalent to approximately $\$ 4$ a day (in 2005 PPPs). ${ }^{4}$

The UBPL is one out of three national poverty lines published by Stats SA in 2015 using a cost-of-basic-needs (CoBN) approach. Of these, the food poverty line (FPL) is the

\footnotetext{
${ }^{3}$ To adjust for inflation, for each line the food component (equal to the FPL) is inflated by using the food specific Stats SA CPI and the non-food component (equal to the difference between the FPL and the UBPL / LBPL respectively) is inflated by using the non-food specific Stats SA CPI (Stats SA, 2011, 2012, 2015).

${ }^{4}$ In this chapter, we use the 2005 PPP conversion factor and not the more recent one as of 2011. This decision was taken to ease comparisons with the class thresholds that have been suggested in the previous literature.
} 
level of consumption below which individuals are unable to purchase sufficient food to fulfil their caloric requirements, even if all expenditure is dedicated to food. The lower-bound poverty line (LBPL) allows for spending on non-food items, but requires that individuals sacrifice some food consumption in order to fulfil their non-food needs. Only at the UBPL, individuals can purchase both adequate food and non-food items. For this reason, it has been chosen as the relevant poverty threshold for the purpose of this study.

We are going to investigate the sensitivity of our results with regard to this choice. For this purpose, at the lower end, we use Stats SA's LBPL, which is set at R629 per person per month, equivalent to approximately $\$ 2.6$ a day (in 2005 PPPs). At the upper end, we use the upper bound poverty line that was recently developed by Budlender, Leibbrandt, and Woolard (2015) for South Africa. This line is set at R1,283 per capita per month, equivalent to approximately $\$ 5.4$ a day (in 2005 PPPs). While both approaches follow Ravallion's (1994) CoBN methodology, the difference to Stats SA's UBPL is mainly due to specific methodological choices, especially with regard to the treatment of outliers and the definition of the "reference group" of the poor (Budlender et al., 2015).

Before proceeding to the analysis, it should be noted that the 2008 NIDS sample was drawn on a nationally representative basis and the poverty headcount calculated from this data closely matches official statistics that draw upon the Living Conditions Survey (LCS) 2008/2009. However, there are reasons to believe that the reduction in poverty observed particularly between the last two survey waves (2012 to 2014/15) may be overstated. ${ }^{5}$ In consequence, in the remainder of this chapter we keep the discussion of time trends observed up to $2014 / 15$ to a minimum and instead focus on the 1993-2008 and 2008-2012 periods. Furthermore, we discuss explicitly how non-random panel attrition may bias our results.

\subsection{Brief historic recap of the extent of income polarisation in South Africa}

Apartheid represented a rigid racialised system of unequal resource distribution, resulting in an extremely polarised society. After two decades of democracy, economic inequality in South Africa remains one of the highest in the world. While survey comparability issues make the analysis of historic trends a challenging task, most researchers will agree that the positive

\footnotetext{
${ }^{5}$ Using household expenditure, poverty increased up to 2010/11, with a remarkable rise of five percentage points in the share of households being pushed below the food poverty line. From 2010/11 to 2014/15 poverty levels decreased, with the strongest fall observed from 2012 to 2014/15. This general trend is consistent across key variables and robust across subsamples. However, particularly the strong reduction in poverty over the last two years of NIDS may raise doubts, given that it was not mirrored by any major event at the macro level and is not reflected in the official country statistics. The trend might in part be explained by changes in the NIDS sample (see Chapter 3), given that individuals with a lower risk of poverty appeared to be somewhat more likely to remain in the sample.
} 
growth in average real incomes has not been accompanied by any decline in South Africa's historically high levels of inequality. In fact, with the post-tax, post-transfer income Ginicoefficient being above 0.65 for every nationally representative survey since 1993 (see Leibbrandt, Woolard, Finn, \& Argent, 2010; Özler, 2007), aggregate inequality measures have generally shown an increase in inequality over the post-apartheid period.

At the same time, the country has seen a considerable decline in poverty rates over the same time horizon. In fact, since the transition to democracy, the incomes of the poorest in society were growing at a faster rate than the average income of the population. An important proportion of this pro-poor growth was facilitated by redistributive policies, particularly the provision of social grants (Finn, Leibbrandt, \& Woolard, 2013b)

This apparent paradox of an episode marked by relative pro-poor growth, on the one hand, and rising income inequality, on the other, is explained by the highly polarised nature of growth for most of the post-apartheid period. As Figure 3.1 illustrates, not only did those in the bottom 40 per cent of the income distribution experience above average income growth from 1993 to 2008, but the same holds true for the richest 5 per cent of the South African society. By contrast, the incomes of those in the middle of the income distribution - especially between the 40th and 95th percentiles - were growing at a slower pace than the mean annual growth rate of close to 2 per cent.

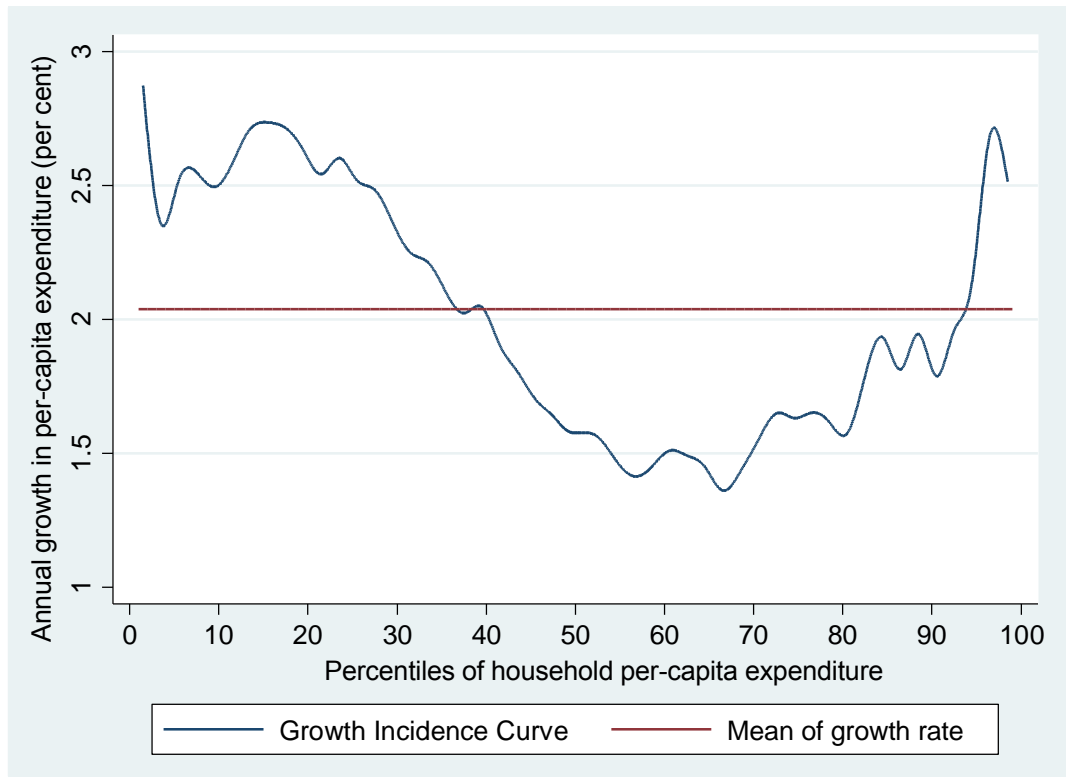

Figure 2.1 Growth incidence curve, 1993-2008

The polarised nature of this growth pattern becomes even more apparent once we account for the fact that growth for those at the lower end of the income distribution occurred from an extremely low base. The apparently impressive growth rates, especially at the very 
bottom of the distribution, imply a decline in the depth of poverty, but were largely insufficient to lift those households into an economically stable situation. As Table 3.3 below indicates, in 2008 about one third of the South African population still did not have sufficient money for food, and almost two thirds could not afford to meet both food and non-food needs.

Table 2.1 Poverty incidence in 2008 according to different poverty lines

\begin{tabular}{lrrrr}
\hline \hline Poverty Lines & & \multicolumn{1}{c}{ Stats SA } \\
$(2015)$ & $\begin{array}{c}\text { Budlender et al. } \\
(2015)\end{array}$ & $\begin{array}{r}\text { International } \\
(2011 \text { PPP })\end{array}$ \\
\hline Food (extreme) & Rands & 430 & 432 & $346(=\$ 1.9)$ \\
& Headcount & $34.87 \%$ & $35.04 \%$ & $25.88 \%$ \\
\hline Lower Bound & Rands & 629 & 669 & $564(=\$ 3.1)$ \\
& Headcount & $48.12 \%$ & $50.46 \%$ & $44.12 \%$ \\
\hline Upper Bound & Rands & 963 & 1,283 & \\
& Headcount & $60.75 \%$ & $67.31 \%$ & \\
\hline \hline
\end{tabular}

Note: Poverty lines have been converted to January 2015 prices using Stats SA's headline consumer price index (Stats SA, 2015a).

In contrast, incomes at the top of the income distribution grew from an already high base in 1993, leading to an increasing concentration towards the richest ventile. Figure 2.2 illustrates this gain in economic power experienced by those at the top 5 per cent of the income distribution. While the share in national income going to the bottom 40 per cent stayed virtually constant between 1993 and 2008, the top 5 per cent saw their share increasing by about 3.6 percentage points to just above 40 per cent in 2008. As income growth was lowest for those between the 40th and 95th percentiles (see Figure 3.1), those in the (upper) middle of the income distribution actually lost in economic power to the same extent as the top 5 per cent were gaining.

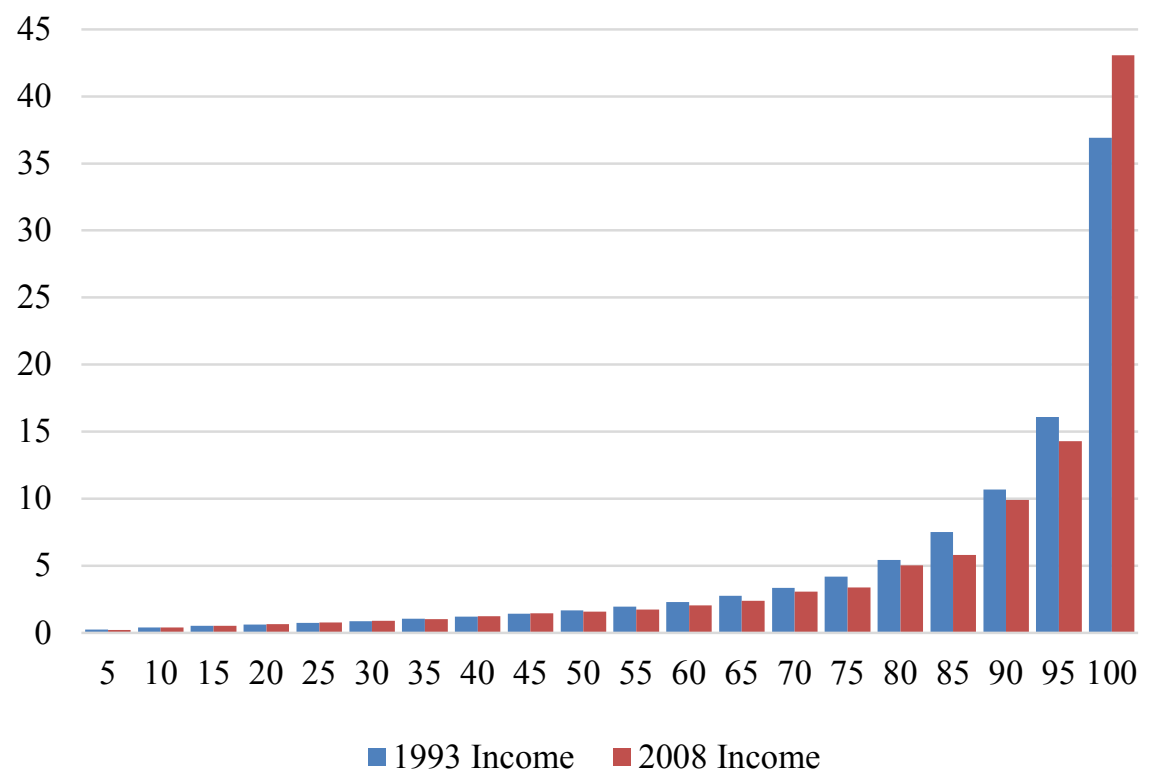

Figure 2.2 Shares of total income by ventile, 1993 and 2008 


\subsection{Literature Review}

Notwithstanding the popularity of the middle-class concept, there is no universally accepted understanding of who constitutes the middle class in South Africa and beyond (see Burger, McAravey, \& Van der Berg, 2017). On the one hand, sociologists have focused their attention on the functional role of the middle class. These definitions generally draw on people's educational achievements and/or occupational status, their attitudes and values, or their access to political power and authority (for South Africa, see Garcia Rivero, Du Toit, \& Kotze, 2003; Seekings \& Nattrass, 2006; Southall, 2016). To this extent, there is some overlap with ethnographic explorations of the middle class, which tend to focus on people's education, relationships of dependency, and their position in the social hierarchy (see Sumich, 2016 on Mozambique). In contrast to these externally defined criteria, some scholars have also used purely subjective definitions based on people's aspirations and self-perception. ${ }^{6}$

Economists, on the other hand, generally define the middle class in relation to their economic resources - especially in terms of income or expenditure, but also including other living standard measures such as assets ownership (for South Africa, see Finn et al., 2013a; Levy, Hirsch, \& Woolard, 2014; Ncube et al., 2011; Udjo, 2008; Visagie \& Posel, 2013). This more restricted, unidimensional view is adopted partly due to data availability and measurement issues, but also because people's material welfare has generally been assumed to be highly correlated with other dimensions of social class, such as education or occupation (see Reeves, Guyot, \& Krause, 2018).

In theory, there should be an important overlap between the varying approaches to defining the middle class - both within and across disciplines. However, in practice, the chosen indicator(s) of social class will certainly make a clear difference not only with respect to the estimated size and growth of the middle class, but especially with regard to its characteristics, needs, and relationship to other economic or political outcomes (Burger et al. 2015; Visagie \& Posel 2013). Therefore, when studying the middle class, it is extremely important to think carefully about which definition appears the most appropriate in view of both the given country context and the main research objective, and be clear about the reasons that motivate this choice. The following review of alternative approaches, along with a discussion of their pros and cons, may provide some guidance in this regard.

\footnotetext{
${ }^{6}$ Several studies have found a weak correlation between subjectively and objectively identified class measures, with a greater share of South Africans self-identifying themselves as standing on the middle rung of society's ladder, when they are in fact at the top or the bottom (Seekings, 2007; Burger et al., 2015). This apparent mismatch could be explained by the reference-group hypothesis, according to which respondents allocate themselves in reference their own peer group instead of the entire population (Phadi \& Ceruti, 2011).
} 


\subsubsection{Definitions of the middle class based on money metric measures}

While mainstream approaches in economics define the middle class based on money metric measures, alternative approaches have recently been suggested that build more closely on the sociological class literature. In what follows, we first review the most prominent definitions based on absolute or relative monetary thresholds. Alternative non-money metric measures will be discussed in Section 2.4.3.

\section{Relative thresholds}

The lowest common denominator in the debate on who constitutes the middle class is that its members should be "somewhere in the middle." Proceeding from this assumption, relative definitions locate the middle class in the literal middle of the income distribution.

Two different concepts can be distinguished in this regard. First, a range of studies locate the middle class according to particular segments of the cumulative income or consumption distribution. In this regard, for example, Alesina and Perotti (1996) use the third and fourth quintile (the 40th to 80th percentiles), Partridge (1997) uses only the third quintile (the 40th to 60th percentiles), Easterly (2001) and Foster and Wolfson (2009) refer to the three middle quintiles (the 20th to 80th percentiles), and Solimano (2008) uses the third to tenth decile (the 30th to 90th percentiles). For the specific case of South Africa, Finn et al. (2013b) and Levy et al. (2014) use income decile groups four to seven to define the middle class (the 40th to 70th percentiles), groups eight and nine to define the upper class and decile ten to identify the top income group. The main drawback of these purely relative approaches is that the population share of the middle class is held constant over time, which means that the relative share of the middle class will neither grow nor shrink in response to economic and social conditions, increased polarisation, or other distributional changes.

Second, "central tendency" measures define the middle class in a specific symmetric range around the median of the income distribution. In this regard, for example, Birdsall, Graham, \& Pettinato (2000) draw on a definition that was first proposed by Thurow (1987). They consider those individuals to be middle class, who have between 75 and 125 per cent of the per capita median income at their disposal. By comparison, other authors choose a wider range from 50 to 150 per cent (Visagie \& Posel, 2013, based on Davis \& Huston, 1992) or even from 60 to 225 per cent (Blackburn \& Bloom, 1985) of the per capita median income.

There are several reasons why one may be interested in the median earner of society and those households who fall within a specific range of the median: As Visagie (2013) argues in the South African context: 
"First, evidence suggests that the relative growth of the share of total income of those in the actual middle of the income distribution leads to greater political stability, to a citizenry with higher levels of human development (including better education and health) and even to higher levels of economic growth (Perotti, 1996; Easterly, 2001, 2007). Secondly, changes in the middle income interval would help to assess whether growth has benefited the ‘average South African’ in post-1994 South Africa” (Visagie, 2013: 2).

However, in developing economies typically characterised by a high concentration of the population at the lower end of the income distribution, this middle will likely still be poor in absolute terms and "is unlikely to be the middle class as either historically defined or understood" (Bhalla, 2007: 94). That is, while central tendency measures can be useful in assessing the degree of polarization or inequality in the income distribution, they do not adequately capture the actual welfare of the middle class. This is especially true in a high inequality country such as South Africa, where "thinking about what it means to be middle class is complicated by the low average and median levels of incomes in the country and the very wide distribution of income. Households who have achieved a modest standard of living are actually near the top of the national income ladder" (Visagie, 2013: 1).

\section{Absolute thresholds}

Alternatively, the middle class has commonly been identified according to an absolute income or expenditure range seen as adequate to be considered middle class. The main question that has been fuelling a heated debate on the definition of these thresholds is what it actually means to be middle class. In other words, where does poverty end and the middle class start, and when can somebody be considered rich? The important decision researchers are confronted with in this regard is whether those who move above the poverty line automatically enter the middle class, or whether there should be some intermediate group that separates those who can satisfy their most basic needs (but remain on the verge of falling into poverty) from a more economically stable middle class.

Several scholars, such as Banerjee and Duflo (2008) and Ravallion (2010), in fact define the middle class in the developing world simply as those who are no longer poor by international standards, using the two-dollar-a-day poverty line as the relevant threshold. What this implies is that someone living on the equivalent of $\$ 1.99$ a day (in 2005 purchasing power parities (PPPs)) would still be considered poor, while just one additional cent would push the same person into the middle class. The main argument for using this definition is that 
despite being admittedly still very poor, those within this range are still much better off than the poorest in society, who live below the poverty line. However, as noted by Ravallion (2010), those falling into this classification still remain at a high risk of poverty.

Picking up on this notion, other scholars have argued that the middle class should actually only comprise “those 'comfortably' clear of being at-risk-of-poverty” (Atkinson \& Brandolini, 2013: 83). With this in mind, Rose (2016) defines the middle class in the United States (US) as families with incomes of at least 150 per cent of the national poverty line. In reference to recent polls conducted by the Pew Research Centre, in which 1 to 2 per cent of the US population self-identified as upper class, he defines an upper cut-off that excludes the top 1.8 per cent of income earners from being middle class. Alternatively, Sawhill and Haskins (2009) locate the US middle class in an income range from 100 to 700 per cent of the poverty line, subdivided into three groups: "lower middle" (100-299 per cent), "middle" (300499 per cent), and "upper middle" (500-699 per cent).

Most prominently in the African context, the African Development Bank released a report in 2011, which - following a similar idea - suggests three subdivisions of the African middle class: "floating" (\$2-\$4), "lower middle" (\$4-\$10), and "upper middle" (\$10-\$20) (in 2005 PPPs). Combining these three groups, the report estimates that 34.3 per cent of all Africans belonged to the middle class in 2010. However, when excluding the floating class, the size of the middle class shrinks by almost two-thirds to 13.4 of the African population (see Ncube et al., 2011).

While appealing in their simplicity, a main limitation of these suggested approaches is that the boundaries that differentiate the "actual" middle class from the poor and the lower middle class are chosen arbitrarily. To address this shortcoming and derive a more robust and theoretically sound definition, López-Calva and Ortiz-Juarez (2014) pioneered an empirical strategy to defining the middle class anchored in the notion of economic security. Using panel data from Chile, Mexico, and Peru, households are ranked by their estimated probability of remaining in or falling into poverty within the next three to five years. In contrast to Banerjee and Duflo (2008), who cap the middle class at a maximum daily per capita income of $\$ 10$, López-Calva and Oritz-Juarez (2014) argue that a minimum income level of $\$ 10$ a day (in 2005 PPPs) is required for being middle class. At this threshold, people are estimated to face a maximum chance of 10 per cent of falling into poverty in the near future, which they consider an acceptable degree of vulnerability for the middle class. The upper cut-off is (arbitrarily) fixed at \$50 a day (in 2005 PPPs). 
The derived lower threshold is consistent with Kharas' definition of the global middle class, which he locates in a range of $\$ 10$ to $\$ 100$ a day (in 2005 PPPs) (Kharas, 2010; UNDP, 2013). ${ }^{7}$ Similarly, combining absolute and relative measures, Birdsall (2010) defines the middle class in developing countries as those with a minimum income of $\$ 10$ a day (in 2005 PPPs), excluding the top 5 per cent of the national income distribution. While the absolute lower bound is meant to identify those individuals who are too poor to be middle class in any society, the upper threshold excludes those who are considered rich at least by their own country standards.

Following a similar vein as López-Calva and Ortiz-Juarez's (2014) ambition for a more theoretically founded class analysis, there are an increasing number of studies that use the ownership of tangible and intangible assets, employment status, occupation, education, or possibilities for upward social mobility as criteria for class identification (see Section 2.4.3). Among these, Visagie and Posel (2013) locate South Africa's "affluent" middle class in an income range of R1,400 to R10,000 per person per month (in 2008 money terms), equivalent to about $\$ 8$ to $\$ 58$ a day (in 2005 PPPs). These thresholds correspond to the expected income interval for households in which the highest income earner is in an occupation that has typically been associated with the middle class. ${ }^{8}$

\subsubsection{The size of South Africa's middle class under alternative money metric measures}

Before returning to this more "productionist" understanding of middle class, in what follows we aim to take stock of the definitions introduced up to this point (summarised in Figure 2.3) and assess their implications for the size and growth of the South African middle class from 1993 to 2008 (see Table 2.2).

As Figure 2.3 illustrates, depending on the chosen classification method, very different parts of the South African population are identified as middle class. Most evident, all definitions that identify the middle class either in relation to the actual middle (or median) of the national income distribution, or just above the international two-dollar-a-day poverty line, classify many South Africans as middle class, who would be considered poor by national standards. This implies that many of those who are assigned middle-class status under these

\footnotetext{
${ }^{7}$ Trying to develop a global classification, Kharas (2010) defines the global middle class such that it excludes those who are poor in the poorest advanced European economies (average poverty line of Italy and Portugal) and those who are rich in the richest advanced European country (twice the median income of Luxembourg).

${ }^{8}$ Middle class occupations include white collar professions such as managers, senior officials, legislators, professionals (e.g. teachers and nurses), associate professionals, technicians and clerks; whereas working class occupations would include plant and machinery operators, craft and related trade workers, skilled agriculture and fishery workers, service and market sales workers and all elementary occupations (Visagie \& Posel, 2013).
} 
definitions still lack the financial means to afford even the most basic things in life. For example, Easterly's (2001) definition of the three middle quintiles, frequently quoted in the development literature, includes in the middle class even some of those who cannot purchase enough food. As pointed out by Visagie and Posel (2013), there is very little overlap between those in the actual middle of the national income distribution, and a South African middle class defined by an absolute level of affluence and economic stability. By contrast, the vulnerability- and economic empowerment-based approaches suggested by López-Calva and Ortiz-Juarez (2014) and Visagie and Posel (2013) respectively closely overlap.

Finn et al., 2013a; Levy et al., 2014 Easterly, 2001; Foster \& Wolfson (2009) Solimano, 2008 Blackburn \& Bloom, 1985 Visagie \& Posel, 2013 Birdsall et al., 2000

Sawhill \& Haskins, 2009 (excl. lower class) Banerjee \& Duflo, 2008 Ncube et al., 2011 (excl. floating class) Visagie \& Posel, 2013 López-Calva \& Ortiz-Juarez, 2014 Kharas, 2010; UNDP 2013 Rose, 2016 Birdsall, 2010

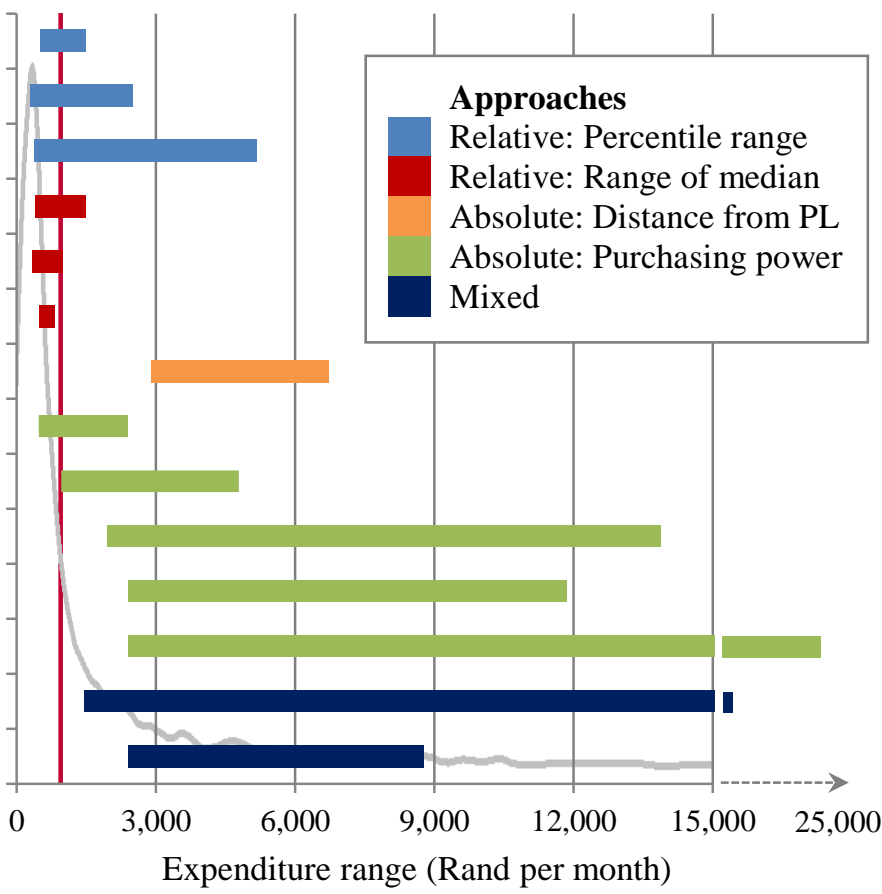

Figure 2.3 Comparison of rival approaches to the definition of the middle class

Note: Conversion between Int. \$ and South African Rand uses the PPP conversion factor for private consumption (LCU per international \$) provided by the World Bank. In 2005, Int. \$1 (PPP) was equivalent to R4.57. All thresholds have been converted to constant prices of January 2015 using the Statistics South Africa Consumer Price Index. The red line indicates Stats SA's UBPL fixed at R963. The grey line gives the kernel density distribution of monthly household expenditure per capita calculated from NIDS 2008 data.

Given these discrepancies, the choice of definition will make an important difference when estimating the size and growth of South Africa's middle class. As Table 2.2 illustrates, depending on the chosen classification method, its relative population share in 2008 can vary between 10 and 60 per cent. If we consider only those thresholds that were designed with specific reference to South Africa, the spread reduces to a still wide range of 22 to 38 per cent (see approaches by Finn et al., 2013a; Levy et al., 2014; Ncube et al., 2001 [excl. floating class]; Visagie \& Posel, 2013 displayed in Table 2.2). ${ }^{9}$

\footnotetext{
${ }^{9}$ Note that the population shares we show here (based on our own calculations) are not necessarily the same as the ones produced by these authors themselves.
} 


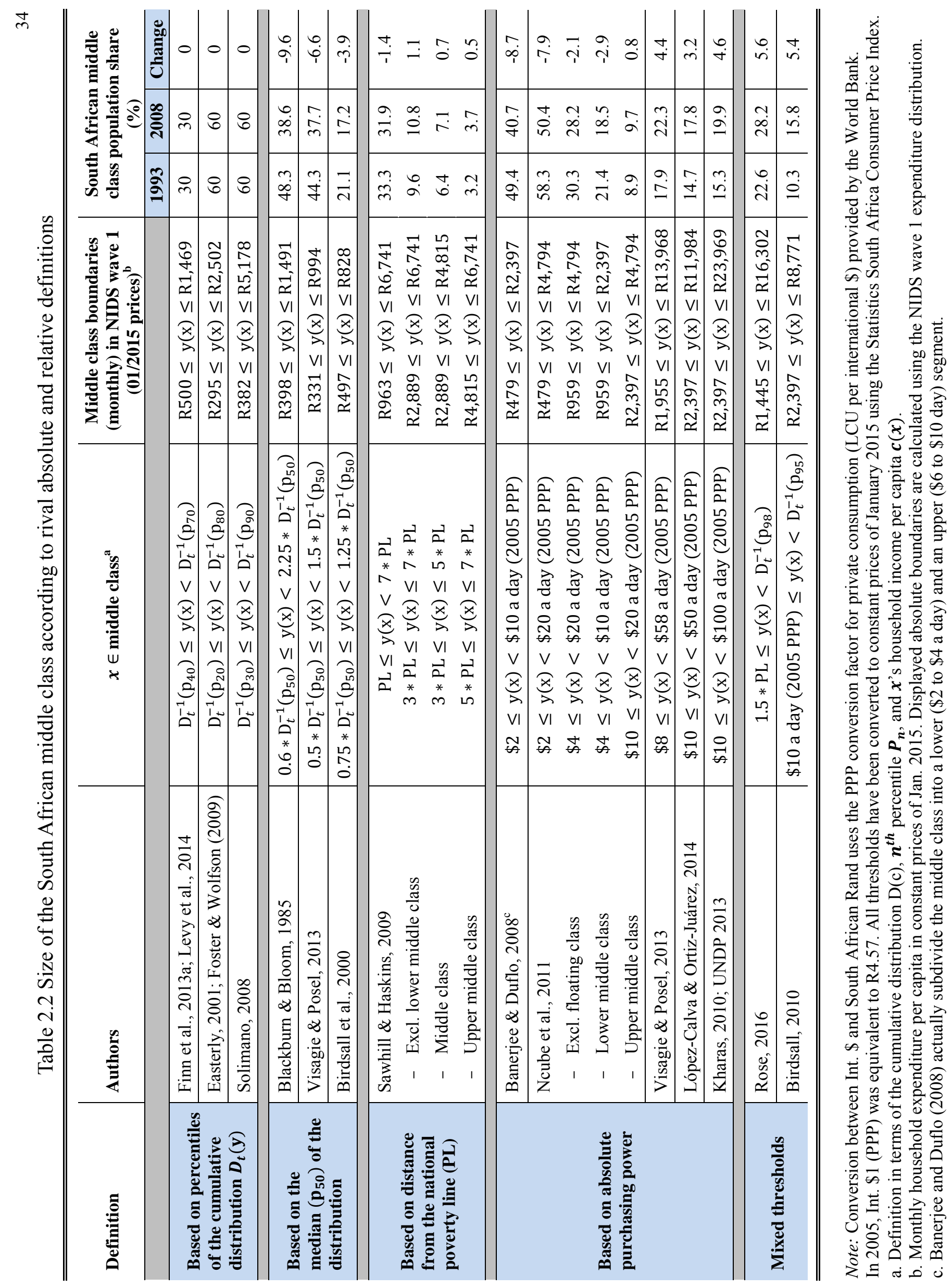


Furthermore, it is worth noting that by using different thresholds, researchers will identify opposing trends in the evolution of the size of the middle class. Holding the middle class share fixed by definition, approaches based on percentiles of the cumulative income or expenditure distribution are unsuitable to capture changes in class size over time. Since poverty has declined since the end of apartheid, those definitions that include the UBPL in the income interval used to identify the middle class - that is, which include an important share of the poor in their definition - show a decline in class size from 1993 to 2008. By contrast, those approaches that locate the middle class in a higher range with some distance to the poverty line show an increase in the middle-class share by about three to five percentage points over the same period (see Table 2.2).

\subsubsection{Definitions of the middle class based on non-money metric measures}

As indicated above, sociologists tend to define the middle class based on its functional role in society, typically captured by determinants of social power, such as work, occupation, wealth, and education. ${ }^{10}$ Against this background, more than a few scholars have criticised those definitions (dominant in the economics literature) that exclusively define the middle class with respect to its purchasing power. These "consumptionist" approaches are deemed "blind to the fact that the source, and not the sum, of revenue, determines life chances" (Torche \& López-Calva, 2013: 413; for further discussion, see also Southall, 2016).

This concern is mitigated to some extent by those studies that - despite ultimately identifying the middle class in monetary terms - use a more "productionist" approach to derive the class thresholds. For example, this applies to the definition suggested by Visagie and Posel (2013), which is based on the expected income in "typical" middle-class occupations. López-Calva and Ortiz-Juarez's (2014) vulnerability approach can also be considered "productionist" in the sense that the risk to poverty is estimated based on a set of observable household characteristics, including education and occupation of the head.

Other studies, although not being strictly "productionist" in nature, have used asset indices to proxy for household wealth as a determinant of social power (see Udjo, 2008, for an application using categories from the South African Advertising Research Foundation's Living Standard Measure). Exceptionally comprehensive in this regard is the study conducted

\footnotetext{
${ }^{10}$ Most studies on South Africa following this vein use occupational categories (sometimes combined with a skill measure) to identify the middle class (see, for example, Crankshaw, 1997; Seekings \& Nattrass, 2005; Southall, 2016). These definitions can be criticised for creating a very heterogeneous "residual" group of households - representing about one-third of the South African population - that comprises "unemployed people dependent upon government grants," on the one hand, and "a relatively small number of people enjoying a prosperous retirement funded by pensions and investments," on the other (Southall, 2016: 55).
} 
by McEwan, Hughes, and Bek (2015), who employ a multidimensional indicator of social class that differentiates consumers into ten groups according to 29 indicators of living standards in South Africa (including asset ownership, race, and degree of urbanisation, amongst others). Despite providing a better understanding of the actual standard of living of the middle class, these approaches again remain silent on the sources of wealth. Especially when basic goods and services are governmentally provided, the derived measure is likely to overstate the social power and life chances of the thus-defined middle class.

Picking up on the Weberian idea that members of the same class should share common life chances, Schotte (2016) has recently suggested another multidimensional approach that combines a living standard measure to approximate material welfare with a measure of selfperceived chances for social upward mobility (see also Chapter 5).

Thinking along similar lines, Burger et al. (2017) have suggested an approach to the definition of the middle class that builds on Sen's capability approach. ${ }^{11}$ As opposed to relying on income or consumption measures alone, they propose a multidimensional approach combining four defined capabilities that they suggest to better capture the meaning of the middle class as "empowered, capacitated and economically secure individuals who are free to pursue their personal goals and aspirations" (Burger et al., 2017: 2). These four core capabilities include: (i) freedom from concern about survival and meeting basic needs, (ii) financial discretion and buying power, (iii) labour market power, and (iv) access to information and the ability to process information. Using these capabilities to identify the middle class, Burger et al. identify very strong growth in the middle class since 1993 - from 27 per cent of the population to 35 per cent in 2008 and 48 per cent in 2012.

While Burger et al.'s approach represents an important advance in the understanding of the middle class in the South African context, the four measurable "functionings" they choose as proxies of the four identified core capabilities (representing the outcomes of exercising capabilities) seem to be capturing very basic needs rather than a situation of economic empowerment (see Section 2.5.4 for further discussion). ${ }^{12}$ Consequently, much of the growth they observe in the middle class can likely be attributed to the considerable expansion of government service provision since 1993. Another disadvantage of the approach is that it does not lend itself to identify an elite, which would seem particularly relevant in the South African context marked by high income concentration at the top of the distribution.

\footnotetext{
${ }^{11}$ Sen defines capabilities as "substantive freedoms [one] enjoys to lead the kind of life he or she has reason to value", where income is only instrumentally valuable insofar as it expands capabilities (1999: 87).

${ }^{12}$ The four measures used include: (i) adequate sanitation and clean water, (ii) ownership of a stove and fridge, (iii) at least one employed member of the household, and (iv) TV and radio ownership, and literacy.
} 


\subsection{A vulnerability approach to defining the middle class in South Africa}

From the above discussion, López-Calva and Ortiz-Juarez's (2014) vulnerability approach to defining the middle class seems well-suited to the South African context. It has been specifically designed to identify a "stable" middle class whose members are free from concern about meeting basic needs - both statically and dynamically.

As discussed, we consider Stats SA's UBPL as the absolute minimum consumption floor necessary for long-term physical well-being. In fact, this line closely coincides with the poverty line of $\$ 4$ a day (in 2005 PPPs) used by López-Calva and Ortiz-Juarez (2014). Nevertheless, the derived vulnerability threshold that divides the "actual" or "stable" middle class from the group of the vulnerable (see Figure 2.4) may not be directly applicable to South Africa, given that it has been derived using a different set of countries. Therefore, in what follows, we replicate their original approach using South African panel data. In doing so, we also discuss a number of methodological choices that are critical for this approach.

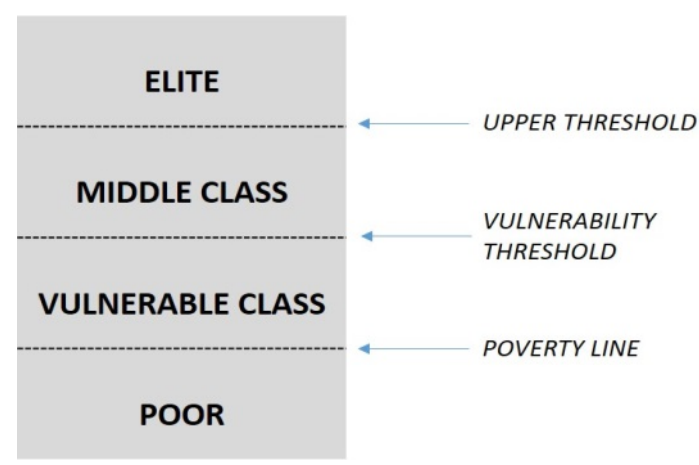

Figure 2.4 Four-tiered class stratification following a vulnerability-based approach

\subsubsection{Methodology}

Following López-Calva and Ortiz-Juarez (2014), the identification of the vulnerability threshold proceeds in three steps: First, we identify a number of characteristics associated with the probability of being poor in South Africa. Second, for each individual, we quantify the predicted risk of poverty, given these characteristics. Third, we use these predicted probabilities to find the income bands associated with a risk of poverty of 10 per cent. This is considered the maximum acceptable degree of vulnerability to be identified as middle class

Importantly, in line with the original approach, the last step relies not on the observed but the predicted income (or rather expenditure) level (given initial household characteristics). This is because the latter is considered less volatile and can be assumed to better reflect the household's income generation capacity. For details on the methodology, please refer to Appendix A.1. 
In a last step, we calculate the upper threshold that divides the middle class from the elite. Here we depart from the original approach suggested by López-Calva and Oritz-Juarez (2014), who arbitrarily fix the upper bound at $\$ 50$ (2005 PPP). ${ }^{13}$ Instead, we define the upper threshold as the average predicted per capita income (or expenditure) level of those in the bottom one percentile of the predicted poverty probability distribution. ${ }^{14}$ It thus identifies the elite as those who are the least likely to become poor over time.

The poverty risk estimates are derived using NIDS panel data. We use 2008 as the base year and focus on the poverty transitions that occurred from 2008 to 2012 (waves 1 to 3). This time-frame is mainly chosen due to data concerns. First, attrition was lowest between these two survey waves (see Section 2.2). Second, the impacts of the 2008/2009 financial crisis led to an increase in poverty particularly up to 2010/11 (wave 2), which may be little generalizable to other periods. Third, the strong decline in poverty observed from 2012 to 2014/15 in NIDS (waves 3 to 4) may raise doubts, given that it was not mirrored by any major event at the macro level and is not reflected in the official country statistics (see Section 2.2). The resulting four-year period from 2008 to 2012 furthermore closely coincides with the medium-term time horizon of three to five years studied by López-Calva and Oritz-Juarez (2014). A robustness check with regard to the chosen time-frame will be provided in Section 2.5.3.

\subsubsection{Results}

As a preliminary step for the subsequent analysis, it is important to get a first glance of the extent of poverty transitions in South Africa during the period under study. As can be seen from Table 2.3, about 29.8 per cent of all South Africans who were non-poor in 2008 had fallen into poverty in 2012 (ca. 5.8 million people). By contrast, about 16.1 per cent (ca. 4.9 million people) of those who were poor in 2008 had moved above the poverty line in 2012. A simple cross-sectional comparison, showing an increase in the poverty headcount by close to two percentage points (from 60.8 to 63 per cent) from 2008 to 2012, would mask these dynamics.

\footnotetext{
${ }^{13}$ The definition of the upper or elite threshold is not the focus of this study. The size of the middle class can be expected to be relatively robust to minor variations in this threshold, given that it lies in the upper tail of the distribution. However, while we consider the exact cut-off point to be less of a concern, we believe the definition of an elite group to be particularly relevant in the South African context, which is marked by an outstanding concentration of wealth at the top of the distribution, particularly in the top quintile (see Chapter 3).

${ }^{14} \mathrm{We}$ prefer this approach over specifying a probability cut-off to identify the elite due to the generally lower accuracy and high density of probit models towards the tails of the distribution.
} 
Table 2.3 Poverty transition matrix, 2008 to 2012

\begin{tabular}{lc|cc|c}
\hline \hline & & Non-poor in 2012 & Poor in 2012 & Total \\
\hline Non-poor in 2008 & $\%$ & 70.16 & 29.84 & 100 \\
& Million & 13.65 & 5.80 & 19.45 \\
\hline Poor in 2008 & $\%$ & 16.12 & 83.88 & 100 \\
& Million & 4.85 & 25.25 & 30.11 \\
\hline \hline
\end{tabular}

Note: The total South African population in 2008 was 49.56 million (UN population statistics).

\section{Regression analysis}

To gain a better understanding of the characteristics that correlate with these observed dynamics, we draw on the modelling framework suggested by López-Calva and Oritz-Juarez (2014). We use a probit specification to regress respondents' poverty status in 2012 on a set of initial household characteristics observed in 2008. Our explanatory variables in the base specification include household size and geographic location (area and province) in 2008, as well as a set of initial characteristics of the household head, including demographics (age, age squared, gender, and race), educational attainment, and labour market status or occupation. This model correctly predicts the poverty status for 78.6 per cent of all observations.

As the results reported in Table 2.4 column (1) below indicate, race remains a strong predictor of poverty in South Africa, with Africans being at the highest risk of poverty, whereas whites are the least likely to be poor, even after controlling for differences in education and employment. Members of larger, female headed, or rural agricultural households also face a higher risk of poverty, as do those living in a household where the head is unemployed. By contrast, having more household members in employment and specifically having a higher educated household head who is working, ideally in a management position or other white-collar occupation, are strong predictors for lower vulnerability to poverty. ${ }^{15}$ By contrast, having a working household head in a low-skilled occupation has no significant risk-reducing effect. Casual (non-permanent/informal) forms of work are associated with a significantly elevated risk to poverty.

Using the estimated coefficients reported in column (1), we predict, for every individual, the probability of being poor in 2012. In addition, we predict for each household the per capita income and expenditure level in the base period (2008) using the same explanatory variables (see Appendix A.3). The respective thresholds associated with a risk of poverty of 10 per cent are reported at the bottom of Table 2.4 column (1).

\footnotetext{
${ }^{15}$ In line with Visagie and Posel's (2013) division between middle-class and working-class professions, whitecollar occupations include managers, professionals, technicians and associate professionals, and clerks; whereas blue-collar class occupations include plant and machinery operators, craft and related trade workers, skilled agriculture and fishery workers, service and market sales workers and all elementary occupations.
} 
In a next step, we construct an asset index (capturing initial housing conditions and ownership of consumer durables), which is added as an additional control to the model (see Table 2.4 column (2)). ${ }^{16}$ Following the line of reasoning presented by Carter and May (2001) and Carter and Barret (2006), we assume assets to be less sensitive to temporary fluctuations than the level of income or consumption observed in a single cross-section. In this sense, the asset controls can be understood as a proxy for initial household wealth, which is likely to determine the propensity to poverty in subsequent waves. As may be expected, we observe that the differences in poverty risks by race and (to a lesser extent) education groups are in part attributable to differences in initial household wealth. However, these differences remain large and significant even after asset controls have been added.

Last, given that NIDS is a panel of individuals that may move between households, we account for shifts in household composition over time. ${ }^{17}$ Specifically, we add the (absolute) change in household size and in the number of employed household members between 2008 and 2012 to our set of explanatory variables. This raises the number of correct classifications by the model to 83.9 per cent. Unsurprisingly, while an increase in the number of dependent household members goes in line with a higher risk to poverty, an increase in the number of working household members is associated with a lower likelihood of being poor at the end of the period (see Table 2.4 column (3)). Including these controls in the probit model reduces the estimated vulnerability threshold to below R3,000. Given that we are looking at a four-year time horizon which makes it unlikely to observe any fertility effect, this result is likely driven by household splits leading to lower household sizes.

It is worth noting that after controlling for changes in the number of employed household members (including the household head), we estimate a negative and significant risk-reducing effect also for other forms of work of the household head, including wage employment in blue-collar occupations, self-employment, and personal agricultural work. From this we may conclude that having a household head who is working is generally associated with a lower risk of poverty. However, for this to be true, the employment relationship must be maintained over time. This implies that temporary and informal forms of work will often not suffice to reduce poverty risk in the medium run (see Chapters 3 and 4).

\footnotetext{
${ }^{16}$ To construct the asset index, we use the responses to 11 questions that relate to the household's housing conditions (dwelling type, water source, toilet facility), on the one hand, and ownership of durable assets (television, electric stove, fridge/freezer, DVD/Blu-ray player, microwave, washing machine, car, computer), on the other. In order to reduce these binary categorical variables into a single index with appropriate weighting, multiple correspondence analysis is used (for details on the methodology see, for example, Booysen, Van der Berg, Burger, Von Maltitz, \& Du Rand, 2008; Shimeles \& Ncube, 2015). The weights are estimated using NIDS 2008 data (see Appendix A.2).

${ }^{17}$ Note that this is done only for the dynamic poverty model, not for the static income model.
} 
Table 2.4 Probit estimates (average marginal effects) on probability of being poor in 2012

\begin{tabular}{|c|c|c|c|}
\hline & $\begin{array}{l}\text { Base } \\
\text { (1) }\end{array}$ & $\begin{array}{c}\text { As (1) } \\
\text { with asset } \\
\text { controls } \\
\text { (2) }\end{array}$ & $\begin{array}{c}\text { As }(2) \\
\text { with controls } \\
\text { for changes in } \mathrm{HH} \\
\text { composition } \\
\text { (3) }\end{array}$ \\
\hline \multicolumn{4}{|l|}{ Characteristics of the head of household (HoH) in wave 1} \\
\hline HoH age & $\begin{array}{c}-0.0059 * * \\
(0.0026)\end{array}$ & $\begin{array}{l}-0.0011 \\
(0.0024)\end{array}$ & $\begin{array}{l}-0.0017 \\
(0.0024)\end{array}$ \\
\hline HoH age squared (x0.01) & $\begin{array}{c}0.0024 \\
(0.0024)\end{array}$ & $\begin{array}{l}-0.0009 \\
(0.0022)\end{array}$ & $\begin{array}{l}-0.0003 \\
(0.0023)\end{array}$ \\
\hline $\mathrm{HoH}$ is female & $\begin{array}{c}0.0426 * * * \\
(0.0146)\end{array}$ & $\begin{array}{c}0.0429 * * * \\
(0.0144)\end{array}$ & $\begin{array}{c}0.0457 * * * \\
(0.0127)\end{array}$ \\
\hline \multicolumn{4}{|l|}{ HoH race group (base: African) } \\
\hline Coloured & $\begin{array}{l}-0.0254 \\
(0.0465)\end{array}$ & $\begin{array}{c}0.0371 \\
(0.0485)\end{array}$ & $\begin{array}{c}0.0404 \\
(0.0373)\end{array}$ \\
\hline Asian/Indian & $\begin{array}{c}-0.3531 * * * \\
(0.0405)\end{array}$ & $\begin{array}{c}-0.1844^{* * *} \\
(0.0502)\end{array}$ & $\begin{array}{c}-0.1376^{* * * *} \\
(0.0505)\end{array}$ \\
\hline White & $\begin{array}{l}-0.3255^{* * *} \\
(0.0571)\end{array}$ & $\begin{array}{l}-0.2208 * * * \\
(0.0534)\end{array}$ & $\begin{array}{l}-0.1963 * * * \\
(0.0603)\end{array}$ \\
\hline \multicolumn{4}{|l|}{ HoH education (base: no schooling) } \\
\hline Less than primary completed & $\begin{array}{c}-0.0586^{* *} \\
(0.0242)\end{array}$ & $\begin{array}{c}-0.0477 * * \\
(0.0233)\end{array}$ & $\begin{array}{c}-0.0468 * * \\
(0.0212)\end{array}$ \\
\hline Primary completed & $\begin{array}{c}-0.0848^{* * *} \\
(0.0272)\end{array}$ & $\begin{array}{c}-0.0587 * * \\
(0.0290)\end{array}$ & $\begin{array}{c}-0.0802 * * * \\
(0.0278)\end{array}$ \\
\hline Secondary not completed & $\begin{array}{l}-0.1199 * * * \\
(0.0259)\end{array}$ & $\begin{array}{c}-0.0720^{* * *} \\
(0.0260)\end{array}$ & $\begin{array}{l}-0.0822 * * * \\
(0.0252)\end{array}$ \\
\hline Secondary completed & $\begin{array}{c}-0.2673 * * * \\
(0.0324)\end{array}$ & $\begin{array}{c}-0.1847^{* * *} \\
(0.0332)\end{array}$ & $\begin{array}{c}-0.1575 * * * \\
(0.0316)\end{array}$ \\
\hline Tertiary & $\begin{array}{c}-0.3971 * * * \\
(0.0352)\end{array}$ & $\begin{array}{c}-0.2927 * * * \\
(0.0390)\end{array}$ & $\begin{array}{c}-0.2692 * * * \\
(0.0341)\end{array}$ \\
\hline \multicolumn{4}{|l|}{ HoH employment status (base: inactive) } \\
\hline Unemployed (discouraged) & $\begin{array}{c}0.0504 \\
(0.0387)\end{array}$ & $\begin{array}{c}0.0399 \\
(0.0404)\end{array}$ & $\begin{array}{c}0.0118 \\
(0.0333)\end{array}$ \\
\hline Unemployed (strict) & $\begin{array}{l}0.0504^{*} \\
(0.0283)\end{array}$ & $\begin{array}{l}0.0495^{*} \\
(0.0272)\end{array}$ & $\begin{array}{l}0.0441^{*} \\
(0.0257)\end{array}$ \\
\hline Wage employment in white-collar occupation & $\begin{array}{c}-0.0969 * * * \\
(0.0288)\end{array}$ & $\begin{array}{l}-0.0539^{*} \\
(0.0280)\end{array}$ & $\begin{array}{c}-0.0873 * * * \\
(0.0254)\end{array}$ \\
\hline Wage employment in blue-collar occupation & $\begin{array}{c}-0.0204 \\
(0.0220)\end{array}$ & $\begin{array}{l}-0.0028 \\
(0.0235)\end{array}$ & $\begin{array}{c}-0.0564 * * * \\
(0.0215)\end{array}$ \\
\hline Self-employment & $\begin{array}{l}-0.0130 \\
(0.0270)\end{array}$ & $\begin{array}{c}0.0144 \\
(0.0274)\end{array}$ & $\begin{array}{l}-0.0505^{* *} \\
(0.0257)\end{array}$ \\
\hline Paid casual work & $\begin{array}{c}0.0712 * * \\
(0.0308)\end{array}$ & $\begin{array}{l}0.0573^{*} \\
(0.0315)\end{array}$ & $\begin{array}{l}-0.0141 \\
(0.0303)\end{array}$ \\
\hline Personal agricultural work ${ }^{\mathrm{a}}$ & $\begin{array}{c}0.0294 \\
(0.0334)\end{array}$ & $\begin{array}{c}0.0358 \\
(0.0334)\end{array}$ & $\begin{array}{c}-0.0621^{* *} \\
(0.0312)\end{array}$ \\
\hline \multicolumn{4}{|l|}{ Characteristics of the household (HH) in wave 1} \\
\hline $\begin{array}{l}\text { Composition of the } \mathrm{HH} \\
\text { No. of members in } \mathrm{HH}\end{array}$ & $\begin{array}{c}0.0336 * * * \\
(0.0032)\end{array}$ & $\begin{array}{c}0.0359^{* * *} \\
(0.0034)\end{array}$ & $\begin{array}{c}0.0713 * * * \\
(0.0035)\end{array}$ \\
\hline No. of workers in $\mathrm{HH}$ (excl. HoH) & $\begin{array}{c}-0.0357 * * * \\
(0.0115)\end{array}$ & $\begin{array}{c}-0.0257^{* *} \\
(0.0103)\end{array}$ & $\begin{array}{l}-0.0743 * * * \\
(0.0108)\end{array}$ \\
\hline \multicolumn{4}{|l|}{ Geographic location (base: traditional) ${ }^{\mathrm{b}}$} \\
\hline Urban & $\begin{array}{c}-0.0727 * * * \\
(0.0221)\end{array}$ & $\begin{array}{l}-0.0101 \\
(0.0216)\end{array}$ & $\begin{array}{c}0.0047 \\
(0.0186)\end{array}$ \\
\hline Farms & $\begin{array}{c}0.0149 \\
(0.0319)\end{array}$ & $\begin{array}{c}0.0278 \\
(0.0337)\end{array}$ & $\begin{array}{l}0.0659 * * \\
(0.0332)\end{array}$ \\
\hline $\begin{array}{l}\text { Access to basic goods and services } \\
\text { Asset index score ( } 0 \text { to } 1)\end{array}$ & & $\begin{array}{c}-0.3505^{* * *} \\
(0.0367)\end{array}$ & $\begin{array}{c}-0.3489 * * * \\
(0.0342)\end{array}$ \\
\hline
\end{tabular}




\begin{tabular}{lccc}
\hline Changes in the HH composition between waves 1 and 3 & & & $0.0651^{* * *}$ \\
Abs. change in no. of members in HH & & & $(0.0032)$ \\
& & & $-0.0691^{* * *}$ \\
& & & $(0.0085)$ \\
Abs. change in no. of workers in HH (incl. HoH) & YES & YES & YES \\
& 18,055 & 17,567 & 17,567 \\
\hline Province fixed effects & 0.335 & 0.358 & 0.467 \\
\hline Observations & 78.55 & 80.12 & 83.93 \\
R-squared & & & \\
Correctly classified (\%) & 3,408 & 3,274 & 2,794 \\
\hline Threshold associated with a predicted 10\% risk to poverty & 3,696 & 3,403 & 2,915 \\
\hline Expenditure cut-off (predicted) & & & \\
\hline Income cut-off (predicted)
\end{tabular}

Robust standard errors (adjusted for 400 survey clusters) in parentheses.

$* * * \mathrm{p}<0.01, * * \mathrm{p}<0.05, * \mathrm{p}<0.1$

Note: Individuals are predicted to be poor if their predicted poverty propensity exceeds the average probability of being poor in the final year (that is, the 2012 poverty headcount).

a Personal agricultural work includes working on own plot or looking after livestock.

${ }^{\mathrm{b}}$ In line with the 2011 census, three settlement types are distinguished in NIDS:Urban - A continuously built-up area that is established through cities, towns, townships', small towns, and hamlets. Traditional - Communally owned land under the jurisdiction of traditional leaders. Settlements within these areas are villages. Farms Land allocated for and used for commercial farming including the structures and infrastructure on it.

\section{Class thresholds}

Using the model specification reported in Table 2.4 column (3), we fix the vulnerability threshold at R2,779 per month (in January 2015 prices), equivalent to about \$11.6 per day in 2005 PPPs. This threshold corresponds to about three times the poverty line. A very similar threshold of R2,942 would have been obtained when using income instead of expenditure as the relevant welfare measure (see Table 2.4 above). The upper threshold that separates the middle class from the elite is set at R10,954 per month (in January 2015 prices), equivalent to $\$ 45.7$ in 2005 PPPs.

To evaluate the performance of our derived thresholds, we take a look at the share of individuals by initial class status that actually fell into poverty from 2008 to 2012. As reported in Table 2.5, almost every second person who was considered vulnerable in 2008 was observed to be poor in 2012. In comparison, the same was true for one in ten members of the middle class, indicating a reasonably low degree of vulnerability. ${ }^{18}$

Using these thresholds, we identify a South African middle class that is only about half the size compared to previous studies (see Section 2.4.2). Moreover, this "stable" middle class has been growing sluggishly - from 12.4 per cent of the total population in 1993 to 15 per cent in 2008. Despite this, there has been a considerable demographic transformation within the middle class, with Africans now outnumbering whites by a significant margin.

\footnotetext{
${ }^{18}$ Surprisingly, also 4 per cent of those who were elite in 2008 reported an expenditure level below the poverty line in 2012. This finding may likely partly be driven by measurement error that is well known to be an issue, especially with regard to the rich in household survey data. For a further discussion, see Section 2.5.3 below.
} 
However, even though the share of Africans in the middle class has tripled since 1993, it still falls far short of demographic representativeness (see Table 2.6).

Table 2.5 Movements in and out of poverty by initial class status, 2008 to 2012

\begin{tabular}{l|cccc}
\hline \hline Population share by class in 2008 that & Poor & Vulnerable & Middle Class & Elite \\
\hline - was non-poor in 2012 & 16.12 & 54.11 & 91.12 & 95.95 \\
$\quad$ - was poor in 2012 & 83.88 & 45.89 & 8.88 & 4.05 \\
\hline Expenditure bounds in January 2015 prices & $<963$ & $963-2,794$ & $2,794-10,954$ & $10,954+$ \\
Expenditure bounds in 2005 Int. \$ PPP & $<4.0$ & $4.0-11.7$ & $11.7-45.7$ & $45.7+$ \\
\hline \hline
\end{tabular}

Table 2.6 Relative class shares in South Africa, 1993 to 2014/15

\begin{tabular}{|c|c|c|c|c|c|c|}
\hline \multicolumn{2}{|c|}{ Population share (\%) by class } & \multirow{2}{*}{$\frac{\text { Poor }}{63.36}$} & \multirow{2}{*}{$\begin{array}{c}\text { Vulnerable } \\
23.37\end{array}$} & \multirow{2}{*}{$\frac{\text { Middle Class }}{12.38}$} & \multirow{2}{*}{$\begin{array}{c}\text { Elite } \\
0.89\end{array}$} & \multirow{2}{*}{$\frac{\text { Total }}{100}$} \\
\hline 1993 & Total & & & & & \\
\hline & Share of Black African in Total & 93.87 & 70.23 & 16.53 & 1.88 & 77.83 \\
\hline \multirow[t]{2}{*}{2008} & Total & 60.75 & 20.95 & 15.00 & 3.30 & 100 \\
\hline & Share of Black African in Total & 92.19 & 78.43 & 40.12 & 15.21 & 78.95 \\
\hline \multirow[t]{2}{*}{ 2010/11 } & Total & 65.06 & 18.02 & 13.74 & 3.18 & 100 \\
\hline & Share of Black African in Total & 91.81 & 76.61 & 39.84 & 12.89 & 79.42 \\
\hline \multirow[t]{2}{*}{2012} & Total & 63.00 & 21.40 & 12.64 & 2.97 & 100 \\
\hline & Share of Black African in Total & 91.86 & 71.61 & 50.17 & 17.45 & 80.05 \\
\hline \multirow[t]{2}{*}{$2014 / 15$} & Total & 55.79 & 25.70 & 15.20 & 3.32 & 100 \\
\hline & Share of Black African in Total & 92.62 & 79.45 & 50.12 & 23.27 & 80.48 \\
\hline
\end{tabular}

\subsubsection{Sensitivity analysis and caveats of the approach}

In this section, we assess the sensitivity of the calculated vulnerability threshold to some of the choices we made in deriving it, and discuss the main limitations of the approach.

\section{Sensitivity to the chosen time-frame and macroeconomic conditions}

While vulnerability to poverty is a forward looking concept, the measurement of vulnerability is necessarily backward looking (Cafiero \& Vakis, 2006). Consequently, our analysis implicitly assumes that the economic conditions which determined vulnerability in the past remain unchanged in the present and the future. This may not be true if there were important changes in the macroeconomic and/or institutional environment affecting poverty risks. Thus, while the vulnerability threshold is absolute in the sense that the risk of being poor is fixed at 10 per cent, the monetary value associated with it is likely to shift as conditions change. ${ }^{19}$

\footnotetext{
${ }^{19}$ Similarly, to apply the vulnerability threshold to measuring the middle class in countries other than the country in which it was calculated is to assume that the macroeconomic conditions in both countries are the same, which may be even more problematic. For a discussion of approaches to defining and measuring the global middle class see Jayadev, Lahoti, and Reddy (2015).
} 
Nevertheless, as shown in Table 2.7, we find that the middle class as of 2008 remained relatively resilient to poverty over the three subsequent survey waves. Specifically, while 8.9 per cent of the initial middle class were observed to be poor in 2012, a somewhat larger share of 9.4 per cent had fallen into poverty in 2010/11. The fact that this difference is relatively small - in spite of the effects of the 2008/2009 financial crisis that were probably felt strongest during this period - increases our confidence in the economic stability of the identified middle class. Furthermore, in line with the drop in poverty between NIDS waves 3 and 4, only 7 per cent of the 2008 middle class were observed to be poor in 2014/15. Accordingly, if we had calculated the vulnerability threshold using 2008 to 2014/15 as the reference period, a substantially lower threshold of R2,379 would have been estimated. However, this difference may at least partly be attributable to sampling issues.

Finally, it is worth noting that even those in the "stable" middle class can face a higher cumulative risk of poverty. In fact, 19.4 per cent of those who were middle class in 2008 had fallen into poverty in at least one out of three subsequent survey waves (see Table 2.7). However, they were very unlikely to remain poor persistently. That is, among the initial middle class, only 3.6 per cent were observed to be poor in all three following survey waves.

Table 2.7 Population share falling into poverty by initial class status in 2008

\begin{tabular}{l|cccc}
\hline \hline Class in 2008 & Poor & Vulnerable & Middle Class & Elite \\
\hline Poor in 2010/11 (\%) & 86.84 & 48.77 & 9.44 & 4.20 \\
Poor in 2012 (\%) & 83.88 & 45.89 & 8.88 & 4.05 \\
Poor in 2014/15 (\%) & 73.24 & 35.97 & 7.02 & 3.28 \\
Poor in 2010/11, 2012, OR 2014/15 (\%) & 96.99 & 67.07 & 19.43 & 7.87 \\
Poor in 2010/11, 2012, AND 2014/15 (\%) & 61.07 & 22.40 & 3.53 & 1.52 \\
\hline \hline
\end{tabular}

\section{Sensitivity to the choice of the probability cut-off}

The choice of the probability cut-off is clearly critical to our analysis. We follow López-Calva and Ortiz-Juarez (2014) in fixing the threshold at 10 per cent. However, it would have been in principle possible to make an argument for the use of any other probability threshold in a potential range of, for example, 5 to 20 per cent.

Table 2.8 compares the calculated vulnerability line and the associated size of the middle class using a range of alternative cut-off points. We find a sharp drop in the derived vulnerability threshold particularly over the probability interval between 10 and 15 per cent from R2,794 to R1,991. Using this latter threshold, the population share held by the middle class in 2008 would have been about six percentage points larger. 
Table 2.8 Sensitivity of the vulnerability thresholds to the choice of the probability cut-off

\begin{tabular}{l|cccc}
\hline \hline $\begin{array}{l}\text { Allowed maximum predicted } \\
\text { risk of falling into poverty }\end{array}$ & $\begin{array}{c}\text { Vulnerability } \\
\text { Threshold (in January } \\
\text { 2015 prices) }\end{array}$ & $\begin{array}{c}\text { Middle class } \\
\mathbf{( \% )} \text { in 1993 }\end{array}$ & $\begin{array}{c}\text { Middle class } \\
\text { (\%) in 2008 }\end{array}$ & $\begin{array}{c}\text { Middle class } \\
\text { growth (ppts) }\end{array}$ \\
\hline 5 per cent & 3,250 & 10.42 & 12.96 & 2.54 \\
10 per cent & 2,794 & 12.38 & 15.00 & 2.62 \\
15 per cent & 1,991 & 17.31 & 20.95 & 3.64 \\
20 per cent & 1,708 & 20.02 & 23.79 & 3.77 \\
\hline \hline
\end{tabular}

\section{Sensitivity to the choice of the poverty line}

Naturally, the estimated probability of being poor and the associated vulnerability cut-off will depend on where we set the poverty line. In order to investigate the sensitivity of our results to the choice of Stats SA's UBPL (2015), we first replicate the same approach using the UBPL that was recently suggested by Budlender et al. (2015). The use of this slightly higher poverty line results in a somewhat higher vulnerability threshold of R3,053 per month $(\$ 12.7$ a day). While the population share held by the middle class is about one percentage point lower under this definition, its growth from 1993 to 2008 is very similar across specifications.

Second, we replicate our analysis using Stats SA's LBPL (2015). Using this lower poverty line, a substantially lower vulnerability threshold of R1,830 and upper threshold of R4,794 are estimated, equivalent to an approximate range of $\$ 7.6$ to $\$ 20.0$ a day (in 2005 PPPs). Using these thresholds, the relative size of the middle class is surprisingly similar to the original specification using the UBPL. However, if we held the upper threshold fixed, then the share of the middle class would increase by close to 50 per cent under this specification (to 18.7 per cent in 1993 and 22.7 per cent in 2008).

Table 2.9 Sensitivity of the vulnerability thresholds to the choice of the poverty line

\begin{tabular}{l|ccc|cc|c}
\hline \hline $\begin{array}{l}\text { Poverty Line in January } \\
\text { 2015 prices }\end{array}$ & $\begin{array}{c}\text { Poverty } \\
\text { line }\end{array}$ & $\begin{array}{c}\text { Vulnerability } \\
\text { Threshold }\end{array}$ & $\begin{array}{c}\text { Upper } \\
\text { Threshold }\end{array}$ & $\begin{array}{c}\text { Middle } \\
\text { class (\%) } \\
\text { in 1993 }\end{array}$ & $\begin{array}{c}\text { Middle } \\
\text { class (\%) } \\
\text { in 2008 }\end{array}$ & $\begin{array}{c}\text { Middle } \\
\text { class growth } \\
\text { (ppts) }\end{array}$ \\
\hline Stats SA UBPL (2015) & 963 & 2,794 & 10,954 & 12.38 & 15.00 & 2.62 \\
\hline Budlender et al. (2015) & 1,283 & 3,053 & 11,157 & 11.27 & 13.83 & 2.56 \\
- holding upper bound fix & 1,283 & 3,053 & 10,954 & 11.23 & 13.73 & 2.50 \\
\hline $\begin{array}{l}\text { Stats SA LBPL (2015) } \\
\text { - holding upper bound fix }\end{array}$ & 629 & 1,830 & 4,794 & 13.17 & 14.89 & 1.72 \\
\hline \hline
\end{tabular}

Certainly, it is important to keep in mind that the interpretation of the group that is identified using the LBPL is qualitatively different. As explained in Section 2.2, individuals with a per capita expenditure level equal to the LBPL will need to sacrifice some food consumption in order to fulfil their non-food needs. In consequence, despite being at low risk of falling under the minimum subsistence level, the middle class that we identify in reference 
to the LBPL will still face an elevated risk of slipping into a precarious situation in the sense of not being able to purchase both adequate food and non-food items.

\section{Sample attrition and changes in the composition of households}

As in any panel data study, sample attrition is a concern. Despite using panel weights throughout the analysis, we cannot fully rule out the possibility that the derived vulnerability threshold could be affected by non-random attrition.

Out of 26,776 original sample members, 5,385 individuals (20.1 per cent) had left the sample in 2012. The attrition rate was lower among initially poor (16.8 per cent) than initially non-poor individuals (28.7 per cent) and was highest in the top decile of the expenditure distribution (43.4 per cent). Accordingly, if one suspects that those at higher risk of poverty were generally more likely to remain in the panel, our estimate of the vulnerability threshold could be upwardly biased.

In an attempt to quantify this bias, we rerun the log-linearised per capita expenditure model with data from 2012 and use the estimated regression coefficients to impute values of per capita household expenditure level and poverty status for those in the baseline sample (2008), who could not be followed up at the end of the period (2012). Since we have no information on the change in the household size and number of employed household members, in a next step we rerun the probability estimation including these imputed observations using the model specification presented in Table 2.4 column (2). ${ }^{20}$ The predicted vulnerability threshold associated with a risk of poverty of 10 per cent including imputations is R3,198, as compared to R3,274 without imputations using the same model specification (see bottom of Table 2.4 column (2)). This suggests that our chosen lower middle class threshold may be upwardly biased by about R76 due to sample attrition, which would imply a minor underestimation of the size of the middle class by 0.5 percentage points.

Moreover, NIDS is a panel study which follows individuals and not households. This means that individuals that belong to a particular household in wave 1 will not necessarily belong to the same household in subsequent waves. Our analysis nevertheless works on the assumption that household resources in wave 1 are relevant in determining poverty status in wave 3, adding a limited set of controls for changes in the household composition. Investigating to what extent dynamics of household formation as well as changes in the geographic location of households are driving mobility will be a worthwhile line of research for future investigation, which is beyond the scope of this dissertation.

\footnotetext{
${ }^{20}$ This increases the number of observation used in the probit estimation from 17,567 to 22,152 .
} 


\section{Measurement error in income or expenditure data}

The presented vulnerability analysis essentially builds on investigating the correlates of movements into and out of poverty observed in the available panel data. However, if the expenditure variable that determines the poverty status of the household is measured with error, which will generally be the case in survey data, this noise in the data may lead us to overstate the actual degree of mobility and thus the actual risk of falling into poverty.

While a number of studies investigate the degree of income or expenditure mobility and poverty transitions using panel data, relatively few have suggested ways to correct for error bias in these analyses (see Lee, Ridder, and Strauss, 2010). The most promising attempt using NIDS data has been presented by Burger, Klasen, and Zoch (2016). Their instrumental variables approach, however, is more concerned with understanding the extent of "true" overall income mobility in NIDS, but does not allow quantifying measurement error at the individual level. Their results suggest that up to 20 per cent of the variation in reported household income in the first three waves of NIDS is attributable to measurement error.

Replicating the above analysis for a simulated "measurement-error free" data set would be a highly valuable but not straight-forward exercise, which unfortunately is beyond the scope of the analysis presented in this dissertation.

\subsubsection{Comparison to rival approaches}

Importantly, the applied vulnerability threshold does not impose any condition that would directly ensure that other capabilities or functionings associated with being middle class going beyond our understanding of being free from poverty - are being met. Therefore, in this section, we define a set of six criteria to compare this approach to three alternative definitions that have been suggested in the South African literature. Our results suggest that being (in-)vulnerable to poverty is in fact a good proxy for the attainment of other capabilities.

The six selected criteria are displayed in Table 8 below. The column on the left indicates the criteria used for comparison and the column on the right specifies how these criteria are measured empirically. The first four conditions (and their operationalisations) closely resemble Burger et al.'s (2017) capability approach to defining the middle class (see Section 2.4.3). While Burger et al. understand "labour market power" as access to labour market income in general, we add an additional distinction that takes the type of employment into consideration. This is motivated by our analysis, which showed that poverty risks vary importantly with the stability of employment. It also aligns with Visagie and Posel's (2013) understanding of middle-class versus working-class professions, which forms the basis for the 
class thresholds that they derive (see Section 2.4.3). The last two conditions reflect freedom from poverty - both statically and dynamically. These are the key requirements for being middle class specified in this chapter.

Table 2.10 Criteria for comparing approaches to defining the middle class in South Africa

\begin{tabular}{l|l|l}
\hline \hline & CONDITION & EMPIRICAL IDENTIFICATION \\
\hline 1 & Access to basic services & $\begin{array}{l}\text { Access to clean water (piped water tap in the dwelling, } \\
\text { on site or in the yard) and sanitation (either a flush or } \\
\text { chemical toilet) }\end{array}$ \\
\hline 2 & Financial discretion and buying power & $\begin{array}{l}\text { Ownership of electric stove and fridge } \\
\text { Ownership of a TV or radio, and at least one adult } \\
\text { member (15+ years) has completed primary education }\end{array}$ \\
\hline 3 & Access to information and literacy & $\begin{array}{l}\text { A) At least one household member in employment } \\
\text { (excl. where all adult members are students or } \\
\text { pensioners) }\end{array}$ \\
\hline 4 & Labour market power & $\begin{array}{l}\text { B) At least one household member in employment in } \\
\text { white-collar occupation (excl. where all adult members } \\
\text { are students or pensioners) }\end{array}$ \\
\hline 5 & Capable to meet basic food and non-food needs & $\begin{array}{l}\text { P.c. expenditure above UBPL (R963) in 2008 } \\
\text { P.c. expenditure above UBPL (R963) in 2008 \& } 2012\end{array}$ \\
\hline 6 & Financially secured against precarity & \\
\hline \hline
\end{tabular}

Table 2.11 reports the results. First, we consider the relative approach to defining the middle class suggested by Finn et al. (2013a) and Levy et al. (2014). As expected (see Sections 2.4.1 and 2.4.2 above), those in in the "statistical middle" (the 40th-70th percentiles) of the expenditure distribution, are generally still too poor to meet the specified criteria. Following this approach, almost every second member of the middle class lacks access to clean water and adequate sanitation. Even though two-thirds live in households with access to income from the labour market, less than 10 per cent have a household member working in a white-collar occupation. Furthermore, two in three members cannot satisfy their basic food and non-food needs at present and only one in ten can sustain a living standard above subsistence over the medium term.

Next, we use a capability approach similar to that developed by Burger et al. (2017). To this end, we define the middle class as those who meet the first four conditions. The class that is identified is similar in size but fares much better with respect to the specified criteria (for the first four criteria by definition). ${ }^{21}$ Its members have access to information, labour market income, and basic services (which may be governmentally provided); and are able to economise on other spending to afford some basic household appliances. Nonetheless, many in this class still have relatively low purchasing power. That is, they cannot afford adequate food and non-food items at the same time and remain at risk of slipping into poverty.

\footnotetext{
${ }^{21}$ Note that the size of the middle class calculated by us is smaller than the class share (of 34.5 per cent in 2008) derived by Burger et al. (2017). This is likely due to methodological differences in the definition of the criteria.
} 
Third, we look at the "affluent" middle class as defined by Visagie and Posel (2013). The lower middle class boundary under this definition $(\mathrm{R} 1,995)$ is very close to the threshold that identifies those at a maximum risk of 15 per cent $(\mathrm{R} 1,991)$ of falling below the UBPL. It is also not far from the threshold that identifies those at a maximum risk of 10 per cent of falling below the LBPL $(1,830)$. Both the "affluent" middle class and the "stable" middle class as defined using the vulnerability approach fare similarly well with respect to the first four criteria. Interestingly, even though Visagie and Posel's (2013) class thresholds correspond to the expected income interval for households in which the highest income earner is in a white-collar profession, only 43.4 per cent of the individuals in this class actually live in a household where at least one members works in a white-collar occupation. This share is almost identical to the equivalent share among the middle class that is identified using the capability approach and almost ten percentage points lower than the one among the middle class that is identified using the vulnerability approach.

Table 2.11 Comparing rival approaches to defining the middle class in South Africa in 2008

\begin{tabular}{|c|c|c|c|c|c|c|}
\hline & APPROACH & $\begin{array}{l}\text { Statistical } \\
\text { middle } \\
(40-70 \text { th } \\
\text { percentile })\end{array}$ & $\begin{array}{l}\text { Capability } \\
\text { approach }\end{array}$ & $\begin{array}{l}\text { "Affluent" } \\
\text { middle } \\
\text { (R1,955- } \\
\text { R13,968) }\end{array}$ & $\begin{array}{c}\text { Vulnerability } \\
\text { approach } \\
\text { (R2,794- } \\
\text { R10,954) }\end{array}$ & $\begin{array}{l}\text { POOR } \\
(<\mathrm{R} 963)\end{array}$ \\
\hline \multicolumn{2}{|c|}{ Population share in $2008(\%)$} & 30 & 27.16 & 22.29 & 15.00 & 60.75 \\
\hline \multirow{7}{*}{ 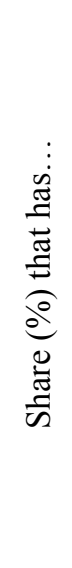 } & Access to basic services & 54.62 & $\begin{array}{c}100 \\
\text { (by definition) }\end{array}$ & 90.60 & 93.51 & 33.99 \\
\hline & $\begin{array}{l}\text { Financial discretion and } \\
\text { buying power }\end{array}$ & 51.35 & $\begin{array}{c}100 \\
\text { (by definition) }\end{array}$ & 81.27 & 86.51 & 36.69 \\
\hline & $\begin{array}{l}\text { Access to information } \\
\text { and literacy }\end{array}$ & 82.62 & $\begin{array}{c}100 \\
\text { (by definition) }\end{array}$ & 94.51 & 95.64 & 76.98 \\
\hline & Labour market power A & 66.32 & $\begin{array}{c}100 \\
\text { (by definition) }\end{array}$ & 81.58 & 84.49 & 57.03 \\
\hline & Labour market power B & 9.94 & 43.59 & 43.48 & 52.32 & 4.57 \\
\hline & $\begin{array}{l}\text { Capable to meet basic } \\
\text { food \& non-food needs }\end{array}$ & 30.80 & 75.50 & $\begin{array}{c}100 \\
\text { (by definition) }\end{array}$ & $\begin{array}{c}100 \\
\text { (by definition) }\end{array}$ & $\begin{array}{c}0 \\
\text { (by definition) }\end{array}$ \\
\hline & $\begin{array}{l}\text { Dynamically secured } \\
\text { against precarity }\end{array}$ & 12.91 & 58.56 & 84.87 & 91.12 & $\begin{array}{c}0 \\
\text { (by definition) }\end{array}$ \\
\hline
\end{tabular}

\subsection{Conclusion}

This chapter set out to provide some guidance to those researchers who wish to study the middle class in the Global South. To this end, we discussed a broad range of alternative approaches to defining the middle class that have been suggested in the economics literature, along with their pros and cons, using South Africa as a case study. 
Our analysis reveals that, depending on the chosen classification method, very different parts of society are identified as middle class, which can make up between 10 and 60 per cent of the national population. While none of these definitions should be seen as right or wrong (Reeves et al., 2018), we argue that in country contexts marked by high levels of inequality along with widespread poverty - as in the case of South Africa - some definitions can be considered more suitable than others. In this regard, we highlight four main limitations of existing approaches that researchers should be aware of:

First, in contexts where the median income earner falls below the poverty line, central tendency measures that locate the middle class in the literal middle of the income distribution will in fact capture a stratum of society that is still poor and deprived in basic needs (see also Visagie and Posel, 2013).

Second, absolute income thresholds that enjoy particular popularity in the context of cross-country analyses often locate the middle class just above the poverty line (see, for example, Ravallion, 2010). This is to ignore that being able to afford a certain basket of goods at a given point in time does not give a sufficient indication as to whether the same will be true in the near future. Furthermore, these approaches are generally blind to how this income is acquired, and thus fail to provide any insight into the long-term sustainability of observed welfare levels. This is particularly problematic since a number of studies in the social sciences as well as in the psychology and health literature have shown that a situation of vulnerability and economic instability can be welfare reducing, even if poverty does not materialise (Dercon, 2006; Cafiero and Vakis, 2006).

Third, a number of recent studies in the developing country context have come up with absolute income boundaries in order to differentiate the lower middle class that is still on the verge of poverty from a more economically secure "actual" middle class (see, for example, Ncube et al., 2011). While appealing in their simplicity, a main limitation of these suggested approaches is that the chosen class boundaries are often arbitrarily defined, lacking a clear theoretical underpinning. However, also those approaches where the applied class thresholds are grounded both on theoretical and empirical arguments - as in the case of López-Calva and Ortiz-Juarez's (2014) vulnerability approach - should be interpreted with caution, keeping the impact of implicit modelling choices in mind.

Lastly, bridging the gap between the sociological and economic class literature, there have been several attempts to define the middle class based on the notion of "empowerment". These approaches either focus on labour market power exclusively or use a broader set of capabilities associated with middle-class status (see, for example, Burger et al., 2017). Despite 
being conceptually compelling, it is important to note that the criteria used to operationalise the latter should be carefully selected. In our view, they should not only represent a measure of multidimensional deprivation, but be suitable to identify a middle class that can actually be considered "empowered" in the sense of being self-sufficient. This includes the requirement that individuals have the financial discretion to satisfy both their basic food and non-food needs, and are able to sustain this standard of living over time - even in the face of negative events.

Under the above aspects, López-Calva and Ortiz-Juarez's (2014) vulnerability approach to defining the middle class seems well-suited to country contexts where significant parts of the population are confronted with poverty risks. It has been designed specifically to allow the identification of a "stable" middle class whose members are free from concern about meeting basic needs - both statically and dynamically. Importantly, the class thresholds are derived based on an in-depth analysis of the household characteristics that grant a minimum degree of economic stability in the given country context. In this sense, the vulnerability threshold can be understood as an attempt at measuring the welfare level that corresponds to the ability of households to respond adequately to negative stochastic events. Just as the upper bound poverty line indicates an expenditure level at which individuals are typically able to satisfy their basic needs, the vulnerability line indicates the minimum monetary threshold above which individuals are typically able to afford the cost of insuring against the risk of falling into poverty. Depending on which degree of vulnerability researchers consider the maximum acceptable, our analysis suggests that - in the case of South Africa - a minimum per capita income of two to three times the poverty line is required for being stably middle class.

Finally, at least two limitations of this approach deserve attention. First, the derived vulnerability threshold will generally be country and context-specific and cannot easily be transferred. Replications of this methodology thus critically rely on the availability of at least two waves of panel data. Second, calculating the vulnerability threshold requires a number of modelling choices that must be made transparent. Especially the choice of the probability cutoff, which is arbitrarily fixed at 10 per cent, will crucially affect the size of the threshold that is derived. Moreover, the estimated probability of being poor and the associated vulnerability line will critically depend on where researchers set the poverty line. 



\title{
CHAPTER 3
}

\section{A poverty dynamics approach to social stratification: The South African case}

\author{
Simone Schotte, Rocco Zizzamia, and Murray Leibbrandt \\ This chapter appeared as Schotte, S., Zizzamia, R., \& Leibbrandt, M. (2018). \\ A poverty dynamics approach to social stratification: The South African \\ case. World Development, 110, 88-103.
}

\begin{abstract}
In the economics literature, most scholars agree that being middle class entails being free from poverty, which means being able to afford the basic things in life - not only today, but also tomorrow. In consequence, there is an increasing tendency to define the middle class based on a lack of vulnerability to poverty. In this chapter, we strengthen and expand on these existing approaches in three ways: First, we incorporate the differentiation between the middle class and a (non-poor) vulnerable group into a broader social-stratification schema that additionally differentiates between transient and chronic poverty. Second, in estimating the risk of poverty, we employ a multivariate regression model that explicitly allows for possible feedback effects from past poverty experiences and accounts for the potential endogeneity of initial conditions, unobserved heterogeneity, and non-random panel attrition - four factors insufficiently addressed in existing studies. Third, we highlight the value of paying attention to these conceptual and modelling issues by showing that class divisions based on monetary thresholds inadequately capture a household's chances of upward and downward mobility. We then apply our conceptual framework to the South African case. We find that only one in four South Africans can be considered stably middle class or elite. Access to stable labour market income is a key determinant of achieving economic stability. A lack of jobs as well as the prevalence of precarious forms of work drive high levels of vulnerability, which in turn constrains the development of an emergent middle class - not only in South Africa but likely also in other parts of the developing world that face similar labour market challenges.
\end{abstract}

Acknowledgements: This chapter has been produced with financial assistance from the Programme to Support Pro-Poor Policy Development (PSPPD), located within the Department of Planning, Monitoring and Evaluation (DPME), and from the World Bank Group, Poverty Global Practice Unit, Africa Region. We are grateful to Francois Bourguignon, Denis Cogneau, Arden Finn, Lena Giesbert, Kanishka Kacker, Stephan Klasen, Jann Lay, Nga Thi Viet Nguyen, Victor Sulla, Martin Wittenberg, Ingrid Woolard, Precious Zikhali, and three anonymous reviewers for helpful suggestions. Any remaining errors are our own. 


\title{
CHAPTER 4
}

\section{Structural poverty dynamics in urban South Africa: A mixed method investigation}

\author{
Simone Schotte
}

\begin{abstract}
This chapter applies a livelihoods framework to examine the extent and determinants of structural poverty dynamics in South Africa, with special attention given to the urban African population. Economic transition matrices based on panel data from the National Income Dynamics Study show considerable income mobility. Recognising that these transitions can represent distinctly different experiences, this chapter estimates how much of the observed poverty entries and exits is reflected in the depletion and accumulation of livelihood assets respectively, and conversely how much can be accounted for by stochastic factors. To gain a better understanding of the complex processes, livelihood strategies, and asset dynamics that condition movements into and out of structural poverty, these quantitative findings are combined with those of a qualitative case study integrating focus group discussions and life history interviews conducted between July and September 2017 in the township of Khayelitsha, Cape Town. Data visualisation methods in the form of asset pentagons and livelihood diagrams help illustrate the multidimensional deprivation and main risk factors that structurally poor urban households experience. Results emphasise meagre job opportunities for low-skilled labour, low schooling quality, and relationships of dependency as important dimensions. Lack of access to financial capital as well as the costs and risks associated with the geographic location of the urban poor, often residing in precarious areas that are spatially separated from the urban centres, further constrain opportunities.
\end{abstract}

Acknowledgements: I am grateful to Jann Lay, Murray Leibbrandt, Stephan Klasen, Nic Spaull, Natalie Quinn, participants at the 2018 CSAE Conference in Oxford, and participants at the 2nd International Conference on Globalization and Development in Göttingen for helpful suggestions on earlier drafts. I am especially grateful to Rocco Zizzamia, who has been an inimitable partner in designing and running the field research in Khayelitsha. We are both also indebted to an exceptional team of fieldworkers, among whom Mzulungile Cabanga, Sibongile Mthini, Andiswa Mtini, and Amanda Moocha deserve special mention. Fieldwork was implemented with the financial and administrative support of the GIGA German Institute for Global and Area Studies, the Southern African Labour and Development Research Unit (SALDRU), and the Department of International Development at the University of Oxford. The views expressed here, and any remaining errors, are my own. 


\subsection{Introduction}

Throughout the developing world, increasing attention is being paid to the study of poverty dynamics. Going beyond cross-sectional comparisons of poor versus non-poor groups, the recent proliferation of panel surveys in developing countries has allowed researchers to separate and quantify the extent of chronic and transient poverty (for sub-Saharan Africa see, for example, Deininger \& Okidi, 2003; Finn \& Leibbrandt, 2017; Kedir \& McKay, 2005; Mberu, Ciera, Elungata, \& Ezeh, 2014; Schotte, Zizzamia, \& Leibbrandt, 2018).

The approach most often taken for these dynamic analyses focuses on investigating movements into and out of monetary poverty, driven by changes in income or consumption expenditure levels in relation to a specified poverty line. However, an important aspect often overlooked by such studies is that not all transitions are equal; for some, the descent into poverty may have been caused by a decline in productive assets or a reduction in their returns, brought on by changes in the broader economy (structural poverty descent), while others may have simply been unlucky in the present period (stochastic poverty descent). Analogously, for some of those exiting poverty, the escape may have been facilitated by an accumulation of productive assets or an increase in their returns (structural poverty escape), while others may have simply been lucky in the present period without any accompanying change in underlying income-generating processes and asset structure (stochastic poverty escape). These structural versus stochastic poverty transitions represent distinctly different experiences (Carter \& Barrett, 2006; Radeny, Van den Berg, \& Schipper, 2012) that are likely to result in dissimilar long-term livelihood trajectories.

South Africa is among the few countries where the use of asset-based approaches to distinguish between structural and stochastic forms of poverty has a longstanding tradition (Carter \& May, 1999, 2001). However, earlier work in this area has been confined to exploring poverty traps and transition pathways in predominantly rural settings (Adato, Carter, \& May, 2006; Adato, Lund, \& Mhlongo, 2007; Agüero, Carter, \& May, 2007; Carter \& May, 1999, 2001). As urban populations continue to grow, and poverty becomes an increasingly urban phenomenon (Rakodi, 2002), investigating the building blocks that either pave or bar the way for structural poverty escapes in urban contexts remains underexplored. Azomahou and Yitbarek (2014), Bigsten and Shimeles (2004), Faye, Islam, and Zulu (2011), Islam and Shimeles (2006), Kedir and McKay (2005), and Mberu et al. (2014) are among the relatively few studies that analyse poverty dynamics in urban Sub-Saharan Africa, but none of the above focus on South Africa, and none has made an attempt to differentiate between structural and stochastic mobility. 
Recognizing this gap in the literature, in this chapter I aim to provide a nuanced understanding of the key factors that both facilitate and hinder structural poverty escapes and descents, focusing on the socioeconomically disadvantaged urban African population in South Africa. To this end, going beyond conventional monetary definitions and approaches to studying poverty dynamics, I adopt an asset-based approach that is based on the concept of sustainable livelihoods. My empirical approach, which I apply to panel data from the National Income Dynamics Study, is conceptually similar to the one recently suggested by Radeny et al. (2012), drawing on earlier works by Carter and May $(1999,2001)$ and Carter and Barrett (2006). However, instead of directly estimating the relationship between assets and household income, as a first step I use factor analysis to construct five asset indices. These are intended, in line with the adopted conceptual framework, to capture the income-generating processes and livelihood strategies available to a household, as approximated by its ownership of and access to human capital, financial capital, physical capital, social capital, and geographic capital. As a second step, I map these livelihood-asset scores to the household income or expenditure space and construct an asset poverty line that allows me to decompose monetary poverty into structural and stochastic components.

This asset framework on its own, however, may be insufficient to identify the main determinants that explain transitions into and out of poverty (Radeny et al., 2012). Therefore, I triangulate my quantitative research findings with evidence from a qualitative case study. The primary data source for this qualitative research element consists of 30 life history interviews that I conducted, together with a local research team, between July and September 2017 in the township of Khayelitsha, Cape Town. The qualitative research design was partly informed by the life-history interview techniques used by Davis and Baulch (2011) in rural Bangladesh and Adato et al.'s (2007) "household events mapping” technique used in rural KwaZulu-Natal, which I combined and adopted to the South African urban context. Using this mix of quantitative and qualitative research methods for poverty analysis, I attempt to provide a deeper understanding of the multidimensional causal mechanisms, processes and pathways that underpin welfare transitions (see also Barrett, 2005; De Weerdt, 2010; Kanbur, 2003; Kanbur \& Saffner, 2007; Kedir, 2005; Radeny et al., 2012; White, 2002).

The remainder of this chapter is organised as follows. Section 4.2 briefly introduces the conceptual framework. Section 4.3 describes the panel survey data and the qualitative case-study design. Section 4.4 decomposes the transitions in monetary poverty into structural and stochastic components. Section 4.5 explores the main determinants of transition patterns using a mixed-methods approach. Section 4.6 discusses and concludes. 


\subsection{Sustainable livelihoods framework}

The analysis presented in this chapter is embedded in the sustainable livelihoods framework (SLF), which I adapt to the South African urban context. Drawing on Chambers and Conway (1992), a livelihood is defined as comprising "[...] the capabilities, assets (including both material and social resources) and activities required for a means of living" (Carney, 1998: 4). Coupled with this definition, a livelihood is regarded as sustainable "when it can cope with and recover from stresses and shocks and maintain or enhance its capabilities and assets both now and in the future, while not undermining the natural resource base" (Carney, 1998: 4). Even though the latter element of environmental or ecological sustainability has important linkages to the process of urbanisation, given that cities consume increasing amounts of natural resources and produce most of the world's waste and greenhouse gas emissions, this is not the main topic addressed here. In what follows, I focus my analysis on the first element of sustainability in the sense of lasting and sustained escapes from poverty.

The main components of the livelihoods framework adopted here are depicted in Figure 3.1. Under this framework, households or individuals are assumed to operate in a context of vulnerability. This describes the external uncontrollable factors and sources of insecurity (trends, seasons, positive or negative shocks) to which poor people and their assets are vulnerable. The vulnerability context is influenced by and interacts with the economic, political and institutional, environmental, and social and cultural contexts.

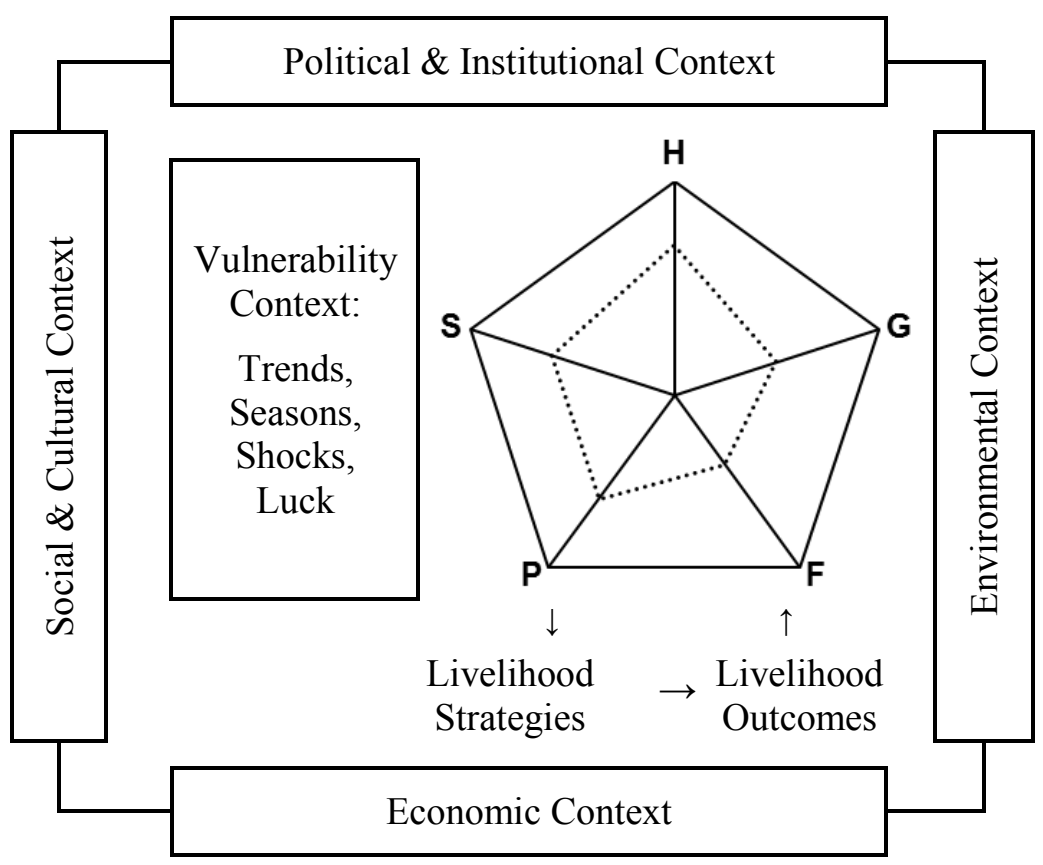

Livelihood Assets

H - Human (household members, education, skills, health)

G - Geographic (location, public infrastructure)

F - Financial (pensions, savings, credit, insurance)

P - Physical (housing, private durable goods)

S - Social (networks and membership in groups, relationships of trust)

Figure 4.1 Livelihoods framework

Source: Developed from Rakodi (2002). 
At the centre of the framework is the portfolio of assets on which households or individuals draw to generate a flow of income or other benefits. This portfolio, which is the focal point of this study, includes both tangible and intangible assets, grouped into five types of capital (human, financial, physical, social, and geographic), briefly defined in Box 4.1.

As a visual analytical tool, a pentagon can be used to describe people's access to each capital type, where the centre point represents zero access, and the outer perimeter represents maximum access to assets (Carney, 1998; Rakodi, 2002). To give an example, the dotted line in Figure 3.1 shows reasonable access to human, physical, and social capital but limited access to geographic and financial capital. While there may be trade-offs, the five capital types complement each other, and households or individuals will need to draw on all five to construct their living. That is, "it is the overall area of a pentagon [...] that is important, rather than the absolute magnitude of access to any particular type of capital" (Carney, 1998: 8).

Box 4.1 Livelihood assets

H Human Capital comprises the quantity and quality of labour resources available to the household. The opportunities for economic activity are typically constrained by the number of household members in working age, their education, skills, experience, and health status, as well as their caregiving demands. Formal qualifications tend to be of higher relevance in urban than in rural labour markets (Rakodi, 2002).

F Financial Capital includes regular financial flows (such as from private pensions, dividends or interest), savings, and access to credit and insurance. It is important to cope with shocks, smooth consumption, and facilitate investment.

P Physical Capital here is understood in the narrow sense, comprising privately owned productive capital and household assets. It includes housing, which in the urban context can be a source of rental income and facilitate home-based business activities (Rakodi, 2002), as well as durable goods and other productive assets.

S Social Capital typically comprises relationships of trust, memberships of groups, social networks, and access to wider institutions in society. While urban living has generally been associated with a fragmentation of social relationships, this may apply less to the urban poor, who are embedded in township community networks and often maintain strong linkages with their rural kin (Du Toit and Neves, 2009).

G Geographic Capital captures access to public infrastructure (such as transport, water and energy supply, sanitation, garbage collection, and street lighting). It enables people to access, and directly supports, income-generating activities. It replaces natural capital (such as land and water) included in the standard SLF, which is of higher relevance in rural than in urban settings.

The ways people combine and use their available assets are described as livelihood strategies, and economic activities are at the core of these. In addition, migration movements, maintenance of and participation in social networks, and investment decisions (such as in 
education or property) can present important components. ${ }^{35}$ The outcomes of these strategies are defined in terms of higher or lower welfare. Importantly, the greater the diversity of livelihood strategies available to a household, the less vulnerable it is to external risk factors (Rakodi, 2002).

\subsection{Data and methodology}

\subsubsection{Panel data description and quantitative poverty measures}

The data for the quantitative analysis comes from the National Income Dynamics Study (NIDS) implemented by the Southern Africa Labour and Development Research Unit (SALDRU) at the University of Cape Town (SALDRU 2016a, b, c, d). NIDS is South Africa's first national panel study, which started in 2008 with a nationally representative sample of over 28,000 individuals in 7,300 households. At present, there are four waves of data available, spaced approximately two years apart. For the dynamic analysis, individuals must be successfully tracked over at least two consecutive survey waves. Data from pairs of consecutive waves were pooled, such that transitions that occurred from wave 1 to 2 , wave 2 to 3 , and wave 3 to 4 are treated identically in the analysis. The sample for the dynamic analysis contains 74,217 individual observations. ${ }^{36}$

\section{Monetary welfare measures}

There are three official poverty lines that have been defined by Statistics South Africa (Stats SA) in 2015 using a cost-of-basic-needs approach (Stats SA, 2015a). Each of these lines captures a different degree of poverty. The food poverty line (FPL) is the level of consumption below which individuals are unable to purchase sufficient food to fulfil their caloric requirements for good health (fixed at about 2,100 kilocalories a day), even if all expenditures are dedicated to food. The lower-bound poverty line (LBPL) allows for spending on non-food items but requires that individuals sacrifice some food consumption to fulfil their

\footnotetext{
${ }^{35}$ The adopted conceptual framework treats the household as the relevant unit of analysis. In doing so, it ignores the internal household decision-making process, which underpins any "household livelihood strategy." A further limitation of the adopted framework is that it tends to treat households as stable units. However, the household composition is not only a determinant of the capabilities, choices, and strategies available to the household, but may itself be the outcome of strategic decisions (Rakodi, 2002).

${ }^{36}$ Panel weights have been constructed to correct for panel attrition, following the approach suggested by Finn and Leibbrandt (2017). For each successive wave, a probit model was estimated with the dependent variable being a dummy indicating whether the individual stayed in the sample or not. Wave 1 to 2 panel members then received a new weight that was the product of the original wave 1 post-stratified survey weight and the inverse of the conditional probability of re-interview. The same process was applied to wave 2 to 3 and wave 3 to 4 .
} 
non-food needs. Only at the upper-bound poverty line (UBPL) can individuals purchase both adequate food and non-food items.

Throughout this chapter, household expenditure is used as the relevant monetary welfare measure, which is assumed to provide a better approximation of permanent household income than reported income. Different to Stats SA's usual practice, all monetary welfare measures are adjusted to account for the fact that large households require more resources than small households to reach a similar level of welfare, that adults need more food and other commodities than children, and that there are some economies of scale in household consumption. In addition, I recognise that school-age children in South Africa will generally require higher expenses (fees for schooling, materials, and transport, for example) than younger children. Using a simple scaling method (similar to May, Carter \& Posel, 1995; Carter \& May, 1999), I define the number of adult equivalences (E) in each household as:

$$
\mathrm{E}=\left(\mathrm{N}_{A}+0.5 \mathrm{~N}_{Y C}+0.75 \mathrm{~N}_{S C}\right)^{0.9}
$$

where $\mathrm{N}_{A}$ is the number of adult (age 16 years or older) household members, $\mathrm{N}_{Y C}$ is the number of young children (age 6 years or younger), $\mathrm{N}_{S C}$ is the number of school-aged children (age 7 to 15 years), and 0.9 is the scaling parameter that captures modest economies of scale in household consumption (see Woolard \& Leibbrandt, 2006, for a comparison of alternative equivalence scales suggested for South Africa).

On this basis, Stats SA's (2015a) three official poverty lines are rescaled using a reference household of five members, including three adults, one school-aged child, and one younger child (reflecting the median household composition of poor households in NIDS). Using this approach, the FPL, LBPL, and UBPL were respectively estimated at R585, R855, and R1,309 per adult equivalent per month, in January 2015 prices. $^{37}$

\section{Asset-based poverty measures}

The asset-based approach used to differentiate between structural and stochastic poverty is conceptually similar to the one recently suggested by Radeny et al. (2012) in their study of rural poverty dynamics in Kenya, drawing on earlier works by Carter and May (1999, 2001) and Carter and Barrett (2006).

A household, $i$, is classified as poor at time $t$ if its consumption expenditure in equivalence scales, $c_{i t}$, falls below the monetary poverty line, PL. That is,

\footnotetext{
${ }^{37}$ All monetary values used in this chapter are deflated to January 2015 prices using the Stats SA's headline consumer price index (2015b). To adjust for inflation, for each line the food component (equal to the FPL) is inflated by using the food-specific Stats SA CPI and the non-food component (equal to the difference between the FPL and the LBPL or UBPL respectively) is inflated by using the non-food-specific Stats SA CPI. Using this approach, the FPL, LBPL, and UBPL were estimated at R430, R629, and R963 per-person-per-month.
} 


$$
\mathrm{c}_{\mathrm{it}}<\mathrm{PL} \text {. }
$$

Parallel to PL, an asset poverty line can be defined. Identification of this threshold requires estimation of the relationship between the per capita adult equivalent expenditure, $c_{i t}$, and the bundle of assets held by the household in period $t, \mathrm{~A}_{\mathrm{it}}$.

To this end, in a first step, I use multiple correspondence analysis to construct five asset indices, normalised to a range between zero and one (for details on the methodology see Chapter 5 or check, for example, Booysen, Van der Berg, Burger, Von Maltitz, \& Du Rand, 2008; Shimeles \& Ncube, 2015). These indices are intended to capture the income-generating processes and livelihood strategies available to a household, as approximated by its ownership of and access to human capital $\left(\mathrm{H}_{\mathrm{it}}\right)$, financial capital $\left(\mathrm{F}_{\mathrm{it}}\right)$, physical capital $\left(\mathrm{P}_{\mathrm{it}}\right)$, social capital $\left(\mathrm{S}_{\mathrm{it}}\right)$, and geographic capital $\left(\mathrm{G}_{\mathrm{it}}\right){ }^{38}$ The choice of variables was guided by the conceptual framework introduced in Section 4.2 and previous similar studies, taking data availability into account (see Table C.1 in Appendix C.1).

In a second step, I map the livelihood-asset scores to the household income or expenditure space, using a regression-based approach. Because the five specified capital types are unlikely to be completely independent of each other, multicollinearity may be a concern. An investigation of the correlation coefficients $(\tau)$ between the derived asset scores, however, only shows a weak $(\tau<0.2)$ to modest $(\tau<0.4)$ relationship across most capital types. The strongest but still moderate link $(\tau=0.46)$ is observed between physical capital and geographical assets (see Table C.2 in Appendix C.1). As a further check for multicollinearity, variance inflation factors (VIFs) and tolerance measures have been calculated using simple linear regression. The results strengthen my assumption that the five derived asset indices measure distinct concepts (see Table C.3 in Appendix C.1).

Endogeneity and reverse causality are another concern inherent to this method. On the one hand, assets play an important role in income-generating activities. On the other hand, assets are commonly accumulated through accumulating income, and negative income shocks can lead to a depletion of assets. I recognise the difficulties in addressing the econometric problems that arise from this circular relationship, but the interest of the subsequent analysis is less about identifying precise marginal returns on the five capital types that would warrant causal interpretations, and more about forming reliable expectations concerning the level of household income conditional on the available asset bundle (see Radeny et al., 2012).

\footnotetext{
${ }^{38}$ Race and gender have been classified as social capital and not human capital indicators, because both variables gain their meaning and value through the prevailing social context. Recent studies show that social networks are typically segregated by race and gender, where access to these social capital resources, especially with regard to informal processes that govern job search and career opportunities, tends to be greatest for white males (McDonald \& Day, 2010). Our field evidence emphasizes this connection in the South African context.
} 
To account for the fact that the relationship between household assets and income or expenditure is very likely to be non-linear (Carter \& May, 1999, 2001; Carter \& Barrett, 2006), I adopt a flexible parametric estimation approach similar to the one used by Radeny et al. (2012). ${ }^{39}$ Using a polynomial expansion, the employed functional form allows for diminishing (or increasing) returns to capital, as well as for interaction effects across capital types. The explicit model is specified as:

$$
\ln \left(c_{i t}\right)=\alpha+\sum_{j} \beta_{j} X_{i t}^{j}+\sum_{k} \sum_{l} \gamma_{k l} X_{i t}^{k} X_{i t}^{l}+\sum_{j} \delta_{j}\left(X_{i t}^{j}\right)^{2}+\sum_{t} \varphi t_{t}+\varepsilon_{i t}
$$

where $\mathrm{X}$ is a vector of asset indices, $j, k$, and $l$ denote the five capital types (with $k \in j, l \in j$, and $k \neq l$ ), $t_{t}$ represents period-specific dummies (controlling for exogenous fluctuations), and $\varepsilon_{i t}$ is an idiosyncratic error term.

To account for unobserved heterogeneity across households, equation (4.3) is fitted to NIDS panel data using a random effects model. ${ }^{40}$ Clustered standard errors are used to allow for intragroup correlations across survey clusters (see Table C.4 in Appendix C.1).

As a robustness check, a non-parametric (NP) kernel estimator has been used that allows $g\left(X_{i t}\right)$ to take on any functional form (Lybbert, Barrett, Desta, \& Coppock, 2004) ${ }^{41}$ :

$$
\ln \left(c_{i t}\right)=g\left(X_{i t}\right)+\epsilon_{i t}=g\left(\mathrm{H}_{i t}, \mathrm{~F}_{i t}, \mathrm{P}_{i t}, \mathrm{~S}_{i t}, \mathrm{G}_{i t}\right)+\epsilon_{i t} .
$$

Drawing on the regression results, the asset poverty line, $\underline{A}_{t}$, simply denotes the combination of assets that yields an expected level of household welfare, $\widehat{\mathrm{c}}\left(A_{i t}\right)$, equal to the money metric poverty line, PL, in the respective period. Accounting for measurement and other random errors in the estimation of $\widehat{\mathrm{c}}\left(A_{i t}\right)$, a household is considered stochastically poor in any period $t$ if its realised income or expenditure falls below PL, and yet I can reject the hypothesis that it is expected to be poor, given its assets (Carter \& May, 2001). That is,

$$
\text { if } c_{i t}<\mathrm{PL} \text { and reject } H_{0}: \widehat{\mathrm{c}}\left(A_{i t}\right)<\mathrm{PL} \text {. }
$$

Analogously, a household is considered stochastically non-poor

$$
\text { if } c_{i t} \geq \mathrm{PL} \text { and reject } H_{0}: \widehat{c}\left(A_{i t}\right) \geq \mathrm{PL} \text {. }
$$

Following Radeny et al. (2012), I use the $95 \%$ confidence bands of $\hat{\mathrm{c}}\left(A_{i t}\right)$ to account for imprecision in the estimation of $\widehat{\mathrm{c}}\left(A_{i t}\right)$. A household with $c_{i t}<\mathrm{PL}$ is stochastically poor if the lower bound estimate of $\hat{\mathrm{c}}\left(A_{i t}\right)$ falls above PL $\left(\hat{\mathrm{c}}_{L B}\left(A_{i t}\right) \geq \mathrm{PL}\right)$, and structurally poor otherwise. Similarly, a household with $c_{i t} \geq \mathrm{PL}$ is stochastically non-poor if the upper bound estimate of $\widehat{\mathrm{c}}\left(A_{i t}\right)$ falls below PL $\left(\widehat{\mathrm{c}}_{U B}\left(A_{i t}\right)<P L\right)$, and structurally non-poor otherwise.

\footnotetext{
${ }^{39}$ Radeny et al. (2012) do not construct asset indices but directly use survey asset variables and demographic characteristics as explanatories of total household expenditure.

${ }^{40}$ I experimented with higher-degree polynomials in equation (4.3) with very similar results.

${ }^{41}$ The estimation is performed using the npregress kernel command in STATA 15.
} 


\subsubsection{Qualitative case-study design and description of study sites}

The primary data source for the qualitative research element consists of 30 semi-structured life-history interviews (LHIs) conducted between July and September 2017 in the township of Khayelitsha, situated about 30 kilometres south east of Cape Town's city centre.

\section{Study sites}

Khayelitsha was selected as a study site because it closely resembles many of the context characteristics that typically condition the livelihoods of the urban poor in South Africa. On the one hand, service delivery, economic activity, and opportunities for employment are generally better in urban than in rural areas and continue to entice rural-to-urban migration (see Chapters 2 and 3). On the other hand, rapid urbanisation has left many on the fringes of society, resulting in a proliferation of informal settlements and increasingly densely populated townships, suffering from high un- and underemployment, socioeconomic insecurity, and crime (Visagie \& Turok, forthcoming).

This dynamic is clearly visible in Khayelitsha. Established in 1985 by the apartheid government as a site for relocations from other overcrowded African townships in Cape Town, it initially accommodated 30,000 people. Since then it has grown rapidly, driven by endogenous population growth and continuing rural-to-urban migration. According to the latest census information (see Table 4.1), in 2011 it comprised a population of 391,749 inhabitants grouped into 118,809 households, making it South Africa's second largest township after Soweto in Johannesburg. Roughly every second inhabitant is under 24 years old, and 55.8 per cent were born outside of the Western Cape, almost all of whom migrated from rural areas in the Eastern Cape. Culturally, the population structure is relatively homogenous in terms of race (98.6 per cent African) and language (90.5 per cent isiXhosa).

The township comprises old formal areas built originally by the apartheid government, which are generally wealthier, and newer areas that contain a mix of informal settlements, government-provided housing, and informal backyard dwellings. Regardless of the important extent of variation in living standards, Khayelitsha overall has high levels of income poverty and faces serious challenges in terms of education, employment, housing, sanitation, and service delivery. Around 55.4 per cent of residents live in informal dwellings, 38.1 per cent need to walk 200 meters or further for clean water access, and 29.3 per cent are not connected to any sewage system. Only 35.6 per cent of residents above the age of 20 have completed high school and only 40.4 per cent of the labour force is employed, of which many work in temporary or informal employment relationships (see Table 4.1). 
Table 4.1 Khayelitsha descriptive statistics, 2011

\begin{tabular}{l|r}
\hline \hline 2011 Census Suburb Khayelitsha & 2011 \\
\hline Population & 391,749 \\
Households (HHs) & 118,809 \\
Average HH size & 3.30 \\
\hline Share (\%) of HHs living in informal dwellings (shack in/not in backyard) & 55.4 \\
Share (\%) of HHs with piped water access (inside dwelling/yard) & 61.9 \\
Share (\%) of HHs connected to sewerage system (flush toilet) & 71.7 \\
Share (\%) of HHs using electricity for lighting & 80.8 \\
Share (\%) of HHs where refuse is removed by local authority/private company at least once a week & 80.9 \\
\hline Share (\%) of HHs with average monthly HH income of less than R3,200 & 73.7 \\
Share (\%) of HHs with average monthly HH income of R3,201-R6,400 & 15.1 \\
Share (\%) of HHs with average monthly HH income of R6,401-R12,800 & 7.2 \\
Share (\%) of HHs with average monthly HH income of R12,801 or more & 4.1 \\
\hline Share (\%) of population under 24 years old & 49.6 \\
Share (\%) of population that is African & 98.6 \\
Share (\%) of population that speaks isiXhosa & 90.5 \\
Share (\%) of population that was born in the Eastern Cape & 50.8 \\
\hline Share (\%) of adult population (aged 20+ years) with completed secondary of higher education & 35.6 \\
Average labour force participation rate (\%) among working age (15 to 64 years) population & 65.1 \\
Average unemployment rate (\%) among working age (15 to 64 years) population & 38.0 \\
Average share (\%) of working age (15 to 64 years) population that is employed & 40.4 \\
\hline \hline
\end{tabular}

Ideally, I would have liked to re-interview households from the NIDS panel to directly link the quantitative and qualitative analysis. However, this was impossible given the risk of this research influencing household responses and attrition in future survey waves. Therefore, data on the small area level from the 2011 Census have been used to ensure adequate coverage of different (i) area types, including formal settlements with low/high density of backyard shacks and informal settlements with low/high access to basic services (using type of toilet facility as a proxy); (ii) wealth levels, as approximated by the average poverty headcount and the share of households where the household head is employed; and (iii) settlement durations, including areas with a low/high share of households that settled in their present location after 2001 (see Appendix C.2).

On this basis, in a first stage, 15 study areas were selected (see Figure 4.2), where a short sampling survey was administered to 300 households chosen using a random walk technique. ${ }^{42}$ The survey collected basic information on the households' human, physical, and financial capital, allowing for a quick wealth assessment. While falling short of making claims of representativeness, this approach guarantees that selected interview participants show some degree of heterogeneity in terms of their asset base and livelihood strategies.

\footnotetext{
${ }^{42}$ Survey questionnaires and interview guides are available from the author upon request.
} 


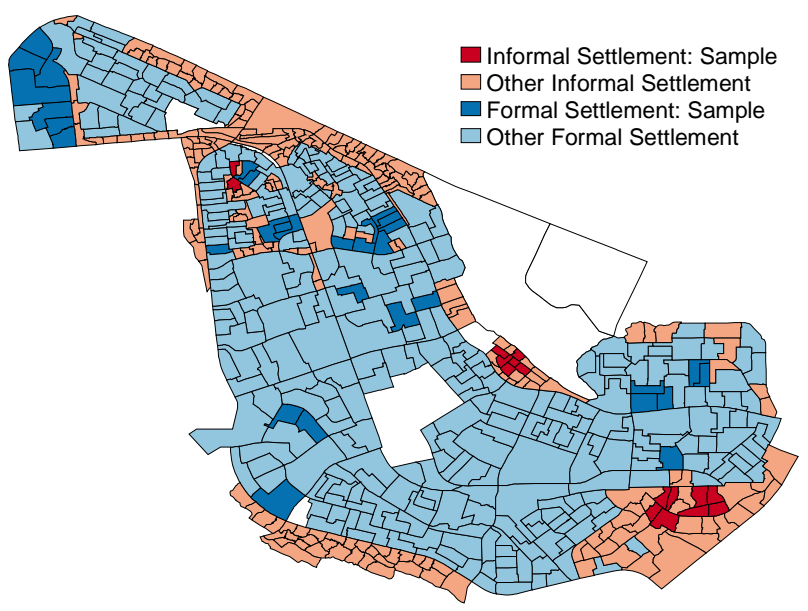

Figure 4.2 Selected study areas

\section{Interview methods and analysis techniques}

Drawing on the sample collected in the first field-research stage, 30 respondents were selected for participation in the LHIs, covering different areas and welfare levels. Participants were asked to recount their individual life history, starting from their parental background and living conditions during childhood, and up to and including the present. ${ }^{43}$ As visual aids, all events reported during the interview were recorded on two sets of cards, where one colour was assigned to positive events and another colour to negative events (following Adato et al.'s, 2007, “household events mapping" technique). At the end of each interview, respondents were asked to rank their own welfare level at different points in time on a fourpoint scale. With the help of the interviewee, the researcher would then map out the respondent's life trajectory on a large sheet of blank paper (in line with the methodology suggested by Davis \& Baulch, 2011), capturing the respondent's welfare level at each stage in life and the events that had caused transitions within and between welfare categories (see Appendix C.3).

As a preparatory step for this final exercise, four focus group discussions (FGDs) were conducted in advance, with participants from the local community (again drawing on the sample collected in the first field-research stage). ${ }^{44}$ The FGDs were designed to develop a scale capturing social and material welfare levels in the local context, which could be used

\footnotetext{
${ }^{43}$ All interviews were conducted in isiXhosa by a moderator who was intensively trained during preparation for fieldwork. Following common practice among qualitative researchers in South Africa, the interviews were simultaneously translated by a second research assistant, and the translation was transcribed by the researcher, who was present during the interview (Du Toit \& Neves, 2007, 2009, 2014; De la Hay \& Beinart, 2017). Transcriptions and audio recordings were analysed and discussed with the moderator and translator in a postinterview de-brief to ensure the accuracy of the translation and transcription and to analyse preliminary findings.

${ }^{44}$ FGDs ranged from between 3 to 10 participants. Two groups were single gender (male/female), and two were mixed. The FGDs were conducted by a trained moderator in isiXhosa and lasted approximately two hours each. In line with the technique used during the LHIs, the discussions were simultaneously translated by a trained research assistant and the translation was transcribed by the researcher, who was present during the discussion.
} 
during the LHIs. This welfare scale was intended to be more subjectively meaningful than narrow, money-metric proxies of income and expenditure, while at the same time facilitating a degree of comparability between cases. To this end, visual aids in the form of four boxes representing different "levels" of society were used during the discussions. ${ }^{45}$

For me, it was important to observe that all groups arrived quite easily and naturally at a common interpretation of what it meant for someone to be on level four (lowest) to one (highest) in the given context and that these perceptions were relatively consistent across groups. The most common characteristics of the various boxes that were converged upon in the FGDs are summarised in Box 4.2. Interestingly, there seemed to be a relatively large distance in terms of the satisfaction of basic needs between boxes one and two, on the one hand, and boxes three and four, on the other. For the subsequent analysis, boxes three and four are thus considered poor, with those in box four being considered food-poor.

\section{Box 4.2 Welfare levels}

Box 1 Those in box one are the economic success stories of the township. They are either successful entrepreneurs in the community, such as taxi or tavern owners, or are stably employed in permanent and well-paid work in the public or private sector. Their children are educated, employed and/or married, and live on their own.

Box 2 Those in box two are neither poor nor wealthy. They are employed, usually in a lower-level white collar or higher-level blue-collar occupation. Compared to those in box one, they tend to face the need to support a larger number of dependents, which may also include members of the extended family.

\section{Poverty}

Box 3 Those in box three have their most elementary needs such as food and electricity satisfied but still need to economise a lot. They cannot put any money to the side because all income is consumed. They tend to derive income from the labour market but are typically in jobs that are poorly paid, are of limited duration, are unregulated by labour legislation, or are subject to seasonal fluctuations. This box also includes smaller households with access to an old-age pension/disability grant.

\section{Food Poverty}

Box 4 Those in box four have repeatedly been characterised as "going to sleep on an empty stomach." They typically have no access to income from the labour market but survive on child-support grants and/or support from others in the community, including food donations by neighbours. Some engage in survivalist forms of selfemployment and/or do ad hoc piece jobs. These people live hand-to-mouth. They have few assets, live in informal dwellings, and lack access to basic services.

\footnotetext{
${ }^{45}$ The boxes were introduced through vague definitions such as "those in box one are the most well-off, and those in box four are the least well-off," while words with strong connotations such as "rich" or "poor" were strictly avoided by the moderator. On this basis, participants were prompted to discuss what it meant for someone to be in each respective box, along with the main determinants of movements between boxes. In both elements of the discussion - defining boxes and discussing dynamics - participants drew on their own experiences and the experiences of people known personally to them. During FGDs, key points were transcribed onto a blackboard, an exercise that helped to anchor the discussions and to gauge both disagreement and consensus for particular claims.
} 


\subsection{Magnitude of structural and stochastic poverty transitions}

In the first part of the analysis, I offer a quick quantitative assessment of the extent of movements into and out of monetary poverty in South Africa. Using the asset-based approach introduced above, I decompose these transitions into structural and stochastic components.

\subsubsection{Movements into and out of monetary poverty}

Apartheid imposed a rigid racialised system of unequal resource distribution on South Africa, resulting in an extremely polarised society. After two decades of democracy, its legacy persists in the country's economic conditions and continues to shape South African society along racial and geographic divides. Even though South Africa ranks as an upper-middle income country, close to two-thirds of its people - and close to three-quarters of the African population - are still living in moderate to extreme poverty. The incidence, depth, and severity of poverty are clearly higher in rural than in urban areas. Nevertheless, it should be emphasised that one in five urban dwellers cannot satisfy their food needs, and almost every second one is unable to purchase adequate food and non-food items (see Table 4.2).

Table 4.2 Measured poverty rates (cumulative percentage shares)

\begin{tabular}{l|cc|cccc|c}
\hline \hline & \multicolumn{3}{|c|}{ By area } & \multicolumn{5}{c|}{ By race group } & \multirow{2}{*}{ TOTAL } \\
\cline { 2 - 7 } & Urban & Rural & African & Coloured & Asian/Indian & White & \\
\hline$c_{i t}<$ FPL & 22.1 & 54.7 & 41.6 & 16.1 & 1.4 & 0.5 & 34.7 \\
$c_{i t}<$ LBPL & 35.1 & 71.5 & 58.0 & 31.5 & 3.2 & 1.1 & 49.2 \\
$c_{i t}<$ UBPL & 49.9 & 84.3 & 72.8 & 49.9 & 14.9 & 3.9 & 63.3 \\
$c_{i t} \geq$ UBPL & 50.1 & 15.8 & 27.2 & 50.1 & 85.1 & 96.1 & 36.8 \\
\hline Share in total & 61.1 & 38.9 & 79.8 & 8.9 & 2.5 & 8.8 & 100 \\
population & & & & & & & \\
\hline \hline
\end{tabular}

Note: Average statistics for pooled NIDS sample, 2008 to 2014/15. The poverty profile is very similar to the one that would have been obtained if no adjustments were made to account for child costs and economies of scale. While there is an important overlap, this does not mean that exactly the same households are identified as poor.

To illustrate the extent of mobility into and out of monetary poverty over time, Table 4.3 presents a set of poverty transition matrices for the pooled sample of wave-to-wave transitions. To account for the depth of poverty, I define five welfare levels in terms of household expenditure per adult equivalent: $c_{i t}<$ FPL, FPL $\leq c_{i t}<$ LBPL, LBPL $\leq c_{i t}<$ UBPL, UBPL $\leq \mathrm{c}_{i t}<2.5 \mathrm{UBPL}, 2.5 \mathrm{UBPL} \leq \mathrm{c}_{\mathrm{it}}$. The values on the diagonal of the transition matrices indicate the share of individuals in each row who remain in the same welfare category between time periods $t$ and $t+1$ (grey shaded area), whereas those below the diagonal are downwardly mobile, and those above the diagonal are upwardly mobile. 
Table 4.3 Measured poverty transition matrix (per cent of row)

\begin{tabular}{|c|c|c|c|c|c|}
\hline & $c_{i t+1}<\mathrm{FPL}$ & $c_{i t+1}<\mathrm{LBPL}$ & $c_{i t+1}<\mathrm{UBPL}$ & $c_{i t+1}<2.5$ UBPL & $2.5 \mathrm{UBPL} \leq c_{i t+1}$ \\
\hline \multicolumn{6}{|l|}{ Total population } \\
\hline$c_{i t}<$ FPL & 61.2 & 17.1 & 11.5 & 8.3 & 1.9 \\
\hline$c_{i t}<\mathrm{LBPL}$ & 40.0 & 20.7 & 19.0 & 16.5 & 3.8 \\
\hline$c_{i t}<$ UBPL & 24.9 & 19.5 & 23.7 & 25.5 & 6.5 \\
\hline$c_{i t}<2.5$ UBPL & 12.5 & 11.7 & 18.5 & 37.9 & 19.4 \\
\hline$c_{i t} \geq 2.5 \mathrm{UBPL}$ & 2.6 & 1.6 & 4.5 & 20.8 & 70.5 \\
\hline \multicolumn{6}{|c|}{ African population } \\
\hline$c_{i t}<\mathrm{FPL}$ & 61.9 & 17.0 & 11.2 & 8.1 & 1.9 \\
\hline$c_{i t}<\mathrm{LBPL}$ & 42.0 & 20.5 & 17.9 & 15.9 & 3.8 \\
\hline$c_{i t}<\mathrm{UBPL}$ & 27.7 & 19.8 & 22.8 & 23.7 & 6.1 \\
\hline$c_{i t}<2.5 \mathrm{UBPL}$ & 15.2 & 13.4 & 19.1 & 36.7 & 15.7 \\
\hline$c_{i t} \geq 2.5 \mathrm{UBPL}$ & 6.6 & 4.0 & 9.1 & 30.3 & 50.0 \\
\hline \multicolumn{6}{|l|}{ Urban population } \\
\hline$c_{i t}<\mathrm{FPL}$ & 52.3 & 19.7 & 14.7 & 11.0 & 2.3 \\
\hline$c_{i t}<\mathrm{LBPL}$ & 33.0 & 20.0 & 21.7 & 20.8 & 4.6 \\
\hline$c_{i t}<$ UBPL & 20.3 & 20.2 & 24.6 & 27.0 & 8.0 \\
\hline$c_{i t}<2.5 \mathrm{UBPL}$ & 9.6 & 10.2 & 17.9 & 40.2 & 22.1 \\
\hline$c_{i t} \geq 2.5 \mathrm{UBPL}$ & 1.2 & 1.4 & 3.9 & 20.1 & 73.4 \\
\hline \multicolumn{6}{|c|}{ Urban African population } \\
\hline$c_{i t}<\mathrm{FPL}$ & 52.7 & 19.6 & 14.5 & 10.8 & 2.4 \\
\hline$c_{i t}<\mathrm{LBPL}$ & 34.9 & 19.9 & 20.2 & 20.5 & 4.5 \\
\hline$c_{i t}<\mathrm{UBPL}$ & 23.8 & 20.2 & 23.0 & 25.6 & 7.4 \\
\hline$c_{i t}<2.5 \mathrm{UBPL}$ & 11.8 & 11.6 & 19.1 & 40.0 & 17.6 \\
\hline$c_{i t} \geq 2.5 \mathrm{UBPL}$ & 3.2 & 3.6 & 8.2 & 30.4 & 54.6 \\
\hline \multicolumn{6}{|c|}{ Urban African population, including rural-to-urban migrants } \\
\hline$c_{i t}<\mathrm{FPL}$ & 50.3 & 19.4 & 15.1 & 12.3 & 2.9 \\
\hline$c_{i t}<\mathrm{LBPL}$ & 34.1 & 19.5 & 20.0 & 21.3 & 5.2 \\
\hline$c_{i t}<\mathrm{UBPL}$ & 23.4 & 19.9 & 23.2 & 26.1 & 7.3 \\
\hline$c_{i t}<2.5 \mathrm{UBPL}$ & 11.7 & 11.6 & 19.1 & 40.0 & 17.6 \\
\hline$c_{i t} \geq 2.5 \mathrm{UBPL}$ & 3.3 & 3.7 & 8.6 & 30.5 & 54.0 \\
\hline
\end{tabular}

Note: Rural-to-urban migrants are defined as those who stayed in rural areas in $t$ and urban areas in $t+1$.

As the results presented in Table 4.3 indicate, persistence is highest at the lower and upper extreme of the income or expenditure distribution. At 61.2 per cent, those living below the FPL are the most likely to be trapped in extreme poverty. Their chance of moving above the UBPL is just above 10 per cent. At the same time, 70.5 per cent of the most well-off $\left(2.5 \mathrm{UBPL} \leq \mathrm{c}_{\mathrm{it}}\right)$ were able to maintain their income position. On average, they face an aggregate risk of 8.7 per cent of falling below the UBPL (in this sense, this group is comparable to the stable middle class that has been identified in Chapter 2). Those falling into one out of the three middle welfare classes (FPL $\leq \mathrm{c}_{\mathrm{it}}<2.5 \mathrm{UBPL}$ ) are substantially more mobile (here none of the main diagonal elements significantly exceeds 40 per cent).

On average, downward mobility is higher among the African population compared to other race groups. Interestingly, the best-off group appears substantially less stable. Only every second person in this group could sustain this income position $\left(2.5 \mathrm{UBPL} \leq \mathrm{c}_{\mathrm{it}}\right)$ from 
one survey wave to the next. Moreover, upward mobility is higher in urban than in rural areas, and rural-to-urban migrants face above-average chances of moving up the income ladder. Specifically, urban dwellers with incomes falling below the FPL are about ten percentage points less likely to be locked in extreme poverty, compared to the population average. Combining the two effects, there is a substantial extent of income mobility - in line with a low extent of stability and security - among the urban African population.

\subsubsection{Decomposing poverty transitions into structural and stochastic components}

The transition estimates presented in the previous section are likely to overestimate the actual extent of poverty dynamics in South Africa for two main reasons: First, the transition matrices presented in Table 4.3 do not distinguish between structural and stochastic mobility. Second, as Burger, Klasen, and Zoch (2016) show, measurement error in household income (or expenditure) tends to inflate transition estimates. Following the methodology outlined in Section 4.3.1, in what follows I therefore decompose poverty transitions into structural and stochastic components. The results are summarised in Table 4.4 below.

The structure of Table 4.4 is a simplified version of Table 4.3 above, in which the various welfare levels have been collapsed into poor and non-poor groups, using the UBPL as the relevant poverty thresholds. Three out of four individuals did not change their poverty status between two subsequent waves of the NIDS data. Out of these, two are observed to be twice poor, and one is observed to be twice non-poor (see Table 4.4 upper panel). ${ }^{46}$ Only about 4 to 5 per cent of these immobile individuals experience what Carter and May (2001) call a dual entitlements failure. That is, their income level places them above (below) the money poverty line in both periods, even though they would (not) be expected to be poor given their asset holdings (see Table $4.4 \mathrm{a}+\mathrm{d}$ ). That is, they are stochastically non-poor (poor) in both periods.

The upwardly mobile, who escape monetary poverty from one period to the next, comprise two very distinct groups of individuals. On the one hand, three-quarters emerge from a situation of structural poverty. Out of these, 44.8 per cent are considered structurally upwardly mobile, while the other 55.2 per cent are stochastically upwardly mobile. That is, more than half of these escapers would still be expected to be poor, given the assets they hold. For them, the observed rise in monetary outcomes may rather be driven by luck or measurement error and therefore must be considered less likely to be sustained through time.

\footnotetext{
${ }^{46}$ All percentage shares refer to the total number of individuals in the pooled sample. As the NIDS is an individual-level panel, individuals can switch households between waves. This implies that members of the same initial household may take different poverty trajectories. Nevertheless, all explanatory variables entering the asset-poverty estimation are measured at the household level.
} 
On the other hand, one quarter of the upwardly mobile emerge from a position of stochastic poverty. For them, the escape from poverty reflects a return to an expected nonpoor standard of living. The previous literature therefore subsumes this group by definition with the group of the stochastically upwardly mobile (Carter \& May, 1999, 2001; Radeny et al., 2012). Because my main research interest here is in the question of which movements into and out of monetary poverty will likely be sustained over time, this definition could lead to confusion. As may be expected, the initially stochastically poor who move out of poverty will generally have access to a stock of assets worth at least $\underline{A}$ and therefore, in period $t+1$, more closely resemble the characteristics of the structurally upwardly mobile (see Table 4.4b). Clearly, these cases will be excluded from any further analysis of structural poverty escapes through the successful accumulation of assets, presented in the next section.

A similar argumentation applies to the downwardly mobile, who move into monetary poverty from one period to the next. About half of this group is made up of initially stochastically non-poor individuals, for whom the descent into poverty presents a regression to their expected level of livelihood. Conversely, the other half initially dispose of asset holdings sufficient to be considered structurally non-poor. For at least every second person (51.3 per cent) in this group, the descent into poverty is structural. That is, it is accompanied by a decline in the asset base that causes the person to slip below the asset poverty line.

Table 4.4 Decomposing poverty transitions (per cent of individuals)

\begin{tabular}{c|c|c}
\hline \hline & $c_{i t+1}<$ PL & $c_{i t+1} \geq$ PL \\
\hline$c_{i t}<$ PL & a) Twice poor: 54.44 & b) Upwardly mobile: 11.17 \\
\hline$c_{i t} \geq$ PL & c) Downwardly mobile: 8.67 & d) Twice non-poor: 25.72 \\
\hline Total & 63.11 & 36.89 \\
\hline \hline
\end{tabular}

\begin{tabular}{c|cc|c|c|c|c}
\hline \hline \multirow{2}{*}{ Poor in $\boldsymbol{t}$} & \multicolumn{3}{|c|}{ a) Twice poor } & \multicolumn{3}{c}{ b) Upwardly mobile } \\
& $\begin{array}{c}\text { Structural } \\
\text { Stochastic }\end{array}$ & Total & Stochastic & Structural & Total \\
& $A_{i t+1}<\underline{A}_{t+1}$ & $A_{i t+1} \geq \underline{A}_{t+1}$ & & $A_{i t+1}<\underline{A}_{t+1}$ & $A_{i t+1} \geq \underline{A}_{t+1}$ & \\
\hline$A_{i t}<\underline{A}_{t}$ & 85.50 & 6.94 & 92.45 & 41.01 & 33.30 & 74.31 \\
$A_{i t} \geq \underline{A}_{t}$ & 3.51 & 4.04 & 7.55 & 3.77 & 21.92 & 25.69 \\
\hline Total & 89.01 & 10.99 & 100 & 44.78 & 55.22 & 100 \\
& $(N P: 87.28)$ & $(N P: 12.72)$ & 100 & $(N P: 44.02)$ & $(N P: 55.98)$ & 100 \\
\hline \hline
\end{tabular}

\begin{tabular}{|c|c|c|c|c|c|c|}
\hline \multirow[t]{2}{*}{ Non-poor in $t$} & \multicolumn{3}{|c|}{ c) Downwardly mobile } & \multicolumn{3}{|c|}{ d) Twice non-poor } \\
\hline & $\begin{array}{c}\text { Structural } \\
A_{i t+1}<\underline{A}_{t+1}\end{array}$ & $\begin{array}{c}\text { Stochastic } \\
A_{i t+1} \geq \underline{A}_{t+1}\end{array}$ & Total & $\begin{array}{c}\text { Stochastic } \\
A_{i t+1}<\underline{A}_{t+1}\end{array}$ & $\begin{array}{c}\text { Structural } \\
A_{i t+1} \geq \underline{A}_{t+1}\end{array}$ & Total \\
\hline $\begin{array}{l}A_{i t}<\underline{A}_{t} \\
A_{i t} \geq \underline{A}_{t}\end{array}$ & $\begin{array}{l}46.07 \\
24.60\end{array}$ & $\begin{array}{c}5.97 \\
23.36\end{array}$ & $\begin{array}{l}52.04 \\
47.96\end{array}$ & $\begin{array}{l}5.25 \\
5.86\end{array}$ & $\begin{array}{c}6.51 \\
82.38\end{array}$ & $\begin{array}{l}11.76 \\
88.24\end{array}$ \\
\hline Total & $\begin{array}{c}70.67 \\
(N P: 68.91)\end{array}$ & $\begin{array}{c}29.33 \\
(N P: 31.09)\end{array}$ & 100 & $\begin{array}{c}11.10 \\
(N P: 10.74)\end{array}$ & $\begin{array}{c}88.90 \\
(N P: 89.26)\end{array}$ & 100 \\
\hline
\end{tabular}

Note: Numbers in parenthesis refer to the decomposition results from the non-parametric (NP) kernel estimation, performed as a robustness check. Differences in cell shares are in a range of one to two percentage points. 
The extent of structural upward mobility tends to be higher, and the share of structural downward mobility tends to be lower in urban compared to rural areas. Nonetheless when restricting the sample to urban African respondents, still 54.7 per cent of the descents into poverty and only 49.6 per cent of the escapes from poverty are structural (see Figure 4.3).

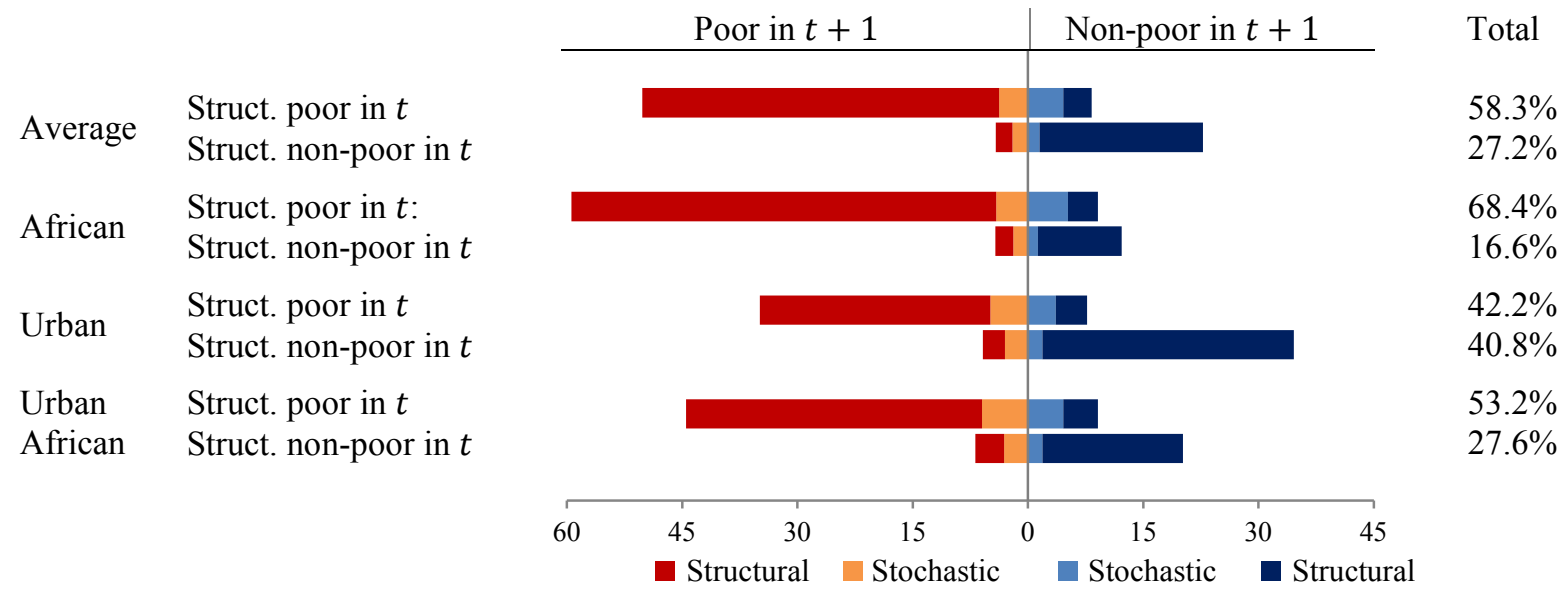

Figure 4.3 Decomposing poverty transitions

It is worth noting that the differentiation between structural and stochastic transitions only gives an indication that a movement into or out of poverty is more or less likely to be sustained over time. Clearly, also those who experience structural upward mobility remain vulnerable to a number of risk factors that threaten their asset base, as discussed in more detail the next section. In fact, two thirds of the stochastically upwardly mobile and one third of the structurally upwardly mobile urban African population, classified based on the mobility patterns observed between $t$ and $t+1$, had slipped back into poverty in $t+2$ (see Table 4.5). Conversely, for those who experience a structural descent into poverty, the asset base provides little reason to expect any re-escape from poverty in the near future. However, poverty tends to be self-perpetuating (see Chapter 3) and even for those who hold assets above the asset poverty line, a descent into monetary poverty may manifest in a gradual dissolution of the asset base. In fact, only about half of the stochastically downwardly mobile had moved out of poverty two years later (see Table 4.5).

Table 4.5 Transition patterns, urban African population

\begin{tabular}{c|lcc}
\hline \hline & \multicolumn{2}{c}{ Poverty status in $\mathrm{t}+2$} \\
\hline \multicolumn{2}{c|}{ Transition pattern between periods $\mathrm{t}$ and $\mathrm{t}+1$} & $\mathrm{c}_{\mathrm{it}+2}<\mathrm{PL}$ & $\mathrm{c}_{\mathrm{it}+2} \geq \mathrm{PL}$ \\
\hline \multirow{3}{*}{$c_{i t}<\mathrm{PL}$} & Twice poor & 78.80 & 21.20 \\
& Stochastically upwardly mobile & 67.05 & 32.95 \\
& Structurally upwardly mobile & 32.66 & 67.34 \\
\hline \multirow{3}{*}{$c_{i t} \geq \mathrm{PL}$} & Structurally downwardly mobile & 69.41 & 30.59 \\
& Stochastically downwardly mobile & 47.77 & 52.23 \\
& Twice non-poor & 15.62 & 84.38 \\
\hline \hline
\end{tabular}

Note: Sample restricted to African population living in urban areas in period $t$. 


\subsection{Drivers of structural poverty escapes and descents}

In this second part of the analysis, I combine quantitative and qualitative research methods to gain a more comprehensive understanding of the multidimensional causal processes and pathways that condition poverty escapes and descents. To this end, each life history diagram was examined and placed into one out of ten categories defined in Table 2.4 below (following a similar approach as Davis \& Baulch, 2011, and Hulme \& Shephard, 2003). The first important distinguishing criterion is whether the respondent started off structurally poor or structurally non-poor (based on the schema of social stratification introduced in Box 4.2). Second, in line with the analysis presented in Section 4.4, patterns of upward and downward mobility are explored, distinguishing between structural and stochastic movements.

Table 4.6 Livelihood trajectory patterns and poverty dynamics (LHIs)

\begin{tabular}{|c|c|c|c|c|c|}
\hline \multicolumn{3}{|c|}{ Starting Poor } & \multicolumn{3}{|c|}{ Starting Non-Poor } \\
\hline Trajectory Pattern & Depiction & $\begin{array}{c}\text { Cases } \\
\text { (migrant) }\end{array}$ & Trajectory Pattern & Depiction & $\begin{array}{c}\text { Cases } \\
\text { (migrant) }\end{array}$ \\
\hline $\begin{array}{l}\text { Structurally poor } \\
\text { (generally with } \\
\text { fluctuation into and out } \\
\text { of food poverty) }\end{array}$ & $\uparrow$ & $10(6)$ & $\begin{array}{l}\text { Structurally non- } \\
\text { poor and upwardly } \\
\text { mobile } \\
\text { (stably non-poor and } \\
\text { further accumulation of } \\
\text { livelihood assets) }\end{array}$ & $\uparrow$ & $2(0)$ \\
\hline $\begin{array}{l}\text { Stochastically } \\
\text { upwardly mobile } \\
\text { (structurally poor with } \\
\text { one single short-lived } \\
\text { poverty escape not } \\
\text { accompanied by change } \\
\text { in asset base) }\end{array}$ & $\uparrow$ & $4(4)$ & $\begin{array}{l}\text { Structurally non- } \\
\text { poor and stable } \\
\text { (stably structurally non-poor } \\
\text { but contraction of livelihood } \\
\text { assets towards old age) }\end{array}$ & $\uparrow$ & $3(1)$ \\
\hline $\begin{array}{l}\text { Churners } \\
\text { (livelihood assets above } \\
\text { typical structurally poor } \\
\text { level, but always just at } \\
\text { the edge to poverty) }\end{array}$ & $\uparrow$ & $2(1)$ & $\begin{array}{l}\text { Structurally } \\
\text { downwardly mobile } \\
\text { (one-step) } \\
\text { (dissolution of assets caused } \\
\text { by single shock or series of } \\
\text { co-occurring shocks) }\end{array}$ & $\uparrow$ & $2(2)$ \\
\hline $\begin{array}{l}\text { Structurally } \\
\text { upwardly mobile } \\
\text { (reverted) } \\
\text { (structural poverty } \\
\text { escape during working } \\
\text { life, reverted in old age) }\end{array}$ & $\uparrow$ & $4(4)$ & $\begin{array}{l}\text { Structurally } \\
\text { downwardly mobile } \\
\text { (multiple steps) } \\
\text { (gradual dissolution of } \\
\text { livelihood assets interrupted } \\
\text { by short periods of recovery) }\end{array}$ & $\uparrow$ & $2(0)$ \\
\hline $\begin{array}{l}\text { Structurally } \\
\text { upwardly mobile } \\
\text { (non-reverted) } \\
\text { (structural poverty } \\
\text { escape that is not } \\
\text { reverted) }\end{array}$ & $\uparrow$ & $\mathbf{0}(0)$ & $\begin{array}{l}\text { U-shaped } \\
\text { (prolonged period of } \\
\text { difficulty, but sufficient } \\
\text { asset base to prevent a fall } \\
\text { into deep poverty) }\end{array}$ & $\uparrow$ & $1(0)$ \\
\hline
\end{tabular}

Note: Numbers in brackets indicate cases in which respondents migrated from a rural area in the Eastern Cape. 


\subsubsection{Starting poor}

\section{Markers of structural poverty}

In line with the livelihoods framework introduced in Section 4.2, the quantitative (see Figure 4.4) and qualitative (see Table 4.6) evidence concordantly suggest that those classified as structurally poor will generally be deprived in all five livelihood dimensions.

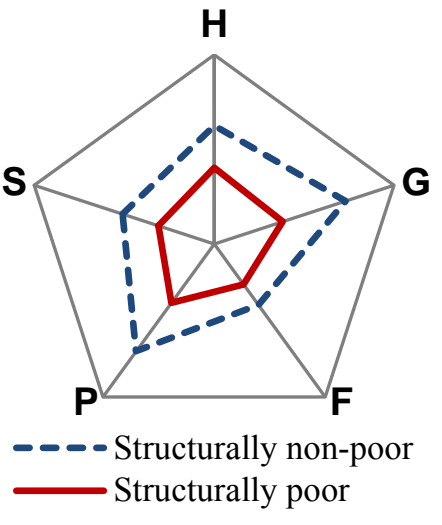

a) Average

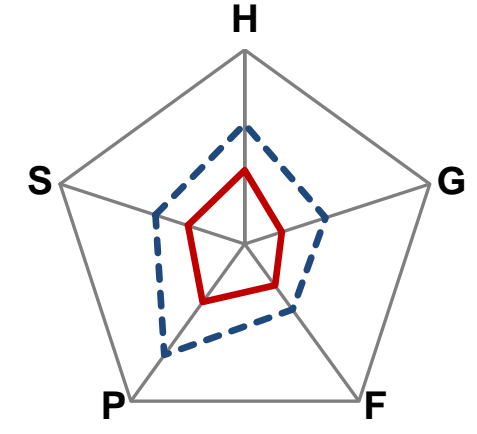

Rural structurally non-poor Rural structurally poor

b) Rural

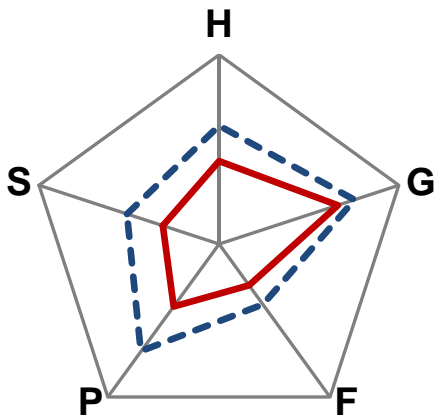

- - - Urban structurally non-poor Urban structurally poor

c) Urban

Figure 4.4 Asset pentagons, urban versus rural areas (NIDS)

Two thirds of the LHI respondents (20 out of 30) started off in a situation of structural poverty (boxes three or four), and half of these never ascended to boxes two or one (see the example of Lindelwa in Appendix C.3). These structurally poor respondents were typically born into families with no or little livestock and/or other physical assets, often but not always in a rural context. Also, they reported having been deprived in terms of human and social capital. They often grew up with a single parent or were raised by other relatives, following the death or separation of their biological parents. In many cases, they dropped out of school with at most primary education complete, due to a lack of money and the need to support the family, or other events such as pregnancy. As a consequence, during later life they were constrained to relying primarily on temporary (piece) jobs in unqualified occupations with low pay, which were rarely kept for more than two years. They generally faced a combination of different constraints (affecting either them directly or their close family members), including sickness or disability, alcohol and/or substance abuse, crime, and domestic violence. These were intensified by an unstable family network, a large number of dependents, and a lack of financial and physical capital to (re-)start business activities.

According to the quantitative evidence, the key criterion that distinguishes the urban poor from those located in rural areas is the overall better access to public infrastructure (compare Figure 4.4b and Figure 4.4c). During the LHIs, respondents who had migrated from rural areas confirmed this picture to the extent that they typically rated their living and 
housing conditions in Khayelitsha higher than before migration. Nevertheless, the quality and delivery of public services was often perceived as poor. This was evident in issues such as leaking roofs and pipes in government-provided housing, frequent electricity cuts, high transport costs for work, and overcrowded township schools confronted with challenges such as youth gangsterism and poorly trained teachers.

\section{Stochastic versus structural poverty escapes}

Overall, there is much overlap between the key factors that explain structural poverty escapes in the quantitative and qualitative data. However, the data from life histories provide a more nuanced understanding of the role played by human capital accumulation in this regard. They also suggest that not all social networks provide stability and support. These complexities cannot adequately be captured by the available quantitative data (compare Figure 4.5).

All four LHI respondents who experienced structural upward mobility were born in rural areas in the Eastern Cape. In contrast, those who remained structurally poor were integrated into better-functioning family networks and were more successful in seizing opportunities to enhance their human capital. They were more effective and strategic in their job search after arriving in Cape Town and experienced an important gradual improvement in their standard of living, often facilitated by successful job-to-job transitions, with only brief spells of unemployment in between. Importantly, at least some of these jobs were kept for prolonged periods of time of 10 to 20 years.

In the other four cases in which respondents experienced stochastic upward mobility, these short-lived poverty escapes were also made possible when individuals found employment in better paying jobs. In these cases, what made this upward mobility temporary was the fact that employment in these jobs could not be maintained over the longer term, due to issues such as contract expiration, business closure, or health issues. In addition, the time period during which these individuals benefitted from higher wage income was too brief to build up financial, physical, or human capital which could have pushed these individuals onto a path of sustained upward mobility (compare Figure 4.6).

Based on the small number of cases, it is difficult to trace the factors that facilitate structural as opposed to stochastic poverty escapes. To some extent, the timing of migration and the type and duration of the first job taken on after migrating seem to have played a role. Compared to the structurally upwardly mobile group, those who experienced a short-lived stochastic poverty escape tended to be younger and, on average, came to Cape Town at a later point in time when pass laws, which until 1987 under apartheid restricted the movement of the non-white population to urban centres, had been abolished, and competition for jobs was 
picking up. However, this does not hold in all cases. Furthermore, those migrating to places where they already had contacts that could facilitate acquiring employment were more successful. Among those who had more difficulty in finding a permanent job at the start, gaining additional qualifications was decisive. This is, while these individuals were not necessarily more educated than the structurally poor at the outset, their success in acquiring work experience and supplementary training consequentially improved their fortunes in the labour market (see the example of Mcingini in Appendix C.3).

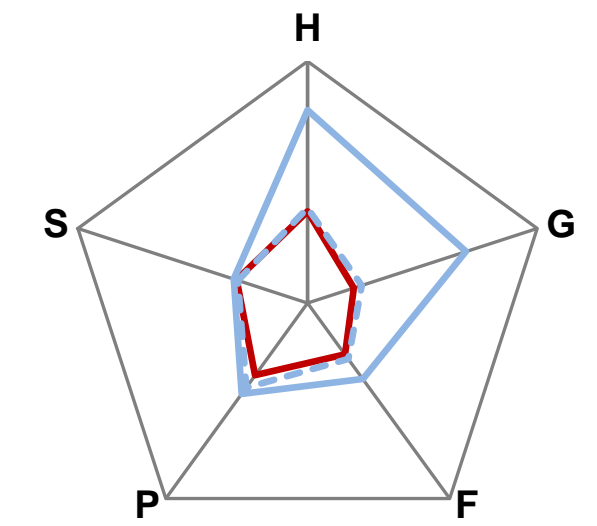

Rural structurally poor

--- Structurally upwardly mobile (before)

- Structurally upwardly mobile (after)

a) Rural-to-urban migrants

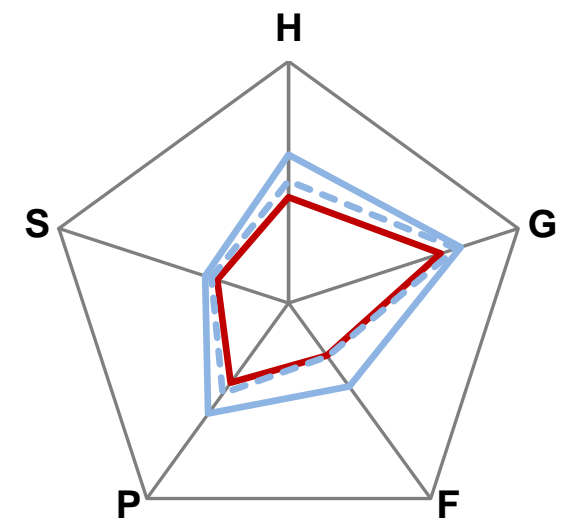

U Urban structurally poor

--- Structurally upwardly mobile (before)

Structurally upwardly mobile (after)

b) Urban born

Figure 4.5 Asset pentagons, structurally poor versus structurally upwardly mobile (NIDS)

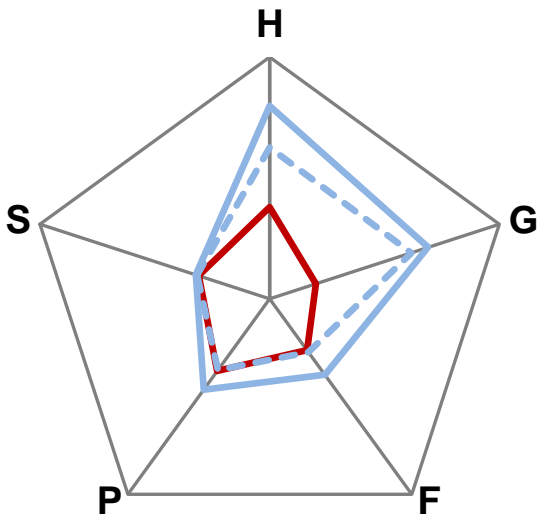

Rural structurally poor

$-\infty$ Stochastically upwardly mobile (after)

Structurally upwardly mobile (after)

a) Rural-to-urban migrants

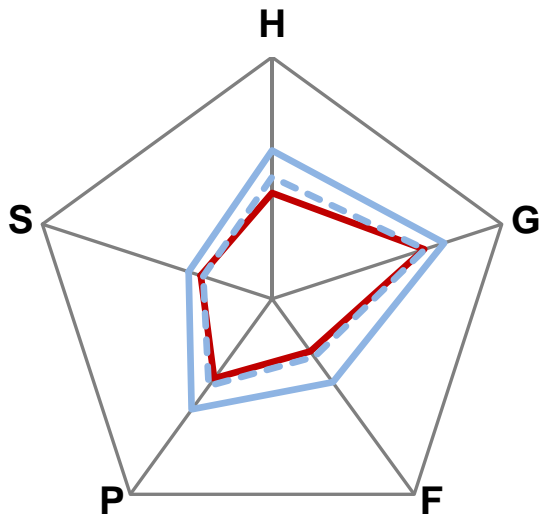

Urban structurally poor

$-\infty$ Stochastically upwardly mobile (after)

Structurally upwardly mobile (after)

b) Urban born

Figure 4.6 Asset pentagons, stochastically versus structurally upwardly mobile (NIDS)

In contrast, for those who were stochastically upwardly mobile, finding a better job (which facilitated the temporary escape from poverty) was often considered a "lucky" event, which was not accompanied by a change in other livelihood assets or entitlements. In this regard, the rise in human capital among rural-to-urban migrants classified as stochastically 
upwardly mobile tends to be overestimated in the empirical analysis (see Figure 4.6). This rise can mainly be attributed to a change in the household composition, as single persons leave their rural family homes to migrate to the cities. This, however, does not adequately account for the fact that most rural-to-urban migrants maintain strong linkages with their rural kin, generally supporting a large number of dependents through regular remittance flows.

Importantly, none of the structural poverty escapes observed in the life histories was sustained beyond retirement. This is mainly due to a decline in human capital, as health and the capacity to work deteriorate toward old age. This implies that even those among the poor who were structurally upwardly mobile failed to accumulate sufficient financial capital over their working lives to provide for old age. This is what differentiates them from the group of individuals classified as initially structurally non-poor and upwardly mobile (see discussion below). Concordantly, shocks to human capital (and their interlinkages) were the most frequently reported source of both upward and downward mobility, as Figure 4.7 illustrates.

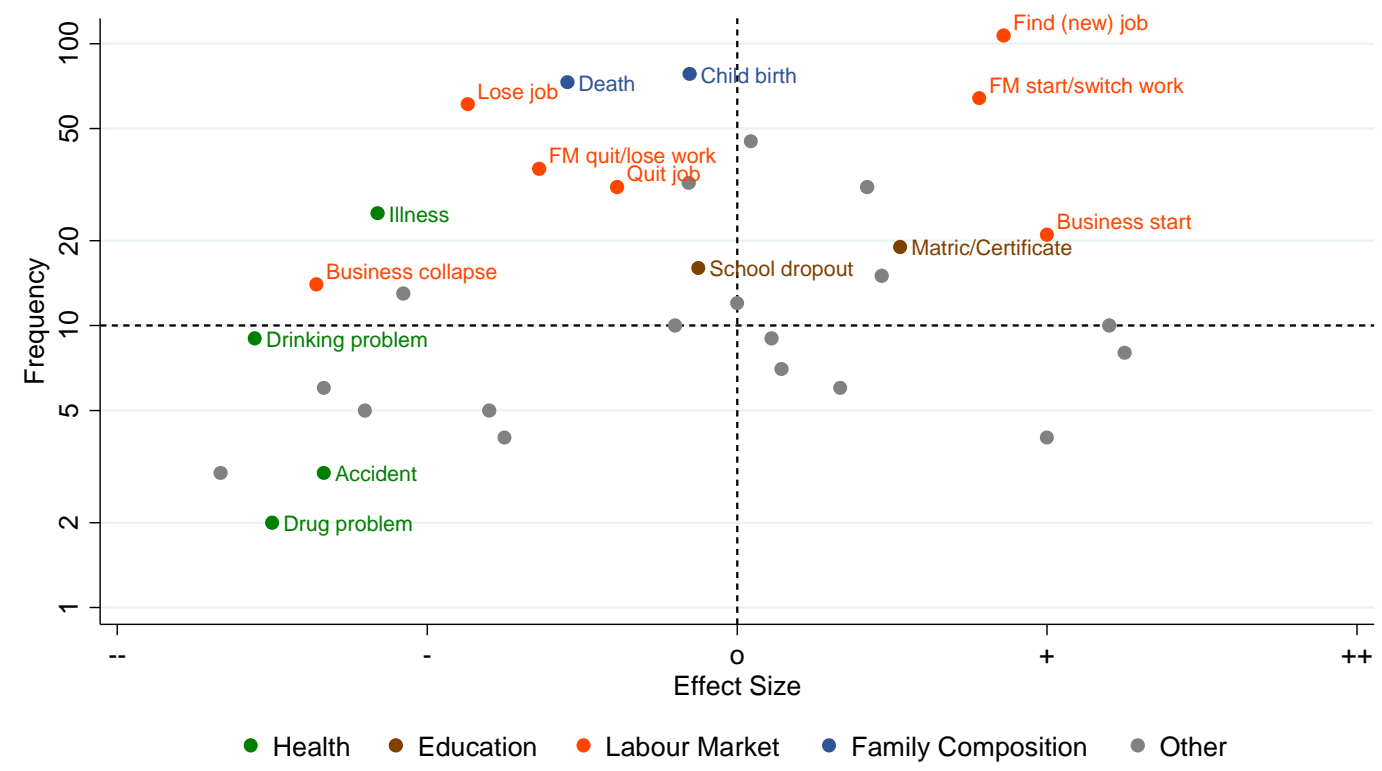

Figure 4.7 Trigger events associated with a rise/fall in human capital (LHIs)

Note: In total, 786 events had been reported during the LHIs, grouped into 35 event categories. Each event was manually coded and transformed into numerical information.

Based on the interview transcript and the life-history diagram, four effect sizes are distinguished: large negative (--), small negative (-), no effect (0), small positive $(+)$, and large positive $(++)$.

\section{Churners}

Last, two LHI respondents are classified as churners because they remained very close to the edge of poverty for most of their life cycle - in one of the two cases with frequent fluctuations between boxes two and three. These churners grew up in households with reasonable but declining and/or unstable access to livelihood assets. This unsecure position was attributable to the presence of only one main breadwinner working at low or unstable pay, often without a 
permanent work contract, who kept the close and extended family (generally a large number of dependents) with their heads just above water.

\subsubsection{Starting non-poor}

\section{Socioeconomic security and structural upward mobility}

One third of the LHI respondents (10 out of 30) were not affected by poverty early in their lives. That is, they were born into a household that had access to a reasonable asset base (compare Figure 4.4 above) and where basic needs were being met. These individuals generally reported growing up with both parents, of whom at least one was working.

However, only two out of the ten respondents were able to sustain and to improve their livelihood outcomes; that is, they were structurally non-poor and upwardly mobile. Both are female and were born and raised in Cape Town, and both were successful in developing and drawing on all five capital types to construct their living. Despite using two relatively different strategies to enhance their livelihood opportunities, both life histories emphasise the role played by labour market success (see Figure 4.7 above) and access to financial capital (see Figure 4.8 below) in facilitating upward mobility. In one of the cases, a combination of inherited physical, acquired human, pursued social, and borrowed financial capital was key. After dropping out of high school, the respondent took a course in hairdressing and decided to go into business with her father, who had a barber shop. After his death, she inherited the barber shop, joined a business organisation - through which she gained access to credit - and gradually expanded the business, such that today she rents out different working stations in the community. In the second example, the individual seized the opportunities offered by the changing political environment at the end of apartheid, relying on a combination of human capital accumulation, contacts, and access to financial capital. After finishing high school, she started working at a medical aid establishment as an administrator - she was the first African to work for that company. She then got a bursary to go to college, studied to become a teacher, and then completed two additional diplomas to move to higher positions. In both of these cases, insurance types (funeral policies, burial societies, and life insurance) played an important role in buffering negative events. Furthermore, both respondents used their access to finance, through credit and cashed-in pension funds, to build flats at the back of their houses, which they rented out as a form of additional income and provision for retirement.

This old-age provision through accumulation of property and/or other financial assets is the main criterion that distinguishes the two described cases from the three respondents who were also stably structurally non-poor but experienced a dip in livelihood outcomes 
towards the age of retirement, leaving them on the brink of poverty. Throughout their working lives, these respondents relied on a combination of relatively stable employment relationships (sometimes interrupted by short periods of unemployment), formal insurance schemes, and informal support networks (cost sharing and support by family members in employment) to secure their livelihoods (see the example of Vivian in Appendix C.3). ${ }^{47}$ Similar to the discussion above regarding the reversal of structural escapes from poverty, the contraction in livelihood assets towards old age generally resulted from a depletion of human and physical capital due to business closure, job loss or retirement, sometimes in combination with other negative events (such as sickness). Moreover, given their higher access to financial capital, most respondents in the structurally non-poor group took on substantial debt in the form of bonds and loans during their working lives. In one of the cases, this debt became a heavy burden after income from the labour market had dried up.

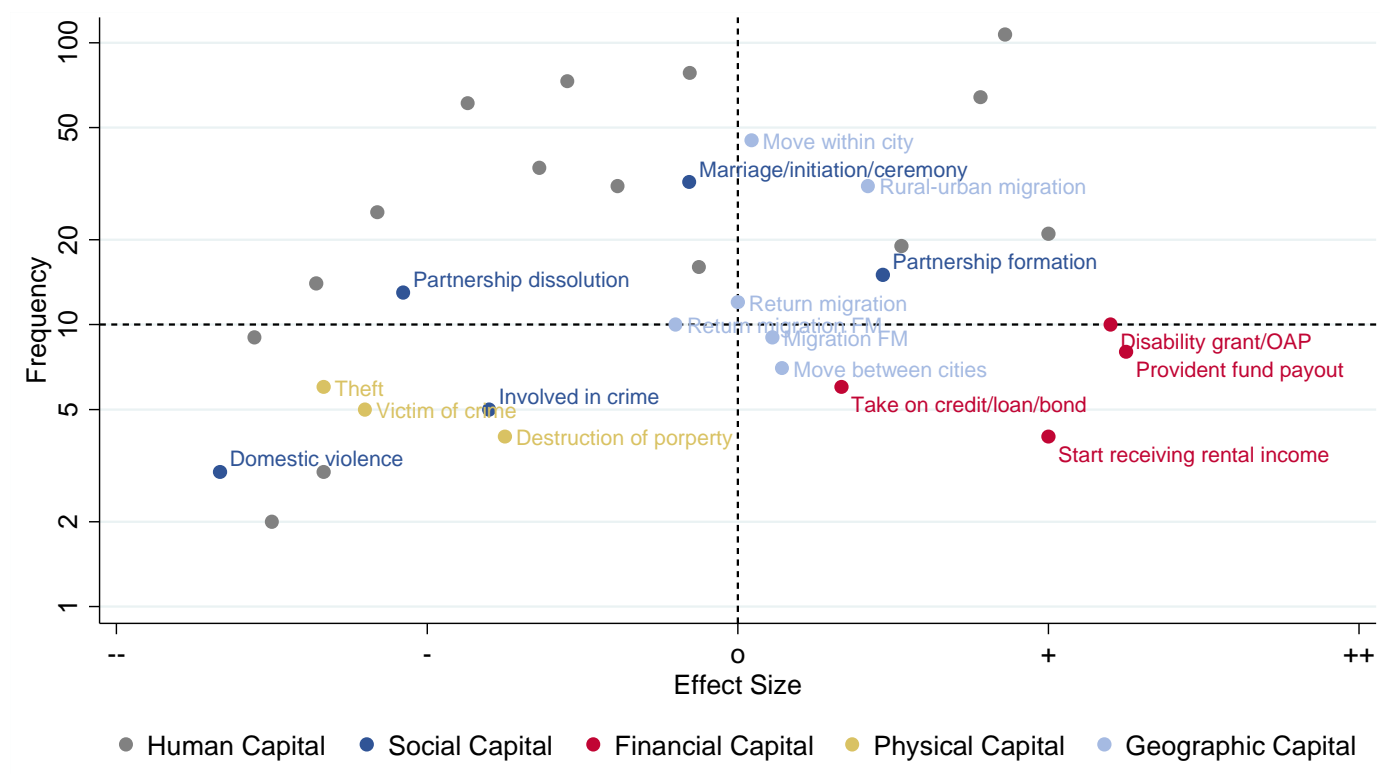

Figure 4.8 Trigger events associated with a rise/fall in other capital types (LHIs)

Note: In total, 786 events had been reported during the LHIs, grouped into 35 event categories. Each event was manually coded and transformed into numerical information.

Based on the interview transcript and the life-history diagram, four effect sizes are distinguished: large negative (--), small negative $(-)$, no effect $(0)$, small positive $(+)$, and large positive $(++)$.

\section{Structural descents into poverty}

Four out of the ten respondents who started off their lives structurally non-poor (box one or top of box two) had fallen into deep structural poverty over time (box four). In two cases, the impoverishment occurred within a narrow time frame (single step), caused by a major external shock that irrevocably destroyed human (Figure 4.7) or physical (Figure 4.8) capital. For one

\footnotetext{
${ }^{47}$ The life history of Vivian (see Appendix C.3) is exceptional in the sense that she managed to sustain a high degree of stability throughout her life despite being in a low-skilled occupation.
} 
of them, who had been self-employed running a spaza shop out of his home, his whole economic base was wiped away by one key event, in his case a natural disaster in form of a fire. The fire destroyed his house, the shop and his savings, which he guarded at home. After this, no successful recovery had been possible particularly due to a lack of access to financial capital to restart the business. In the other case, the descent was caused by a combination of events that occurred simultaneously. This respondent paid a high bride price (lobola) for his wife, giving away the livestock that he had inherited from his father. He then lost his job and since then has only been able to find irregular piece jobs in construction. Currently, neither he nor his wife are working. In addition, their son fell sick and requires regular treatment. Even though the public hospital provides the treatment free of charge, large expenses are required for transport (to the hospital) and for traditional healers, whom they consult in addition.

In the other two cases, the impoverishment occurred rather gradually, in multiple linked steps. Individuals in this group commonly started their lives growing up with both parents. Conditions then began to worsen as one parent fell sick, died, or left the family due to separation. Respondents further experienced an accumulation of several negative and often interrelated events, which included job loss, sickness, being a victim of crime, experiencing the destruction of household property, domestic violence, and alcohol or drug abuse (see Figure 4.7 and Figure 4.8). The lack of a functioning family network to buffer these events is an important criterion distinguishing these cases from those who were able to maintain a stable and economically secure position (see Figure 4.9). Importantly, those who experienced gradual structural downward mobility reported trying to get back on their feet several times, which became increasingly difficult with every additional shock that occurred. Moreover, in both cases discussed above, another family member (husband, father) intentionally and repeatedly negatively interfered with the person's business or employment opportunities.

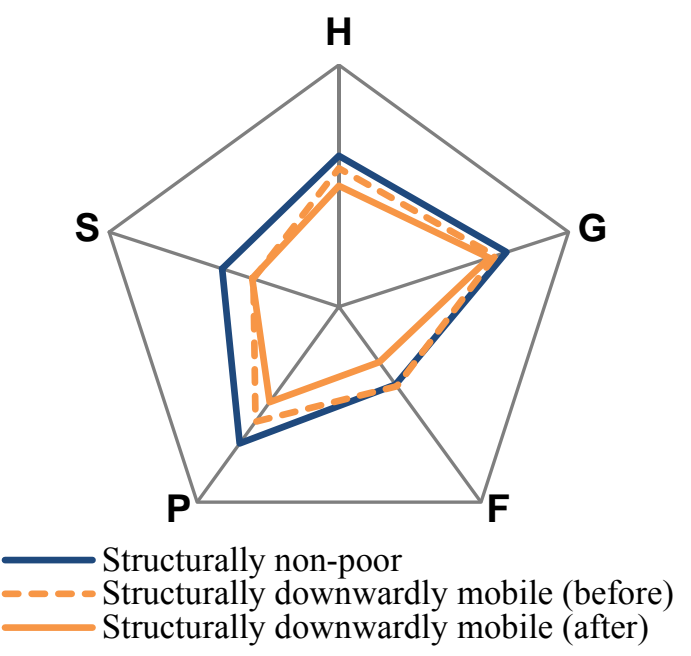

Figure 4.9 Asset pentagons, structurally downwardly mobile (NIDS) 


\subsection{Conclusion}

Combining quantitative and qualitative data and methods, this chapter makes an effort to understand the multidimensional causal pathways that condition structural transitions into or out of poverty in South Africa, with special attention given to the urban African population. The urban focus and differentiation between structural and stochastic movements distinguish this research from previous mixed-method investigations of poverty dynamics in sub-Saharan Africa, which - to my knowledge - either focus on rural settings or do not separate between stochastic and structural mobility patterns.

Using economic transition matrices based on NIDS panel data, I find considerable mobility across income groups, except for the most and the least well-off (this observation matches the findings by Finn, Leibbrandt, \& Ranchhod, 2017, on patterns of intergenerational mobility). Analysing households' access to, and holdings of, livelihood assets in terms of human, financial, physical, social, and geographic capital, I estimate how much of the observed patterns in income mobility can be accounted for by structural as opposed to stochastic factors. My findings suggest that for about half of the individuals who begin in a situation of structural poverty and who experience upward mobility in incomes, the escape from poverty must be considered stochastic, suggesting a limited accumulation of assets that could help facilitate successful long-run escapes from poverty. Conversely, close to 70 per cent of the non-poor who experience downward mobility fall into a situation of structural poverty. One third of this group is made up of initially stochastically non-poor individuals, for whom the descent into structural poverty presents a regression to their expected level of livelihood. The other two-thirds initially dispose of asset holdings sufficient to be considered structurally non-poor. For them, the descent into poverty is accompanied by a dissolution of assets that places them below the asset poverty line.

Using data visualisation methods in form of asset pentagons and livelihood trajectory diagrams, this chapter then combines evidence from quantitative and qualitative data to illustrate the multidimensional deprivation and main risk factors that structurally poor households experience. Four interrelated dimensions characterising urban poverty in South Africa can be extracted from the analysis: First, because work is generally the most important source of household income, transitions into or out of employment and job-to-job transitions are among the main trigger events associated with both poverty entries and exits (this reconfirms the results from Chapters 2 and 3).

Second, given the low returns and high job volatility associated with low-skilled labour, people require additional physical and social assets to achieve and sustain a position of 
economic security (compare Carter \& May, 1999, for rural South Africa). In this regard, family networks and dependency relationships may play a dual role - both enabling and constraining upward mobility. Going beyond the simply mechanical effect that household size has on per-capita incomes in most quantitative assessments (see, for example, Finn et al., 2017), this chapter emphasises that the quality of the network is an important criterion that needs to be taken into consideration.

Third, as is well-established in the literature, higher levels of education constitute an important enabling factor for upward social mobility (see, for example, Adato et al., 2006). Nonetheless, today's youth struggle to enter the labour market and have particular difficulties in finding stable employment, this despite often having completed secondary schooling. This may be related to the poor quality of education as well as to a lack of work experience and the nonexistence of a social network that could facilitate contacts with potential employers (see Spaull, 2015, for further discussion). In line with the previous evidence on intergenerational mobility (Finn et al., 2017), I find that both advantage and disadvantage are being passed on, be it in form of inherited physical capital, the importance parents attach to schooling and their ability to pay for high-quality education, or work contacts.

Fourth, reconfirming the findings by Carter and May (1999) for rural South Africa, poverty is not only a matter of few assets, but also of constraints to effectively using these assets. A specific constraint in this regard concerns the lack of access to financial capital, which especially affects people preparing for retirement. While access to credit generally presents an important enabling factor, my findings also suggest that accumulated debt can easily turn into a curse. Another constraint concerns the environmental or geographic context confronted by the urban poor, who are obliged to live in cheap, high-density locations that are spatially separated from the urban centres. This not only places a cost burden of commuting for work and job search, but is also associated with a higher exposure to risk factors from natural hazards and crime that threaten life and property.

Along all four dimensions, the qualitative data provide more depth of information and offer a more nuanced and differentiated understanding of the processes that condition poverty dynamics, than could be obtained when relying on the available quantitative data alone. A major limitation of this research is that the causal chains of events that lead to poverty entries or exits rely on subjectively perceived information. However, cross-checks with the dynamics observed in NIDS data show that the key drivers of poverty escapes and descents identified above are consistent between the quantitative and qualitative evidence. 


\title{
CHAPTER 5
}

\section{The Anxious and the Climbers: Ambivalent Attitudes towards Democracy among South Africa's Middle Class}

\author{
Simone Schotte \\ An earlier version of this chapter appeared as Schotte, S. (2017). \\ The Anxious and the Climbers: Ambivalent Attitudes towards Democracy among \\ South Africa's Middle Class. GIGA Working Paper, 304.
}

\begin{abstract}
Albeit middle-class citizens have generally been assumed to support democracy, studies investigating this class's political attitudes using survey data have produced mixed results. This chapter argues that one reason for these ambiguities is that the middle class may not be a homogenous group. Specifically, I explore how diverging perceptions of social mobility tend to condition political attitudes toward democracy within different social strata, particularly within the middle class. Drawing upon data from the South African Social Attitudes Survey, the chapter finds that it is not primarily differences in material well-being but in perceived chances of upward social mobility that account for significant variations in people's political attitudes. Specifically, the "climbers", who perceive themselves as upwardly mobile under the present system, display the strongest generic support for democratic governance and believe in voting as an effective tool to influence political outcomes, while the "anxious", who see threats of downward mobility, show signs of political resignation. At the same time, however, the same "climbers" are also more likely to tolerate government constraints on civil liberties and are less likely to oppose corruption. These empirical findings demonstrate the limits to understanding people's political attitudes in relation to their current standard of living alone.
\end{abstract}

Acknowledgements: I am grateful to Jann Lay, Stephan Klasen, Jan Hofmeyr, Sebastian Prediger, Lena Giesbert, and Rocco Zizzamia for their many helpful suggestions, and to Crain Soudien, Derek Davids, and Benjamin Roberts from the Human Sciences Research Council (HSRC) for valuable feedback and data support. Useful comments and discussions on earlier drafts of this chapter were also provided by participants at the $21 \mathrm{st}$ Spring Meeting of Young Economists 2016, the 2016 GIGA Workshop on Inequality and Middle Class Development in Africa, and the 2016 Development Economics Conference "Göttinger Schule." The views expressed here, and any remaining errors, are my own. 


\subsection{Introduction}

Over the past decade, the emergence of a growing middle class has become an increasingly popular way to characterise and explain socioeconomic change in developing countries (see, among others, Bhalla, 2007; Cárdenas, Kharas, \& Henao, 2015), and high expectations have been placed on this class's transformative potential (Giesbert \& Schotte, 2016). Beyond the hopes that Africa's new middle class will trigger further economic growth by shifting the composition of consumer demand, this class has been expected to foster political stability and democratic consolidation (Birdsall, Graham, \& Pettinato, 2000). Middle-class citizens have been assumed to support democracy, good governance, the rule of law, and the fight against corruption (Birdsall, 2015), as well as to promote public investment in health and education (Loayza, Rigolini, \& Llorente, 2012) and infrastructure (Bhalla, 2007).

However, empirical studies that explore the political values, attitudes and behaviours of the middle class at the micro-level only partly support these claims. While most of these studies find no strong evidence of a middle-class particularism in political attitudes and behaviours (Banerjee \& Duflo, 2008, Lopez-Calva, Rigolini, \& Torche, 2012, Resnick, 2015), some confirm that the middle class is significantly more likely to take part in political activities than the upper and lower classes (Amoranto, Chun, \& Deolalikar, 2011) and holds more pro-democratic attitudes (Cheeseman, 2015). Contradicting these findings, other researchers have concluded that the middle class is less likely than the poor to vote or demonstrate (Resnick, 2015) and more likely to opt out of the democratic process (Mattes, 2015).

One potential shortcoming that may partly explain these empirical ambiguities is that, to my knowledge, none of the previous studies on the political attitudes of the middle class has made an attempt to account for heterogeneity within that class. To address this gap, this chapter aims to investigate how diverging perceptions of social mobility condition political attitudes toward democracy within different social strata, particularly within the middle class. The analysis draws on a long-standing tradition in the sociological and political psychology literature of investigating the interplay between social mobility, class and attitudes toward the political system (Lipset \& Bendix, 1959; Jackman, 1972, Janowitz, 1970 [1956], Weakliem, 1992) which has recently gained new impetus (see Acemoglu, Egorov, \& Sonin, 2018).

This chapter uses South Africa as a case study. This focus has been chosen for three main reasons: First, South Africa has been identified as one of the countries in sub-Saharan Africa with a relatively large and growing middle class (Ncube, Lufumpa, \& KayizziMugerwa, 2011). Second, past research has pointed to the importance of accounting for 
upward and downward social mobility when investigating patterns of social stratification in the South African context (see Chapters 2 and 3). Third, the South African Social Attitudes Survey (SASAS), on which the empirical analysis presented here is based, is among the few opinion polls that collect detailed household-level information on housing conditions and asset ownership.

The chapter employs this information to construct a proxy measure of permanent incomes, which is used to distinguish between the poor, the middle class, and the elite. I then combine this information with a measure of self-perceived prospects for upward social mobility to differentiate those who experience poverty as a persistent state from the upwardly mobile poor, who I term the "escapers". Furthermore, I differentiate the "anxious" middle class, who sees threats of downward mobility, from those in the middle class who perceive themselves as being upwardly mobile, the "climbers".

The chapter then studies the correlation between the five identified class categories and people's democratic attitudes, civic values, and political preferences. The analysis suggests that the starkest differences are not to be found between the poor, the middle class and the elite, but rather between the upwardly and downwardly mobile strata within these categories. While the upwardly mobile "climbers" show the strongest generic support for democratic institutions and tend to believe in voting as an effective tool to influence political outcomes, "the anxious" middle-class members show signs of political resignation. At the same time, however, the same "climbers" are also more likely to tolerate government constraints on civil liberties and are less likely to oppose corruption. These empirical findings may help explain the previous ambiguous evidence and demonstrate the limits to understanding people's political attitudes in relation to their current standard of living alone.

The rest of the chapter is structured as follows. Section 5.2 briefly reviews the relevant theoretical literature linking class attitudes and democracy. Section 5.3 describes the data and methodology. Section 5.4 presents the key results. Section 5.5 discusses and concludes the chapter.

\subsection{Literature}

The modernisation literature provides a rich theoretical framework regarding the channels through which the emergence of a larger middle class is likely to support democratisation from a micro-sociological or behavioural perspective. In this tradition, the process of modernisation is expected to enhance people's capabilities and loosen constraints on 
autonomous human choice in three important ways (Inglehart \& Welzel, 2005a, 2010):

1) by raising incomes, which makes people more materially independent (see, for example, Moore, 1966);

2) by increasing formal education and access to information through mass media, which makes people intellectually more independent (see Lipset, 1959);

3) and by diversifying human interaction and allowing people to connect and disconnect more freely, which makes them socially more independent.

This increased material, intellectual, and social independence can be assumed to nurture a sense of existential security and autonomy that leads people to become more articulate, prioritise self-expression values, and demand institutions that allow them to participate in decision-making. Thus, while the interests of the poor are presumably dominated by survival values, which subordinate human freedoms to the satisfaction of basic needs, the modernisation process has been associated with the emergence of a larger, more affluent, and better-educated middle class. Inglehart and Welzel (2005a, 2010) argue that, as the middle class expands in a non-democratic regime, repressing these liberty aspirations would become increasingly costly for the ruling elite.

However, two main arguments challenge this perspective:

First, scholars continue to stumble over the question of whether economic security enables or deters middle-class demands for democracy and good governance. In this regard, a number of studies argue that particularly the upper middle class's desire for stability and securing obtained privileges opposes attempts to overturn the status quo (see, for example, Fukuyama, 2014; Wietzke \& Sumner, 2014). Relatedly, re-evaluating the link between social mobility and the dynamics of political institutions, Acemoglu et al. (2018) show that greater social mobility can both enhance and undermine the stability of democracy. Their theoretical analysis suggests that if members of the middle class expect to move up the social ladder in the future, they are more likely to align their interests with the elite. In this context, they also argue that the middle class will generally oppose social mobility at the bottom; that is, they have an incentive to prevent the poor from entering the ranks of the middle class.

Second, classic models of middle class development regard the financial independence of the middle class from the state as an important prerequisite for the middle class to place checks on government performance. ${ }^{48}$ In many late-developing countries, however, growth

\footnotetext{
${ }^{48}$ Historically, Barrington Moore's (1966) well-known formula "no bourgeoisie, no democracy" rests primarily on the ability of the middle class to act independently of the state, specifically to form political coalitions that
} 
has been state-led and accompanied by a large, patronage-based public sector (Rosenfeld, 2017). Accordingly, several authors have argued that the resulting financial dependence of the middle class on the state tends to undermine this class's responsiveness to politicians' non- or misperformance and reduce its incentives to promote political change (see Handley, 2015, for a discussion on the African context). For the specific case of South Africa, Southall (2016) has argued that certain policy tools such as affirmative action, black economic empowerment, and state development contracts may have drawn large parts of the new black middle class into a partisan "state-party-class coalition."

\subsection{Data and Methods}

\subsubsection{Data sources}

The main data source for the empirical analysis presented in this chapter is the 2012 wave of the South African Social Attitudes Survey (SASAS), which has been conducted annually since 2003 by the Human Sciences Research Council (HSRC, 2012a, 2012b). Each data round is designed to yield a nationally representative sample of the adult population (16 years and older). Respondents are drawn from 500 enumeration areas, stratified by province, geographical subtype, and majority population group.

Following its usual practice, the SASAS used a split-sample design for the 2012 wave. That is, there are two alternative questionnaire versions, each of which was administered to approximately 2,500 respondents. For the empirical analysis, where possible, observations from both questionnaires were pooled. However, some questions relevant to the analysis were only included in the democracy and governance module of the first questionnaire. The direction of the estimated effects presented in Section 5.4 below is robust to restricting the sample to questionnaire-one respondents, but the precision of the coefficient estimates is higher when the larger sample is used (results are available from the author upon request). In addition, the robustness of results was tested by replicating the analysis with data from the 2006 wave (HSRC, 2006a, 2006b), with largely similar findings (see Appendix D.5).

The SASAS has been chosen for this study because of the detailed information it collects, not only on a variety of democratic attitudes and civic values but also on respondents' housing conditions and asset ownership. The latter will allow me to construct a measure of

keep the land elite's hegemonic ambitions in check. Accordingly, he suggests that only societies with a sufficiently strong bourgeoisie would become democratic, whereas societies where the land-owning elite is so strong that the emerging bourgeoisie has no other option but to enter into an alliance with them would turn into dictatorships (Acemoglu \& Robinson 2005). 
respondents' permanent income (see Section 5.3.2). To do so, I match the information on living standards provided in the SASAS with data from a larger dataset - namely, the 2012 wave of the National Income Dynamics Study (NIDS), implemented by the Southern Africa Labour and Development Research Unit (SALDRU) at the University of Cape Town (SALDRU, 2016). A comparison between the two data sources reveals that while the weighted SASAS sample is representative with regard to the geographic and racial spread of the South African population, SASAS respondents tend to be disproportionally better off than the average population (see Appendix D.1). For this reason, I use the distributional information from NIDS to construct the class categories, which are then applied to the SASAS (see below).

\subsubsection{Class categories}

The main explanatory variable used in the analysis refers to the respondents' class position. Following an approach similar to the one adopted in Chapter 3, I derive the class groupings using a two-step procedure. First, a measure of permanent income is constructed, which is then used to differentiate between the poor, the middle class, and the elite. Second, an indicator capturing respondents' (perception of) upward social mobility is used to differentiate between a stagnant or downwardly mobile stratum and an upwardly mobile stratum within the group of the poor and the middle class. This leads to the fivefold classification schema presented in Table 5.1 below. $^{49}$

Table 5.1 Class categories based on living standards and perceptions of social mobility

\begin{tabular}{|c|c|c|c|}
\hline & & \multicolumn{2}{|c|}{ Self-perceived social mobility } \\
\hline & & Stagnant or downwardly mobile $\downarrow$ & Upwardly mobile $\uparrow$ \\
\hline \multirow{3}{*}{ 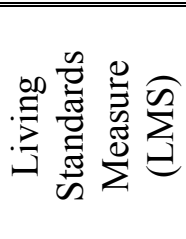 } & Poor & $\begin{array}{l}\text { Persistently Poor } \\
\text { ("Persistent") }\end{array}$ & $\begin{array}{l}\text { Escaping Poor } \\
\text { ("Escapers") }\end{array}$ \\
\hline & Middle Class & $\begin{array}{l}\text { Anxious Middle Class } \\
\text { ("Anxious") }\end{array}$ & $\begin{array}{l}\text { Climbing Middle Class } \\
\text { ("Climbers") }\end{array}$ \\
\hline & Elite & \multicolumn{2}{|c|}{ Elite } \\
\hline
\end{tabular}

Researchers face two alternatives when constructing a measure of living standards in the SASAS. First, there is information available on total household income by income bracket. Second, an asset index can be constructed. I consider the latter preferable for the purpose of this study for two reasons. First, the income information is missing for a

\footnotetext{
${ }^{49}$ To avoid confusion, I on purpose did not use the labelling of the class-sublayers suggested in Chapter 3 . The reason lies in an important difference between the two approaches. The classification schema presented in Chapter 3 is based on people's predicted chances of upward and downward social mobility. These are estimated using a dynamic model of observed poverty transitions. By contrast, the focus in this chapter is on people's perception of their chances of upward and downward social mobility.
} 
disproportionate share of respondents that would be considered better-off according to the asset module. Second, assets are considered to provide a better measure of respondents' permanent income, understood as the long-term level of economic well-being (see LopezCalva et al., 2011; Udjo, 2008). However, the robustness of results was tested by replicating the analysis using income-based class categories, with very similar findings (see Appendix D.4).

To construct the asset index, I use the responses to 13 questions that relate to the following items: housing conditions (dwelling type, water source, toilet facility), ownership of basic durable goods (television, electric stove, fridge/freezer, DVD/Blu-ray player, microwave), and access to high-end consumer durables and services (washing machine, car, pay television, computer, domestic worker). In order to reduce these binary categorical variables into a single index with appropriate weighting, multiple correspondence analysis (MCA) is used (for details on the methodology see, for example, Booysen, Van der Berg, Burger, Von Maltitz, \& Du Rand, 2008; Shimeles \& Ncube, 2015).

Formally, the asset index score of respondent $i$ can be written as

$$
M C A_{i}=\sum_{j=1}^{J} a_{j} R_{i j}
$$

where $a_{j}$ denotes the weight of category $j$ and $R_{i j}$ is the answer of respondent $i$ to category $j$. The weights to calculate the asset index scores are estimated using NIDS data and then applied to the SASAS (see Appendix D.2).

I normalise the index between zero and one using the following formula:

$$
L S M_{i}=\frac{M C A_{i}-\min (M C A)}{\max (M C A)-\min (M C A)} .
$$

Next, I need to define index cut-off values that differentiate the poor from the middle class and the middle class from the elite. The cut-off values are defined using NIDS data and then applied to the SASAS. The index cut-off values are chosen such that the relative population shares of the poor, the middle class, and the elite resemble the shares computed in Schotte et al. (2018) adjusted for differences in sampling. ${ }^{50}$

\footnotetext{
${ }^{50}$ As the SASAS collects information on the South African adult population, all target shares have been calculated reducing the NIDS sample to all individuals aged 16 years and above. Following the approach suggested in Chapter 3, I calculate the poverty headcount as the share of individuals with monthly per capita household expenditures below the upper-bound poverty line set at R834 in 2012 prices (Stats SA, 2017). [As argued in Chapter 3, I choose expenditure as the relevant welfare measure because it is generally assumed to provide a better approximation of permanent household income than the reported income.] Following this definition, 58 per cent of the NIDS adult population can be classified as poor. The index cut-off, which accordingly renders the bottom 58 per cent of the individuals in the asset-index distribution as poor, is set at a value of 0.53 . [Note that this cut-off value is almost identical to the one that would have been obtained if the threshold value was calculated as the average asset index score of households falling in a R10 band around the poverty line]. Analogously, following the approach suggested in Chapter 3, the elite threshold is set arbitrarily at
} 
The resulting fivefold class division is displayed in Table 5.2 below. Clearly, the relative size of the poor, the middle class, and the elite in the SASAS must be treated with caution, as the group of the poor tends to be underrepresented, while the middle class and the elite tend to be overrepresented in the data. The apparent oversampling of the elite in the SASAS, however, has the advantage that the coefficient estimates for this group can be estimated with higher precision (given the larger number of observations for this group).

Table 5.2 Class shares in NIDS and SASAS data

\begin{tabular}{lcccc}
\hline \hline & Poor & Middle Class & Elite & TOTAL \\
\hline NIDS & 58.1 & 37.9 & 4.0 & 100 \\
SASAS & 45.5 & 46.4 & 8.1 & 100 \\
\hline \hline
\end{tabular}

Note: Analysis based on SASAS 2012 Q1+Q2 and NIDS 2012, Wave 3.

Next, taking on a dynamic perspective, I introduce two further sublayers based on the respondents' perception of chances of upward social mobility (see Table 5.1 above). Perceptions of social mobility are captured by two questions in the SASAS (using a threepoint Likert scale): "In the last 5 years, has life improved, stayed the same or gotten worse for people like you?" and "Do you think that life will improve, stay the same or get worse in the next 5 years for people like you?" From these, I construct a binary indicator of upward social mobility that takes on a value of one if respondents think that their life (i) improved over the past five years and will stay the same over the next five years, or (ii) stayed the same over the past five years and will improve over the next five years, or (iii) improved over the past five years and will continue to improve over the next five years. In all other cases, it takes on a value of zero.

Using this binary mobility indicator, I am able to distinguish two sublayers within the group of the poor - namely, the persistently poor and the escaping poor ("escapers"). The latter refers to those respondents classified as poor by their asset index score who perceive themselves as being upwardly mobile. Analogously, I use the same indicator to distinguish the downwardly mobile stratum of the middle class, whom I call the "anxious" given their selfreported fears of not being able to sustain their position in society, from the upwardly mobile stratum of the middle class, whom I call the "climbers" given their strong aspirations to move up the social ladder. This leads to the fivefold class division presented in Table 5.3below.

two standard deviations above the mean per capita household expenditure. Following this definition, 4 per cent of the NIDS adult population can be classified as elite. The index cut-off, which accordingly renders the top 4 per cent of the individuals in the asset-index distribution as elite, is set at a value of 0.93 . 
Table 5.3 Class characteristics in SASAS, 2012

\begin{tabular}{|c|c|c|c|c|c|c|}
\hline & \multicolumn{2}{|c|}{ Poor } & \multicolumn{2}{|c|}{ Middle Class } & \multirow{2}{*}{ Elite } & \multirow{2}{*}{ TOTAL } \\
\hline & Persistent & Escapers & Anxious & Climbers & & \\
\hline Population Share & 21.2 & 23.1 & 24.1 & 22.9 & 8.7 & 100 \\
\hline \multicolumn{7}{|l|}{ LSM } \\
\hline Average asset index score & 0.28 & 0.31 & 0.75 & 0.72 & 0.99 & 0.56 \\
\hline \multicolumn{7}{|l|}{ Gender } \\
\hline Male & 44.3 & 49.4 & 48.3 & 49.1 & 52.0 & 48.2 \\
\hline Female & 55.7 & 50.6 & 51.7 & 51.0 & 48.0 & 51.8 \\
\hline \multicolumn{7}{|l|}{ Geographical subtype } \\
\hline Urban & 45.9 & 39.8 & 86.4 & 80.8 & 94.7 & 66.5 \\
\hline Rural & 54.1 & 60.2 & 13.6 & 19.3 & 5.3 & 33.5 \\
\hline \multicolumn{7}{|l|}{ Ethnicity } \\
\hline Black African & 91.3 & 96.1 & 53.7 & 80.8 & 21.6 & 74.8 \\
\hline Coloured & 7.6 & 3.6 & 16.9 & 11.8 & 9.0 & 10.0 \\
\hline Indian Or Asian & 0.7 & 0.0 & 5.3 & 2.2 & 12.6 & 3.0 \\
\hline White & 0.5 & 0.3 & 24.0 & 5.2 & 56.9 & 12.1 \\
\hline \multicolumn{7}{|l|}{ Level of Education } \\
\hline Primary or less & 29.5 & 22.8 & 9.9 & 12.8 & 1.5 & 17.0 \\
\hline Secondary, excl. matric & 45.2 & 48.3 & 35.9 & 32.9 & 14.1 & 38.2 \\
\hline Matric or equivalent & 22.8 & 26.7 & 36.4 & 41.3 & 39.0 & 32.6 \\
\hline Tertiary education & 2.6 & 2.1 & 17.7 & 13.1 & 45.4 & 12.2 \\
\hline \multicolumn{7}{|l|}{ Employment Status } \\
\hline Employed full time & 12.9 & 15.1 & 28.6 & 25.4 & 54.5 & 23.6 \\
\hline Employed part time or less & 10.1 & 8.3 & 6.7 & 7.2 & 7.2 & 8.0 \\
\hline Unemployed & 43.9 & 41.7 & 30.3 & 32.2 & 6.4 & 34.2 \\
\hline Inactive & 33.2 & 34.9 & 34.5 & 35.2 & 31.9 & 34.2 \\
\hline
\end{tabular}

Note: Analysis based on SASAS 2012 Q1+Q2 and NIDS 2012, Wave 3.

It is important to note that the upwardly and downwardly mobile sublayers within the poor and the middle class are relatively similar in terms of their current living standards and average individual characteristics (see Table 5.3). Nevertheless, in the regression design, controls will be added for the respondent's level of education, employment status, demographic characteristics (age, age squared, gender, race), and geographic location.

Last, it should be noted that the derived mobility indicator is likely to reflect not only the respondent's perceived chances of moving up or down the social ladder, but also the person's general attitude (optimism or pessimism) towards life. In order to disentangle these two effects, I additionally derive an indicator that captures respondents' overall life satisfaction. To this end, I draw on a question that asks: "Taking all things together, how satisfied are you with your life as a whole these days?" I summarise the answer possibilities such that the options "very satisfied" and "satisfied" are coded as one, and zero is used for "neither satisfied nor dissatisfied," "dissatisfied," and "very dissatisfied." 


\subsubsection{Political attitudes}

The outcomes of interest, my dependent variables, are the individual-level political attitudes that can be considered relevant for the functioning of a democratic system. Drawing on Inglehart and Welzel (2005a, 2005b), I broadly base my variable selection on three rival approaches developed within the political culture school to theorise the link between people's attitudes or value orientations and the performance and stability of democratic institutions (see Table 5.4). ${ }^{51}$

Table 5.4 Political culture approaches on the link between attitudes and democracy

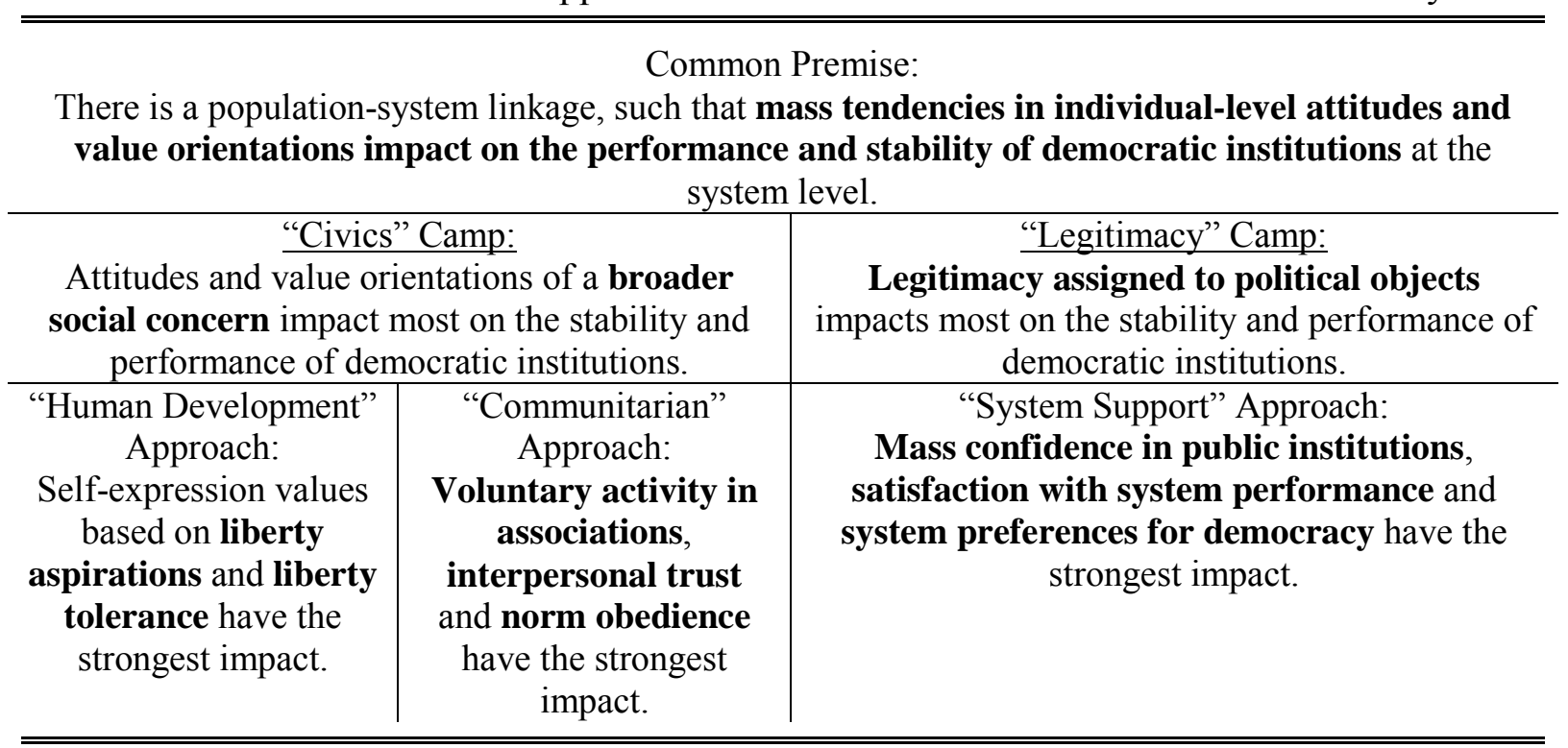

Source: Inglehart and Welzel (2005b: 5).

My focus here lies on the channels or "types of attitudes" that each of the three approaches believes essential to ensuring the quality and stability of democracy. It is important to note that it is not my main concern, and it would be beyond the scope of this dissertation to evaluate or compare the three approaches' relative importance for system performance (see Inglehart \& Welzel, 2005a, 2005b for an empirical assessment). However, I am willing to assume that, in a democratic system, legitimacy and system support as well as support for core civic values are likely relevant for the process of democratic consolidation.

Accordingly, in the following, I first assess the association between class and levels of generalised democratic support (the "legitimacy" camp), including three aspects: (i) support for democracy as the preferred system of governance, (ii) trust in the adherent public institutions, and (iii) satisfaction with system performance and service delivery.

\footnotetext{
${ }^{51}$ The premise common to these approaches is that mass tendencies in individual-level attitudes have some relevance at the system level.
} 
In a second step, given that system support alone is unlikely to suffice for a democracy to flourish, in the second part of the analysis I investigate class differences in attitudes and value orientations of a broader social concern (the "civics" camp). Here I focus on: (i) participation in democratic life in terms of attitudes toward voting, (ii) support for civil liberties and condemnation of corruption, and (iii) priorities for public policy.

For a detailed variable description, please refer to Appendix D.3.

\subsection{Results}

\subsubsection{System support and the legitimacy assigned to democratic institutions}

\section{System preferences for democracy}

The first aspect I focus on is people's general approval of a democratic system. In the SASAS, this system-level support is captured by a question that asks which of the following three statements is closest to the respondents' own opinion: (a) "Democracy is preferable to any other kind of government"; (b) "In some circumstances, a non-democratic government can be preferable"; or (c) "For someone like me, it doesn't matter what kind of government we have." Following Cheeseman (2015), I treat these three answer possibilities as a scale of commitment to democracy and fit an ordered probit regression model to investigate the characteristics that closely associate with people's general attitudes toward democracy. Table 5.5 displays the average marginal effects estimated for answer option (a) "Democracy is preferable to any other kind of government." On average, 44 per cent of all persistently poor respondents prefer democracy to any other kind of government. Everything else equal, those of the poor who perceive themselves as upwardly mobile, the "escapers," are on average about 13 percentage points more likely to prefer democracy. A similar, though less pronounced difference is observed between the downwardly and upwardly mobile strata of the middle class. On average, the "anxious" show a 9 percentage points higher likelihood to favour a democratic government, compared to the "climbers" with 12 percentage points.

These estimated class effects remain relatively robust when controls for education and occupation are added to the model. However, the effect estimated for the elite is sensitive to the inclusion of education. ${ }^{52}$ Without controlling for educational differences, support for democracy appears to be approximately 13 percentage points higher among the elite compared to the persistently poor. However, this conditional difference is partly attributable to the high share of tertiary educated among this group, who are significantly more pro-

\footnotetext{
${ }^{52}$ Lower levels of education had no significant effects.
} 
democracy than those with lower levels of education. After controlling for educational differences, the average marginal effect for the elite drops to about 10 percentage points. ${ }^{53}$

Table 5.5 Relationship between class and support for democracy

Ordered PROBIT regression

Average marginal effect for: "Democracy is preferable to any other kind of government"

(2)

(3)

(4)

\section{Class (Base: Persistently Poor)}

Escapers

$0.1344 * * *$

$0.1372 * * *$

$0.1307^{* * *}$

$0.1354 * * *$

Anxious

$(0.0313)$

(0.0322)

(0.0318)

(0.0327)

$0.0886^{* *}$

$0.0847^{* *}$

$0.0926^{* *}$

$0.0873^{* *}$

Climbers

$(0.0353)$

(0.0362)

$(0.0363)$

$(0.0370)$

Elite

(0.0343)

$0.1268 * * *$

$0.1142 * * *$

$0.1207 * * *$

$0.1282^{* * *}$
$(0.0471)$

(0.0352)

(0.0354)

$(0.0362)$

$0.1022 * *$

$0.1221 * *$

$0.0967 *$

$(0.0471)$

(0.0490)

(0.0494)

(0.0510)

Tertiary education

$0.0842 * *$

$0.0858^{* *}$

Employment (Base: full-time)

(0.0343)

(0.0356)

Part-time or less

0.0227

0.0277

Unemployed

(0.0439)

$(0.0447)$

$-0.0708^{* *}$

-0.0650 **

Inactive

(0.0309)

(0.0315)

$-0.0530^{*}$

$-0.0424$

(0.0322)

(0.0331)

Race (Base: Black African)

Coloured

0.0166
$(0.0341)$
$-0.0789 *$
$(0.0449)$
$0.1076 * * *$

0.0299

0.0169

0.0311

Indian or Asian

(0.0346)

(0.0344)

(0.0349)

$-0.0716$

$-0.0762$

$-0.0703$

White

$0.1076^{* * *}$
$(0.0401)$

$(0.0451)$

(0.0464)

(0.0465)

$0.1007 * * \quad 0.1073 * * *$

$0.1011^{* *}$

(0.0409)

(0.0416)

(0.0423)

Demographic controls ${ }^{\mathrm{a}}$

Geographical subtype fixed effects ${ }^{b}$

\section{YES}

YES

\section{YES}

YES

YES

YES

YES

Province fixed effects ${ }^{c}$

YES

Observations

1,917

YES

YES

YES

R-squared

0.0293

1,844

0.0306

1,847

0.0302

1,779

Standard errors in parentheses.

$* * * \mathrm{p}<0.01, * * \mathrm{p}<0.05, * \mathrm{p}<0.1$

Note: Analysis based on SASAS 2012 Q1.

See Table D.7 in the Appendix D.6 for the coefficient estimates from the ordered probit regression.

${ }^{a}$ Demographic controls include respondent's age in completed years, age squared, and gender.

${ }^{\mathrm{b}}$ Geographical sub-type fixed effects cover four types (urban formal, urban informal, tribal, and rural formal).

${ }^{\mathrm{c}}$ Province fixed effects cover South Africa's nine provinces.

\footnotetext{
${ }^{53}$ Considering the occupational status, I furthermore find a significant difference between those in full-time employment and the unemployed, with the latter being significantly less likely to favour democratic rule.
} 
Last, similar to Cheeseman's (2015) findings with respect to the Kenyan middle class, the data suggest that class is an at least as important correlate of support for democracy in South Africa as race. While I find no significant difference between black African, coloured, and Indian or Asian respondents, white respondents are on average 10 percentage points more likely to prefer a democratic government.

Table 5.6 Determinants of the relationship between class and support for democracy

Ordered PROBIT regression

Average marginal effect for: "Democracy is preferable to any other kind of government"

(1)

(2)

Indicators of social class

LSM

LSM squared $0.4401 * * *$ (0.1509)

$-0.2676^{*}$

$0.4080 * * *$

$0.3891^{* *}$

Upward social mobility

(0.1425)

$(0.1550)$

$(0.1553)$

$-0.2407^{*}$

$-0.2446 *$

(0.1459)

(0.1459)

$0.0697 * * *$

$0.0512 * *$

(0.0225)

$(0.0233)$

$0.0694 * * *$

Life satisfaction

(0.0237)

Tertiary education

$\begin{array}{lll}0.0681^{*} & 0.0751^{* *} & 0.0718^{* *} \\ (0.0351) & (0.0361) & (0.0361)\end{array}$

Employment (Base: full-time)

Part-time or less

0.0234

(0.0436)

Unemployed

$-0.0658 * *$

0.0324

0.0376

(0.0448)

$(0.0449)$

(0.0310)

$-0.0624 * *$

$-0.0524$

Inactive

$-0.0438$

$(0.0318)$

$(0.0321)$

$(0.0323)$

$-0.0425$

$-0.0410$

$(0.0331)$

$(0.0331)$

Race (Base: Black African)

Coloured

$\begin{array}{ccc}-0.0009 & 0.0124 & 0.0170 \\ (0.0331) & (0.0340) & (0.0354) \\ -0.0838^{*} & -0.0731 & -0.0819 * \\ (0.0444) & (0.0460) & (0.0476) \\ 0.0902 * * & 0.0867 * * & 0.0905 * * \\ (0.0406) & (0.0426) & (0.0442)\end{array}$

Demographic controls ${ }^{\text {a }}$

Geographical subtype fixed effects ${ }^{b}$

Province fixed effects ${ }^{c}$

Observations

R-squared

\begin{tabular}{ccc} 
YES & YES & YES \\
YES & YES & YES \\
YES & YES & YES \\
1,896 & 1,774 & 1,768 \\
0.0278 & 0.0341 & 0.0358 \\
\hline
\end{tabular}

Standard errors in parentheses.

$* * * \mathrm{p}<0.01, * * \mathrm{p}<0.05, * \mathrm{p}<0.1$

Note: Analysis based on SASAS 2012 Q1.

See Table D.8 in the Appendix D.6 for the coefficient estimates from the ordered probit regression.

${ }^{a}$ Demographic controls include respondent's age in completed years, age squared, and gender.

${ }^{b}$ Geographical sub-type fixed effects cover four types (urban formal, urban informal, tribal, and rural formal).

${ }^{\mathrm{c}}$ Province fixed effects cover South Africa's nine provinces. 
As a robustness check and in order to further disentangle the factors that may be driving the observed class-attitude associations, a second set of regressions is estimated. Here I directly explore the relationship between respondents' preference for democracy and the derived asset index, the binary indicator for perceived upward social mobility, and the binary indicator for overall life satisfaction.

The results are reported in Table 5.6 above. I find a hump-shaped relationship between household wealth and pro-democratic views, which is robust across specifications. In addition, the results confirm a positive association between the self-perception of being upwardly mobile and a preference for democracy. This effect is only partly explained by overall higher levels of satisfaction among those who perceive themselves as being upwardly mobile. The estimated effect remains positive and significant after the satisfaction dummy is added to the model.

\section{Trust in public institutions}

Next, I look into class differences with regard to trust in public institutions. The SASAS names a number of institutions and asks respondents to indicate their level of trust on a fivepoint scale. From these, I select eight that I believe to be of particular relevance for the functioning of democracy: (a) the national government, (b) the local government, (c) political parties, (d) courts, (e) the Independent Electoral Commission (IEC), (f) the parliament, (g) the police, and (h) the defence force. For each of these dimensions, I summarise the answer possibilities such that the options "strongly trust" and "trust" are coded as one, and zero is used for "neither trust nor distrust," "distrust," and "strongly distrust." I then regress each of these binary trust variables on the set of class indicators and controls using a probit regression.

Figure 5.1 shows the estimated average marginal effects. Everything else being equal, the upwardly mobile escapers tend to have significantly higher trust in public institutions than their persistently poor peers. Similarly, the climbers are, on average, much more trustful of public institutions than those in the downwardly mobile anxious middle class, who overall show the lowest levels of institutional confidence. For example, approximately 45 per cent of the persistently poor either trust or strongly trust the national government. This share is, on average, 19 percentage points higher among the escapers and 16 percentage points higher among the climbers, but 6 percentage points lower among the anxious. Moreover, if class is held fixed, black South Africans generally report higher trust in the selected institutions than respondents of other race groups. 


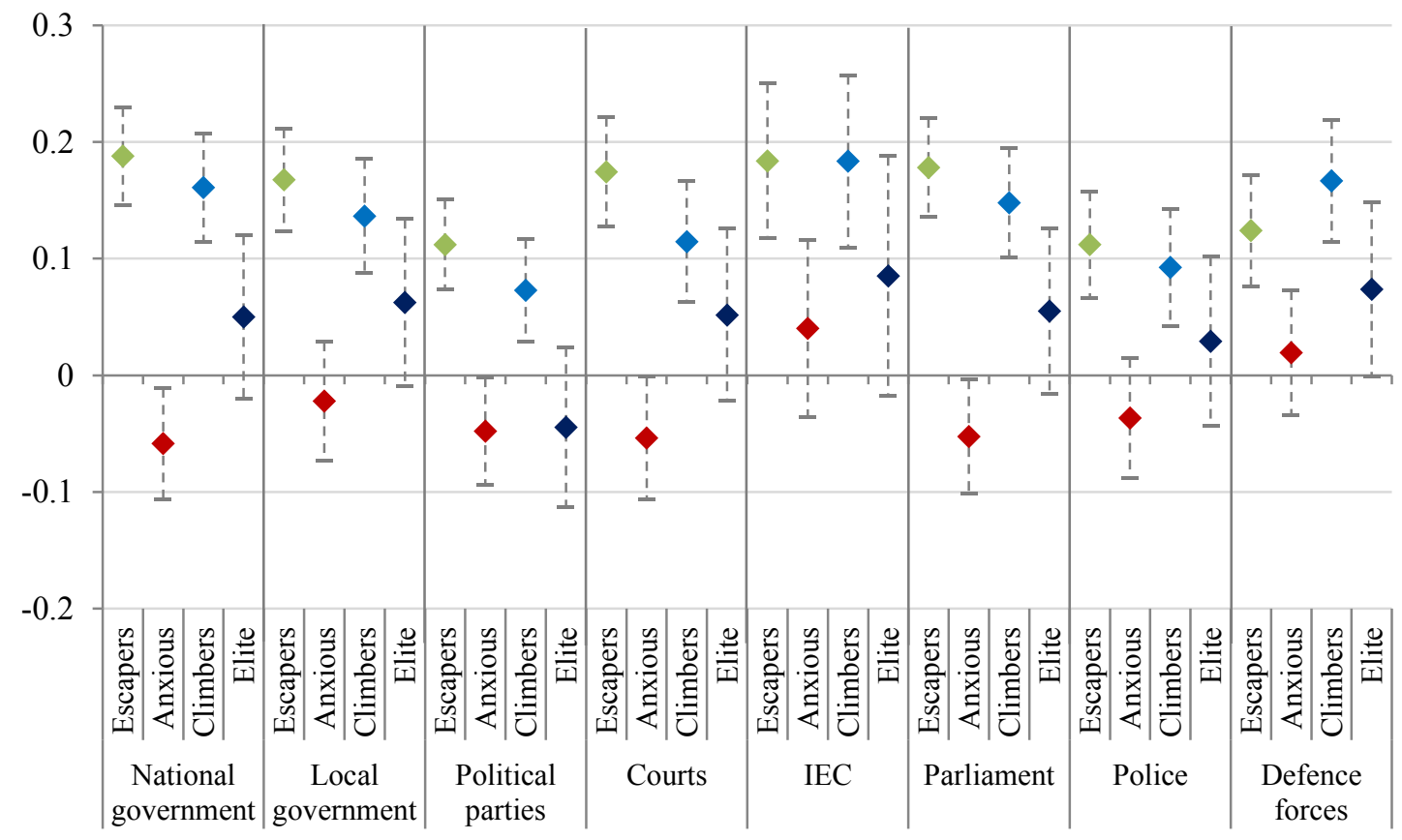

Figure 5.1 Relationship between class and trust in public institutions

Note: Analysis based on SASAS 2012 Q1+Q2. Question on IEC was only included in Q1. Each point shows the estimated marginal effect of class membership, with "Persistently Poor" being the base category. The dashed lines show the 95 per cent confidence intervals. For the full regression results, see Table D.10 in Appendix D.6.

\section{Satisfaction with system performance}

In this subsection, I first investigate people's general satisfaction with the performance of democracy. This analysis is based on a SASAS question that asks respondents how satisfied they are with "the way that democracy is working in South Africa." I subsume the five answer options into a binary indicator variable - equal to one if the respondent is "very satisfied" or "satisfied," and zero otherwise - and fit a probit regression model to investigate the relationship with social class. The results are reported in Figure 5.2 panel a). The patterns are similar to the class differences observed above with respect to people's trust in public institutions. Everything else equal, the escapers and the climbers tend to be the most satisfied with the way democracy is working in South Africa. On the contrary, the persistently poor and the downwardly mobile stratum of the middle class tend to be the least satisfied.

Going beyond this more general question, I additionally assess people's satisfaction with the provision of public goods and services, as two specific aspects of governmental performance not directly linked to being a democracy. I use MCA to construct two separate indicators. The first captures respondents' satisfaction with the provision of public infrastructure, including supply of water and sanitation, provision of electricity, and affordable housing. The second captures respondents' satisfaction with the provision of other public goods and social services, including access to healthcare, treatment for sexually transmitted 
infections (including HIV/AIDS), provision of social grants (such as child support grant or old age pension), and education. Both indicators are normalised to a range between zero and one, where higher values indicate higher levels of satisfaction.

The results reported in Figure 5.2 b) and c) suggest that those who experience poverty as a more persistent state are significantly less satisfied with the provision of public infrastructure than the rest. However, the wealthiest people are not the most satisfied. Indeed, I find evidence of a non-linear but hump-shaped relationship between household wealth and average levels of satisfaction with the provision of basic public goods, which also expands to basic social services. This estimated relationship remains significant even after controlling for overall life satisfaction (see Table D.12 in the Appendix D.6).
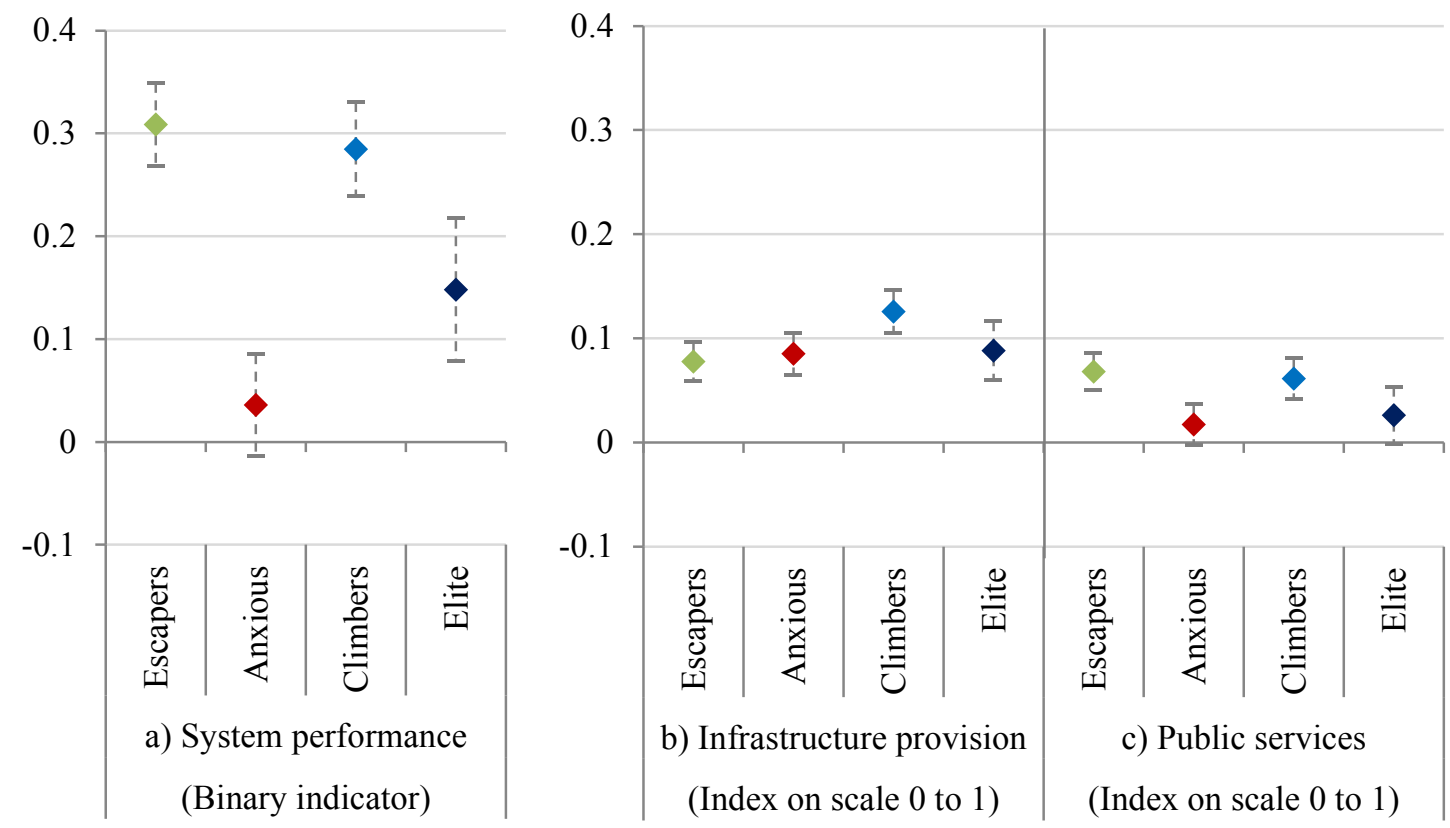

Figure 5.2 Relationship between class and satisfaction with governmental performance

Note: Analysis based on SASAS 2012 Q1+Q2. Each point shows the estimated marginal effect of class membership, with "Persistently Poor" being the base category. The dashed lines show the 95 per cent confidence intervals. For the full regression results, see Table D.12 in the Appendix D.6.

\subsubsection{Attitudes and Value Orientations of a Broader Social Concern}

\section{Attitudes toward voting}

In this section, I explore class differences in attitudes toward voting. This assessment is based on the respondents degree of agreement or disagreement (scale 1-5) with the following four statements: (a) "Whether I vote or not makes no difference"; (b) "After being elected all parties are the same, so voting is pointless"; (c) "It is the duty of all citizens to vote"; and (d) 
"Voting is meaningless because no politician can be trusted." For statements (a), (b), and (c), I subsume the five answer options into a binary indicator variable, which takes on a value of one if the respondent disagrees or strongly disagrees with the statement, and zero otherwise. For statement (c), I analogously construct a binary indicator variable, which takes on a value of one if the respondent agrees or strongly agrees with the statement, and zero otherwise. For all four indicators, a value of one thus implies positive attitudes toward voting. The association between class and the four indicators is estimated using probit regression.

The average marginal effects for the five class categories are reported in Figure 5.3 below. The upwardly mobile strata and the elite display the firmest beliefs in voting as a meaningful tool to influence political processes. By contrast, the anxious - albeit comparable to the climbers in terms of standard of living, education, and employment - are closest in their attitudes the persistently poor.

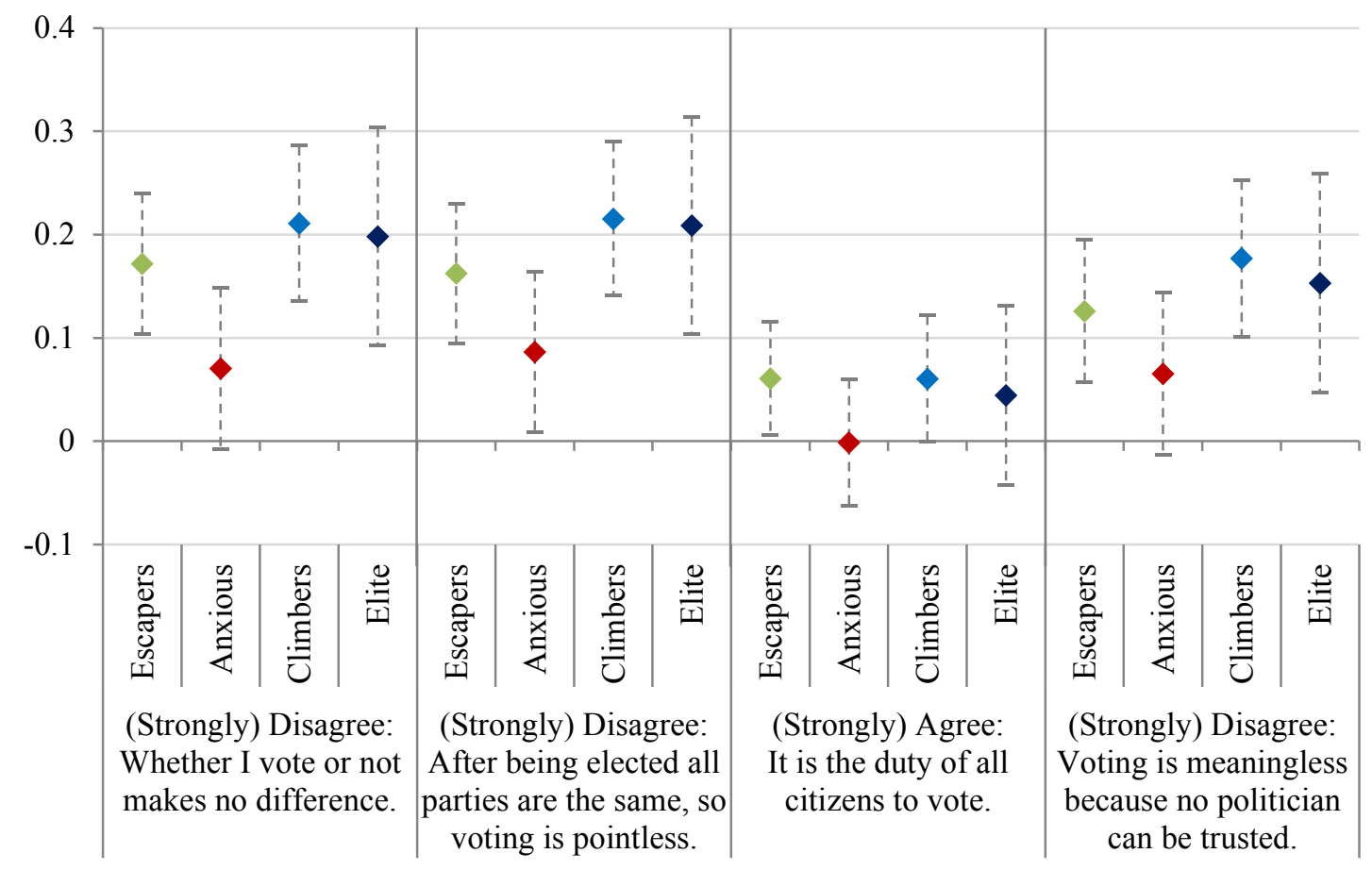

Figure 5.3 Relationship between class and attitudes toward voting

Note: Analysis based on SASAS 2012 Q1. Each point shows the estimated marginal effect of class membership, with "Persistently Poor" being the base category. The dashed lines show the 95 per cent confidence intervals. For the full regression results, see Table D.13 in the Appendix D.6.

The detected patterns are confirmed when looking at the indicators individually (see Table D.14 in the Appendix D.6). The estimates show that especially upward social mobility, and to a lesser extent overall life satisfaction, are significantly positively correlated with a stronger belief in voting as an effective instrument to influence politics. Moreover, better educated respondents tend to show more positive attitudes toward voting. 


\section{Support for civil liberties}

I now look at people's tolerance for government constraints on their rights as citizens, a critical limitation to the exercise of "effective democracy."

The analysis builds on a set of five statements included in the SASAS questionnaire. Respondents are asked to state their level of agreement with various views on how the country should be governed. The first four statements capture respondents' support for civil liberties, while the fifth captures attitudes towards corruption. All five variables are measured on a fivepoint Likert scale recoded such that higher values indicate higher support for civil rights. For a detailed variable description, please refer to Appendix D.3.

Figure 5.4 reports the average marginal effects estimated for the five class categories. I find that those who perceive themselves as upwardly mobile tend to be less opposed to government constraints placed on the freedom of opinion and freedom of the press and media, and to be less likely to demand the immediate dismissal of corrupt politicians (see also Table D.16 in the Appendix D.6). When investigating the direct link between people's civic values and the derived asset index, I furthermore find some support for a hump-shaped relationship between living standards and support for the freedom of association and freedom to protest (see Table D.16 in the Appendix D.6).

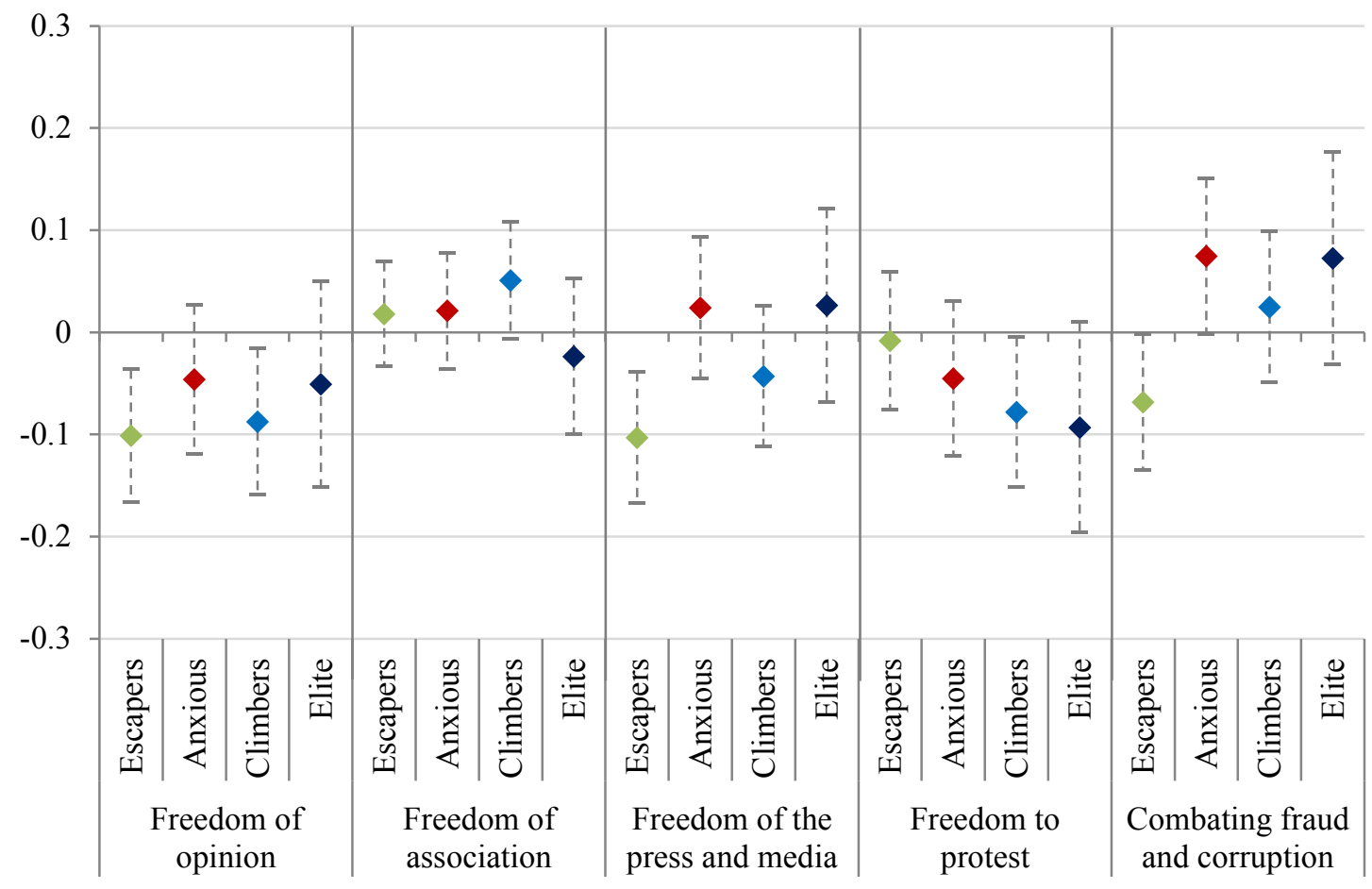

Figure 5.4 Relationship between class and civic values

Note: Analysis based on SASAS 2012 Q1. Each point shows the estimated marginal effect of class membership, with "Persistently Poor" being the base category. The dashed lines show the 95 per cent confidence intervals. For the full regression results, see Table D.15 in the Appendix D.6. 
In line with the theoretical argument on partisanship discussed in Section 5.2, there are reasons to suspect that the detected negative association between people's perceptions of social mobility and support for the freedom of opinion, freedom of the press and media, and the dismissal of corrupt politicians may be driven by an affiliation of the upwardly mobile with the national government. In fact, I observe that the two upwardly mobile strata tend to feel closest to the governing African National Congress (ANC) ${ }^{54}$ Table D.17 in the Appendix D.6 investigates this channel. When controlling for this self-rated closeness, the negative association between upward mobility and support for the freedom of opinion and freedom of the press and media remains significant, but the estimated effect size decreases by about 3 percentage points. Furthermore, the negative effect on support for the dismissal of corrupt politicians turns insignificant.

\section{Priorities for public policy}

In this final part of my analysis, I assess the association between class and different public policy priorities. Specifically, I focus on a SASAS question that asks respondents to select the three most important challenges facing South Africa today from a list of 18 policy areas. I limit the analysis to the seven top challenges named by at least 10 per cent of all respondents: (a) unemployment, (b) crime and safety, (c) poverty, (d) HIV/AIDS, (e) corruption, (f) service provision/delivery, and $(\mathrm{g})$ education.

Figure 5.5 shows the results. Approximately three-quarters of all respondents select unemployment among the top three challenges. Class does not seem to have any impact on this choice. Naturally, those looking for a job place greater emphasis on this challenge. Crime and safety are most of a concern among the downwardly mobile anxious middle class, followed by the climbers. Poverty tends to be less of a concern among the better-off and the upwardly mobile. Interestingly, I find that the climbers are least likely to rank poverty among the most important challenges that South Africa is facing. The most relevant factors that relate to the selection of HIV/AIDS among the top three challenges are race and geography. ${ }^{55}$ Interestingly, those with tertiary education are less likely to prioritise HIV/AIDS as a main concern (see Table D.19 in the Appendix D.6). In line with the findings presented in the previous section, I find a strong and significant negative association between mobility and

\footnotetext{
${ }^{54}$ In fact, 62 per cent of the escapers and 54 per cent of the climbers report feeling "very close" or "quite close" to the ANC, while the same is true for 49 per cent of the persistently poor, 31 per cent of the anxious and 13 per cent of the elite.

${ }^{55}$ Due to considerably lower infection rates, white and coloured South Africans are found to be significantly less concerned with HIV/AIDS. While prevalence remains high among the general population, it infection rates vary markedly between regions.
} 
prioritising corruption (see Table D.19 in the Appendix D.6). Last, I observe that materially better-off South Africans tend to prioritise education, and are less likely to prioritise basic service provision.

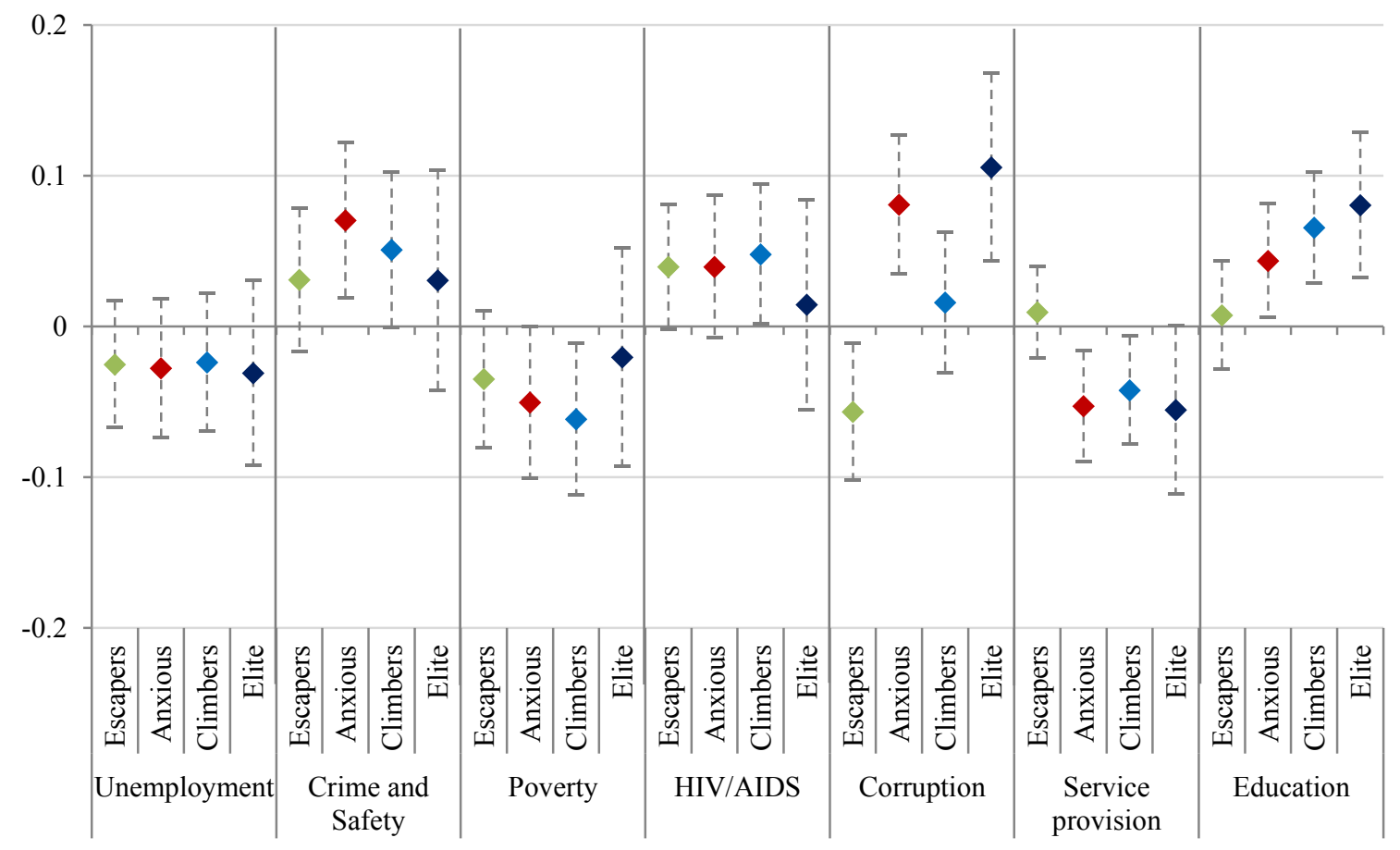

Figure 5.5 Relationship between class and priorities for public policy

Note: Analysis based on SASAS 2012 Q1+Q2. Each point shows the estimated marginal effect of class membership, with "Persistently Poor" being the base category. The dashed lines show the 95 per cent confidence intervals. For the full regression results, see Table D.18 in the Appendix D.6.

\subsection{Conclusion}

The positive relationship between the size of the middle class and democracy found in macro cross-country analyses has frequently been linked to this class's pro-democratic attitudes (see, for example, Barro, 1999; Chun, Hasan, \& Ulubasoglu, 2011; Easterly, 2001; Josten, 2013; Loayza et al., 2012; Solimano, 2008). However, micro studies on the political values, attitudes and behaviours of the middle class find mixed results. While some studies find suggestive evidence consistent with pro-democratic civic and political engagement on the part of the middle class (see, for example, Cheeseman, 2015), others have, quite to the contrary, concluded that this class appears rather "apathetic" in terms of their political participation (Resnick, 2015).

This study helps to reconcile these two opposing views by allowing for heterogeneity within the groups of the poor and the middle class. I show how asymmetries in perceived chances of upward social mobility of different groups condition their political attitudes. 
Specifically, I find that the two upwardly mobile strata - the "escapers" and the "climbers" show the strongest generic support for democratic rule. They also display the highest levels of trust in public institutions and inherit the firmest beliefs that voting is an effective tool to influence political processes in the country. By contrast, the downwardly mobile "anxious" middle class - despite being comparable to the climbers in terms of their standard of living, levels of education, and employment - shows signs of political resignation. To this effect, their political attitudes are closest to the attitudes displayed by the persistently poor.

Some important messages emerge from these findings for the South African case. Since the transition from apartheid to democracy, concerns about the quality of democracy have become increasingly central to political discourse in South Africa. In particular, the ANC's dominant character and the lack of a system of opposition institutions, which are essential for the healthy functioning of democracy (Jung and Shapiro, 1995), have been exposed as the main threats to democratic consolidation and accountability (see also Giliomee $\&$ Simkins, 1999). These concerns have intensified over the past decade, particularly due to several corruption scandals involving officeholders and increased government interference in the work of the media. This has resulted in the downgrading of South Africa's press freedom status to "partly free" (Freedom House, 2010). Against this background, some commentators have placed high expectations on South Africa's emerging (black) middle class to become a key agent in demanding greater political accountability and placing checks on government performance (Everatt, 2013, 2014). My findings caution against these expectations.

The results presented in this chapter imply that governmental performance is likely to be perceived differently by members of different social strata, who may be affected differently by government policies (see also Newton \& Norris, 2000). Particularly those people who perceive themselves as upwardly mobile may have earned some of their privileges through the existing political system and therefore, on average, are less likely to take on a more critical or demanding stance in politics. That is, those who are doing well under the current government and expect to do even better in the future are more likely to tolerate government constraints on the freedom of opinion and freedom of the press and media and less likely to advocate for the immediate dismissal of corrupt politicians. In contrast, those who perceive themselves as being stuck or downwardly mobile are much less trusting of public institutions and less satisfied with governance performance. However, instead of raising their concerns, I find that those who have been cut off from opportunities to ascend the social ladder show signs of disillusionment about the influence of their vote on politics in the country and are thus more likely to opt out of the political process. 



\section{REFERENCES}

Acemoglu, D., Egorov, G., \& Sonin K. (2018). Social mobility and stability of democracy: Reevaluating de Tocqueville, The Quarterly Journal of Economics, 133(2), 1041-1105. Acemoglu, D., \& Robinson, J. A. (2005). Economic origins of dictatorship and democracy. Cambridge, UK: Cambridge University Press.

Acemoglu, D., \& Zilibotti, F. (1997). Was Prometheus unbound by chance? Risk, diversification, and growth. Journal of Political Economy, 105(4), 709-751.

Amoranto, G., Chun, N., \& Deolalikar, A. B. (2010). Who are the middle class and what values do they hold? Evidence from the World Values Survey. Asian Development Bank Economics Working Paper Series, 229.

Adato, M., Lund, F., \& Mhlongo, P. (2007). Methodological innovations in research on the dynamics of poverty: A longitudinal study in KwaZulu-Natal, South Africa. World Development, 35(2), 247-263.

Adato, M., Carter, M. R., \& May, J. (2006). Exploring poverty traps and social exclusion in South Africa using qualitative and quantitative data. The Journal of Development Studies, 42(2), 226-247.

Agüero, J., Carter, M. R., \& May, J. (2007). Poverty and inequality in the first decade of South Africa's democracy: What can be learnt from panel data from KwaZulu-Natal?. Journal of African Economies, 16(5), 782-812.

Atkinson, A. B., \& Brandolini, A. (2013). On the identification of the middle class. In Gornick, J. C., \& Jäntti, M. (Eds.). Income inequality: Economic disparities and the middle class in affluent countries (pp. 77-100). Stanford, CA: Stanford University Press.

Azomahou, T. T., \& Yitbarek, E. A. (2015). Poverty persistence and informal risk management: Micro evidence from urban Ethiopia. UNU-MERIT Working Paper Series, 2015-006. Maastricht: Maastricht Economic and social Research institute on Innovation and Technology (UNU-MERIT) \& Maastricht Graduate School of Governance (MGSoG).

Bane, M., \& Ellwood, D. (1986). Slipping into and out of poverty: The dynamics of spells. Journal of Human Resources, 21(1), 1-23. 
Banerjee, A.V., \& Duflo, E. (2008). What is middle class about the middle classes around the world?. American Economic Association. Journal of Economic Perspectives, 22(2), 328.

Barro, R. J. (1999). Determinants of democracy. Journal of Political Economy, 107(S6), S158S183.

Berntsen, D., Rubin, D. C., \& Siegler, I. C. (2011). Two versions of life: emotionally negative and positive life events have different roles in the organization of life story and identity. Emotion, 11(5), 1190.

Bhalla, S. S. (2007). Second among equals: The middle class kingdoms of India and China. Book draft Chapter 5. Retrieved from www.oxusinvestments.com

Bhorat, H., \& Van Der Westhuizen, C. (2013). Temporary employment services in South Africa: A brief note. Background Paper for the World Development Report 2013. Washington, DC: World Bank Publications.

Biewen, M. (2009). Measuring state dependence in individual poverty histories when there is feedback to employment status and household composition. Journal of Applied Econometrics, 24(7), 1095-1116.

Bigsten, A., \& Shimeles, A. (2004). Dynamics of poverty in Ethiopia. UNU-WIDER Research Paper No. 2004/39. Helsinki: United Nations University (UNU).

Birdsall, N. (2015). Does the rise of the middle class lock in good government in the developing world?. The European Journal of Development Research, 27(2), 217-229.

Birdsall, N. (2010). The (indispensable) middle class in developing countries. In Kanbur, R., \& Spence, M. (Eds.). Equity and growth in a globalizing world (pp. 157-188). Washington, DC: World Bank Publications.

Birdsall, N., Graham, C., \& Pettinato, S. (2000). Stuck in tunnel: Is globalization muddling the middle?. Center on Social and Economic Dynamics, Working Paper No. 14. Washington, DC: Brookings Institution Press.

Blackburn, M. L., \& Bloom, D. E. (1985). What is happening to the middle class?. American Demographics, 7(1), 18-25.

Booysen, F., Van Der Berg, S., Burger, R., Von Maltitz, M., \& Du Rand, G. (2008). Using an asset index to assess trends in poverty in seven Sub-Saharan African countries. World Development, 36(6), 1113-1130.

Budlender, J., Leibbrandt, M., \& Woolard, I. (2015). South African poverty lines: A review and two new money-metric thresholds. SALDRU Working Paper No. 151. Cape Town: SALDRU, University of Cape Town. 
Burger, R., McAravey, C., \& Van der Berg, S. (2017). The Capability Threshold: Reexamining the definition of the middle class in an unequal developing country. Journal of Human Development and Capabilities, 18(1), 89-106.

Burger, R., Van der Berg, S., Van der Walt, S., \& Yu, D. (2017). The long walk: Considering the enduring spatial and racial dimensions of deprivation two decades after the fall of apartheid. Social Indicators Research, 130(3), 1101-1123.

Burger, R. P., Klasen, S., \& Zoch, A. (2016). Estimating income mobility when income is measured with error: The case of South Africa. ERSA Working Paper No. 607. Cape Town: Economic Research Southern Africa.

Burger, R., Steenekamp, C. L., Van der Berg, S., \& Zoch, A. (2015). The emergent middle class in contemporary South Africa: Examining and comparing rival approaches. Development Southern Africa, 32(1), 25-40.

Cafiero, C., \& Vakis, R. (2006). Risk and vulnerability considerations in poverty analysis: Recent advances and future directions, Social Protection Discussion Paper 0610. Washington, DC: World Bank Publications.

Cappellari, L., \& Jenkins, S. P. (2008). Estimating low pay transition probabilities accounting for endogenous selection mechanisms. Journal of the Royal Statistical Society: Series C (Applied Statistics), 57(2), 165-186.

Cappellari, L., \& Jenkins, S. P. (2004). Modelling low income transitions. Journal of Applied Econometrics, 19(5), 593-610.

Cappellari, L., \& Jenkins, S. P. (2002). Who stays poor? Who becomes poor? Evidence from the British Household Panel Survey. The Economic Journal, 112(478), C60-C67.

Cárdenas, M., Kharas, H., \& Henao, C. (2015). Latin America’s global middle class: A preference for growth over equality. In Dayton-Johnson, J. (Ed.). Latin America's Emerging Middle Classes: Economic Perspectives (pp. 51-69). London: Palgrave Macmillan.

Carney, D. (Ed.) (1998) Sustainable rural livelihoods - What contribution can we make?. London: Department for International Development (DFID).

Carter, M. R., \& Barrett, C. B. (2006). The economics of poverty traps and persistent poverty: An asset-based approach. The Journal of Development Studies, 42(2), 178-199.

Carter, M., \& May, J. (2001). One kind of freedom: Poverty Dynamics in post-apartheid South Africa. World Development, 29(12), 1987-2006.

Carter, M. R., \& May, J. (1999). Poverty, livelihood and class in rural South Africa. World Development, 27(1), 1-20. 
Cheeseman, N. (2015). "No bourgeoisie, no democracy"? The political attitudes of the Kenyan middle class. Journal of International Development, 27(5), 647-664.

Chun, N., Hasan, R., \& Ulubasoglu, M. (2011). The role of the middle class in economic development: What do cross-country data show? Asian Development Bank Economics Working Paper Series, 245.

Corral Rodas, P. A., Molini, V., \& Oseni, G. (2017). No condition is permanent: middle class in Nigeria in the last decade. The Journal of Development Studies, 1-17.

Davis, P., \& Baulch, B. (2011). Parallel realities: exploring poverty dynamics using mixed methods in rural Bangladesh. The Journal of Development Studies, 47(1), 118-142.

Deininger, K., \& Okidi, J. (2003). Growth and poverty reduction in Uganda, 1999-2000: Panel data evidence. Development Policy Review, 21(4), 481-509.

De la Hey, M., \& Beinart, W. (2017). Why have South African smallholders largely abandoned arable production in fields? A Case Study. Journal of Southern African Studies, 43(4), 753-770.

Deloitte (2012). The rise and rise of the African middle class. Deloitte on Africa Collection, 1. Johannesburg: Deloitte \& Touche.

Dercon, S. (2006). Vulnerability: A micro perspective. In Bourguignon, F., Pleskovic, B., \& Van der Gaag, J. (Eds.). Securing development in an unstable world (pp. 117-146). Washington, DC: World Bank Publications.

De Weerdt, J. (2010). Moving out of poverty in Tanzania: Evidence from Kagera. The Journal of Development Studies, 46(2), 331-349.

Dubow, E. F., Boxer, P., \& Huesmann, L. R. (2009). Long-term effects of parents' education on children's educational and occupational success: Mediation by family interactions, child aggression, and teenage aspirations. Merrill-Palmer quarterly (Wayne State University. Press), 55(3), 224.

Du Toit, A. \& Neves, D. (2014). The government of poverty and the arts of survival: mobile and recombinant strategies at the margins of the South African economy. The Journal of Peasant Studies, 41(5), 833-853.

Du Toit, A. \& Neves, D. (2009). Informal social protection in post-apartheid migrant networks: Vulnerability, social networks and reciprocal exchange in the Eastern and Western Cape, South Africa. BWPI Working Paper No. 74. Manchester: Brooks World Poverty Institute (BWPI). 
Du Toit, A. \& Neves, D. (2007). In search of South Africa's second economy: Chronic poverty, economic marginalisation and adverse incorporation in Mt. Frere and Khayelitsha. Chronic Poverty Research Centre Working Paper No. 102.

Easterly, W. (2007). Inequality does cause underdevelopment: Insights from a new instrument. Journal of Development Economics, 84(2), 755-776.

Easterly, W. (2001). The middle class consensus and economic development. Journal of Economic Growth, 6(4), 317-335.

Everatt, D. (2013). The South African middle class. In Bernstein, A. (Ed.). Rising middle classes in India, Brazil and South Africa: What is happening and what are the implications? (pp. 33-35). Johannesburg: Centre for Development and Enterprise.

Everatt, D. (2014). Gauteng and the arrival of uncertainty. The Journal of the Helen Suzman Foundation, 74, 10-18.

Faye, O., Islam, N., \& Zulu, E. M. (2011). Poverty dynamics in Nairobi's slums: Testing for true state dependence and heterogeneity effects. CEPS/INSTEAD Working Paper No. 2011-56.

Finn, A. \& Leibbrandt, M. (2017). The dynamics of poverty in South Africa. SALDRU Working Paper No. 174, NIDS Discussion Paper No. 2016/1. Cape Town: SALDRU, University of Cape Town.

Finn, A., Leibbrandt, M., \& Ranchhod, V. (2017). Patterns of persistence: Intergenerational mobility and education in South Africa. SALDRU Working Paper No. 175, NIDS Discussion Paper No. 2016/2. Cape Town: SALDRU, University of Cape Town.

Finn, A. (2015). A national minimum wage in the context of the South African labour market. SALDRU Working Paper No. 153. Cape Town: SALDRU, University of Cape Town.

Finn, A., Leibbrandt, M., \& Woolard, I. (2013a). The significant decline in poverty in its many dimensions since 1993, Econ3x3. Retrieved from www.econ3x3.org

Finn, A., Leibbrandt, M., \& Woolard, I. (2013b). The middle class and inequality in South Africa. SALDRU Research Brief. Cape Town: SALDRU, University of Cape Town.

Freedom House (2010). South Africa country report: Freedom of the press. Retrieved from www.freedomhouse.org

Fukuyama, F. (2014). Political order and political decay: From the industrial revolution to the globalization of democracy. London: Macmillan.

Galor, O., \& Zeira, J. (1993). Income distribution and macroeconomics. The Review of Economic Studies, 90(4), 869-887. 
Garcia-Rivero, C., Du Toit, P., \& Kotzé, H. (2003). Tracking the development of the middle class in democratic South Africa. Politeia, 22(3), 6-29.

Giesbert, L., \& Schotte, S. (2016). Africa's new middle class: Fact and fiction of its transformative power. GIGA Focus Africa, 1.

Giliomee, H., \& Simkins, C. (1999). Conclusion. In H. Giliomee \& C. Simkins (Eds.). The awkward embrace: One-party domination and democracy (pp. 337-354). Amsterdam: Harwood.

Glewwe, P., \& Gibson, J. (2005). Analysis of poverty dynamics. In Kamanou, G., Morduch, J., Isidero, D. P., Gibson, J., Ivo, H., \& Ward, M. (Eds.). Handbook on poverty statistics: Concepts, methods and policy use (pp. 324-369). New York, NY: The United Nations Statistics Division.

Handley, A. (2015). Varieties of Capitalists? The Middle-Class, Private Sector and Economic Outcomes in Africa. Journal of International Development, 27(5), 609-627.

Haskins, R., \& Sawhill, I. V. (2009). Creating an opportunity society. Washington, DC: Brookings Institution Press.

Hattingh, D., Russo, B., Sun-Basorun, A., \& Van Wamelen, A. (2012). The rise of the African consumer. Report from McKinsey’s Africa Consumer Insights Center. Johannesburg: McKinsey \& Company.

Heckman, J. J. (1976). The common structure of statistical models of truncation, sample selection and limited dependent variables and a simple estimator for such models. Annals of Economic and Social Measurement, 5, 475-492.

Heckman, J. J. (1981). The incidental parameters problem and the problem of initial conditions in estimating a discrete time-discrete data stochastic process. In Manski C. F., \& McFadden, D. (Eds.). Structural analysis of discrete data with econometric applications (pp. 179-195), Cambridge, MA: MIT Press.

Hulme, D., \& Shepherd, A. (2003). Conceptualizing chronic poverty. World Development, 31(3), 403-423.

Human Sciences Research Council, HSRC (2012b). South African Social Attitudes Survey (SASAS) 2012, Questionnaire 2 -All provinces [dataset]. SASAS 2012 Q2. Version 1.0. Pretoria: HSRC [producer] 2012, HSRC [distributor] 2014. Retrieved from http://dx.doi.org/doi:10.14749/1417607512 
Human Sciences Research Council, HSRC (2012a). South African Social Attitudes Survey (SASAS) 2012, Questionnaire 1 - All provinces [dataset]. SASAS 2012 Q1. Version 1.0. Pretoria: HSRC [producer] 2012, HSRC [distributor] 2015. Retrieved from http://dx.doi.org/doi:10.14749/1413216779

Human Sciences Research Council, HSRC (2006a). South African Social Attitudes Survey (SASAS) 2006, Questionnaire 1 -All provinces [dataset]. SASAS 2006 Q1. Version 1.0. Pretoria: HSRC [producer] 2006, HSRC [distributor] 2010. Retrieved from http://dx.doi.org/doi:10.14749/1400836844

Human Sciences Research Council, HSRC (2006b). South African Social Attitudes Survey (SASAS) 2006, Questionnaire 2 - All provinces [dataset]. SASAS 2006 Q2. Version 1.0. Pretoria: HSRC [producer] 2006, HSRC [distributor] 2010. Retrieved from http://dx.doi.org/doi:10.14749/1400836859

Inglehart, R., \& Welzel, C. (2010). Changing mass priorities: The link between modernization and democracy. Perspectives on Politics, 8(2), 551-567.

Inglehart, R., \& Welzel, C. (2005a). Modernization, cultural change and democracy: The human development sequence. Cambridge: Cambridge University Press.

Inglehart, R., \& Welzel, C. (2005b). Modernization, cultural change and democracy: The human development sequence. Draft version. Retrieved from http://isites.harvard.edu/ fs/docs/icb.topic96263.files/culture_democracy.pdf

Inglehart, R. (1990). Culture shift in advanced industrial society. Princeton: Princeton University Press.

International Labour Office, ILO (2004). Economic security for a better world. Geneva: International Labour Office.

Jackman, M. (1972). Social mobility and attitude toward the political system. Social Forces, $50,462-72$.

Jalan, J., \& Ravallion, M. (1998). Transient poverty in post-reform rural China. Journal of Comparative Economics, 26(2), 338-357.

Janowitz M. (1970 [1956]). Social and political consequences of social mobility. In Janowitz, M., Political Conflict (pp. 71-87). Chicago: Quadrangle.

Jayadev, A., Lahoti, R., \& Reddy, S. (2015). The middle muddle: Conceptualizing and measuring the global middle class. Courant Research Centre: Poverty, Equity and Growth, Discussion Paper No. 193. Göttingen: Courant Research Centre.

Jenkins, S. P. (2011). Changing Fortunes: Income mobility and poverty dynamics in Britain. Oxford: Oxford University Press. 
Jenkins, S. P., \& Schluter, C. (2003). Why are child poverty rates higher in Britain than in Germany? A longitudinal perspective. Journal of Human Resources, 38(2), 441-465. Josten, S. D. (2013). Middle-class Consensus, Social Capital and the Fundamental Causes of Economic Growth and Development. Journal of Economic Development, 38(1), 1-26. Jung, C., \& Shapiro, I. (1995). South Africa's Negotiated Transition: Democracy, Opposition, and the New Constitutional Order. Politics and Society, 23(3), 269-308.

Kanbur, R., \& Shaffer, P. (2007). Epistemology, normative theory and poverty analysis: Implications for Q-squared in practice. World Development, 35(2), 183-196.

Kanbur, R. (Ed.). (2003). Q-squared: Combining qualitative and quantitative methods in poverty appraisal. Delhi: Permanent Black.

Kedir, A. M. (2005). Understanding urban chronic poverty: Crossing the qualitative and quantitative divide. Environment and Urbanization, 17(2), 43-54.

Kedir, A. M., \& McKay, A. (2005). Chronic poverty in urban Ethiopia: Panel data evidence. International Planning Studies, 10(1), 49-67.

Kerr, A. (2018). Job Flows, Worker Flows and Churning in South Africa. South African Journal of Economics, 86(S1), 141-166.

Kharas, H. 2010. The emerging middle class in developing countries. OECD Development Centre Working Paper No. 285. Paris: OECD Development Centre.

Klasen, S., \& Povel, F. (2013). Defining and Measuring Vulnerability: State of the Art and New Proposals. In Klasen, S., \& Povel, H. (Eds.). Vulnerability to poverty (pp.17-49). London: Palgrave.

Klasen, S., \& Woolard, I. (2009). Surviving unemployment without state support: unemployment and household formation in South Africa. Journal of African Economies, 18(1), 1-51.

Lee, N., Ridder, G., \& Strauss, J. (2017). Estimation of poverty transition matrices with noisy data. Journal of Applied Econometrics, 32(1), 37-55.

Leibbrandt, M., Finn, A., \& Woolard, I. (2012). Describing and decomposing post-apartheid income inequality in South Africa. Development Southern Africa, 29(1), 19-34.

Leibbrandt, M., Woolard, I., Finn, A., \& Argent, J. (2010). Trends in South African Income Distribution and Poverty since the fall of Apartheid. OECD Social, Employment and Migration Working Papers, No. 101. Paris: OECD Publishing.

Levy, B., Hirsch, A., \& Woolard, I. (2014). South Africa's evolving political settlement in comparative perspective. SALDRU Working Paper No 138. Cape Town: SALDRU, University of Cape Town.

Lipset, S. (1960). Political Man: The Social Bases of Politics. Garden City: Doubleday. 
Lipset, S., \& Bendix, R. (1959). Social Mobility in Industrial Society. Berkeley: University of California Press.

Loayza, N., Rigolini, J., \& Llorente, G. (2012). Do middle classes bring about institutional reforms?. Economics Letters, 116(3), 440-444.

Lopez-Calva, L. F., Rigolini, J., \& Torche, F. (2016). Is there such thing as middle class values? Class differences, values and political orientations in Latin America. Journal of Globalization and Development, 7(2).

López-Calva, L. F., \& Ortiz-Juarez, E. (2014). A vulnerability approach to the definition of the middle class. The Journal of Economic Inequality, 12(1), 23-47.

Lybbert, T. J., Barrett, C. B., Desta, S., \& Layne Coppock, D. (2004). Stochastic wealth dynamics and risk management among a poor population. The Economic Journal, 114(498), 750-777.

Mattes, R. (2015). South Africa's Emerging Black Middle Class: A Harbinger of Political Change? Journal of International Development, 27(5), 665-692.

May, J., Carter, M., \& Posel, D. (1995). The composition and persistence of rural poverty in South Africa. Land and Agriculture Policy Centre Working Paper No. 15.

Mberu, B. U., Ciera, J. M., Elungata, P., \& Ezeh, A. C. (2014). Patterns and determinants of poverty transitions among poor urban households in Nairobi, Kenya. African Development Review, 26(1), 172-185.

McDonald, S., \& Day, J. C. (2010). Race, gender, and the invisible hand of social capital. Sociology Compass, 4(7), 532-543.

McEwan, C., Hughes, A., \& Bek, D. (2015). Theorising middle class consumption from the Global South: A study of everyday ethics in South Africa's Western Cape. Geoforum, 67, 233-243.

Moore, B. (1966). The Social Origins of Dictatorship and Democracy: Lord and Peasant in the Making of the Modern World. Boston: Beacon Press.

Murphy, K. M., Shleifer, A., \& Vishny, R. W. (1989a). Income distribution, market size, and industrialization. Quarterly Journal of Economics, 104(3). 537-564.

Neubert, D. (2014). What is "Middle Class"? In search for an appropriate concept. Middle East-Topics \& Arguments, 2, 23-35.

Newton, K., \& Norris, P. (2000). Confidence in public institutions: Faith, culture, or performance? In Pharr, S. J., \& Putnam, R. D. (Eds.). Disaffected Democracies: What's Troubling the Trilateral Countries? Princeton: Princeton University Press, 52-73. 
Ncube, M., Lufumpa, C. L., \& Kayizzi-Mugerwa, S. (2011). The Middle of the Pyramid: dynamics of the middle class in Africa. Market Brief, 20 April 2011. Tunis: African Development Bank.

Özler, B. (2007). Not Separate, Not Equal: Poverty and Inequality in Post-apartheid South Africa, Economic Development and Cultural Change, 55(3). 487-529.

Perotti, R. (1996). Growth, income distribution, and democracy: What the data say. Journal of Economic growth, 1(2), 149-187.

Phadi, M., \& Ceruti, C. (2011). The multiple meanings of the middle class in Soweto, South Africa. African Sociological Review, 15(1), 87-107.

Radeny, M., Van den Berg, M., \& Schipper, R. (2012). Rural poverty dynamics in Kenya: Structural declines and stochastic escapes. World Development, 40(8), 1577-1593.

Rakodi, C. (2002). A livelihoods approach - Conceptual issues and definitions. In Rakodi, C. with Lloyd-Jones, T. (Eds.). Urban livelihoods: A people-centred approach to reducing poverty. London: Earthscan Publications Ltd.

Ravallion, M. (2010). The Developing World's Bulging (but Vulnerable) Middle Class. World Development, 38(4), 445-454.

Ravallion, M. (1994). Poverty comparisons. Switzerland: Harwood Academic Publishers.

Reeves, R. V., Guyot, K., Krause, E. (2018). Defining the middle class: Cash, credentials, or culture?. Washington, DC: Brookings Institution. Retrieved from www.brookings.edu.

Resnick, D. (2015). The Middle Class and Democratic Consolidation in Zambia, Journal of International Development, 27(5), 693-715.

Rose, S. (2016). The growing size and incomes of the upper middle class. Research report. Washington, DC: The Urban Institute.

Rosenfeld, B. (2017). Reevaluating the Middle-Class Protest Paradigm: A Case-Control Study of Democratic Protest Coalitions in Russia. American Political Science Review, 111(4), $637-652$.

SALDRU (2016a). National Income Dynamics Study 2008, Wave 1 [dataset]. Version 5.3. Cape Town: SALDRU [producer],Cape Town: DataFirst [distributor].

SALDRU (2016b). National Income Dynamics Study 2010-2011, Wave 2 [dataset]. Version 2.3. Cape Town: SALDRU [producer], Cape Town: DataFirst [distributor]. SALDRU (2016c). National Income Dynamics Study 2012, Wave 3 [dataset]. Version 1.3. Cape Town: SALDRU [producer], Cape Town: DataFirst [distributor]. 
SALDRU (2016d). National Income Dynamics Study 2014-2015, Wave 4 [dataset]. Version 1.0. Cape Town: SALDRU [producer], Cape Town: DataFirst [distributor], Pretoria: Department of Planning Monitoring and Evaluation [commissioner].

Schotte, S. (2017). The Anxious and the Climbers: Ambivalent Attitudes towards Democracy among South Africa's Middle Class. GIGA Working Paper, 304.

Schotte, S., Zizzamia, R., \& Leibbrandt, M. (2018). A poverty dynamics approach to social stratification: The South African case. World Development, 110, 88-103.

Seekings, J. (2007). Perceptions of class and income in post-apartheid Cape Town. (CSSR Working Paper No. 198). Cape Town, South Africa: Centre for Social Science Research, University of Cape Town.

Seekings, J., \& Nattrass, N. (2005). Class, Race and Inequality in South Africa. New Haven and London: Yale University Press.

Sen, A. (1999). Development as Freedom. New York, NY: Oxford University Press.

Shimeles, A., \& Ncube, M. (2015). The making of the middle-class in Africa: Evidence from DHS data. The Journal of Development Studies, 51(2), 178-193.

Solimano, A. (2008). The middle class and the development process: International evidence. Santiago, Chile: Economic Commission for Latin America and the Caribbean, ECLAC. Mimeographed document

Southall, R. (2016). The New Black Middle Class in South Africa. Johannesburg: Jacana Media.

Spaull, N. (2015). Schooling in South Africa: How low-quality education becomes a poverty trap. South African Child Gauge, 12, 34-41.

Stats SA (2015a). Consumer Price Index: January 2015. (Statistical release P0141). Pretoria: Statistics South Africa. Retrieved from http://www.statssa.gov.za/publications/P0141/ P0141February2015.pdf

Stats SA (2015b). Methodological report on rebasing of national poverty lines and development of pilot provincial poverty lines. Technical Report No. 03-10-11. Pretoria: Statistics South Africa.

Stats SA (2012). Consumer Price Index: December 2012. (Statistical release P0141). Pretoria: Statistics South Africa. Retrieved from http://www.statssa.gov.za/publications/P0141/ P0141December2012.pdf

Stats SA (2011). Consumer Price Index: March 2011. (Statistical release P0141). Pretoria: Statistics South Africa. Retrieved from http://www.statssa.gov.za/publications/P0141/ P0141March2011.pdf 
Stewart, M. B., \& Swaffield, J. K. (1999). Low pay dynamics and transition probabilities. Economica, 66(261), 23-42.

Sumich, J. (2016). The middle class of Mozambique and the politics of the blank slate. In Melber, H. (Ed.). The rise of Africa's middle class: myths, realities and critical engagements. London: Zed Books.

Torche, F., \& López-Calva, L. F. (2013). Stability and Vulnerability of the Latin American Middle Class, Oxford Development Studies, 41(4). 409-435.

Udjo, E. O. (2008). The Demographics of the Emerging Black Middle Class in South Africa, University of South Africa Bureau of Market Research Reports Paper, 375. Pretoria: Bureau of Market Research.

United Nations Development Programme, UNDP (2013). The rise of the South: Human progress in a diverse world. Human Development Report 2013. New York, NY: United Nations Development Programme.

Visagie, J., \& Turok, I. (Forthcoming). Rural-urban migration as a means of getting ahead. In Turok, B. (Ed.), Confronting inequality. Cape Town: Institute for African Alternatives. Visagie, J. (2015). Growth of the middle class: Two perspectives that matter for policy. Development Southern Africa, 32(1), 3-24.

Visagie, J. (2013). Who are the middle class in South Africa? Does it matter for policy?. Econ3x3. Retrieved from www.econ3x3.org

Visagie, J., \& Posel, D. (2013). A reconsideration of what and who is middle class in South Africa. Development Southern Africa, 30(2). 149-167.

Ward, P. S. (2016). Transient poverty, poverty dynamics, and vulnerability to poverty: An empirical analysis using a balanced panel from rural China. World Development, 78, 541-553.

Weakliem, D. L. (1992). Does social mobility affect political behaviour?. European Sociological Review, 8(2), 153-165.

Wietzke, B., \& Sumner, A. (2014). The political and social implications of the "new middle classes" in developing countries: A Literature review and avenues for future research. EADI Policy Paper Series.

Zizzamia, R., Schotte, S., Leibbrandt, M., \& Ranchhod, V. (2016). Vulnerability and the middle class in South Africa. SALDRU Working Paper Number 188, NIDS Discussion Paper 2016/15. Cape Town: SALDRU, University of Cape Town. 


\section{APPENDIX A}

\section{A.1. Vulnerability approach to defining the middle class}

In the first step, we model the probability of being poor in time $t^{\prime}$, given the household characteristics observed in the base year $t$, where $t^{\prime}>t$. We assume that individuals can be characterised by a latent poverty propensity $p_{i t}^{*}$, and an observed poverty status $p_{i t}$, of the following form:

$$
p_{i t,}^{*}=\boldsymbol{\beta} \boldsymbol{X}_{i t}+u_{i \prime} \text { and } p_{i t,}=I\left(p_{i t}^{*}>0\right)
$$

where $i=1, \ldots, N$ indexes individuals, $\boldsymbol{X}_{i t}$ is a set of explanatory variables describing individual $i$ in her household in terms of base year values, $\boldsymbol{\beta}$ is a vector of parameters to be estimated, and the error term $u_{i t}$, follows the standard normal distribution $\left(u_{i t}, N(0,1)\right)$. $I\left(p_{i t+1}^{*}>0\right)$ denotes an indicator function which takes on the value of 1 if the corresponding latent variable exceeds some observed threshold (which can be set equal to 0 without loss of generality) and 0 otherwise.

In the second step, for each individual $i$ we predict the probability of being poor in period $t^{\prime}$, based on the coefficient estimates from equation (A2) and base year characteristics (that is, $\hat{p}_{i t,}^{*}=\widehat{\boldsymbol{\beta}} \boldsymbol{X}_{i t}$ ).

Third, using the same time-fix predictor variables as in the probability model, we use a linear regression model to estimate a cross-sectional income equation (using expenditure as a proxy for permanent income) for the base year $t$ at the household level as:

$$
\ln Y_{i t}=\boldsymbol{\gamma} \boldsymbol{X}_{i t}+\varepsilon_{i t}
$$

where $\ln Y_{i t}$ is the household per capita income (or expenditure) in logarithmic scale in the initial point in time $t$. For each individual $i$ we then predict the per capita income (or expenditure) in $t$ associated to each probability, using the coefficient estimates from equation (A2) and initial household characteristics.

To derive the vulnerability threshold, we calculate the predicted average per capita income (or expenditure) level associated with a predicted poverty propensity in $t^{\prime}$ of 10 per cent. To reduce the sensitivity of the calculated threshold to the 10 per cent cut-off point and to have enough observations to get a more robust estimate of the mean income (or expenditure) level associated with this probability estimate, we calculate the vulnerability threshold as the mean predicted per capita income (or expenditure) in $t$ for all individuals with a predicted poverty propensity in $t^{\prime}$ of 8 to 12 per cent. 


\section{A.2. Derivation of the asset index}

Index based on characteristics of the main dwelling the household occupies and the set of assets present in the household (in working order).

Table A.1 Variables included in and weights obtained from MCA analysis

\begin{tabular}{|c|c|c|c|}
\hline \multicolumn{2}{|c|}{ Variable } & \multirow{2}{*}{$\begin{array}{l}\text { Categories } \\
\text { House, cluster, townhouse }\end{array}$} & \multirow{2}{*}{$\frac{\text { Weights }}{0.581}$} \\
\hline \multirow{6}{*}{ 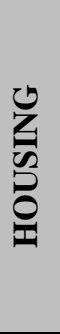 } & Dwelling Type & & \\
\hline & & Other & -1.003 \\
\hline & Water source & Tap water in house/on plot & 0.715 \\
\hline & & Other & -1.290 \\
\hline & Toilet facility & Flush toilet in/outside house & 1.001 \\
\hline & & Other & -1.064 \\
\hline \multirow{16}{*}{ 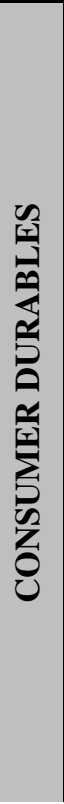 } & TV set & Yes - Owns a TV set & 0.783 \\
\hline & & No & -1.321 \\
\hline & Electric stove & Yes - Owns an electric stove & 0.793 \\
\hline & & No & -1.188 \\
\hline & Fridge/freezer combination & Yes - Owns a fridge/freezer combination & 0.981 \\
\hline & & No & -1.194 \\
\hline & DVD player/Blu-ray player & Yes - Owns a DVD player/Blu-ray player & 1.575 \\
\hline & & No & -0.685 \\
\hline & Microwave oven & Yes - Owns a microwave oven & 1.629 \\
\hline & & No & -0.770 \\
\hline & Washing machine & Yes - Owns a washing machine & 2.000 \\
\hline & & No & -0.626 \\
\hline & Motor vehicle & Yes - Owns a motor vehicle & 2.092 \\
\hline & & 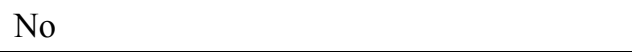 & -0.461 \\
\hline & Computer (desktop or laptop) & Yes - Owns a computer (desktop or laptop) & 2.443 \\
\hline & & No & -0.301 \\
\hline
\end{tabular}

Note: Analysis based on NIDS 2008 (wave 1). 6,655 observations at the household level. 


\section{A.3. Derivation of expected household income or expenditure in 2008}

Table A.2 Linear model of household income or expenditure in 2008

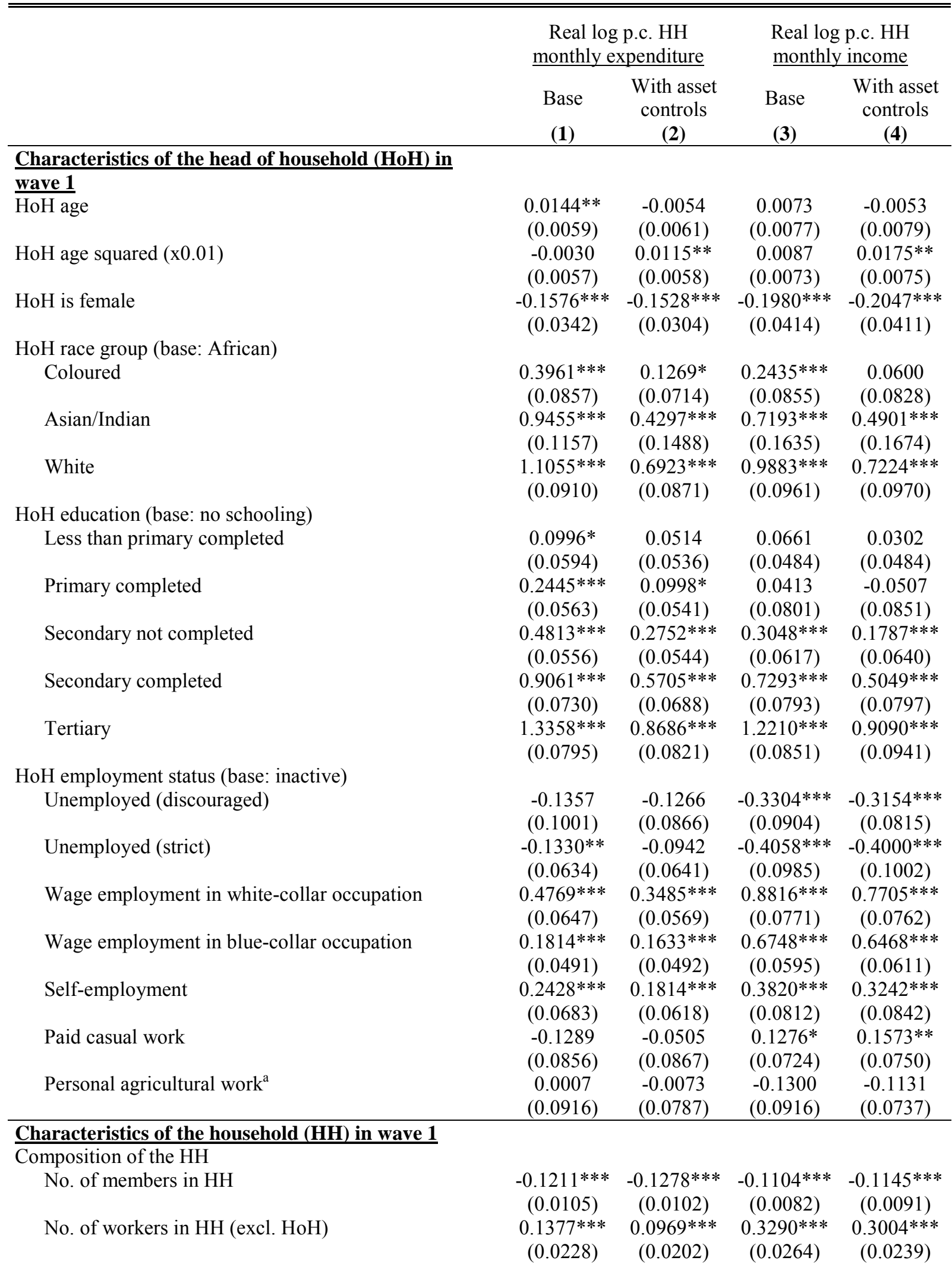


Geographic location (base: traditional) ${ }^{b}$

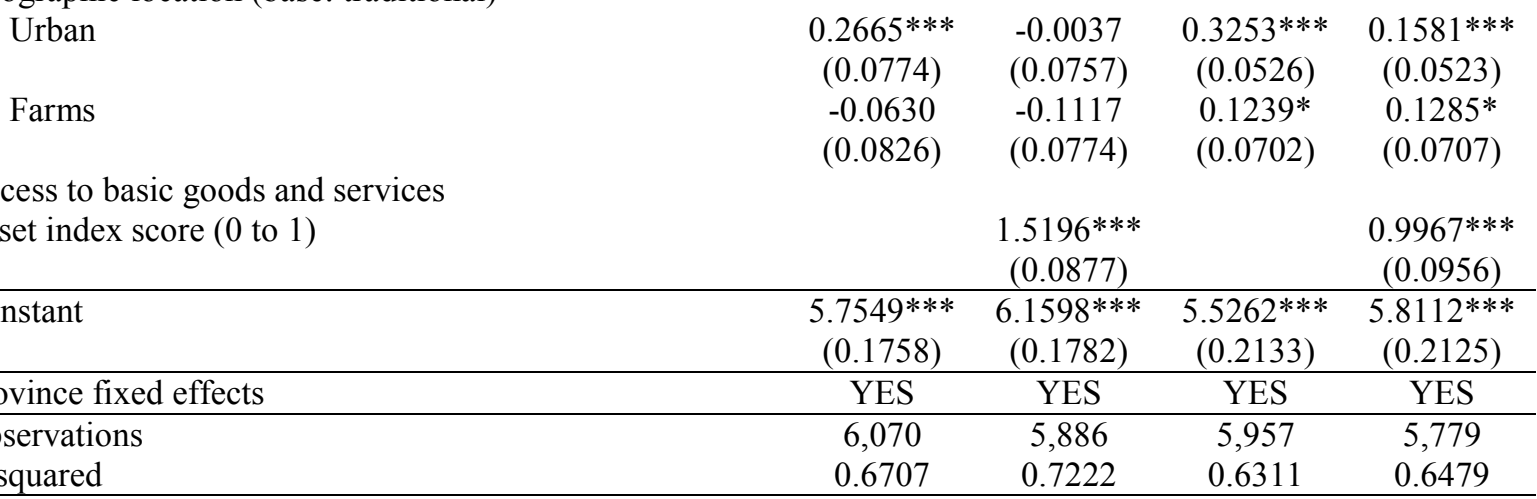

R-squared

Robust standard errors (adjusted for 400 survey clusters) in parentheses.

$* * * \mathrm{p}<0.01, * * \mathrm{p}<0.05, * \mathrm{p}<0.1$

Note: Individuals are predicted to be poor if their predicted poverty propensity exceeds the average probability of being poor in the final year (that is, the 2012 poverty headcount).

a Personal agricultural work includes working on own plot or looking after livestock.

${ }^{b}$ In line with the 2011 census, three settlement types are distinguished in NIDS:Urban - A continuously built-up area that is established through cities, towns, townships, small towns, and hamlets. Traditional - Communally owned land under the jurisdiction of traditional leaders. Settlements within these areas are villages. Farms Land allocated for and used for commercial farming including the structures and infrastructure on it. 
APPENDIX B 


\section{APPENDIX C}

\section{C.1. Developing an asset-based poverty measure}

Table C.1 Variables included in and weights obtained from MCA analysis

\begin{tabular}{|c|c|c|c|}
\hline LIVELIHOOD ASSET & EMPIRICAL IDENTIFICATION & WEIGHT & $\begin{array}{l}\text { SHARE } \\
(\%) \text { of } \\
\text { HHs }\end{array}$ \\
\hline \multicolumn{4}{|l|}{ Human capital $\left(\mathrm{H}_{\mathrm{it}}\right)$} \\
\hline \multicolumn{4}{|l|}{ Characteristics of the head of household $(\mathrm{HoH})$} \\
\hline \multirow[t]{5}{*}{ Age } & $\mathrm{HoH}$ age $<30$ years & 1.294 & 17.51 \\
\hline & HoH age $30-39$ years & 0.796 & 24.92 \\
\hline & HoH age $40-49$ years & 0.227 & 22.67 \\
\hline & HoH age $50-59$ years & -0.251 & 17.23 \\
\hline & $\mathrm{HoH}$ age $60+$ years & -1.971 & 17.67 \\
\hline \multirow[t]{6}{*}{ Educational attainment } & Tertiary & 1.347 & 17.43 \\
\hline & Secondary completed & 1.217 & 15.77 \\
\hline & Secondary not completed & 0.423 & 36.02 \\
\hline & Primary completed & -0.429 & 6.59 \\
\hline & Less than primary completed & -0.824 & 14.31 \\
\hline & No schooling & -1.573 & 9.88 \\
\hline \multirow[t]{2}{*}{ Work experience } & $\begin{array}{l}\text { Ever worked for pay or profit or helped } \\
\text { in a household business }\end{array}$ & 0.945 & 56.77 \\
\hline & Never worked & -0.943 & 43.23 \\
\hline \multicolumn{4}{|l|}{ Characteristics of the household $(\mathrm{HH})$} \\
\hline \multirow{4}{*}{$\begin{array}{l}\text { Work capacity ratio } \\
\text { (no. of members who can theoretically work / } \\
\text { no. of HH members) }\end{array}$} & $<0.25$ & -1.552 & 13.14 \\
\hline & $0.25-0.50$ & -1.001 & 19.87 \\
\hline & $0.50-1$ & 0.000 & 33.72 \\
\hline & 1 & 1.977 & 33.26 \\
\hline \multirow{5}{*}{$\begin{array}{l}\text { Child dependency ratio } \\
\text { (no. of members aged between } 0 \text { and } 14 \text { years / } \\
\text { no. of members aged between } 15 \text { and } 59 \text { years) }\end{array}$} & 0 & 1.163 & 47.59 \\
\hline & $0-1$ & -0.532 & 26.94 \\
\hline & $1-2$ & -0.649 & 19.40 \\
\hline & $2-3$ & -1.287 & 4.13 \\
\hline & $3+$ & -1.719 & 1.95 \\
\hline \multirow[t]{3}{*}{ Average perceived health status of all members } & Excellent & 0.895 & 42.07 \\
\hline & Good & 0.253 & 16.88 \\
\hline & Fair to Poor & -0.766 & 41.05 \\
\hline \multicolumn{4}{|l|}{ Financial Capital $\left(F_{i t}\right)$} \\
\hline \multicolumn{4}{|l|}{ Characteristics of the head of household $(\mathrm{HoH})$} \\
\hline \multirow[t]{6}{*}{ Access to credit and saving schemes } & Yes - Has a bank account & 1.516 & 59.09 \\
\hline & No & -1.482 & 40.91 \\
\hline & Yes - Has a personal loan from a bank & 4.952 & 8.65 \\
\hline & No & -0.361 & 91.35 \\
\hline & Yes - Member of a stokvel & 2.435 & 7.61 \\
\hline & No & -0.213 & 92.39 \\
\hline \multicolumn{4}{|l|}{ Characteristics of the $\mathrm{HH}$} \\
\hline \multirow[t]{2}{*}{ Access to insurance } & Yes - Funeral policies or burial societies & 1.087 & 44.37 \\
\hline & No & -1.042 & 55.63 \\
\hline \multirow[t]{4}{*}{ Regular financial flows } & $\begin{array}{l}\text { Yes - Income from private pensions, } \\
\text { dividends or interest }\end{array}$ & 1.273 & 4.99 \\
\hline & No & -0.055 & 95.01 \\
\hline & Yes - Received rental income & 2.302 & 6.55 \\
\hline & No & -0.105 & 93.45 \\
\hline
\end{tabular}




\begin{tabular}{|c|c|c|c|}
\hline Physical Capital $\left(\mathbf{P}_{\mathrm{it}}\right)$ & & & \\
\hline Characteristics of the $\mathrm{HH}$ & & & \\
\hline Dwelling Type & House, cluster, townhouse & 0.682 & 63.68 \\
\hline & Other & -1.292 & 36.32 \\
\hline Buying power & Yes - Owns an electric stove & 0.765 & 75.89 \\
\hline & No & -2.006 & 24.11 \\
\hline & Yes - Owns a fridge/freezer combination & 1.062 & 68.78 \\
\hline & 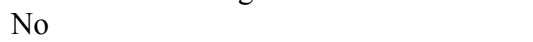 & -2.021 & 31.22 \\
\hline & Yes - Owns a microwave oven & 1.879 & 45.22 \\
\hline & No & -1.210 & 54.78 \\
\hline & Yes - Owns a washing machine & 2.412 & 32.37 \\
\hline & No & -0.871 & 67.63 \\
\hline Access to information and communication & Yes - Owns a TV set or radio & 0.422 & 87.37 \\
\hline & 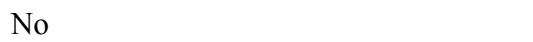 & -2.485 & 12.63 \\
\hline & Yes - Owns at least one computer & 2.991 & 19.51 \\
\hline & No & -0.440 & 80.49 \\
\hline & Yes - Cellular telephone available & 0.238 & 86.27 \\
\hline & No & -1.124 & 13.73 \\
\hline Transport and mobility & $\begin{array}{l}\text { Yes - Owns at least one private or } \\
\text { commercial motor vehicle }\end{array}$ & 2.801 & 24.21 \\
\hline & No & -0.571 & 75.79 \\
\hline & Yes - Owns at least one bicycle & 2.529 & 8.35 \\
\hline & No & -0.188 & 91.65 \\
\hline Inputs for agricultural production & Yes - Owns at least one plough & 0.134 & 1.78 \\
\hline & No & -0.004 & 98.22 \\
\hline & Yes - Owns at least one tractor & 2.351 & 0.70 \\
\hline & No & -0.024 & 99.30 \\
\hline & Yes - Owns at least one wheelbarrow & 0.912 & 20.65 \\
\hline & No & -0.280 & 79.35 \\
\hline & Yes - Owns at least one grinding mill & 1.952 & 0.97 \\
\hline & No & -0.022 & 99.03 \\
\hline Social Capital $\left(G_{i t}\right)$ & & & \\
\hline Characteristics of the head of household (HoH) & & & \\
\hline Gender & $\mathrm{HoH}$ is female & -1.172 & 45.85 \\
\hline & $\mathrm{HoH}$ is male & 1.593 & 54.15 \\
\hline Race & African & -0.387 & 77.54 \\
\hline & Coloured & 1.213 & 8.21 \\
\hline & Asian/Indian & 2.248 & 2.33 \\
\hline & White & 3.082 & 11.92 \\
\hline Marital status & Married & 1.715 & 36.46 \\
\hline & Living with partner & 1.309 & 7.71 \\
\hline & Widow/Widower & -2.000 & 12.78 \\
\hline & Divorced/Separated & -0.186 & 5.62 \\
\hline & Never Married & -0.822 & 37.42 \\
\hline Relationships of trust: Believe in likeliness of & Very likely & 0.502 & 14.94 \\
\hline neighbour returning wallet containing R200 & Somewhat likely & 0.385 & 17.67 \\
\hline & Not likely & -0.191 & 67.39 \\
\hline Characteristics of the $\mathrm{HH}$ & & & \\
\hline Frequency of theft and burglary in neighbourhood & Never happens & 0.619 & 17.77 \\
\hline & Very rare & 0.341 & 23.10 \\
\hline & Fairly common & -0.121 & 33.83 \\
\hline & Very common & -0.647 & 25.30 \\
\hline
\end{tabular}




\begin{tabular}{|c|c|c|c|}
\hline \multicolumn{4}{|l|}{ Geographic Capital $\left(\mathrm{G}_{\mathrm{it}}\right)$} \\
\hline \multicolumn{4}{|l|}{ Characteristics of the $\mathrm{HH}$} \\
\hline \multirow[t]{7}{*}{ Access to water } & Tap water in house/on plot & 0.609 & 79.19 \\
\hline & Public tap in less than $100 \mathrm{~m}$ & -1.112 & 7.79 \\
\hline & Public tap in $100-200 \mathrm{~m}$ & -1.299 & 3.77 \\
\hline & Public tap in more than $200 \mathrm{~m}$ & -1.425 & 2.97 \\
\hline & Other water source in less than $100 \mathrm{~m}$ & -1.502 & 1.90 \\
\hline & Other water source in $100-200 \mathrm{~m}$ & -1.720 & 1.69 \\
\hline & Other water source in more than $200 \mathrm{~m}$ & -1.808 & 2.68 \\
\hline \multirow[t]{2}{*}{ Connected to sewage system } & Yes - Flush toilet in/outside house & 1.050 & 64.42 \\
\hline & 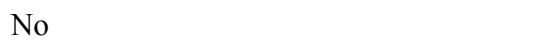 & -1.186 & 35.58 \\
\hline \multirow[t]{2}{*}{ Access to electricity } & Yes & 0.251 & 85.27 \\
\hline & No & -1.149 & 14.73 \\
\hline \multirow[t]{2}{*}{ Rubbish gets removed at least once a week } & Yes & 1.087 & 63.31 \\
\hline & No & -1.118 & 36.69 \\
\hline \multirow[t]{3}{*}{ Public street lighting in area of residence } & Yes - Currently in working condition & 1.097 & 51.77 \\
\hline & Yes - Not currently in working condition & 0.756 & 6.36 \\
\hline & No & -0.908 & 41.87 \\
\hline \multirow[t]{3}{*}{ Geographical subtype } & Urban & 0.992 & 68.35 \\
\hline & Traditional & -1.385 & 26.56 \\
\hline & Farms & -0.298 & 5.09 \\
\hline \multirow[t]{9}{*}{ Province } & Western Cape & 1.375 & 10.90 \\
\hline & Eastern Cape & -0.617 & 11.60 \\
\hline & Northern Cape & 0.609 & 2.64 \\
\hline & Free State & 1.074 & 5.65 \\
\hline & KwaZulu-Natal & -1.011 & 16.76 \\
\hline & North West & -0.190 & 5.51 \\
\hline & Gauteng & 1.182 & 30.30 \\
\hline & Mpumalanga & -0.135 & 8.15 \\
\hline & Limpopo & -1.098 & 8.48 \\
\hline District dummies have been added. & & & \\
\hline
\end{tabular}

Table C.2 Checking for multicollinearity: Correlation matrix

\begin{tabular}{lccccc}
\hline \hline & $\mathrm{H}_{\text {it }}$ & $\mathrm{F}_{\text {it }}$ & $\mathrm{P}_{\text {it }}$ & $\mathrm{S}_{\text {it }}$ & $\mathrm{G}_{\text {it }}$ \\
\hline Human capital index $\left(\mathrm{H}_{\text {it }}\right)$ & 1.0000 & & & & \\
Financial capital index $\left(\mathrm{F}_{\text {it }}\right)$ & 0.1863 & 1.0000 & & & \\
Physical capital index $\left(\mathrm{P}_{\mathrm{it}}\right)$ & 0.1064 & 0.3802 & 1.0000 & & \\
Social capital index $\left(\mathrm{S}_{\mathrm{it}}\right)$ & 0.1857 & 0.1105 & 0.2932 & 1.0000 & \\
Geographic capital index $\left(\mathrm{G}_{\text {it }}\right)$ & 0.3017 & 0.2343 & 0.4646 & 0.2456 & \multirow{2}{*}{1.0000} \\
\hline \hline
\end{tabular}

Table C.3 Checking for multicollinearity: Variance inflation factor (VIF)

\begin{tabular}{|c|c|c|c|c|c|c|c|c|}
\hline \multirow{2}{*}{$\begin{array}{l}\text { Dependent variable: } \\
\text { Log HH expenditure in adult equivalences }\end{array}$} & \multicolumn{2}{|c|}{2008} & \multicolumn{2}{|c|}{ 2010/11 } & \multicolumn{2}{|c|}{2012} & \multicolumn{2}{|c|}{$2014 / 15$} \\
\hline & VIF & $1 / \mathrm{VIF}$ & VIF & $1 / \mathrm{VIF}$ & VIF & $1 / \mathrm{VIF}$ & VIF & $1 / \mathrm{VIF}$ \\
\hline Human capital index $\left(\mathrm{H}_{\mathrm{it}}\right)$ & 1.70 & 0.59 & 1.52 & 0.66 & 1.42 & 0.70 & 1.41 & 0.71 \\
\hline Financial capital index $\left(\mathrm{F}_{\mathrm{it}}\right)$ & 1.47 & 0.68 & 1.43 & 0.70 & 1.39 & 0.72 & 1.35 & 0.74 \\
\hline Physical capital index $\left(\mathrm{P}_{\mathrm{it}}\right)$ & 1.28 & 0.78 & 1.16 & 0.86 & 1.15 & 0.87 & 1.21 & 0.82 \\
\hline Social capital index $\left(\mathrm{S}_{\mathrm{it}}\right)$ & 1.23 & 0.82 & 1.14 & 0.87 & 1.13 & 0.89 & 1.18 & 0.84 \\
\hline Geographic capital index $\left(G_{i t}\right)$ & 1.13 & 0.89 & 1.13 & 0.89 & 1.12 & 0.89 & 1.11 & 0.90 \\
\hline Average & 1.36 & & 1.28 & & 1.24 & & 1.25 & \\
\hline
\end{tabular}

Note: Tolerance, defined as $1 / \mathrm{VIF}$, is used to check on the degree of collinearity. A tolerance value lower than 0.1 suggests that the variable could be considered as a linear combination of other independent variables. 
Table C.4 Parametric regression: Average marginal effects

\begin{tabular}{|c|c|c|c|c|c|}
\hline & 2008 & 2010/11 & 2012 & $2014 / 15$ & Panel \\
\hline \multicolumn{6}{|l|}{ Mean } \\
\hline $\begin{array}{l}\text { Log household expenditure } \\
\text { per adult equivalent }\left(\ln \left(c_{i t}\right)\right)\end{array}$ & $\begin{array}{c}7.001 * * * \\
(0.045)\end{array}$ & $\begin{array}{c}6.813 * * * \\
(0.051)\end{array}$ & $\begin{array}{r}6.916^{* * *} \\
(0.041)\end{array}$ & $\begin{array}{c}7.075^{* * *} \\
(0.036)\end{array}$ & $\begin{array}{c}6.959 * * * \\
(0.029)\end{array}$ \\
\hline \multicolumn{6}{|l|}{ Effect } \\
\hline Human capital index $\left(\mathrm{H}_{\mathrm{it}}\right)$ & $\begin{array}{c}1.265 * * * \\
(0.057)\end{array}$ & $\begin{array}{c}1.311 * * * \\
(0.062)\end{array}$ & $\begin{array}{c}1.439 * * * \\
(0.053)\end{array}$ & $\begin{array}{l}1.472 * * * \\
(0.045)\end{array}$ & $\begin{array}{c}1.337 * * * \\
(0.033)\end{array}$ \\
\hline Financial capital index $\left(\mathrm{F}_{\mathrm{it}}\right)$ & $\begin{array}{c}1.557 * * * \\
(0.093)\end{array}$ & $\begin{array}{c}1.666^{* * *} \\
(0.112)\end{array}$ & $\begin{array}{c}1.214 * * * \\
(0.082)\end{array}$ & $\begin{array}{c}1.058 * * * \\
(0.065)\end{array}$ & $\begin{array}{c}1.239 * * * \\
(0.043)\end{array}$ \\
\hline Physical capital index $\left(\mathrm{P}_{\mathrm{it}}\right)$ & $\begin{array}{c}2.113^{* * *} \\
(0.087)\end{array}$ & $\begin{array}{c}1.587 * * * \\
(0.089)\end{array}$ & $\begin{array}{c}2.039 * * * \\
(0.072)\end{array}$ & $\begin{array}{c}2.016^{* * *} \\
(0.067)\end{array}$ & $\begin{array}{c}1.811^{* * *} \\
(0.048)\end{array}$ \\
\hline Social capital index $\left(S_{i t}\right)$ & $\begin{array}{l}0.104^{*} \\
(0.062)\end{array}$ & $\begin{array}{c}0.251^{* * *} \\
(0.081)\end{array}$ & $\begin{array}{c}0.209^{* * *} \\
(0.067)\end{array}$ & $\begin{array}{c}0.219^{* * *} \\
(0.064)\end{array}$ & $\begin{array}{c}0.231 * * * \\
(0.044)\end{array}$ \\
\hline Geographic capital index $\left(G_{i t}\right)$ & $\begin{array}{c}0.553 * * * \\
(0.058)\end{array}$ & $\begin{array}{c}0.499 * * * \\
(0.061)\end{array}$ & $\begin{array}{c}0.659 * * * \\
(0.053)\end{array}$ & $\begin{array}{c}0.639 * * * \\
(0.045)\end{array}$ & $\begin{array}{c}0.646^{* * *} \\
(0.039)\end{array}$ \\
\hline \multicolumn{6}{|l|}{ Time fixed effects } \\
\hline $2010 / 11$ & & & & & $\begin{array}{c}-0.137 * * * \\
(0.016)\end{array}$ \\
\hline 2012 & & & & & $\begin{array}{c}-0.147 * * * \\
(0.015)\end{array}$ \\
\hline $2014 / 15$ & & & & & $\begin{array}{c}-0.080 * * * \\
(0.015)\end{array}$ \\
\hline Observations & 7,277 & 6,765 & 8,025 & 9,610 & 31,677 \\
\hline R-squared & 0.6092 & 0.4597 & 0.5304 & 0.5153 & 0.5308 \\
\hline Within & & & & & 0.1058 \\
\hline Between & & & & & 0.5927 \\
\hline
\end{tabular}

Standard errors (adjusted for 400 survey clusters) in parentheses.

$* * * \mathrm{p}<0.01, * * \mathrm{p}<0.05, * \mathrm{p}<0.1$

Table C.5 Non-parametric regression: Average marginal effects

\begin{tabular}{lcccc}
\hline \hline & 2008 & $2010 / 11$ & 2012 & $2014 / 15$ \\
\hline Mean & & & & \\
Log household expenditure & $7.040^{* * *}$ & $6.845^{* * *}$ & $6.990^{* * *}$ & $7.117^{* * *}$ \\
per adult equivalent $\left(\ln \left(c_{\mathrm{it}}\right)\right)$ & $(0.012)$ & $(0.015)$ & $(0.012)$ & $(0.011)$ \\
\hline Effect & & & & \\
Human capital index $\left(\mathrm{H}_{\mathrm{it}}\right)$ & $1.352^{* * *}$ & $1.328^{* * *}$ & $1.493^{* * *}$ & $1.471^{* * *}$ \\
& $(0.051)$ & $(0.056)$ & $(0.046)$ & $(0.045)$ \\
Financial capital index $\left(\mathrm{F}_{\mathrm{it}}\right)$ & $1.347^{* * *}$ & $1.475^{* * *}$ & $1.135^{* * *}$ & $1.032^{* * *}$ \\
& $(0.062)$ & $(0.084)$ & $(0.064)$ & $(0.058)$ \\
Physical capital index $\left(\mathrm{P}_{\mathrm{it}}\right)$ & $2.319^{* * *}$ & $1.708^{* * *}$ & $2.060^{* * *}$ & $1.988^{* * *}$ \\
& $(0.063)$ & $(0.073)$ & $(0.063)$ & $(0.057)$ \\
Social capital index $\left(\mathrm{S}_{\mathrm{it}}\right)$ & $0.131^{* *}$ & $0.249^{* * *}$ & $0.338^{* * *}$ & $0.195^{* * *}$ \\
& $(0.038)$ & $(0.081)$ & $(0.057)$ & $(0.045)$ \\
Geographic capital index $\left(\mathrm{G}_{\mathrm{it}}\right)$ & $0.464 * * *$ & $0.439^{* * *}$ & $0.595^{* * *}$ & $0.650^{* * *}$ \\
& $(0.056)$ & $(0.040)$ & $(0.039)$ & $(0.033)$ \\
\hline Observations & 7,277 & 6,765 & 8,025 & 9,610 \\
R-squared & 0.6436 & 0.4973 & 0.5451 & 0.5340 \\
Bootstrapped standard errors $(100$ replications) in parentheses. & & \\
$* * * \mathrm{p}<0.01, * * \mathrm{p}<0.05, * \mathrm{p}<0.1$ & & & & \\
\hline \hline
\end{tabular}




\section{C.2. Sample selection}

\section{a) Formal versus informal settlements}

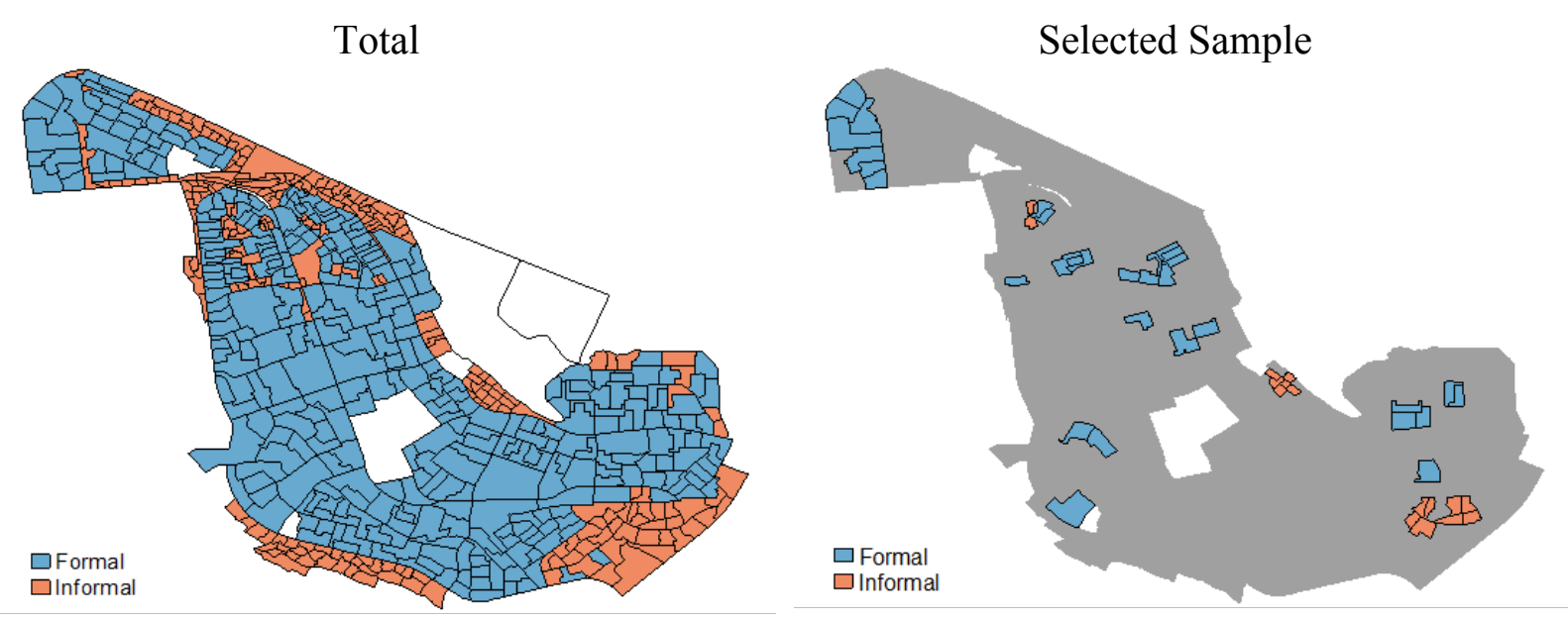

b) Poverty status based on approximated mean per capita income

Total

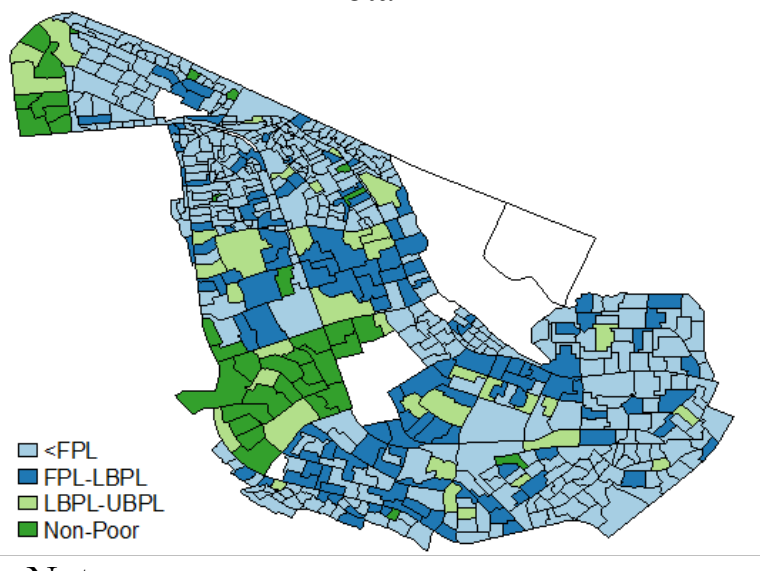

Selected Sample

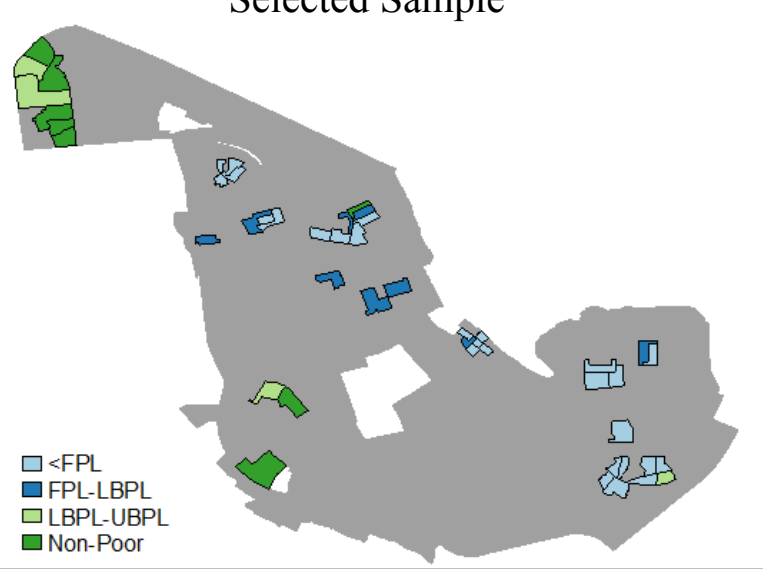

Note:

c) Share of households with household head in employment

Total

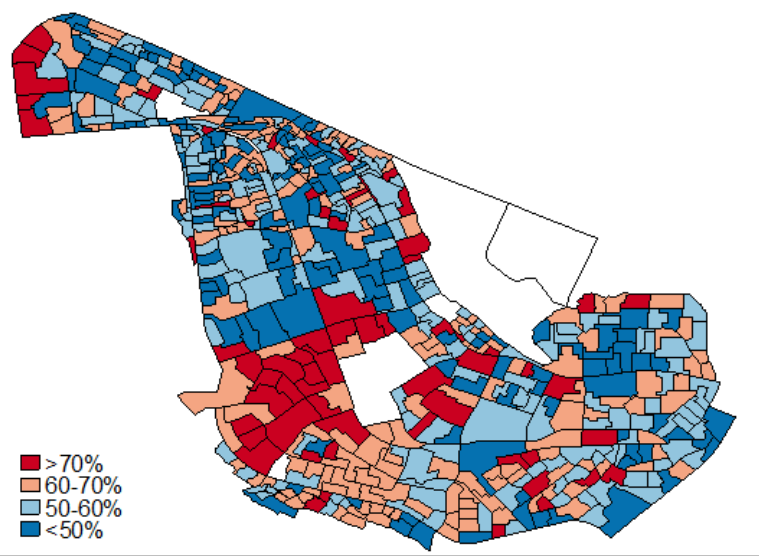

Selected Sample

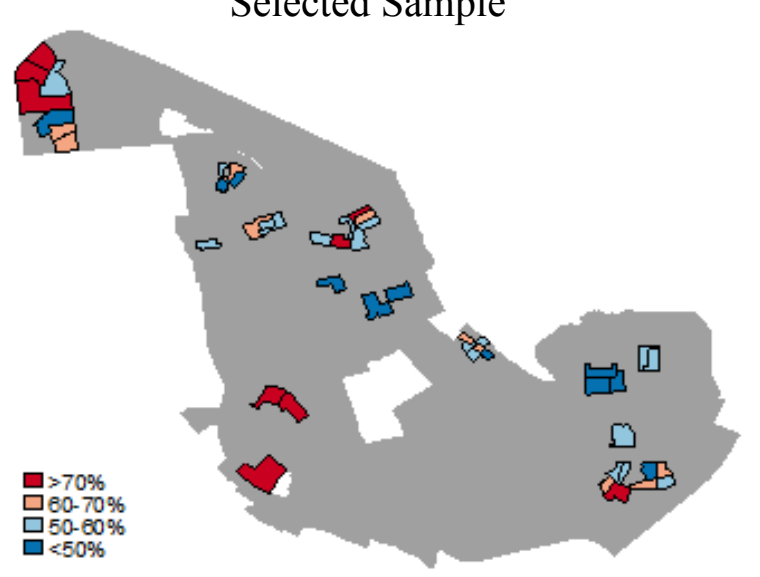


d) Formal settlements: Share of households living in backyard shack

Total

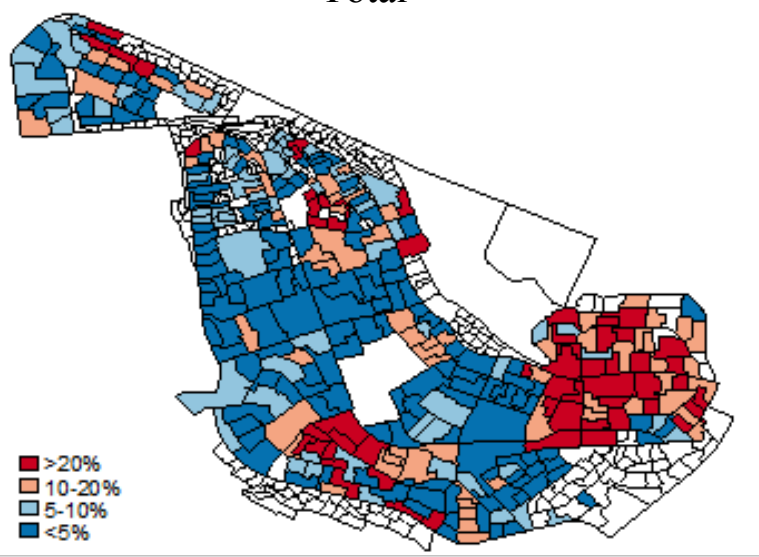

Selected Sample

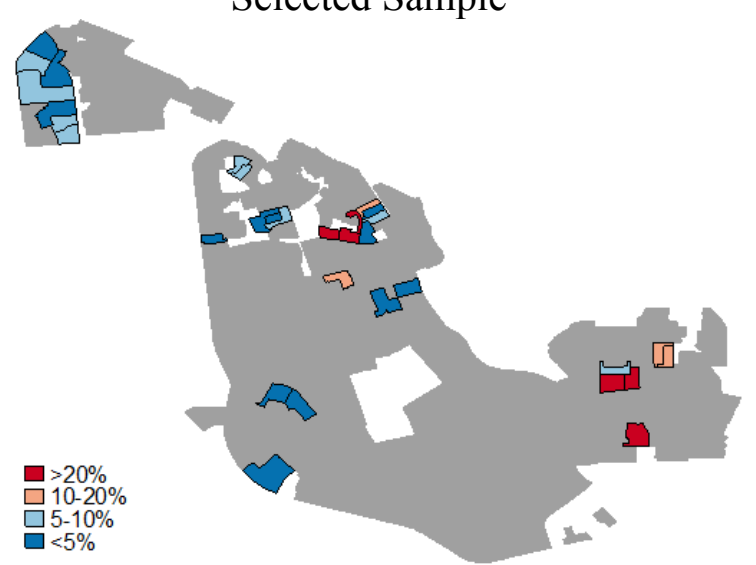

e) Informal settlements: Share of households without access to toilet facility (flush, chemical, or pit toilet)

Total

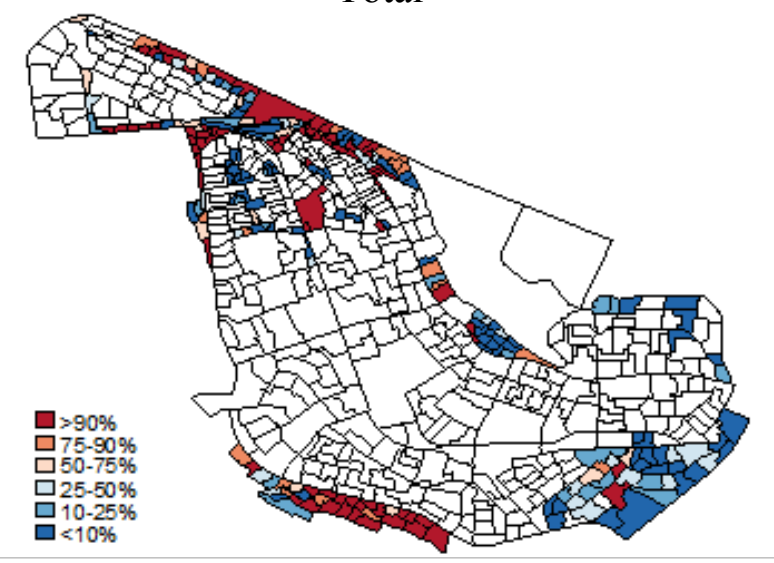

Selected Sample

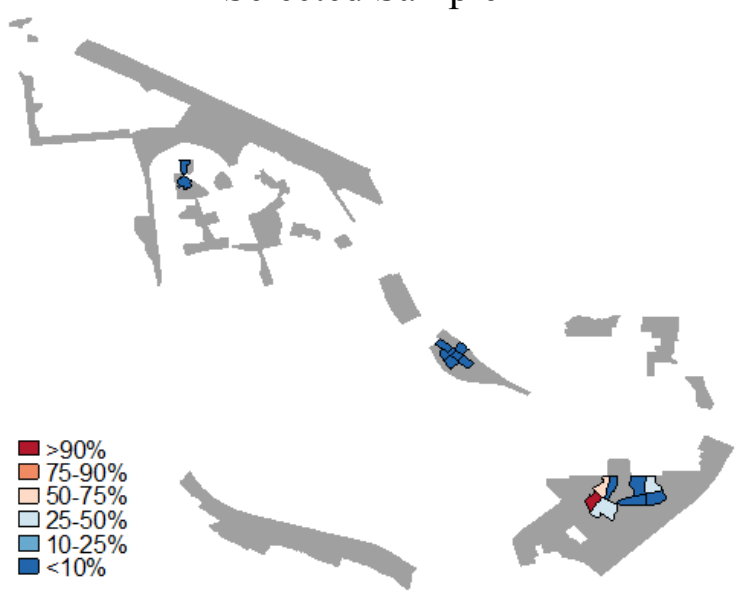

f) Share of households that moved to location after 2001

Total

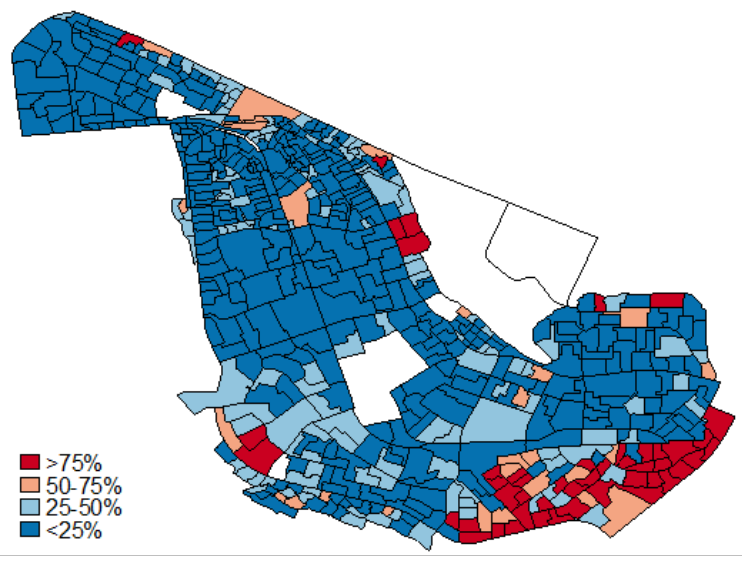

Selected Sample

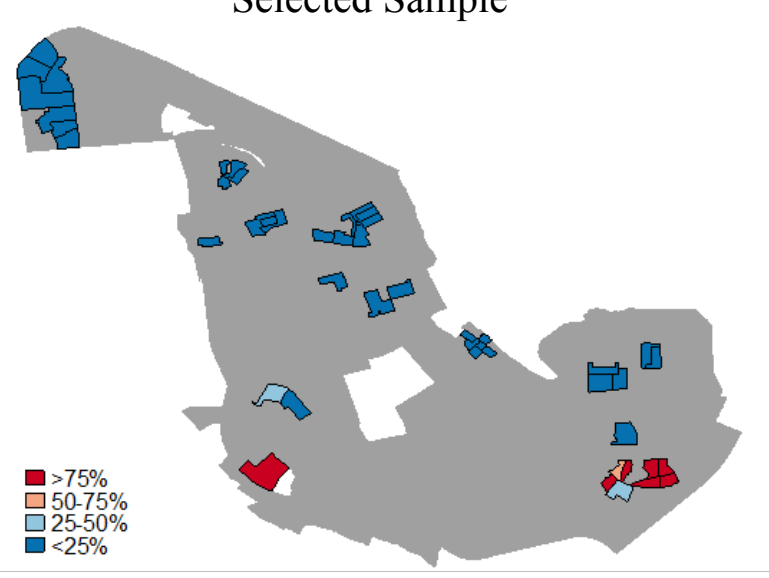

Figure C.1 Sample selection 


\title{
C.3. Life-history examples
}

\author{
Box C.1 Survivalist entrepreneur
}

Lindelwa was born in 1959 in the Eastern Cape. It was a poor home, and there were no animals in the kraal. After the birth of her younger sister, the parents separated and in 1965 her mother moved to Cape Town, where she started working as a domestic worker. The children stayed behind and were living at other people's houses. At the age of 9, Lindelwa moved in with her aunt, who sent her to school. Two years later, she was staying at her teacher's house. After school, she had to work in the household until late at night. At age 13, she moved back in with her aunt; she was doing housework and dropped out of school (grade 6). In 1976 she got married, but in 1985, by the time the second child was born, she and her husband separated, and her former husband cut off all financial support for her and her children. By that time, she started to teach herself how to sew, using a machine that her mother had bought long time back. Her mother would send material from Cape Town, and in 1987 Lindelwa moved to Cape Town herself. When her sewing business was not going well, she started selling grilled intestines to support herself.

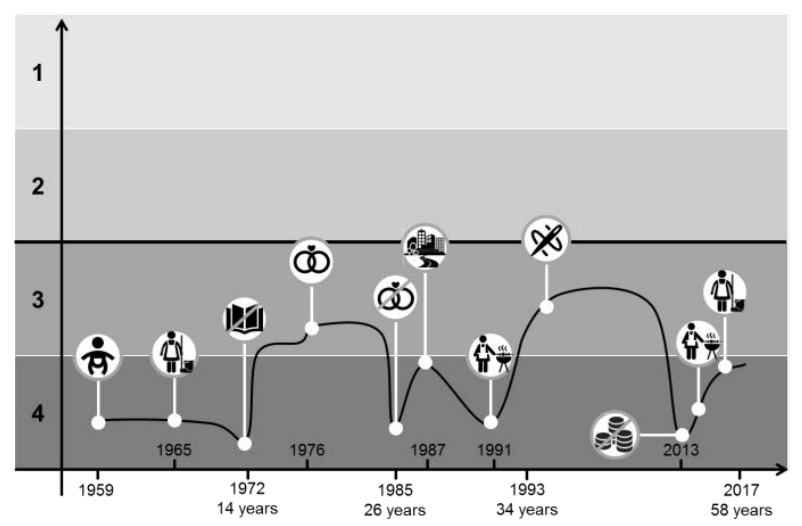

In 1993 she started sewing for various churches, and this way had regular orders. However, in 2011, she got an order from her own church, and different to her usual business practice, she did not ask for an advance payment. She bought the material using her own money and sewed five church attires worth R1750 (approx. 130 USD) in total, but never received the money. After this, her business went down and collapsed in 2013. Now, she is again supporting herself selling intestines in the street, but the business is very weather dependent. One of her children is doing piece jobs as a domestic worker, and the other one is unemployed.

Figure C.2 Lindelwa's life history

\section{Box C.2 Escape from poverty during working life and re-impoverishment at old age}

Mcingini was born in 1948 in the Eastern Cape. He grew up with both his parents and seven siblings in a simple stone house in the mountains. They had a kraal, but the number of cattle fluctuated as a result of droughts and veterinary infections. At the age of 17, he left school (grade 8) and moved to Cape Town in search of work. He found a job as a fisher and was sending money home. The contract ended after six months, and he started moving from one temporary job to the next working in different low-skilled occupations. In 1969 he got a job as a driver at a factory; he says he taught himself how to drive. He worked there for almost 20 years. During this time, he got married, and his wife opened a crèche at their home, such that there were two incomes. In 1988 Mcingini fell sick and had to leave his job and move back to the Eastern Cape.

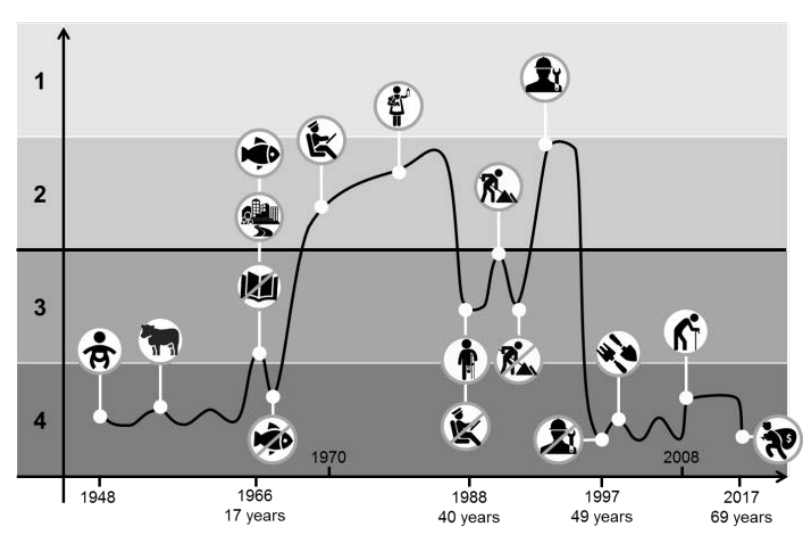

Figure C.3 Mcingini’s life history
He was supported by his older brother for three years, until he got better and moved back to Cape Town. He then was working at a construction site for a year. The contract ended, and after another short period of unemployment, he found a job as a mechanic. In 1997 he lost this job. After that, he was only able to find piece work as a gardener but retired from this in 2006 because he would get no more jobs (people told him he was too old). Since 2008 he has been receiving the state old-age pension. His wife still works as a nanny, but the number of children has decreased as a result to the expansion of public crèches. In 2017, they were robbed at their house. 


\section{Box C.3 High stability from long-term employment and family networks}

Vivian is an elderly domestic worker living with her sister and niece in Makhaza, Khayelitsha. She was born in 1958 in a smaller town in the Western Cape, where she grew up with both parents and five siblings. Her father was working, and they were living in a formal house. They were not suffering at all when she grew up. At the age of 14 she became pregnant and dropped out of school (grade 5). In 1975 when her child was 2 years old, she moved to Cape Town, leaving the child with her family. She started working as a domestic worker. After three years, she switched jobs and started working for a couple, for whom she still works today. She has been working for this family for almost 40 years. They always treated her well, and her salary increased whenever the couple got a pay rise. Vivian's household has experienced several traumatic deaths in the last 20 years. Between 1997 and 1999, both her parents and her brother died in short succession. More recently two nephews were murdered, and her daughter died from sickness.

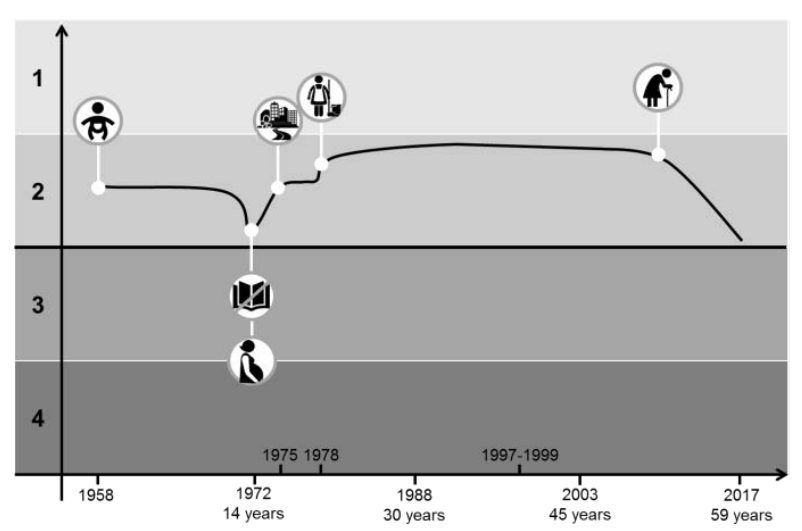

Several factors helped to maintain the household as financially stable: 1) Vivian is the breadwinner of the household, and her income was unaffected; 2) Membership of burial schemes minimised the immediate cost of funeral expenses; and 3), the extended family united in solidarity to ensure that costs were shared. However, things became difficult in the last years. For health reasons, Vivian now can only work three days a week and thus earns less. In addition, she is paying for the living expenses of her granddaughter, who is the first one in the family who is attending university (which makes Vivian very proud).

Figure C.4 Vivian's life history 


\section{APPENDIX D}

\section{D.1. Comparison between SASAS and NIDS data}

Table D.1 Descriptive statistics in SASAS vs. NIDS, 2012

\begin{tabular}{|c|c|c|c|}
\hline & NIDS & SASAS & Difference \\
\hline \multicolumn{4}{|l|}{ Gender } \\
\hline Male & 47.8 & 47.5 & -0.3 \\
\hline Female & 52.2 & 52.5 & 0.3 \\
\hline \multicolumn{4}{|l|}{ Geographical subtype } \\
\hline Urban & 63.0 & 66.0 & 3.1 \\
\hline Rural & 37.1 & 34.0 & -3.1 \\
\hline \multicolumn{4}{|l|}{ Ethnicity } \\
\hline Black African & 76.8 & 73.4 & -3.4 \\
\hline Coloured & 9.5 & 11.1 & 1.6 \\
\hline Indian Or Asian & 2.9 & 3.5 & 0.7 \\
\hline White & 10.8 & 12.0 & 1.2 \\
\hline \multicolumn{4}{|l|}{ Provinces } \\
\hline Western Cape & 11.7 & 12.0 & 0.4 \\
\hline Eastern Cape & 11.8 & 12.0 & 0.1 \\
\hline Northern Cape & 2.5 & 2.2 & -0.4 \\
\hline Free State & 5.6 & 4.9 & -0.6 \\
\hline KwaZulu-Natal & 19.4 & 19.5 & 0.1 \\
\hline North West & 5.3 & 6.6 & 1.3 \\
\hline Gauteng & 26.4 & 25.1 & -1.3 \\
\hline Mpumalanga & 8.5 & 7.7 & -0.7 \\
\hline Limpopo & 8.9 & 10.0 & 1.1 \\
\hline \multicolumn{4}{|l|}{ Age groups } \\
\hline $16-19$ years & 12.5 & 8.9 & -3.6 \\
\hline $20-29$ years & 27.7 & 21.7 & -6.1 \\
\hline $30-39$ years & 21.4 & 19.0 & -2.4 \\
\hline $40-49$ years & 15.9 & 18.0 & 2.1 \\
\hline $50-59$ years & 11.3 & 14.7 & 3.3 \\
\hline $60-69$ years & 7.0 & 10.8 & 3.9 \\
\hline $70+$ years & 4.2 & 7.0 & 2.8 \\
\hline \multicolumn{4}{|l|}{ Assets } \\
\hline House, cluster, town house & 66.3 & 74.0 & 7.7 \\
\hline Tap water in house/on plot & 78.3 & 73.4 & -5.0 \\
\hline Flush toilet in/outside house & 61.1 & 61.1 & -0.1 \\
\hline TV set & 77.6 & 82.3 & 4.8 \\
\hline Electric stove & 73.8 & 77.1 & 3.3 \\
\hline Fridge/freezer combination & 69.7 & 76.7 & 7.0 \\
\hline DVD player/Blu-ray player & 44.7 & 65.9 & 21.2 \\
\hline Microwave oven (in working order) & 43.4 & 59.4 & 15.9 \\
\hline Washing machine & 33.3 & 40.5 & 7.2 \\
\hline Motor vehicle & 21.3 & 34.6 & 13.4 \\
\hline Subscription-based private satellite TV & 19.3 & 34.7 & 15.4 \\
\hline Computer (desktop or laptop) & 17.1 & 29.5 & 12.4 \\
\hline \multicolumn{4}{|l|}{ Asset index score } \\
\hline Mean & 0.50 & 0.56 & 0.06 \\
\hline Median & 0.49 & 0.58 & 0.08 \\
\hline \multicolumn{4}{|l|}{ Per capita household expenditure/income ${ }^{*}$} \\
\hline Mean & R 1,918 & R 2,002 & R 84 \\
\hline Median & R 800 & R 680 & R 120 \\
\hline
\end{tabular}

Note: Analysis based on SASAS 2012 Q1+Q2 and NIDS 2012, Wave 3.

*In NIDS, monthly per capita household expenditure is used as the relevant welfare measure. In the SASAS, expenditure is approximated using information on total household income by income bracket. I calculate the per capita value by dividing the median value of the income bracket by the number of household members. 


\section{D.2. Derivation of the Living Standards Measure (LSM)}

Index based on characteristics of the main dwelling the household occupies and the set of assets present in the household (in working order).

Table D.2 Variables included in and weights obtained from MCA analysis

\begin{tabular}{|c|c|c|c|}
\hline \multicolumn{2}{|c|}{ Variable } & \multirow{3}{*}{$\begin{array}{l}\text { Categories } \\
\text { House, cluster, townhouse } \\
\text { Other }\end{array}$} & \multirow{2}{*}{$\frac{\text { Weights }}{0.472}$} \\
\hline \multirow{6}{*}{ 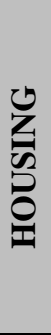 } & Dwelling Type & & \\
\hline & & & -0.978 \\
\hline & Water source & Tap water in house/on plot & 0.646 \\
\hline & & Other & -1.488 \\
\hline & Toilet facility & Flush toilet in/outside house & 0.953 \\
\hline & & Other & -1.089 \\
\hline \multirow{10}{*}{ ֻ } & TV set & Yes - Owns a TV set & 0.592 \\
\hline & & No & -1.907 \\
\hline & Electric stove & Yes - Owns an electric stove & 0.572 \\
\hline & & No & -1.803 \\
\hline & Fridge/freezer combination & Yes - Owns a fridge/freezer combination & 0.770 \\
\hline & & No & -1.720 \\
\hline & DVD player/Blu-ray player & Yes - Owns a DVD player/Blu-ray player & 1.096 \\
\hline & & No & -0.799 \\
\hline & Microwave oven & Yes - Owns a microwave oven & 1.463 \\
\hline & & No & -1.063 \\
\hline \multirow{10}{*}{ 茖 } & Washing machine & Yes - Owns a washing machine & 1.929 \\
\hline & & No & -0.719 \\
\hline & Motor vehicle & Yes - Owns a motor vehicle & 2.320 \\
\hline & & No & -0.411 \\
\hline & Subscription-based private satellite TV & Yes - Has a subscription-based private satellite TV & 2.051 \\
\hline & & No & -0.532 \\
\hline & Computer (desktop or laptop) & Yes - Owns a computer (desktop or laptop) & 2.288 \\
\hline & & No & -0.358 \\
\hline & Domestic worker (live-in/part-time) & Yes - Has a domestic worker (live-in/part-time) & 2.940 \\
\hline & & No & -0.127 \\
\hline
\end{tabular}

Note: Analysis based on NIDS 2012 (wave 3). 7,768 observations at the household level. 


\section{D.3. Description of value indicators}

1. Support for democracy: Answer to the question about which of the following three statements is closest to the respondent's own opinion.

a) Democracy is preferable to any other kind of government.

b) In some circumstances, a non-democratic government can be preferable.

c) For someone like me, it doesn't matter what kind of government we have.

2. Trust in public institutions: Index based on the extent of trust (scale 1-5) respondents have in the following public institutions in South Africa: (a) the national government, (b) the local government, (c) political parties, (d) courts, (e) the Independent Electoral Commission (IEC), (f) the parliament, (g) the police and (h) the defence force.

3. Satisfaction with provision of public infrastructure: Index based on how satisfied or dissatisfied (scale 1-5) respondents are with the way that the government is handling the following matters: (a) supplying water and sanitation; (b) providing electricity; and (c) ensuring affordable housing.

4. Satisfaction with provision of public services: Index based on how satisfied or dissatisfied (scale 1-5) respondents are with the way that the government is handling the following matters: (a) access to healthcare; (b) treatment for sexually transmitted infections (STIs) incl. HIV/AIDS; (c) social grants (such as child support grants, old-age pensions, etc.); and (d) education.

5. Voting: Degree of agreement or disagreement (scale 1-5) with the following statements [Note: (a), (b), and (d) recoded in reverse order such that higher values indicate more positive attitudes toward voting/democracy]:

a) Whether I vote or not makes no difference.

b) After being elected all parties are the same, so voting is pointless.

c) It is the duty of all citizens to vote.

d) Voting is meaningless because no politician can be trusted.

6. Support for fundamental freedoms: Degree of agreement or disagreement (scale 1-5) with the following statements.

6.1. Freedom of opinion: The government should have the authority to prevent citizens from criticising it. [Note: recoded in reverse order such that higher values indicate more liberal/democratic views.] 
6.2. Freedom of association: Citizens should have the right to form or join organisations freely, such as political parties, business associations, trade unions and other interest groups.

6.3. Freedom of the press and media: The government should be in control of what information is given to the public. [Note: recoded in reverse order such that higher values indicate more liberal/ democratic views.]

6.4. Freedom to protest: Mass action is an acceptable way for people to express their views in a democracy.

6.5. Combatting fraud and corruption: Politicians found guilty of bribery or corruption should resign from public office immediately.

7. Most important challenges: The three most important challenges facing South Africa today chosen from a list of 18 policy areas below [plus other (specify) and do not know]. I focus on the top seven challenges that at least 10 per cent of all respondents selected from the list.

Table D.3 Three most important challenges facing South Africa today

\begin{tabular}{|c|c|c|}
\hline & Policy Area & $\begin{array}{l}\text { Share of respondents who chose this } \\
\text { policy area among three most important } \\
\text { challenges }(\%)\end{array}$ \\
\hline 1) & Unemployment & 76.2 \\
\hline 2) & Crime and safety & 46.5 \\
\hline 3) & Poverty & 33.6 \\
\hline 4) & HIV/AIDS & 32.5 \\
\hline 5) & Corruption & 25.4 \\
\hline 6) & Service provision/delivery & 16.5 \\
\hline 7) & Education & 13.4 \\
\hline 8) & Affordable housing & 9.4 \\
\hline 9) & Economic and financial issues & 5.9 \\
\hline 10) & Xenophobia & 4.7 \\
\hline 11) & Racism & 4.4 \\
\hline 12) & Political issues & 4.4 \\
\hline 13) & Environmental issues & 3.0 \\
\hline 14) & Work-related issues & 3.0 \\
\hline 15) & Human rights & 2.8 \\
\hline 16) & Land reform issues & 2.4 \\
\hline 17) & Family and youth issues & 2.3 \\
\hline 18) & Religion and culture issues & 0.8 \\
\hline
\end{tabular}

Note: Analysis based on SASAS 2012 Q1+Q2. 


\section{D.4. Robustness check using monthly per capita household income instead of LSM to differentiate between poor, middle class, and elite}

Table D.4 Class division based on LSM vs. per capita income, 2012

\begin{tabular}{lccccc}
\hline \hline & Poor & Middle Class & Elite & Missing & TOTAL \\
\hline LSM & 45.49 & 46.39 & 8.12 &. & 100 \\
Per capita income & 54.12 & 41.65 & 4.23 &. & 100 \\
\hline LSM & 42.51 & 43.35 & 7.59 & 6.55 & 100 \\
Per capita income & 41.26 & 31.75 & 3.22 & 23.76 & 100 \\
\hline \hline
\end{tabular}

Note: Analysis based on SASAS 2012 Q1+Q2. The SASAS contains information on total household income by income bracket. I calculate the per capita value by dividing the median value of the income bracket by the number of household members.

Table D.5 Overlap of class divisions based on LSM vs. per capita income, 2012

\begin{tabular}{ll|ccccc}
\hline \hline & \multicolumn{4}{c}{ Per capita income } \\
& & Poor & Middle Class & Elite & Missing & TOTAL \\
\hline \multirow{2}{*}{$\sum_{\text {S }}$} & Poor & 61.07 & 25.74 & 0.06 & 13.13 & 100 \\
& Middle Class & 24.66 & 41.46 & 2.75 & 31.13 & 100 \\
& Elite & 0.12 & 27.6 & 26.39 & 45.89 & 100 \\
\hline \hline
\end{tabular}

Note: Analysis based on SASAS 2012 Q1+Q2.

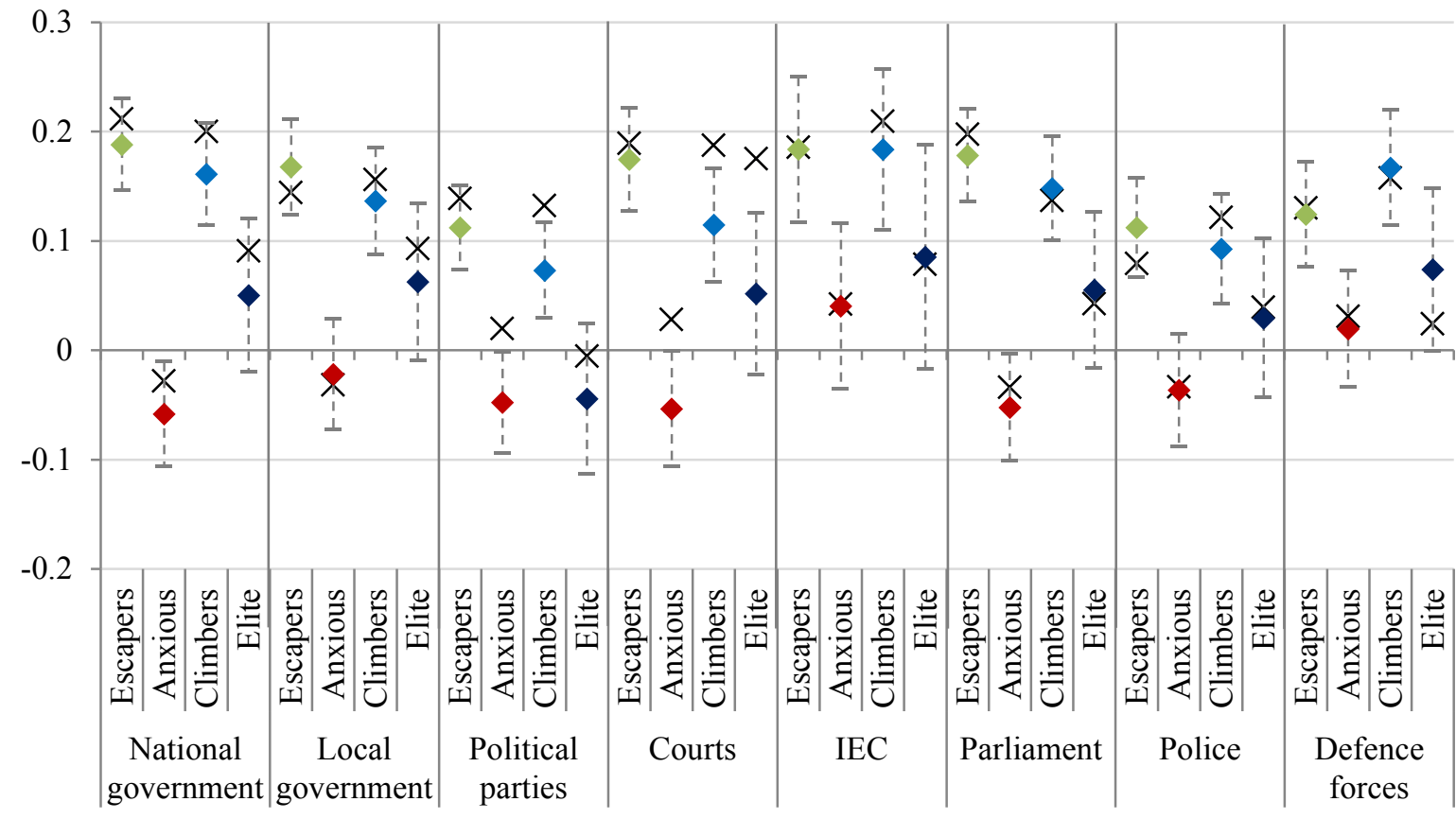

Figure D.1 Relationship between class and trust in public institutions

Note: Analysis based on SASAS 2012 Q1+Q2.Question on IEC was only included in Q1. Each point shows the estimated marginal effect of class membership in 2012, with "Persistently Poor" being the base category. The dashed lines show the 95 per cent confidence intervals. For comparative purposes, each $\times$ shows the estimated marginal effect of class membership when divisions are based in per capita income. 

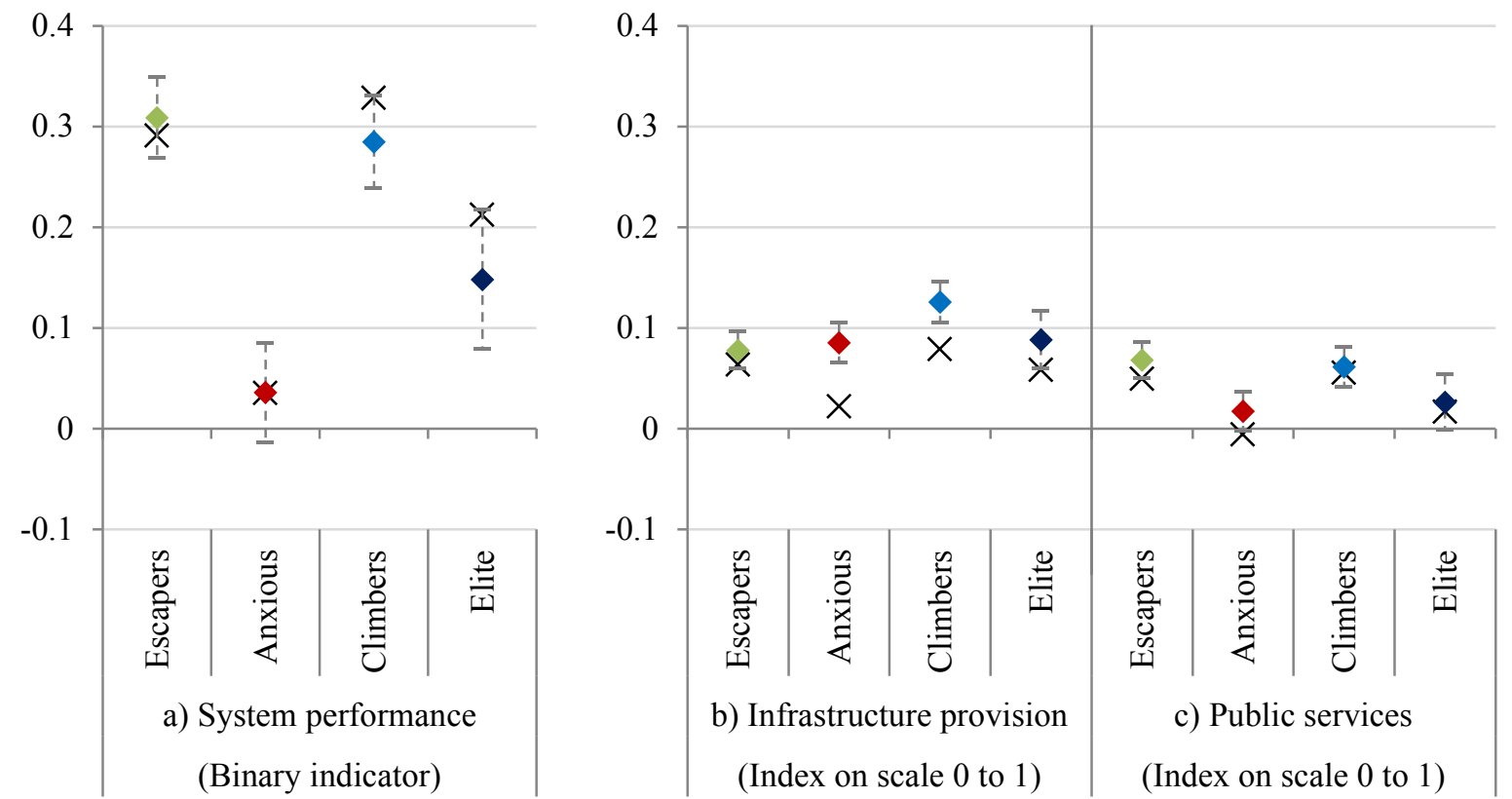

Figure D.2 Relationship between class and satisfaction with governmental performance

Note: Analysis based on SASAS 2012 Q1+Q2. Each point shows the estimated marginal effect of class membership in 2012, with "Persistently Poor" being the base category. The dashed lines show the 95 per cent confidence intervals. For comparative purposes, each $\times$ shows the estimated marginal effect of class membership when divisions are based in per capita income.

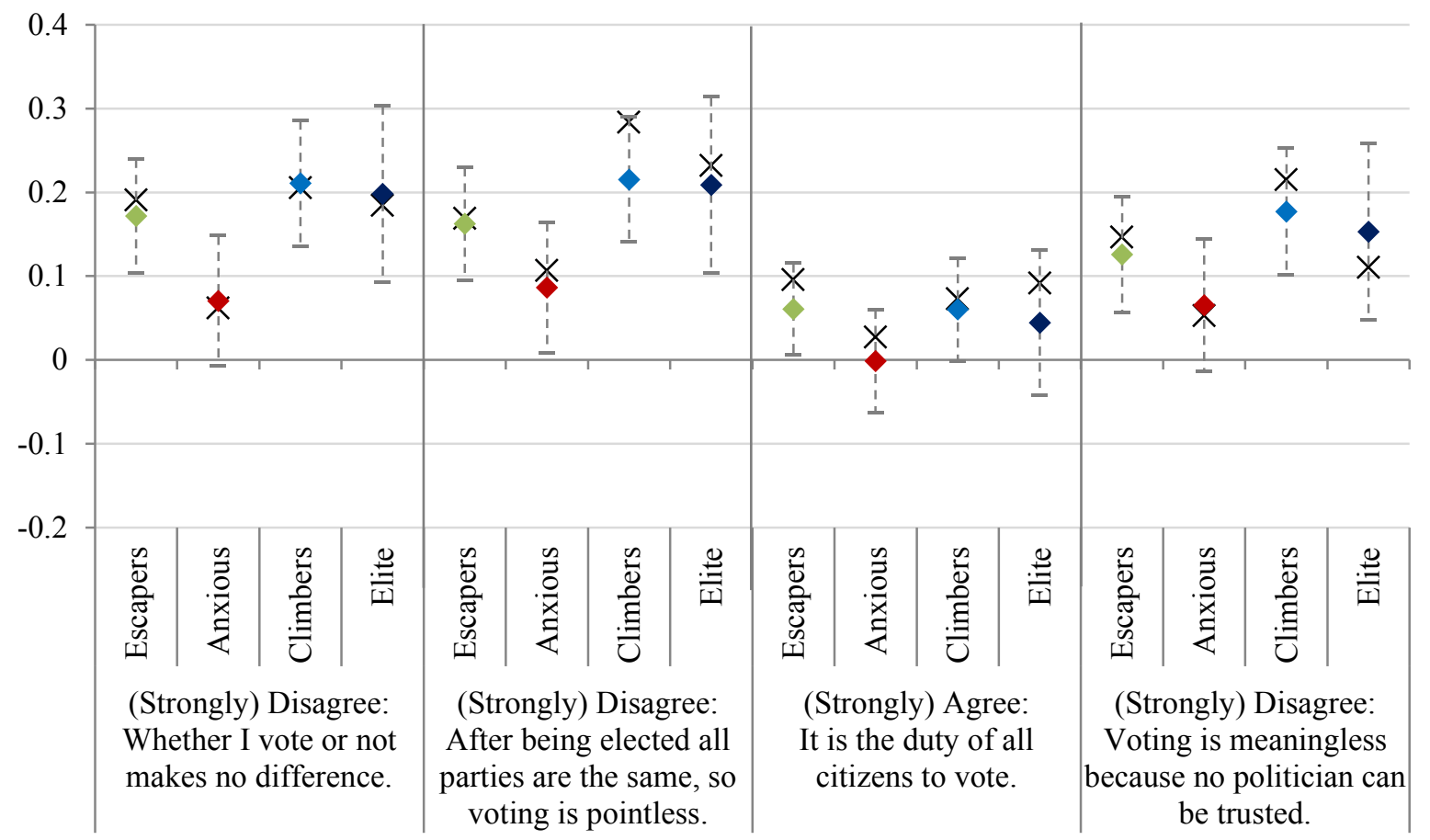

Figure D.3 Relationship between class and attitudes toward voting

Note: Analysis based on SASAS 2012 Q1. Each point shows the estimated marginal effect of class membership in 2012, with "Persistently Poor" being the base category. The dashed lines show the 95 per cent confidence intervals. For comparative purposes, each $\times$ shows the estimated marginal effect of class membership when divisions are based in per capita income. 


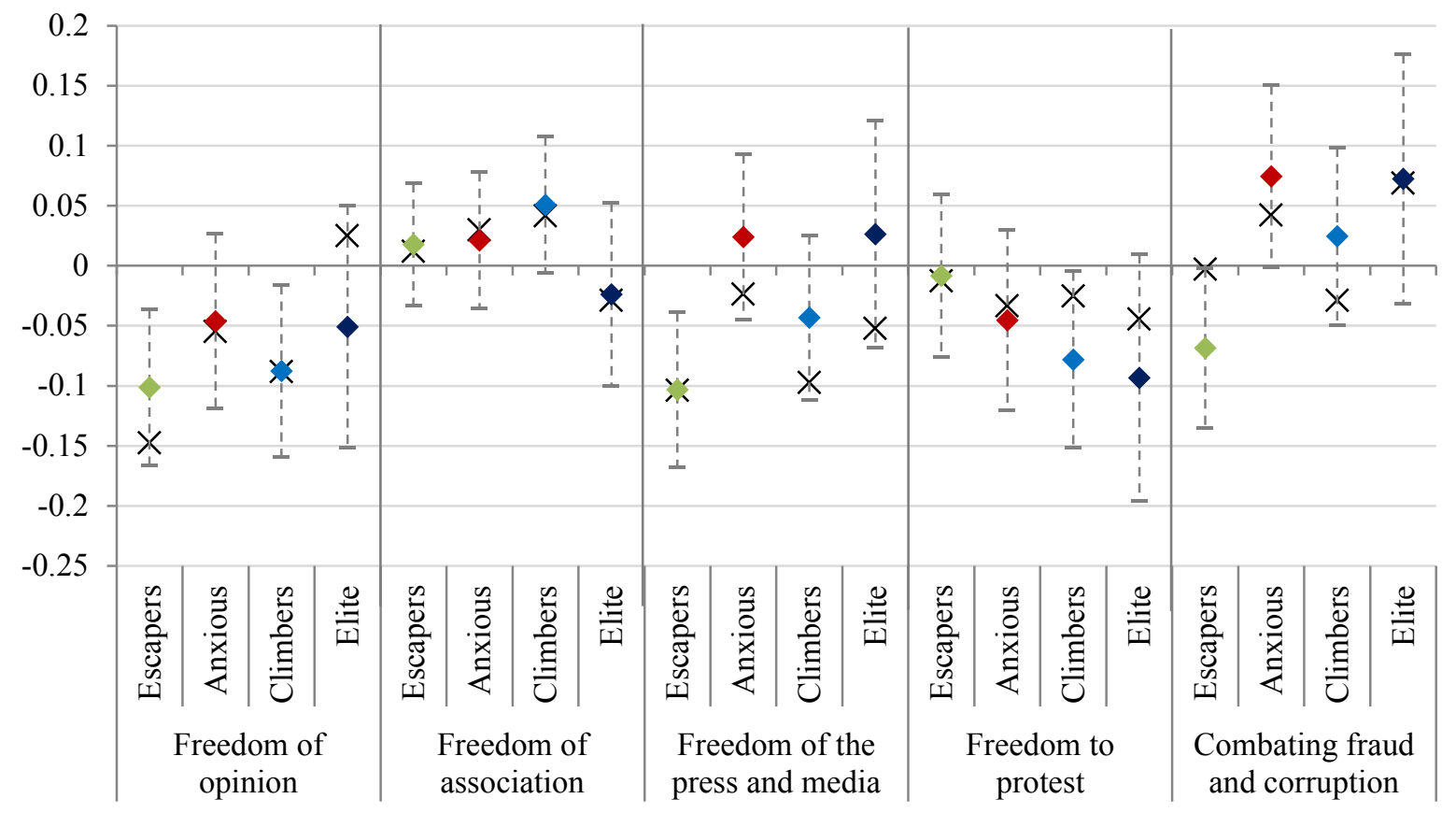

Figure D.4 Relationship between class and civic values

Note: Analysis based on SASAS 2012 Q1. Each point shows the estimated marginal effect of class membership in 2012, with "Persistently Poor" being the base category. The dashed lines show the 95 per cent confidence intervals. For comparative purposes, each $\times$ shows the estimated marginal effect of class membership when divisions are based in per capita income.

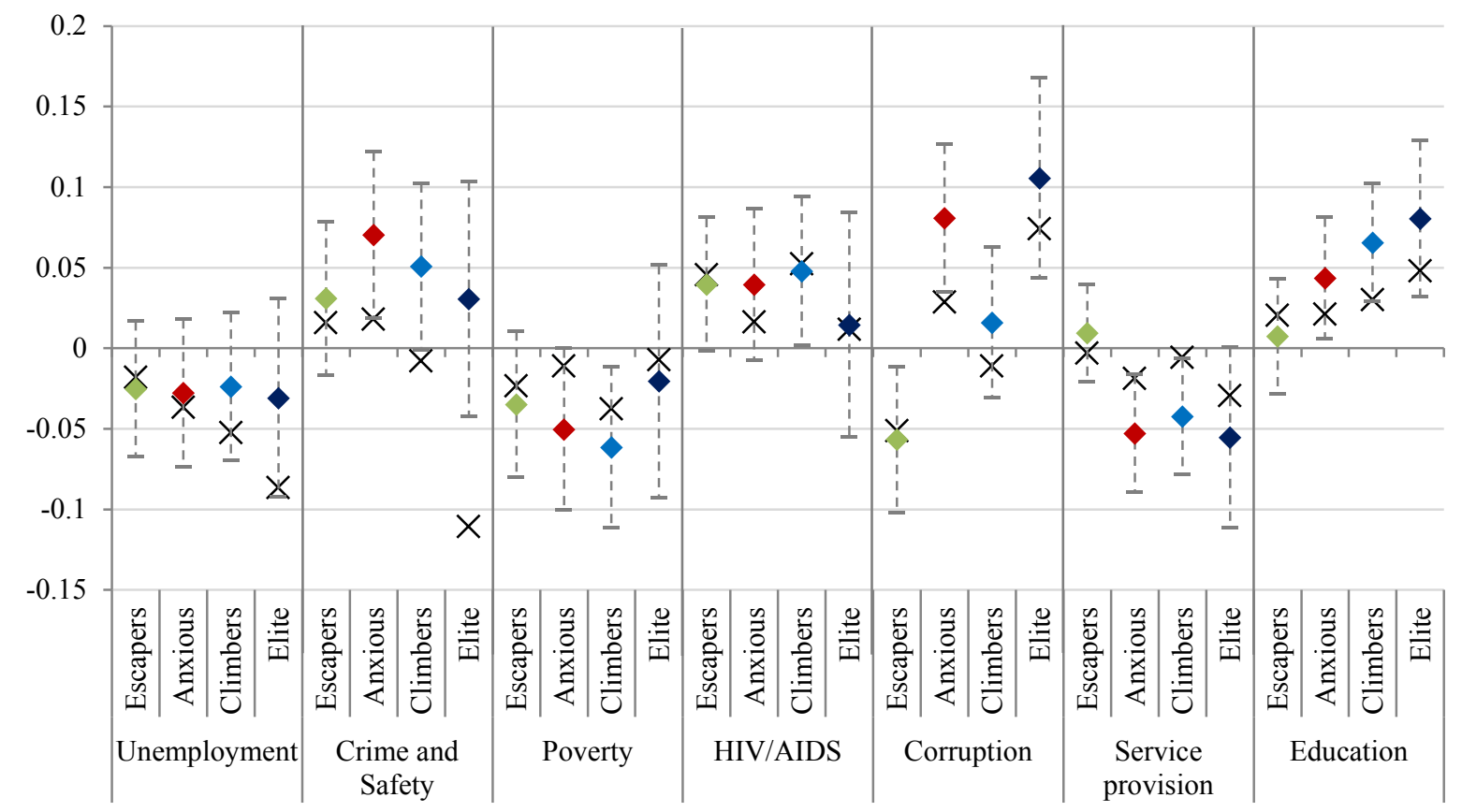

Figure D.5 Relationship between class and priorities for public policy

Note: Analysis based on SASAS 2012 Q1+Q2. Each point shows the estimated marginal effect of class membership in 2012, with "Persistently Poor" being the base category. The dashed lines show the 95 per cent confidence intervals. For comparative purposes, each $\times$ shows the estimated marginal effect of class membership when divisions are based in per capita income. 


\section{D.5. Robustness check using the 2006 SASAS wave}

Note: Jacob Zuma was elected as President of the ANC in the end of 2007 and became president of South Africa in May 2009 following the general election. For comparative purposes, I here contrast the regression results obtained using the 2012 SASAS wave (three years after the election of Zuma as president) to the ones obtained when the 2006 SASAS wave (three years before the election of Zuma as president) is used.

Table D.6 Descriptive class statistics, 2006 vs. 2012

\begin{tabular}{lccc}
\hline \hline & $\mathbf{2 0 0 6}$ & $\mathbf{2 0 1 2}$ & Difference \\
\hline Asset index score & & & \\
Mean & 0.43 & 0.56 & 0.13 \\
Median & 0.39 & 0.58 & 0.19 \\
\hline Class shares (\%) & & & \\
Persistently Poor & 28.6 & 21.2 & -7.4 \\
Escapers & 35.4 & 23.1 & -12.3 \\
Anxious & 15.0 & 24.1 & 9.1 \\
Climbers & 15.1 & 22.9 & 7.8 \\
Elite & 5.9 & 8.7 & 2.8 \\
\hline \hline
\end{tabular}

Note: Analysis based on SASAS 2006 Q1+Q2 and SASAS 2012 Q1+Q2.

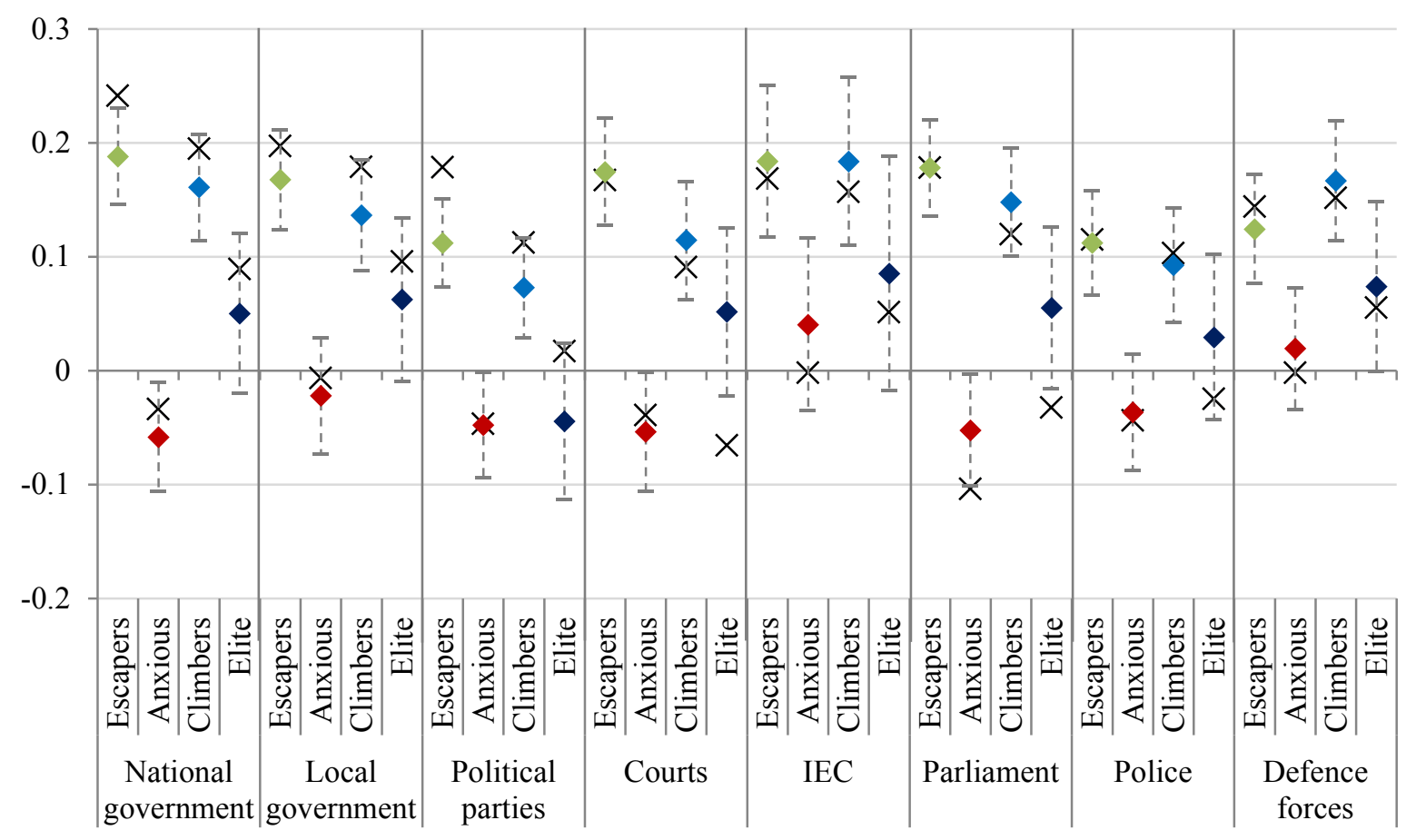

Figure D.6 Relationship between class and trust in public institutions

Note: Analysis based on SASAS 2006 Q1+Q2 and SASAS 2012 Q1+Q2. Question on IEC was only included in Q1. Each point shows the estimated marginal effect of class membership in 2012, with "Persistently Poor" being the base category. The dashed lines show the 95 per cent confidence intervals. For comparative purposes, each $\times$ shows the estimated marginal effect of class membership using the 2006 survey wave. 

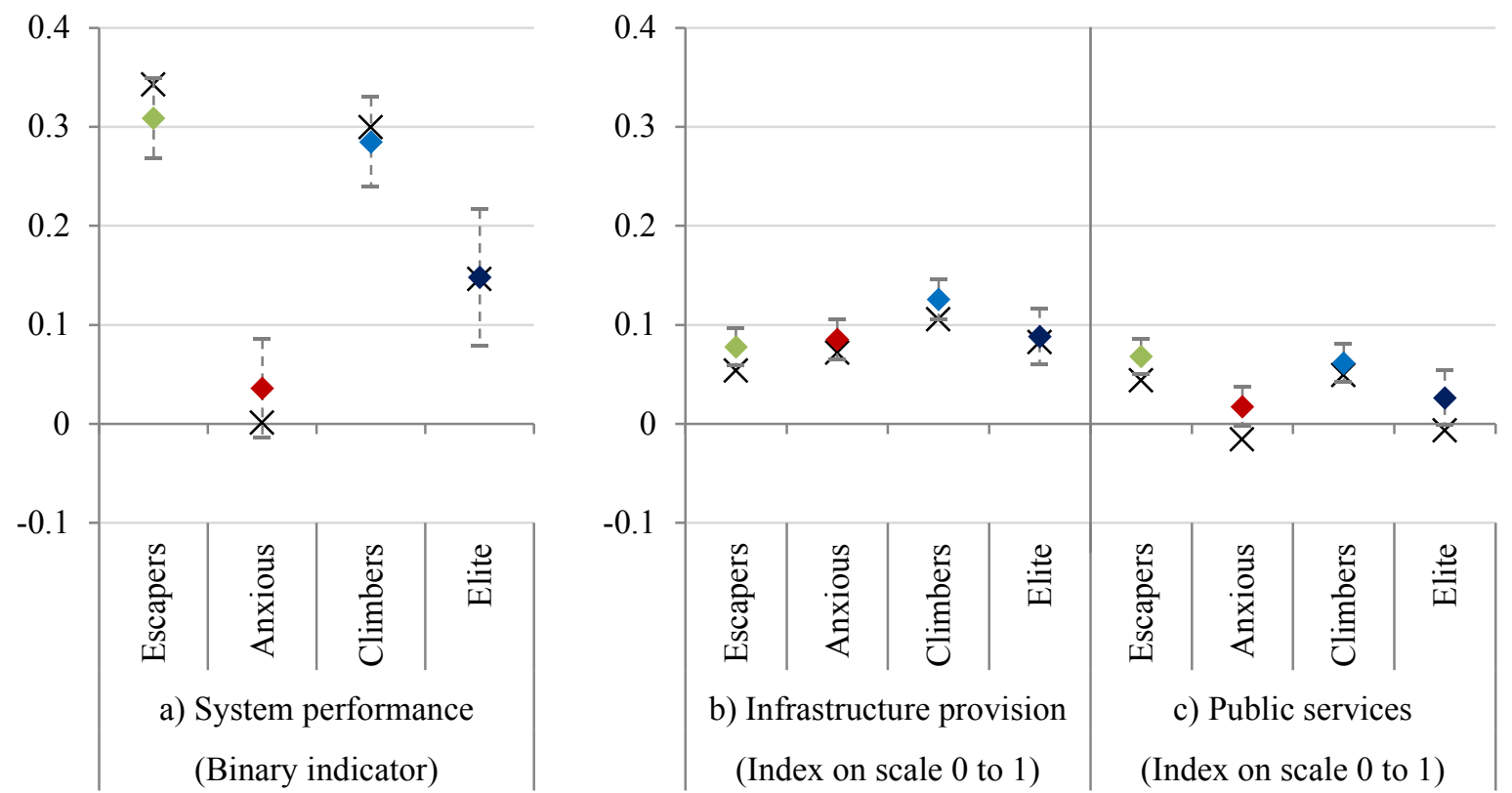

Figure D.7 Relationship between class and satisfaction with governmental performance

Note: Analysis based on SASAS 2006 Q1+Q2 and SASAS 2012 Q1+Q2. Each point shows the estimated marginal effect of class membership in 2012, with "Persistently Poor" being the base category. The dashed lines show the 95 per cent confidence intervals. For comparative purposes, each $\times$ shows the estimated marginal effect of class membership using the 2006 survey wave.

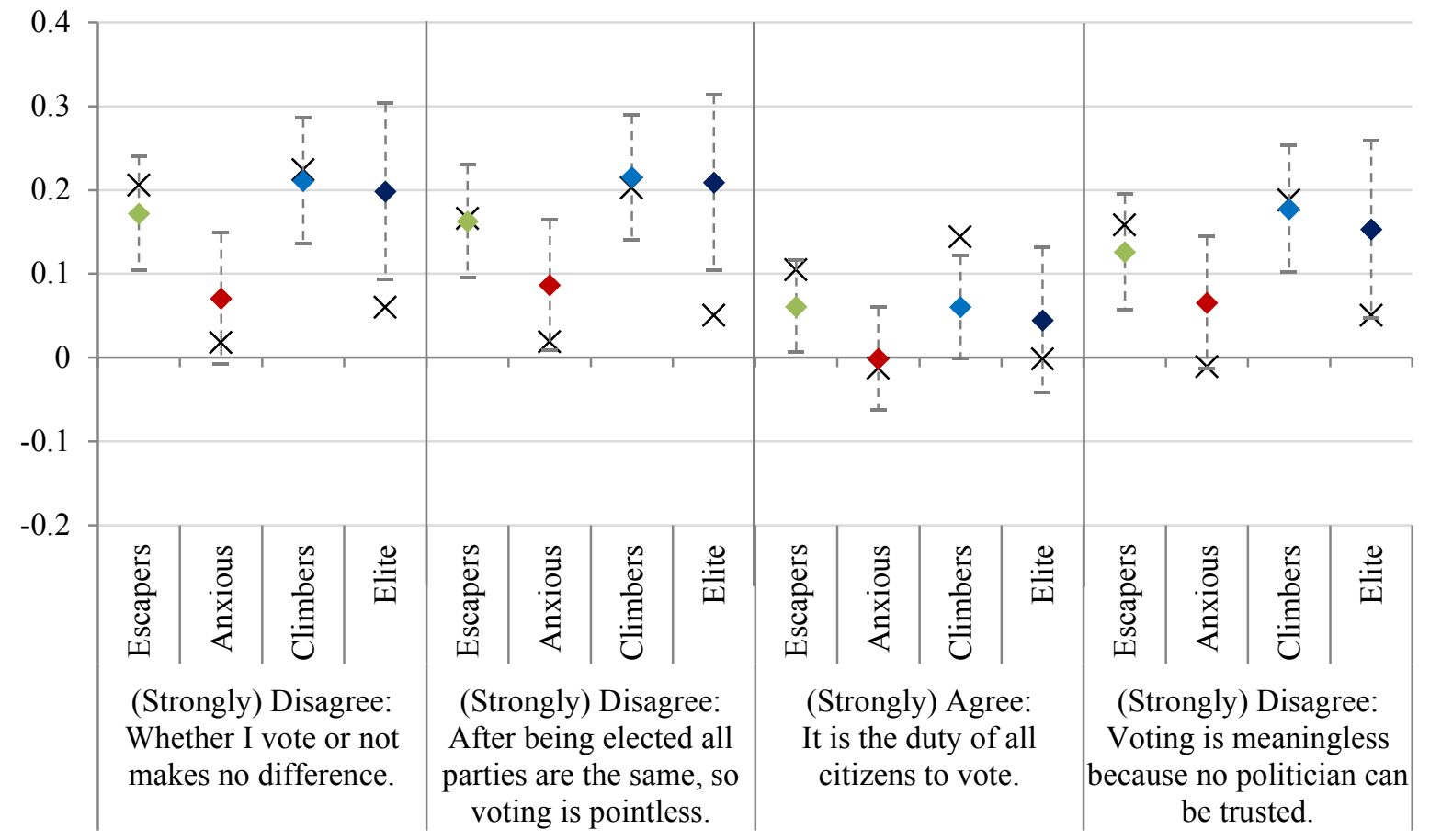

Figure D.8 Relationship between class and attitudes toward voting

Note: Analysis based on SASAS 2006 Q1 and SASAS 2012 Q1. Each point shows the estimated marginal effect of class membership in 2012, with "Persistently Poor" being the base category. The dashed lines show the 95 per cent confidence intervals. For comparative purposes, each $\times$ shows the estimated marginal effect of class membership using the 2006 survey wave. 


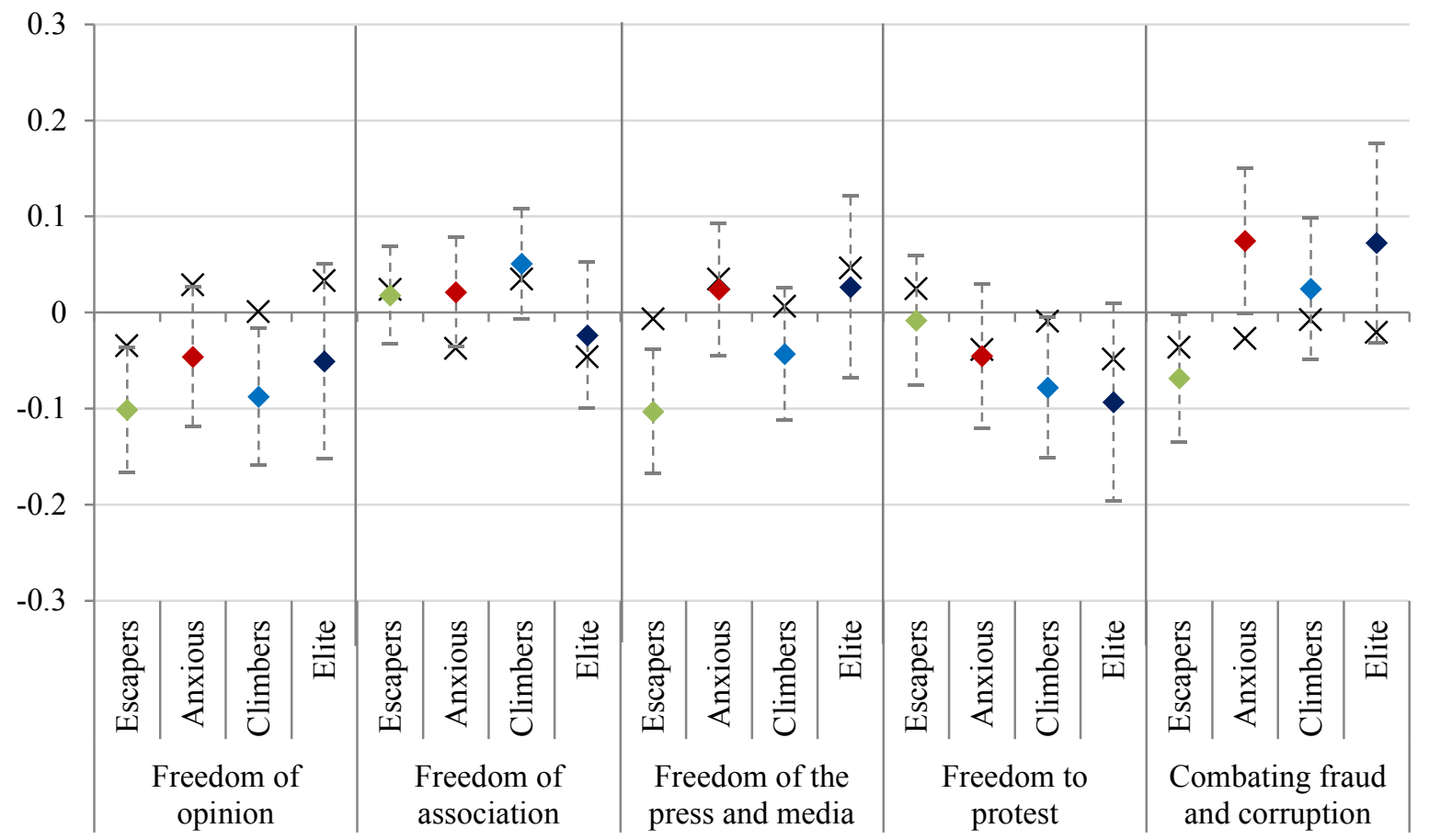

Figure D.9 Relationship between class and civic values

Note: Analysis based on SASAS 2006 Q1 and SASAS 2012 Q1. Each point shows the estimated marginal effect of class membership in 2012, with "Persistently Poor" being the base category. The dashed lines show the 95 per cent confidence intervals. For comparative purposes, each $\times$ shows the estimated marginal effect of class membership using the 2006 survey wave.

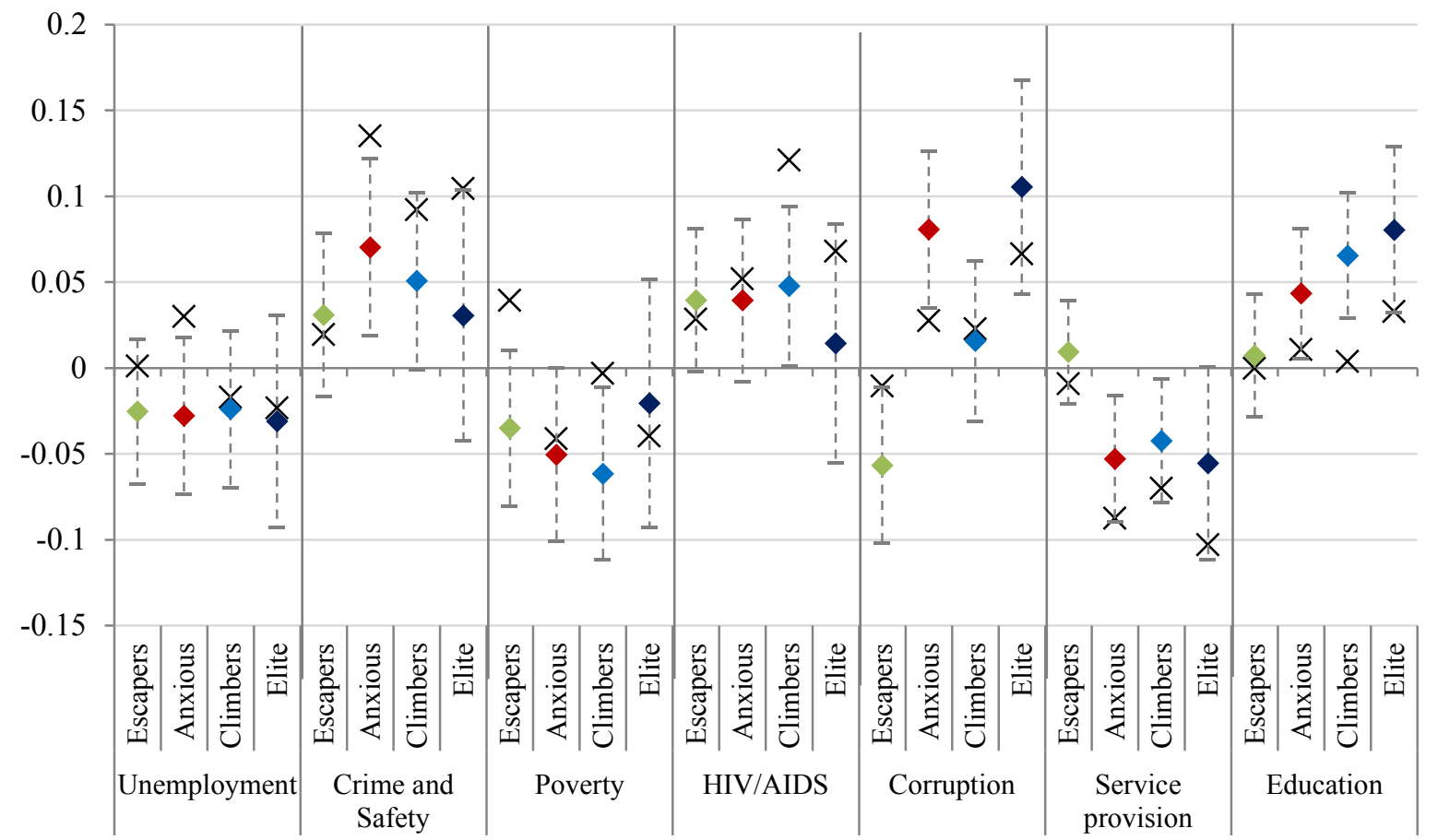

Figure D.10 Relationship between class and priorities for public policy

Note: Analysis based on SASAS 2006 Q1+Q2 and SASAS 2012 Q1+Q2.Each point shows the estimated marginal effect of class membership in 2012, with "Persistently Poor" being the base category. The dashed lines show the 95 per cent confidence intervals. For comparative purposes, each $\times$ shows the estimated marginal effect of class membership using the 2006 survey wave. 


\section{D.6. Regression tables, LSM-based class divisions, SASAS 2012}

Table D.7 Relationship between class and support for democracy

\begin{tabular}{|c|c|c|c|c|}
\hline Ordered PROBIT regression (coefficients) & $(1)$ & $(2)$ & (3) & (4) \\
\hline \multicolumn{5}{|l|}{ Class (Base: Persistently Poor) } \\
\hline Escapers & $\begin{array}{c}0.3521 * * * \\
(0.0830)\end{array}$ & $\begin{array}{c}0.3606 * * * \\
(0.0858)\end{array}$ & $\begin{array}{c}0.3430 * * * \\
(0.0845)\end{array}$ & $\begin{array}{c}0.3564 * * * \\
(0.0872)\end{array}$ \\
\hline Anxious & $\begin{array}{c}0.2322 * * \\
(0.0930)\end{array}$ & $\begin{array}{c}0.2225^{* *} \\
(0.0955)\end{array}$ & $\begin{array}{c}0.2431 * * \\
(0.0956)\end{array}$ & $\begin{array}{c}0.2299 * * \\
(0.0979)\end{array}$ \\
\hline Climbers & $\begin{array}{c}0.3204 * * * \\
(0.0907)\end{array}$ & $\begin{array}{c}0.3333 * * * \\
(0.0933)\end{array}$ & $\begin{array}{c}0.2996 * * * \\
(0.0936)\end{array}$ & $\begin{array}{c}0.3179 * * * \\
(0.0960)\end{array}$ \\
\hline Elite & $\begin{array}{c}0.3361 * * * \\
(0.1239)\end{array}$ & $\begin{array}{c}0.2684 * * \\
(0.1291)\end{array}$ & $\begin{array}{c}0.3205 * * \\
(0.1303)\end{array}$ & $\begin{array}{l}0.2547 * \\
(0.1347)\end{array}$ \\
\hline Tertiary Education & & $\begin{array}{c}0.2213 * * \\
(0.0905)\end{array}$ & & $\begin{array}{c}0.2258 * * \\
(0.0940)\end{array}$ \\
\hline \multicolumn{5}{|l|}{ Employment (Base: full-time) } \\
\hline Part-time or less & & & $\begin{array}{c}0.0597 \\
(0.1153)\end{array}$ & $\begin{array}{c}0.0731 \\
(0.1179)\end{array}$ \\
\hline Unemployed & & & $\begin{array}{c}-0.1857 * * \\
(0.0815)\end{array}$ & $\begin{array}{c}-0.1712 * * \\
(0.0832)\end{array}$ \\
\hline Inactive & & & $\begin{array}{l}-0.1391 \\
(0.0847)\end{array}$ & $\begin{array}{l}-0.1116 \\
(0.0873)\end{array}$ \\
\hline \multicolumn{5}{|l|}{ Race (Base: Black African) } \\
\hline Coloured & $\begin{array}{c}0.0434 \\
(0.0895)\end{array}$ & $\begin{array}{c}0.0786 \\
(0.0911)\end{array}$ & $\begin{array}{c}0.0442 \\
(0.0903)\end{array}$ & $\begin{array}{c}0.0819 \\
(0.0920)\end{array}$ \\
\hline Indian or Asian & $\begin{array}{l}-0.2069 * \\
(0.1179)\end{array}$ & $\begin{array}{l}-0.1881 \\
(0.1187)\end{array}$ & $\begin{array}{l}-0.2000 \\
(0.1219)\end{array}$ & $\begin{array}{l}-0.1851 \\
(0.1228)\end{array}$ \\
\hline White & $\begin{array}{c}0.2819 * * * \\
(0.1057)\end{array}$ & $\begin{array}{c}0.2645^{* *} \\
(0.1080)\end{array}$ & $\begin{array}{c}0.2817 * * \\
(0.1097)\end{array}$ & $\begin{array}{c}0.2661 * * \\
(0.1119)\end{array}$ \\
\hline Demographic controls $^{\text {a }}$ & YES & YES & YES & YES \\
\hline Geographical sub-type fixed effects ${ }^{b}$ & YES & YES & YES & YES \\
\hline Province fixed effects ${ }^{c}$ & YES & YES & YES & YES \\
\hline Observations & 1,917 & 1,844 & 1,847 & 1,779 \\
\hline R-squared & 0.0293 & 0.0306 & 0.0302 & 0.0322 \\
\hline $\begin{array}{l}\text { Standard errors in parentheses } \\
* * * \mathrm{p}<0.01, * * \mathrm{p}<0.05, * \mathrm{p}<0.1\end{array}$ & & & & \\
\hline
\end{tabular}

Note: Analysis based on SASAS 2012 Q1.

Estimated constant effects at cut-off values have been omitted from the regression table.

${ }^{a}$ Demographic controls include respondent's age in completed years, age squared, and gender.

${ }^{\mathrm{b}}$ Geographical sub-type fixed effects cover four types (urban formal, urban informal, tribal, and rural formal).

' Province fixed effects cover South Africa's nine provinces. 
Table D.8 Determinants of the relationship between class and support for democracy

\begin{tabular}{|c|c|c|c|}
\hline Ordered PROBIT regression (coefficients) & $(1)$ & $(2)$ & (3) \\
\hline \multicolumn{4}{|l|}{ Indicators of social class } \\
\hline LSM & $\begin{array}{c}1.1516 * * * \\
(0.3973)\end{array}$ & $\begin{array}{c}1.0770 * * * \\
(0.4110)\end{array}$ & $\begin{array}{c}1.0298 * * \\
(0.4129)\end{array}$ \\
\hline LSM squared & $\begin{array}{l}-0.7003 * \\
(0.3737)\end{array}$ & $\begin{array}{l}-0.6353 * \\
(0.3858)\end{array}$ & $\begin{array}{l}-0.6472 * \\
(0.3870)\end{array}$ \\
\hline Upward social mobility & & $\begin{array}{c}0.1840 * * * \\
(0.0598)\end{array}$ & $\begin{array}{c}0.1355^{* *} \\
(0.0619)\end{array}$ \\
\hline Life satisfaction & & & $\begin{array}{c}0.1838^{* * * *} \\
(0.0631)\end{array}$ \\
\hline Tertiary Education & $\begin{array}{l}0.1781 * \\
(0.0922)\end{array}$ & $\begin{array}{c}0.1982 * * \\
(0.0957)\end{array}$ & $\begin{array}{c}0.1901 * * \\
(0.0958)\end{array}$ \\
\hline \multicolumn{4}{|l|}{ Employment (base: full-time) } \\
\hline Part-time or less & $\begin{array}{c}0.0612 \\
(0.1141)\end{array}$ & $\begin{array}{c}0.0854 \\
(0.1184)\end{array}$ & $\begin{array}{c}0.0995 \\
(0.1188)\end{array}$ \\
\hline Unemployed & $\begin{array}{c}-0.1722 * * \\
(0.0813)\end{array}$ & $\begin{array}{l}-0.1648 * \\
(0.0842)\end{array}$ & $\begin{array}{l}-0.1387 \\
(0.0851)\end{array}$ \\
\hline Inactive & $\begin{array}{l}-0.1147 \\
(0.0846)\end{array}$ & $\begin{array}{l}-0.1121 \\
(0.0875)\end{array}$ & $\begin{array}{l}-0.1085 \\
(0.0876)\end{array}$ \\
\hline \multicolumn{4}{|l|}{ Race (base: Black African) } \\
\hline Coloured & $\begin{array}{c}0.0324 \\
(0.0890)\end{array}$ & $\begin{array}{c}0.0786 \\
(0.0929)\end{array}$ & $\begin{array}{c}0.0449 \\
(0.0936)\end{array}$ \\
\hline Indian or Asian & $\begin{array}{l}-0.1914 \\
(0.1205)\end{array}$ & $\begin{array}{l}-0.1980 \\
(0.1260)\end{array}$ & $\begin{array}{l}-0.2166^{*} \\
(0.1264)\end{array}$ \\
\hline White & $\begin{array}{c}0.2268^{* *} \\
(0.1117)\end{array}$ & $\begin{array}{c}0.2625^{* *} \\
(0.1167)\end{array}$ & $\begin{array}{c}0.2396^{* *} \\
(0.1172)\end{array}$ \\
\hline Demographic controls & YES & YES & YES \\
\hline Geographical sub-type fixed effects & YES & YES & YES \\
\hline Province fixed effects & YES & YES & YES \\
\hline Observations & 1,896 & 1,774 & 1,768 \\
\hline R-squared & 0.0278 & 0.0341 & 0.0358 \\
\hline
\end{tabular}

Standard errors in parentheses

$* * * \mathrm{p}<0.01, * * \mathrm{p}<0.05, * \mathrm{p}<0.1$

Note: Analysis based on SASAS 2012 Q1.

Estimated constant effects at cut-off values have been omitted from the regression table. 
Table D.9 Robustness check for the relationship between class and support for democracy

Multinomial PROBIT regression (average marginal effect)

Base: Democracy is preferable For someone like me, it doesn't matter to any other kind of what kind of government we have

In some circumstances, a non-democratic to any other
government

(2)

(3)

(1)

(2)

(3)

Measures of social class

LSM

LSM squared

Upward social mobility

Life satisfaction

Tertiary Education
Employment (base: full-tim
Part-time or less
Unemployed
Inactive
Race (base: Black African)
Coloured
Indian or Asian
White

$$
\begin{array}{cccccc}
-0.3886 * * * & -0.3614 * * * & -0.3478 * * & 0.0223 & 0.0343 & 0.0409 \\
(0.1361) & (0.1390) & (0.1394) & (0.1370) & (0.1418) & (0.1423) \\
0.2350^{*} & 0.2110 & 0.2128 & -0.0074 & -0.0121 & -0.0114 \\
(0.1310) & (0.1339) & (0.1339) & (0.1271) & (0.1312) & (0.1315) \\
& -0.0644 * * * & -0.0525 * * & & -0.0017 & 0.0409 \\
& (0.0207) & (0.0214) & & (0.0202) & (0.1423) \\
& & -0.0423 * & & & -0.0321 \\
& & (0.0218) & & & (0.0214)
\end{array}
$$

\begin{tabular}{|c|c|c|c|c|c|c|}
\hline Demographic controls & YES & YES & YES & YES & YES & YES \\
\hline Geographical sub-type fixed eff. & YES & YES & YES & YES & YES & YES \\
\hline Province fixed effects & YES & YES & YES & YES & YES & YES \\
\hline Observations & 1,896 & 1,774 & 1,768 & 1.896 & 1.774 & 1,768 \\
\hline
\end{tabular}

$$
\begin{array}{cccccc}
-0.0778 * * & -0.0836 * * & -0.0816 * * & 0.0124 & 0.0048 & 0.0057 \\
(0.0349) & (0.0362) & (0.0361) & (0.0302) & (0.0313) & (0.0313) \\
& & & & & \\
-0.0013 & -0.0058 & -0.0084 & -0.0228 & -0.0287 & -0.0331 \\
(0.0399) & (0.0411) & (0.0411) & (0.0394) & (0.0408) & (0.0410) \\
0.0355 & 0.0365 & 0.0304 & 0.0446 & 0.0350 & 0.0299 \\
(0.0286) & (0.0293) & (0.0295) & (0.0276) & (0.0286) & (0.0289) \\
0.0277 & 0.0300 & 0.0291 & 0.0253 & 0.0219 & 0.0208 \\
(0.0300) & (0.0308) & (0.0307) & (0.0286) & (0.0295) & (0.0296)
\end{array}
$$

$\begin{array}{llllll}-0.0333 & -0.0438 & -0.0367 & 0.0408 & 0.0307 & 0.0364\end{array}$ $\begin{array}{llllll}(0.0306) & (0.0316) & (0.0317) & (0.0307) & (0.0320) & (0.0322)\end{array}$

$\begin{array}{llllll}0.0297 & 0.0290 & 0.0328 & 0.0740 * & 0.0750 * & 0.0801 *\end{array}$

$\begin{array}{llllll}(0.0444) & (0.0461) & (0.0460) & (0.0394) & (0.0411) & (0.0413)\end{array}$

$\begin{array}{llllll}-0.1534 * * * & -0.1662 * * * & -0.1601 * * * & 0.0984 * * * & 0.0949 * * & 0.1000 * * *\end{array}$

$\begin{array}{lllllll}(0.0424) & (0.0443) & (0.0442) & (0.0367) & (0.0383) & (0.0385)\end{array}$

Standard errors in parentheses

$* * * \mathrm{p}<0.01, * * \mathrm{p}<0.05, * \mathrm{p}<0.1$

Note: Analysis based on SASAS 2012 Q1. 


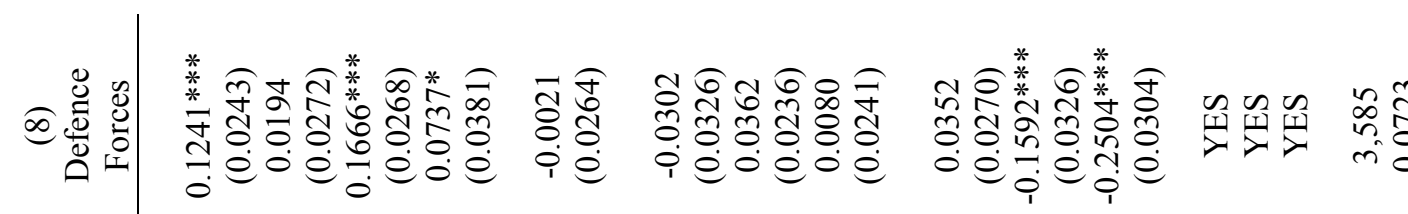

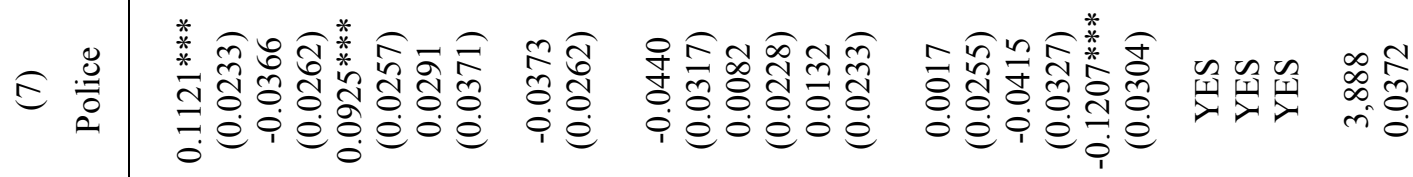

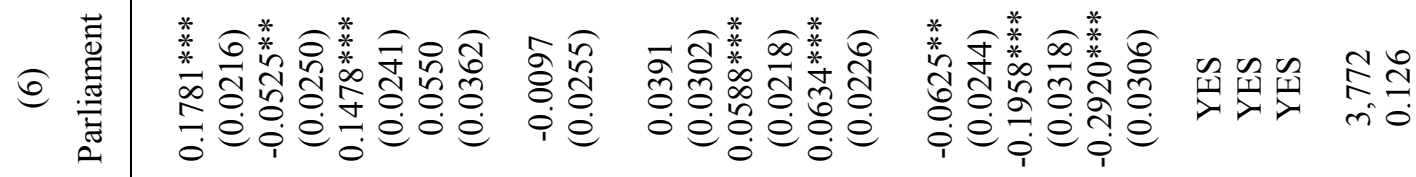

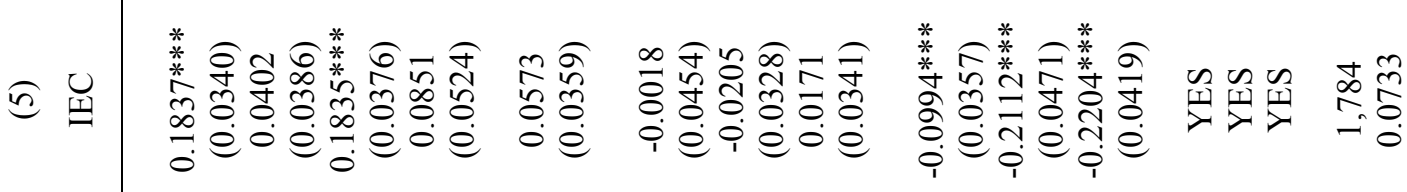

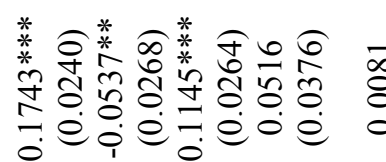

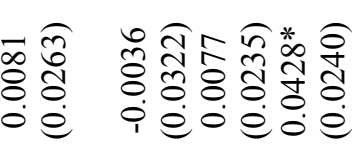

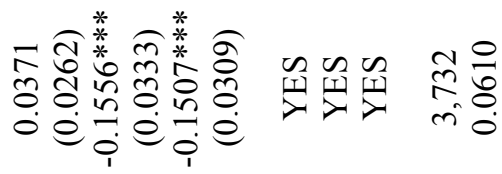

ล):

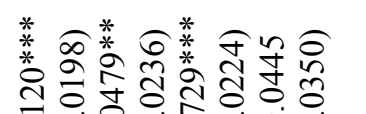

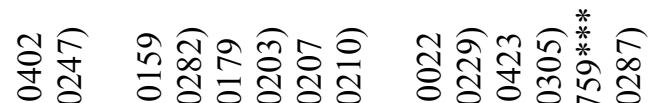

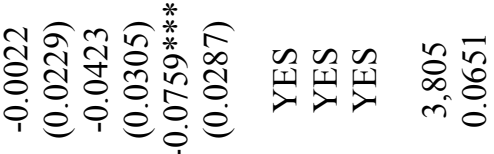

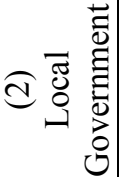

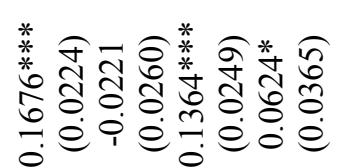

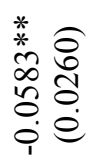

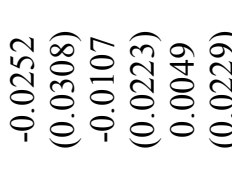

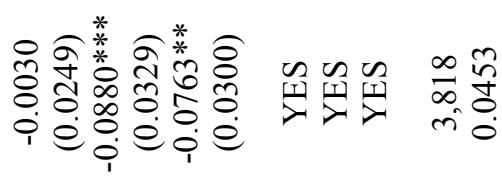

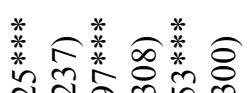

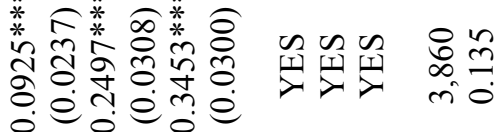




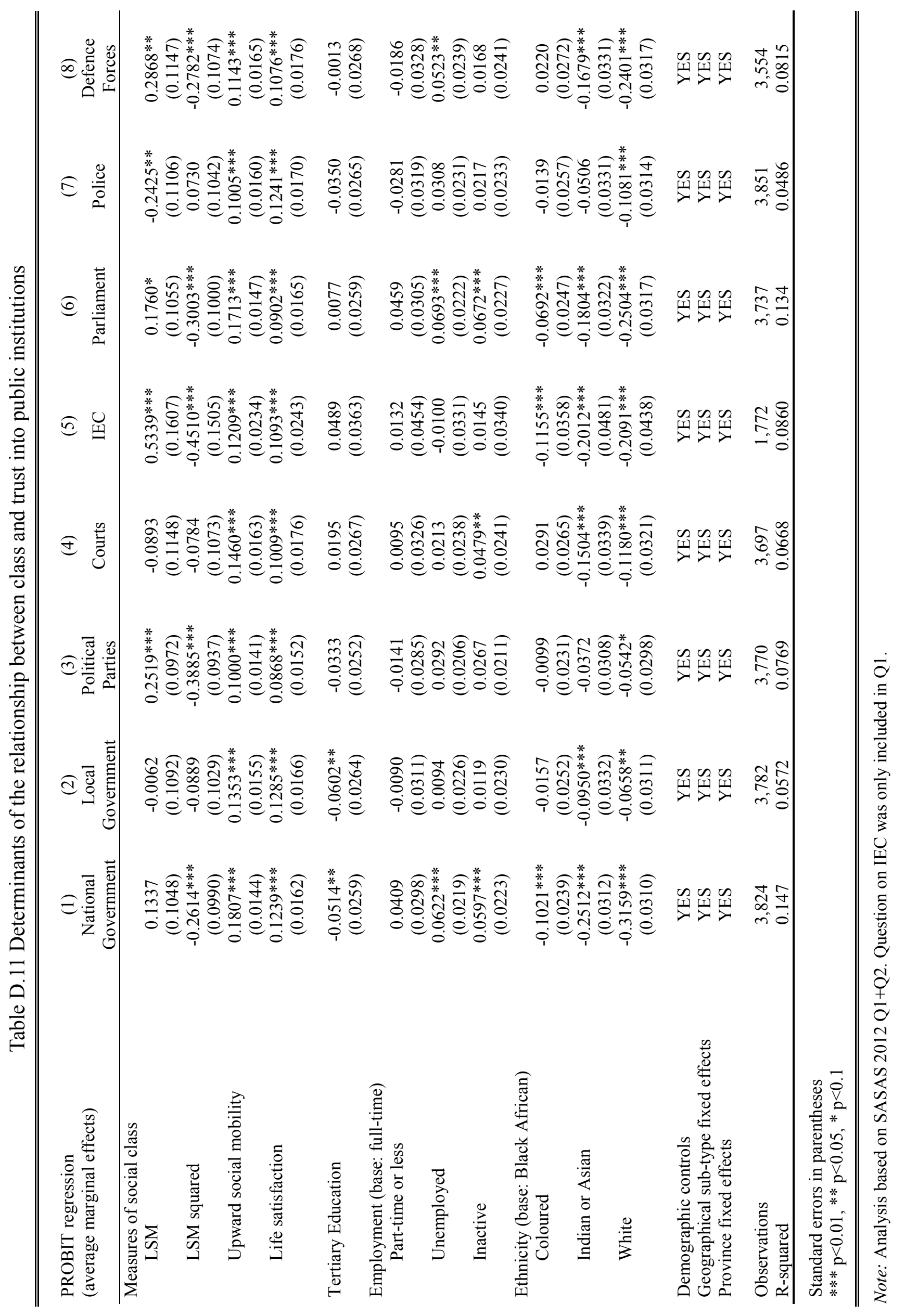


Table D.12 Relationship between class and satisfaction with governmental performance

\begin{tabular}{|c|c|c|c|c|c|c|}
\hline \multirow[t]{2}{*}{$\begin{array}{l}\text { Average marginal effects from PROBIT (1)-(2) } \\
\text { and OLS (3)-(6) regression }\end{array}$} & \multicolumn{2}{|c|}{$\begin{array}{c}\text { System performance } \\
\text { (Binary indicator) }\end{array}$} & \multicolumn{2}{|c|}{$\begin{array}{l}\text { Infrastructure provision } \\
\text { (Index on scale } 0 \text { to } 1 \text { ) }\end{array}$} & \multicolumn{2}{|c|}{$\begin{array}{c}\text { Public services } \\
\text { (Index on scale } 0 \text { to } 1 \text { ) }\end{array}$} \\
\hline & $(1)$ & (2) & (3) & (4) & $(5)$ & $(6)$ \\
\hline \multicolumn{7}{|l|}{ Class (Base: Persistently Poor) } \\
\hline Escapers & $\begin{array}{c}0.3086^{* * *} \\
(0.0206)\end{array}$ & & $\begin{array}{c}0.0777 * * * \\
(0.0094)\end{array}$ & & $\begin{array}{c}0.0681 * * * \\
(0.0090)\end{array}$ & \\
\hline Anxious & $\begin{array}{c}0.0359 \\
(0.0253)\end{array}$ & & $\begin{array}{c}0.0852 * * * \\
(0.0103)\end{array}$ & & $\begin{array}{l}0.0173 * \\
(0.0099)\end{array}$ & \\
\hline Climbers & $\begin{array}{c}0.2846^{* * *} \\
(0.0234)\end{array}$ & & $\begin{array}{c}0.1257 * * * \\
(0.0103)\end{array}$ & & $\begin{array}{c}0.0613 * * * \\
(0.0099)\end{array}$ & \\
\hline Elite & $\begin{array}{c}0.1480^{* * *} \\
(0.0353)\end{array}$ & & $\begin{array}{c}0.0882 * * * \\
(0.0145)\end{array}$ & & $\begin{array}{l}0.0262 * \\
(0.0140)\end{array}$ & \\
\hline \multicolumn{7}{|l|}{ Measures of social class } \\
\hline LSM & & $\begin{array}{c}0.1558 \\
(0.1050)\end{array}$ & & $\begin{array}{c}0.7066^{* * *} \\
(0.0423)\end{array}$ & & $\begin{array}{c}0.1573 * * * \\
(0.0421)\end{array}$ \\
\hline LSM squared & & $\begin{array}{l}-0.2050 * * \\
(0.0988)\end{array}$ & & $\begin{array}{c}-0.4849 * * * \\
(0.0395)\end{array}$ & & $\begin{array}{c}-0.1282 * * * \\
(0.0395)\end{array}$ \\
\hline Upward social mobility & & $\begin{array}{c}0.2476^{* * *} \\
(0.0135)\end{array}$ & & $\begin{array}{c}0.0461 * * * \\
(0.0062)\end{array}$ & & $\begin{array}{c}0.0481 * * * \\
(0.0062)\end{array}$ \\
\hline Life satisfaction & & $\begin{array}{c}0.1358 * * * \\
(0.0159)\end{array}$ & & $\begin{array}{c}0.0399 * * * \\
(0.0065)\end{array}$ & & $\begin{array}{c}0.0391 * * * \\
(0.0065)\end{array}$ \\
\hline Tertiary Education & $\begin{array}{l}-0.0253 \\
(0.0249)\end{array}$ & $\begin{array}{c}-0.0268 \\
(0.0252)\end{array}$ & $\begin{array}{c}0.0111 \\
(0.0101)\end{array}$ & $\begin{array}{c}0.0027 \\
(0.0099)\end{array}$ & $\begin{array}{c}0.0028 \\
(0.0138)\end{array}$ & $\begin{array}{l}-0.0092 \\
(0.0098)\end{array}$ \\
\hline \multicolumn{7}{|l|}{ Employment (base: full-time) } \\
\hline Part-time or less & $\begin{array}{l}-0.0074 \\
(0.0301)\end{array}$ & $\begin{array}{c}0.0156 \\
(0.0302)\end{array}$ & $\begin{array}{l}-0.0065 \\
(0.0124)\end{array}$ & $\begin{array}{c}0.0029 \\
(0.0120)\end{array}$ & $\begin{array}{c}0.0376^{* *} \\
(0.0173)\end{array}$ & $\begin{array}{c}0.0290 * * \\
(0.0119)\end{array}$ \\
\hline Unemployed & $\begin{array}{l}-0.0134 \\
(0.0217)\end{array}$ & $\begin{array}{c}0.0122 \\
(0.0219)\end{array}$ & $\begin{array}{l}-0.0067 \\
(0.0090)\end{array}$ & $\begin{array}{c}0.0007 \\
(0.0088)\end{array}$ & $\begin{array}{c}0.0196 \\
(0.0125)\end{array}$ & $\begin{array}{l}0.0169 * \\
(0.0086)\end{array}$ \\
\hline Inactive & $\begin{array}{c}0.0363 \\
(0.0222)\end{array}$ & $\begin{array}{c}0.0480 * * \\
(0.0222)\end{array}$ & $\begin{array}{c}0.0066 \\
(0.0092)\end{array}$ & $\begin{array}{c}0.0097 \\
(0.0088)\end{array}$ & $\begin{array}{l}0.0255 * \\
(0.0130)\end{array}$ & $\begin{array}{c}0.0262 * * * \\
(0.0088)\end{array}$ \\
\hline \multicolumn{7}{|l|}{ Race (base: Black African) } \\
\hline Coloured & $\begin{array}{c}-0.0776^{* * *} \\
(0.0241)\end{array}$ & $\begin{array}{c}-0.0881^{* * * *} \\
(0.0242)\end{array}$ & & $\begin{array}{c}-0.0321 * * * \\
(0.0098)\end{array}$ & & $\begin{array}{c}-0.0565 * * * \\
(0.0097)\end{array}$ \\
\hline Indian or Asian & $\begin{array}{c}-0.1688^{* * *} \\
(0.0314)\end{array}$ & $\begin{array}{c}-0.1722 * * * \\
(0.0318)\end{array}$ & & $\begin{array}{c}-0.0659 * * * \\
(0.0126)\end{array}$ & & $\begin{array}{c}-0.1324 * * * \\
(0.0125)\end{array}$ \\
\hline White & $\begin{array}{c}-0.1848 * * * \\
(0.0288)\end{array}$ & $\begin{array}{c}-0.1571^{* * *} \\
(0.0297)\end{array}$ & & $\begin{array}{c}-0.0312 * * * \\
(0.0117)\end{array}$ & & $\begin{array}{c}-0.1382 * * * \\
(0.0117)\end{array}$ \\
\hline Constant & & & $\begin{array}{c}0.5013^{* * *} \\
(0.0270)\end{array}$ & $\begin{array}{c}0.2826^{* * *} \\
(0.0284)\end{array}$ & $\begin{array}{c}0.4973 * * * \\
(0.0261)\end{array}$ & $\begin{array}{c}0.4278 * * * \\
(0.0283)\end{array}$ \\
\hline Demographic controls & YES & YES & YES & YES & YES & YES \\
\hline Geographical sub-type fixed effects & YES & YES & YES & YES & YES & YES \\
\hline Province fixed effects & YES & YES & YES & YES & YES & YES \\
\hline Observations & 3,874 & 3,840 & 3,918 & 3,881 & 3,910 & 3,873 \\
\hline R-squared & 0.112 & 0.128 & 0.1553 & 0.2284 & 0.1473 & 0.1597 \\
\hline
\end{tabular}

Standard errors in parentheses

$* * * \mathrm{p}<0.01, * * \mathrm{p}<0.05, * \mathrm{p}<0.1$

Note: Analysis based on SASAS 2012 Q1+Q2. 
Table D.13 Relationship between class and attitudes toward voting

\begin{tabular}{|c|c|c|c|c|}
\hline $\begin{array}{l}\text { PROBIT regression } \\
\text { (average marginal effects) }\end{array}$ & $\begin{array}{c}(1) \\
\text { (Strongly) Disagree: } \\
\text { Whether I vote or } \\
\text { not makes no } \\
\text { difference. }\end{array}$ & $\begin{array}{c}(2) \\
\text { (Strongly) Disagree: } \\
\text { After being elected } \\
\text { all parties are the } \\
\text { same, so voting is } \\
\text { pointless. }\end{array}$ & $\begin{array}{c}(3) \\
\text { (Strongly) Agree: } \\
\text { It is the duty of } \\
\text { all citizens to } \\
\text { vote. }\end{array}$ & $\begin{array}{l}(4) \\
\text { (Strongly) Disagree: } \\
\text { Voting is meaningless } \\
\text { because no politician } \\
\text { can be trusted. }\end{array}$ \\
\hline \multicolumn{5}{|l|}{ Class (Base: Persistently Poor) } \\
\hline Escapers & $\begin{array}{c}0.1717 * * * \\
(0.0347)\end{array}$ & $\begin{array}{c}0.1625 * * * \\
(0.0344)\end{array}$ & $\begin{array}{l}0.0607 * * \\
(0.0279)\end{array}$ & $\begin{array}{l}0.1258 * * * \\
(0.0350)\end{array}$ \\
\hline Anxious & $\begin{array}{l}0.0704 * \\
(0.0398)\end{array}$ & $\begin{array}{l}0.0864 * * \\
(0.0396)\end{array}$ & $\begin{array}{l}-0.0013 \\
(0.0313)\end{array}$ & $\begin{array}{c}0.0653 \\
(0.0402)\end{array}$ \\
\hline Climbers & $\begin{array}{l}0.2108 * * * \\
(0.0383)\end{array}$ & $\begin{array}{c}0.2152 * * * \\
(0.0380)\end{array}$ & $\begin{array}{l}0.0604^{*} \\
(0.0312)\end{array}$ & $\begin{array}{c}0.1770 * * * \\
(0.0386)\end{array}$ \\
\hline Elite & $\begin{array}{c}0.1981 * * * \\
(0.0538)\end{array}$ & $\begin{array}{c}0.2088^{* * *} \\
(0.0535)\end{array}$ & $\begin{array}{c}0.0444 \\
(0.0443)\end{array}$ & $\begin{array}{l}0.1530 * * * \\
(0.0539)\end{array}$ \\
\hline Tertiary Education & $\begin{array}{c}0.0598 \\
(0.0375)\end{array}$ & $\begin{array}{c}0.0946^{* *} \\
(0.0370)\end{array}$ & $\begin{array}{c}0.0346 \\
(0.0312)\end{array}$ & $\begin{array}{l}0.0902 * * \\
(0.0369)\end{array}$ \\
\hline \multicolumn{5}{|l|}{ Employment (base: full-time) } \\
\hline Part-time or less & $\begin{array}{l}0.0964 * * \\
(0.0470)\end{array}$ & $\begin{array}{c}0.0153 \\
(0.0462)\end{array}$ & $\begin{array}{l}-0.0540 \\
(0.0369)\end{array}$ & $\begin{array}{c}0.0165 \\
(0.0464)\end{array}$ \\
\hline Unemployed & $\begin{array}{c}0.0039 \\
(0.0337)\end{array}$ & $\begin{array}{l}-0.0064 \\
(0.0335)\end{array}$ & $\begin{array}{l}-0.0390 \\
(0.0274)\end{array}$ & $\begin{array}{l}-0.0137 \\
(0.0337)\end{array}$ \\
\hline Inactive & $\begin{array}{c}0.0233 \\
(0.0352)\end{array}$ & $\begin{array}{c}0.0194 \\
(0.0350)\end{array}$ & $\begin{array}{l}-0.0049 \\
(0.0290)\end{array}$ & $\begin{array}{c}0.0213 \\
(0.0352)\end{array}$ \\
\hline \multicolumn{5}{|l|}{ Race (base: Black African) } \\
\hline Coloured & $\begin{array}{c}0.0239 \\
(0.0374)\end{array}$ & $\begin{array}{c}0.0287 \\
(0.0370)\end{array}$ & $\begin{array}{c}0.0202 \\
(0.0313)\end{array}$ & $\begin{array}{c}0.0221 \\
(0.0372)\end{array}$ \\
\hline Indian or Asian & $\begin{array}{l}-0.1104 * * \\
(0.0497)\end{array}$ & $\begin{array}{c}-0.1448 * * * \\
(0.0494)\end{array}$ & $\begin{array}{l}-0.0591 \\
(0.0398)\end{array}$ & $\begin{array}{c}-0.1378 * * * \\
(0.0504)\end{array}$ \\
\hline White & $\begin{array}{c}0.0144 \\
(0.0442)\end{array}$ & $\begin{array}{l}0.0830 * \\
(0.0438)\end{array}$ & $\begin{array}{l}-0.0309 \\
(0.0361)\end{array}$ & $\begin{array}{c}0.0183 \\
(0.0438)\end{array}$ \\
\hline Demographic controls & YES & YES & YES & YES \\
\hline Geographical sub-type fixed effect: & YES & YES & YES & YES \\
\hline Province fixed effects & YES & YES & YES & YES \\
\hline Observations & 1,850 & 1,849 & 1,853 & 1,849 \\
\hline R-squared & 0.0340 & 0.0487 & 0.0314 & 0.0351 \\
\hline $\begin{array}{l}\text { Standard errors in parentheses } \\
* * * \mathrm{p}<0.01, * * \mathrm{p}<0.05, * \mathrm{p}<0.1\end{array}$ & & & & \\
\hline
\end{tabular}

Note: Analysis based on SASAS 2012 Q1. 
Table D.14 Determinants of the relationship between class and attitudes toward voting

\begin{tabular}{|c|c|c|c|c|}
\hline $\begin{array}{l}\text { PROBIT regression } \\
\text { (average marginal effects) }\end{array}$ & $\begin{array}{c}(1) \\
\text { (Strongly) Disagree: } \\
\text { Whether I vote or } \\
\text { not makes no } \\
\text { difference. }\end{array}$ & $\begin{array}{c}\text { (2) } \\
\text { (Strongly) Disagree: } \\
\text { After being elected } \\
\text { all parties are the } \\
\text { same, so voting is } \\
\text { pointless. }\end{array}$ & $\begin{array}{c}(3) \\
\text { (Strongly) Agree: } \\
\text { It is the duty of } \\
\text { all citizens to } \\
\text { vote. }\end{array}$ & $\begin{array}{l}(4) \\
\text { (Strongly) Disagree: } \\
\text { Voting is meaningless } \\
\text { because no politician } \\
\text { can be trusted. }\end{array}$ \\
\hline \multicolumn{5}{|l|}{ Indicators of social class } \\
\hline LSM & $\begin{array}{c}0.1898 \\
(0.1683)\end{array}$ & $\begin{array}{c}0.2706 \\
(0.1661)\end{array}$ & $\begin{array}{c}0.1866 \\
(0.1297)\end{array}$ & $\begin{array}{l}-0.0687 \\
(0.1667)\end{array}$ \\
\hline LSM squared & $\begin{array}{c}0.0085 \\
(0.1570)\end{array}$ & $\begin{array}{l}-0.0804 \\
(0.1552)\end{array}$ & $\begin{array}{l}-0.1188 \\
(0.1235)\end{array}$ & $\begin{array}{c}0.1969 \\
(0.1554)\end{array}$ \\
\hline Upward social mobility & $\begin{array}{c}0.1268 * * * \\
0.1898\end{array}$ & $\begin{array}{c}0.1105^{* * *} \\
0.2706\end{array}$ & $\begin{array}{c}0.0365^{*} \\
0.1866\end{array}$ & $\begin{array}{l}0.1078 * * * \\
-0.0687\end{array}$ \\
\hline Life satisfaction & $\begin{array}{c}0.0377 \\
(0.0253)\end{array}$ & $\begin{array}{c}0.0673 * * * \\
(0.0250)\end{array}$ & $\begin{array}{l}0.0374 * \\
(0.0204)\end{array}$ & $\begin{array}{c}0.0133 \\
(0.0254)\end{array}$ \\
\hline Tertiary Education & $\begin{array}{c}0.0445 \\
(0.0382)\end{array}$ & $\begin{array}{l}0.0806 * * \\
(0.0377)\end{array}$ & $\begin{array}{c}0.0282 \\
(0.0317)\end{array}$ & $\begin{array}{l}0.0756 * * \\
(0.0377)\end{array}$ \\
\hline \multicolumn{5}{|l|}{ Employment (base: full-time) } \\
\hline Part-time or less & $\begin{array}{l}0.1124 * * \\
(0.0472)\end{array}$ & $\begin{array}{c}0.0321 \\
(0.0464)\end{array}$ & $\begin{array}{l}-0.0449 \\
(0.0371)\end{array}$ & $\begin{array}{c}0.0258 \\
(0.0466)\end{array}$ \\
\hline Unemployed & $\begin{array}{c}0.0135 \\
(0.0342)\end{array}$ & $\begin{array}{c}0.0056 \\
(0.0340)\end{array}$ & $\begin{array}{l}-0.0335 \\
(0.0280)\end{array}$ & $\begin{array}{l}-0.0033 \\
(0.0343)\end{array}$ \\
\hline Inactive & $\begin{array}{c}0.0255 \\
(0.0353)\end{array}$ & $\begin{array}{c}0.0227 \\
(0.0350)\end{array}$ & $\begin{array}{l}-0.0083 \\
(0.0291)\end{array}$ & $\begin{array}{c}0.0265 \\
(0.0353)\end{array}$ \\
\hline \multicolumn{5}{|l|}{ Race (base: Black African) } \\
\hline Coloured & $\begin{array}{c}0.0083 \\
(0.0378)\end{array}$ & $\begin{array}{c}0.0124 \\
(0.0374)\end{array}$ & $\begin{array}{c}0.0057 \\
(0.0315)\end{array}$ & $\begin{array}{c}0.0151 \\
(0.0377)\end{array}$ \\
\hline Indian or Asian & $\begin{array}{c}-0.1218 * * \\
(0.0509)\end{array}$ & $\begin{array}{c}-0.1563 * * * \\
(0.0506)\end{array}$ & $\begin{array}{l}-0.0687 * \\
(0.0407)\end{array}$ & $\begin{array}{c}-0.1480 * * * \\
(0.0516)\end{array}$ \\
\hline White & $\begin{array}{c}0.0017 \\
(0.0461)\end{array}$ & $\begin{array}{l}0.0789 * \\
(0.0457)\end{array}$ & $\begin{array}{l}-0.0425 \\
(0.0375)\end{array}$ & $\begin{array}{c}0.0096 \\
(0.0457)\end{array}$ \\
\hline Demographic controls & YES & YES & YES & YES \\
\hline Geographical sub-type fixed effect: & YES & YES & YES & YES \\
\hline Province fixed effects & YES & YES & YES & YES \\
\hline $\begin{array}{l}\text { Observations } \\
\text { R-squared }\end{array}$ & $\begin{array}{r}1,839 \\
0,0355\end{array}$ & $\begin{array}{c}1,838 \\
0,0520\end{array}$ & $\begin{array}{c}1,841 \\
0,0334\end{array}$ & $\begin{array}{c}1,838 \\
0,0351\end{array}$ \\
\hline $\begin{array}{l}\text { Standard errors in parentheses } \\
* * * \mathrm{p}<0.01, * * \mathrm{p}<0.05, * \mathrm{p}<0.1\end{array}$ & & & & \\
\hline
\end{tabular}

Note: Analysis based on SASAS 2012 Q1. 
Table D.15 Relationship between class and support for civil rights and condemnation of corruption

\begin{tabular}{|c|c|c|c|c|c|}
\hline $\begin{array}{l}\text { Ordered PROBIT regression } \\
\text { (coefficients) }\end{array}$ & $\begin{array}{l}(1) \\
\text { Freedom of } \\
\text { Opinion }\end{array}$ & $\begin{array}{l}\quad(2) \\
\text { Freedom of } \\
\text { Association }\end{array}$ & $\begin{array}{c}(3) \\
\text { Freedom of } \\
\text { Press \& Media }\end{array}$ & $\begin{array}{c}(4) \\
\text { Right to } \\
\text { Protest }\end{array}$ & $\begin{array}{c}(5) \\
\text { Combating Fraud } \\
\text { \& Corruption }\end{array}$ \\
\hline \multicolumn{6}{|l|}{ Class (Base: Persistently Poor) } \\
\hline Escapers & $\begin{array}{c}-0.2267 * * * \\
(0.0771)\end{array}$ & $\begin{array}{c}0.0055 \\
(0.0809)\end{array}$ & $\begin{array}{c}-0.2522 * * * \\
(0.0773)\end{array}$ & $\begin{array}{c}0.0017 \\
(0.0777)\end{array}$ & $\begin{array}{l}-0.0840 \\
(0.0837)\end{array}$ \\
\hline Anxious & $\begin{array}{l}-0.0889 \\
(0.0872)\end{array}$ & $\begin{array}{c}0.0435 \\
(0.0908)\end{array}$ & $\begin{array}{c}0.0971 \\
(0.0865)\end{array}$ & $\begin{array}{l}-0.0706 \\
(0.0869)\end{array}$ & $\begin{array}{l}0.2297 * * \\
(0.0982)\end{array}$ \\
\hline Climbers & $\begin{array}{c}-0.2262 * * * \\
(0.0853)\end{array}$ & $\begin{array}{c}0.0110 \\
(0.0889)\end{array}$ & $\begin{array}{l}-0.0864 \\
(0.0847)\end{array}$ & $\begin{array}{l}-0.1353 \\
(0.0849)\end{array}$ & $\begin{array}{c}0.0958 \\
(0.0945)\end{array}$ \\
\hline Elite & $\begin{array}{l}-0.1290 \\
(0.1194)\end{array}$ & $\begin{array}{l}-0.1324 \\
(0.1234)\end{array}$ & $\begin{array}{c}0.0730 \\
(0.1188)\end{array}$ & $\begin{array}{l}-0.1262 \\
(0.1184)\end{array}$ & $\begin{array}{l}0.2603 * \\
(0.1360)\end{array}$ \\
\hline Tertiary Education & $\begin{array}{c}0.4092 * * * \\
(0.0826)\end{array}$ & $\begin{array}{c}0.3040 * * * \\
(0.0855)\end{array}$ & $\begin{array}{l}0.2642 * * * \\
(0.0821)\end{array}$ & $\begin{array}{l}-0.0119 \\
(0.0814)\end{array}$ & $\begin{array}{c}0.0543 \\
(0.0934)\end{array}$ \\
\hline \multicolumn{6}{|l|}{ Employment (base: full-time) } \\
\hline Part-time or less & $\begin{array}{l}-0.1979 * \\
(0.1018)\end{array}$ & $\begin{array}{c}-0.2474 * * \\
(0.1053)\end{array}$ & $\begin{array}{l}-0.1525 \\
(0.1024)\end{array}$ & $\begin{array}{c}0.0566 \\
(0.1020)\end{array}$ & $\begin{array}{c}-0.2377 * * \\
(0.1117)\end{array}$ \\
\hline Unemployed & $\begin{array}{c}-0.1634 * * \\
(0.0739)\end{array}$ & $\begin{array}{l}-0.0237 \\
(0.0771)\end{array}$ & $\begin{array}{l}-0.1108 \\
(0.0738)\end{array}$ & $\begin{array}{l}-0.0262 \\
(0.0739)\end{array}$ & $\begin{array}{c}0.0374 \\
(0.0831)\end{array}$ \\
\hline Inactive & $\begin{array}{l}-0.1322 * \\
(0.0771)\end{array}$ & $\begin{array}{l}-0.0001 \\
(0.0802)\end{array}$ & $\begin{array}{l}-0.1191 \\
(0.0772)\end{array}$ & $\begin{array}{c}0.0357 \\
(0.0770)\end{array}$ & $\begin{array}{l}-0.1236 \\
(0.0872)\end{array}$ \\
\hline \multicolumn{6}{|l|}{ Race (base: Black African) } \\
\hline Coloured & $\begin{array}{c}0.2276 * * * \\
(0.0815)\end{array}$ & $\begin{array}{l}-0.0498 \\
(0.0846)\end{array}$ & $\begin{array}{l}0.2464 * * * \\
(0.0810)\end{array}$ & $\begin{array}{c}-0.3279 * * * \\
(0.0812)\end{array}$ & $\begin{array}{c}0.3279 * * * \\
(0.0938)\end{array}$ \\
\hline Indian or Asian & $\begin{array}{c}0.3803 * * * \\
(0.1083)\end{array}$ & $\begin{array}{l}-0.1394 \\
(0.1131)\end{array}$ & $\begin{array}{l}0.4479 * * * \\
(0.1086)\end{array}$ & $\begin{array}{c}-0.2655^{* *} \\
(0.1087)\end{array}$ & $\begin{array}{l}0.2549 * * \\
(0.1245)\end{array}$ \\
\hline White & $\begin{array}{c}1.0040 * * * \\
(0.0989)\end{array}$ & $\begin{array}{l}-0.1419 \\
(0.1004)\end{array}$ & $\begin{array}{l}1.0373 * * * \\
(0.0988)\end{array}$ & $\begin{array}{c}-1.0057 * * * \\
(0.0971)\end{array}$ & $\begin{array}{l}0.2614 * * \\
(0.1103)\end{array}$ \\
\hline Demographic controls & YES & YES & YES & YES & YES \\
\hline Geographical sub-type fixed effect: & YES & YES & YES & YES & YES \\
\hline Province fixed effects & YES & YES & YES & YES & YES \\
\hline Observations & 1,841 & 1,847 & 1,852 & 1,843 & 1,860 \\
\hline R-squared & 0.0527 & 0.0175 & 0.0677 & 0.0477 & 0.0378 \\
\hline $\begin{array}{l}\text { Standard errors in parentheses } \\
* * * p<0.01, * * p<0.05, * p<0.1\end{array}$ & & & & & \\
\hline
\end{tabular}

Note: Analysis based on SASAS 2012 Q1.

Estimated constant effects at cut-off values have been omitted from the regression table. 
Table D.16 Determinants of the relationship between class and support for civil rights and condemnation of corruption

\begin{tabular}{|c|c|c|c|c|c|}
\hline $\begin{array}{l}\text { Ordered PROBIT regression } \\
\text { (coefficients) }\end{array}$ & $\begin{array}{c}(1) \\
\text { Freedom of } \\
\text { Opinion }\end{array}$ & $\begin{array}{l}\quad(2) \\
\text { Freedom of } \\
\text { Association }\end{array}$ & $\begin{array}{c}(3) \\
\text { Freedom of } \\
\text { Press \& Media }\end{array}$ & $\begin{array}{l}(4) \\
\text { Right to } \\
\text { Protest }\end{array}$ & $\begin{array}{c}(5) \\
\text { Combating Fraud } \\
\text { \& Corruption }\end{array}$ \\
\hline \multicolumn{6}{|l|}{ Measures of social class } \\
\hline LSM & $\begin{array}{l}-0.3011 \\
(0.3642)\end{array}$ & $\begin{array}{l}0.6554^{*} \\
(0.3803)\end{array}$ & $\begin{array}{l}-0.2007 \\
(0.3647)\end{array}$ & $\begin{array}{l}0.6782 * \\
(0.3663)\end{array}$ & $\begin{array}{c}0.0866 \\
(0.4048)\end{array}$ \\
\hline LSM squared & $\begin{array}{c}0.2654 \\
(0.3401)\end{array}$ & $\begin{array}{l}-0.5970 * \\
(0.3557)\end{array}$ & $\begin{array}{c}0.5043 \\
(0.3406)\end{array}$ & $\begin{array}{c}-0.6795 * * \\
(0.3420)\end{array}$ & $\begin{array}{c}0.4815 \\
(0.3840)\end{array}$ \\
\hline Upward social mobility & $\begin{array}{c}-0.2112 * * * \\
(0.0547)\end{array}$ & $\begin{array}{c}0.0007 \\
(0.0570)\end{array}$ & $\begin{array}{c}-0.2423 * * * \\
(0.0547)\end{array}$ & $\begin{array}{l}-0.0095 \\
(0.0547)\end{array}$ & $\begin{array}{l}-0.1249 * * \\
(0.0610)\end{array}$ \\
\hline Life satisfaction & $\begin{array}{c}0.0303 \\
(0.0556)\end{array}$ & $\begin{array}{l}-0.0018 \\
(0.0580)\end{array}$ & $\begin{array}{l}-0.0392 \\
(0.0558)\end{array}$ & $\begin{array}{l}-0.0434 \\
(0.0556)\end{array}$ & $\begin{array}{l}-0.0632 \\
(0.0625)\end{array}$ \\
\hline Tertiary Education & $\begin{array}{l}0.3944 * * * \\
(0.0842)\end{array}$ & $\begin{array}{l}0.3053 * * * \\
(0.0871)\end{array}$ & $\begin{array}{l}0.2241 * * * \\
(0.0838)\end{array}$ & $\begin{array}{c}0.0044 \\
(0.0828)\end{array}$ & $\begin{array}{c}0.0101 \\
(0.0954)\end{array}$ \\
\hline \multicolumn{6}{|l|}{ Employment (base: full-time) } \\
\hline Part-time or less & $\begin{array}{l}-0.1906^{*} \\
(0.1024)\end{array}$ & $\begin{array}{c}-0.2475 * * \\
(0.1058)\end{array}$ & $\begin{array}{l}-0.1527 \\
(0.1031)\end{array}$ & $\begin{array}{c}0.0575 \\
(0.1026)\end{array}$ & $\begin{array}{c}-0.2293 * * \\
(0.1125)\end{array}$ \\
\hline Unemployed & $\begin{array}{l}-0.1609 * * \\
(0.0752)\end{array}$ & $\begin{array}{l}-0.0164 \\
(0.0784)\end{array}$ & $\begin{array}{l}-0.1086 \\
(0.0752)\end{array}$ & $\begin{array}{l}-0.0349 \\
(0.0752)\end{array}$ & $\begin{array}{c}0.0533 \\
(0.0845)\end{array}$ \\
\hline Inactive & $\begin{array}{l}-0.1240 \\
(0.0774)\end{array}$ & $\begin{array}{c}0.0039 \\
(0.0804)\end{array}$ & $\begin{array}{l}-0.1141 \\
(0.0775)\end{array}$ & $\begin{array}{c}0.0186 \\
(0.0772)\end{array}$ & $\begin{array}{l}-0.1164 \\
(0.0875)\end{array}$ \\
\hline \multicolumn{6}{|l|}{ Race (base: Black African) } \\
\hline Coloured & $\begin{array}{c}0.2143^{* * * *} \\
(0.0825)\end{array}$ & $\begin{array}{l}-0.0439 \\
(0.0856)\end{array}$ & $\begin{array}{c}0.2344 * * * \\
(0.0821)\end{array}$ & $\begin{array}{c}-0.3209 * * * \\
(0.0820)\end{array}$ & $\begin{array}{c}0.3125 * * * \\
(0.0949)\end{array}$ \\
\hline Indian or Asian & $\begin{array}{l}0.3290 * * * \\
(0.1110)\end{array}$ & $\begin{array}{l}-0.1223 \\
(0.1161)\end{array}$ & $\begin{array}{l}0.3871 * * * \\
(0.1113)\end{array}$ & $\begin{array}{c}-0.2237 * * \\
(0.1114)\end{array}$ & $\begin{array}{c}0.1992 \\
(0.1281)\end{array}$ \\
\hline White & $\begin{array}{l}0.9733 * * * \\
(0.1030)\end{array}$ & $\begin{array}{l}-0.1404 \\
(0.1049)\end{array}$ & $\begin{array}{l}1.0034 * * * \\
(0.1031)\end{array}$ & $\begin{array}{c}-0.9819 * * * \\
(0.1012)\end{array}$ & $\begin{array}{c}0.1801 \\
(0.1153)\end{array}$ \\
\hline Demographic controls & YES & YES & YES & YES & YES \\
\hline Geographical sub-type fixed effects & YES & YES & YES & YES & YES \\
\hline Province fixed effects & YES & YES & YES & YES & YES \\
\hline Observations & 1,830 & 1,836 & 1,841 & 1,834 & 1,850 \\
\hline R-squared & 0.0542 & 0.0172 & 0.0710 & 0.0480 & 0.0408 \\
\hline $\begin{array}{l}\text { Standard errors in parentheses } \\
* * * \mathrm{p}<0.01, * * \mathrm{p}<0.05, * \mathrm{p}<0.1\end{array}$ & & & & & \\
\hline
\end{tabular}

Note: Analysis based on SASAS 2012 Q1.

Estimated constant effects at cut-off values have been omitted from the regression table. 
Table D.17 Determinants of the relationship between class and support for civil rights and condemnation of corruption, controlling for closeness to the ANC

\begin{tabular}{|c|c|c|c|c|c|}
\hline $\begin{array}{l}\text { Ordered PROBIT regression } \\
\text { (coefficients) }\end{array}$ & $\begin{array}{l}(1) \\
\text { Freedom of } \\
\text { Opinion }\end{array}$ & $\begin{array}{l}\quad(2) \\
\text { Freedom of } \\
\text { Association }\end{array}$ & $\begin{array}{c}(3) \\
\text { Freedom of } \\
\text { Press \& Media }\end{array}$ & $\begin{array}{l}\text { (4) } \\
\text { Right to } \\
\text { Protest }\end{array}$ & $\begin{array}{c}(5) \\
\text { Combating Fraud } \\
\text { \& Corruption }\end{array}$ \\
\hline \multicolumn{6}{|l|}{ Measures of social class } \\
\hline LSM & $\begin{array}{l}-0.1985 \\
(0.3834)\end{array}$ & $\begin{array}{c}0.5576 \\
(0.4014)\end{array}$ & $\begin{array}{l}-0.0708 \\
(0.3845)\end{array}$ & $\begin{array}{l}0.7499 * \\
(0.3866)\end{array}$ & $\begin{array}{c}0.0556 \\
(0.4267)\end{array}$ \\
\hline LSM squared & $\begin{array}{c}0.1490 \\
(0.3629)\end{array}$ & $\begin{array}{l}-0.5053 \\
(0.3804)\end{array}$ & $\begin{array}{c}0.4494 \\
(0.3639)\end{array}$ & $\begin{array}{c}-0.7827 * * \\
(0.3651)\end{array}$ & $\begin{array}{c}0.4999 \\
(0.4111)\end{array}$ \\
\hline Upward social mobility & $\begin{array}{c}-0.1879 * * * \\
(0.0586)\end{array}$ & $\begin{array}{c}0.0223 \\
(0.0614)\end{array}$ & $\begin{array}{c}-0.2064 * * * \\
(0.0586)\end{array}$ & $\begin{array}{l}-0.0591 \\
(0.0587)\end{array}$ & $\begin{array}{l}-0.0953 \\
(0.0656)\end{array}$ \\
\hline Life satisfaction & $\begin{array}{c}0.0389 \\
(0.0592)\end{array}$ & $\begin{array}{l}-0.0230 \\
(0.0621)\end{array}$ & $\begin{array}{l}-0.0375 \\
(0.0595)\end{array}$ & $\begin{array}{l}-0.0658 \\
(0.0594)\end{array}$ & $\begin{array}{l}-0.0526 \\
(0.0666)\end{array}$ \\
\hline Feeling close to the ANC & $\begin{array}{c}-0.2449 * * * \\
(0.0622)\end{array}$ & $\begin{array}{c}0.0251 \\
(0.0652)\end{array}$ & $\begin{array}{c}-0.2737 * * * \\
(0.0621)\end{array}$ & $\begin{array}{c}0.1636 * * * \\
(0.0624)\end{array}$ & $\begin{array}{l}-0.0969 \\
(0.0688)\end{array}$ \\
\hline Tertiary Education & $\begin{array}{c}0.4053 * * * \\
(0.0932)\end{array}$ & $\begin{array}{c}0.3310^{* * *} \\
(0.0968)\end{array}$ & $\begin{array}{c}0.1496 \\
(0.0924)\end{array}$ & $\begin{array}{c}0.0205 \\
(0.0915)\end{array}$ & $\begin{array}{c}0.0769 \\
(0.1066)\end{array}$ \\
\hline \multicolumn{6}{|l|}{ Employment (base: full-time) } \\
\hline Part-time or less & $\begin{array}{l}-0.1922 * \\
(0.1096)\end{array}$ & $\begin{array}{c}-0.3131 * * * \\
(0.1137)\end{array}$ & $\begin{array}{l}-0.2006 * \\
(0.1106)\end{array}$ & $\begin{array}{c}0.0091 \\
(0.1098)\end{array}$ & $\begin{array}{l}-0.1912 \\
(0.1210)\end{array}$ \\
\hline Unemployed & $\begin{array}{l}-0.1591 * \\
(0.0815)\end{array}$ & $\begin{array}{l}-0.0581 \\
(0.0854)\end{array}$ & $\begin{array}{l}-0.1142 \\
(0.0816)\end{array}$ & $\begin{array}{l}-0.0310 \\
(0.0816)\end{array}$ & $\begin{array}{c}0.0462 \\
(0.0915)\end{array}$ \\
\hline Inactive & $\begin{array}{l}-0.1592 * \\
(0.0840)\end{array}$ & $\begin{array}{l}-0.0517 \\
(0.0877)\end{array}$ & $\begin{array}{l}-0.1596 * \\
(0.0842)\end{array}$ & $\begin{array}{c}0.0018 \\
(0.0839)\end{array}$ & $\begin{array}{l}-0.1300 \\
(0.0951)\end{array}$ \\
\hline \multicolumn{6}{|l|}{ Race (Base: Black African) } \\
\hline Coloured & $\begin{array}{c}0.1252 \\
(0.0921)\end{array}$ & $\begin{array}{c}0.0008 \\
(0.0964)\end{array}$ & $\begin{array}{c}0.1478 \\
(0.0921)\end{array}$ & $\begin{array}{c}-0.1874 * * \\
(0.0919)\end{array}$ & $\begin{array}{l}0.2552 * * \\
(0.1066)\end{array}$ \\
\hline Indian or Asian & $\begin{array}{l}0.2457 * \\
(0.1269)\end{array}$ & $\begin{array}{l}-0.0293 \\
(0.1336)\end{array}$ & $\begin{array}{c}0.3304 * * * \\
(0.1274)\end{array}$ & $\begin{array}{l}-0.1604 \\
(0.1276)\end{array}$ & $\begin{array}{c}0.1756 \\
(0.1481)\end{array}$ \\
\hline White & $\begin{array}{c}0.8937 * * * \\
(0.1155)\end{array}$ & $\begin{array}{l}-0.1317 \\
(0.1182)\end{array}$ & $\begin{array}{c}0.8565 * * * \\
(0.1149)\end{array}$ & $\begin{array}{c}-0.8806^{* * *} \\
(0.1137)\end{array}$ & $\begin{array}{c}0.0777 \\
(0.1297)\end{array}$ \\
\hline Demographic controls & YES & YES & YES & YES & YES \\
\hline Geographical sub-type fixed effects & YES & YES & YES & YES & YES \\
\hline Province fixed effects & YES & YES & YES & YES & YES \\
\hline Observations & 1,613 & 1,615 & 1,620 & 1,610 & 1,625 \\
\hline R-squared & 0.0599 & 0.0187 & 0.0734 & 0.0506 & 0.0423 \\
\hline $\begin{array}{l}\text { ndard errors in parentheses } \\
\mathrm{p}<0.01, * * \mathrm{p}<0.05, * \mathrm{p}<0.1\end{array}$ & & & & & \\
\hline
\end{tabular}

Note: Analysis based on SASAS 2012 Q1.

Estimated constant effects at cut-off values have been omitted from the regression table. 


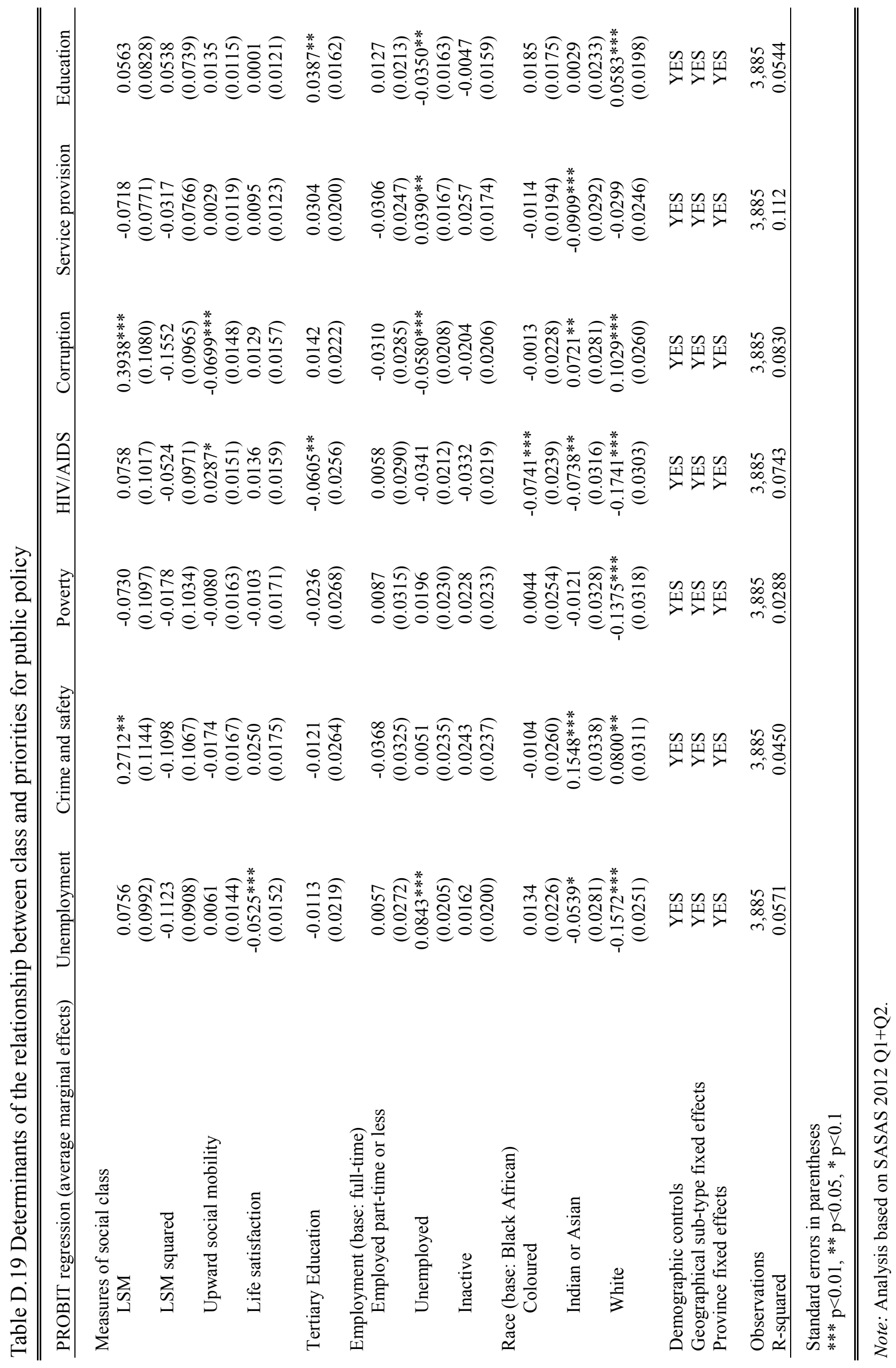





\section{GEORG-AUGUST-UNIVERSITÄT GÖTTINGEN}

Ph.D. Programme in Economics

\section{Declaration for admission to the doctoral examination}

I confirm

1. that the dissertation that I submitted

Poverty, social mobility, and the middle class

The case of South Africa

was produced independently without assistance from external parties, and not contrary to high scientific standards and integrity,

2. that I have adhered to the examination regulations, including upholding a high degree of scientific integrity, which includes the strict and proper use of citations so that the inclusion of other ideas in the dissertation are clearly distinguished,

3. that in the process of completing this doctoral thesis, no intermediaries were compensated to assist me neither with the admissions or preparation processes, and in this process,

- No remuneration or equivalent compensation were provided

- No services were engaged that may contradict the purpose of producing a doctoral thesis

4. that I have not submitted this dissertation or parts of this dissertation elsewhere.

I am aware that false claims (and the discovery of those false claims now, and in the future) with regards to the declaration for admission to the doctoral examination can lead to the invalidation or revoking of the doctoral degree. 



\section{GEORG-AUGUST-UNIVERSITÄT GÖTTINGEN \\ Ph.D. Programme in Economics}

\section{Declaration about co-authored papers}

This dissertation features four stand-alone research articles presented in Chapters 2 to 5.

While all four contributions can be read and understood independently, they are connected to each other thematically and build successively upon each other.

Chapter 2 is joint work with Rocco Zizzamia, Murray Leibbrandt, and Vimal Ranchhod from the Southern Africa Labour and Development Research Unit (SALDRU) at the University of Cape Town. Drawing on this research, Chapter 3 is joint work with Rocco Zizzamia and Murray Leibbrandt. Both chapters were conceptualised jointly by all authors. Rocco Zizzamia helped with the data cleaning and descriptive statistics. I did the majority of the empirical analysis and Rocco Zizzamia and I both contributed to the writing of the drafts.

The field research that informs the qualitative research element presented in Chapter 4 was conceptualised, planned and conducted in collaboration with Rocco Zizzamia. I performed the quantitative and qualitative analysis independently. The presentation, interpretation and discussion of the results are my own.

I am the single author of Chapter 5.

I confirm that that there are no other persons who satisfy the criteria for authorship but are not listed. 